SÍLVIA SANTOS

Cinética do cultivo em biorreator de Neisseria meningitidis sorogrupo B 


\title{
Cinética do cultivo em biorreator de Neisseria meningitidis sorogrupo B
}

\author{
SÍLVIA SANTOS
}

Dissertação apresentada ao Programa de PósGraduação Interunidades em Biotecnologia USP / Instituto Butantan / IPT, para obtenção do Título de Mestre em Biotecnologia.

São Paulo

2007 


\title{
Cinética do cultivo em biorreator de Neisseria meningitidis sorogrupo B
}

\author{
SÍLVIA SANTOS
}

Dissertação apresentada ao Programa de PósGraduação Interunidades em Biotecnologia USP / Instituto Butantan / IPT, para obtenção do Título de Mestre.

Área de concentração:

Biotecnologia

Orientadora:

Prof ${ }^{a}$. Dr ${ }^{\mathrm{a}}$. Rocilda Perazzini Furtado Schenkman

Co-orientadora:

Prof ${ }^{a}$. Dra ${ }^{a}$ Júlia Baruque Ramos

São Paulo

2007 
A Deus pelo dom da vida, aos meus pais, Sívio Santose Antonia Josefa Bispo dos Santos, por caminharem sempre ao meu lado, as minhas irmãs Sônia e Simone por torcerem e acreditarem na minha conquista, aos amigos que mesmo de longe estiveram perto e a aqueles que precisaram vê para crê na realização deste trabalho. 


\section{AGRADECIMENTOS}

A Deus por estar ao meu lado e me carregar em seus braços durante todo caminho percorrido.

À minha família que com amor e carinho secaram minhas lagrimas e não me deixaram desistir.

À $\mathscr{D} r^{a}$. Rocilda Perazzini Furtado Schenķman pela oportunidade, confiança, paciência e orientação.

À Prof ${ }^{a}$. Dr ${ }^{a}$. Júlia Baruque Ramos pelos ensinamentos, dedicação, comprometimento e co-orientação.

À Dra. Mickie Takagi do Laboratório de Fermentação pelos ensinamentos, disponibilidade e atenção contribuindo com a elaboração deste trabalho.

Ao Dr. Prof. Eduardo de Aquino Ximenes, pelo incentivo e pelos primeiros passos na área da pesquisa.

À equipe do Laboratório de Fermentação que contribuiu, na execução desta dissertação, em especial ao Sr.

Lourivaldo Inácio de Souza, Sra. Inês do Amaral Maurelli, Sra. Nidia,, Sr. Máximo de Moraes, e Sr. Hélio Fernandes Chagas.

Ao Prof. Dr. Ivo Lebrun e a Ms. Sandra Barreto do Caboratório de Bioquímica pelas análises dos aminoácidos.

À Dra. Sylvia M. Carneiro do Laboratório de Biologia Celular do Instituto Butantan pela realização da microscopia eletrônica.

Aos amigos Juberly Costa Amorim, Maria das Dores de Lima Guedes, Alberto Silva Ramos, Vendel Costa Amorim por me acolherem nos seios de seus lares durante e pós ingresso no Mestrado.

À Sra. Maria e Josy por me acolherem com afeto e carinho quando cheguei em São Paulo.

À amiga Jane Gandra companheira dos momentos difíceis e alegres, pelo apoio, incentivo e paciência.

À amiga Marta Santos Serafim machado pelas palavras sábias, pelo apoio nas minhas escolhas e decisões e pelo ombro amigo de todo instante.

À Ms. Vera Regina F. Ferreira pelas palavras amigas de incentivo.

Aos pesquisadores, funcionários e estagiários do Centro de Biotecnologia do Instituto Butantan que de maneira direta e indireta contribuíram para a realização deste trabalho.

À Secretaria de Saúde do Estado da Bahia (SESAB) e aos amigos e funcionários do Hospital Especializado Dom Rodrigo de Menezes (HEDRM) por contribuírem para a minha permanência em São Paulo.

Ao Conselho Nacional de Desenvolvimento Cientifico e Tecnológico (CNPPq), pela concessão de bolsa de estudo que favoreceu a efetivação deste projeto de Mestrado.

Á Fundação de Amparo à Pesquisa do Estado de São Paulo (FAPESP) 06/60712-0 pela contribuição nesta pesquisa.

Aos que colaboraram direta ou indiretamente com a realização deste trabalho.

Muito obrigada. 
“Alguns homens vêem as coisas como elas são e perguntam 'por que?" Eu sonho com as coisas que nunca foram feitas e pergunto 'por que não?'” 


\section{RESUMO}

SANTOS, S. Cinética do cultivo em biorreator de Neisseria meningitidis sorogrupo B. 2007. 155 f. Dissertação (Mestrado em Biotecnologia) - Instituto de Ciências Biomédicas, Universidade de São Paulo, São Paulo, 2007.

Neisseria meningitidis B libera vesículas de membrana externa, conhecidas pela sigla OMV. Essas possuem os mesmos componentes da membrana externa da bactéria e podem ser utilizadas como antígenos em vacinas contra a meningite B. As vesículas devem, também, expressar proteínas da membrana externa (OMP) e proteínas reguladoras do íon ferro (IRP). O objetivo deste trabalho é estudar a cinética de crescimento bacteriano, consumo das fontes de carbono e nitrogênio - especialmente os limitantes de crescimento - e produção de OMV visando melhorar a produção desse antígeno. Realizaram-se cultivos descontínuos em biorreator, com duração de $20 \mathrm{~h}$, empregando meio de Catlin com limitação de ferro e modificações nas concentrações de lactato, aminoácidos e glicerol. As condições do cultivo foram: 4,2 $\mathrm{L}$ de meio, temperatura de $36^{\circ} \mathrm{C}$, pressão de $0,5 \mathrm{~atm}$, vazão de ar $1 \mathrm{~L} / \mathrm{min}$, agitação entre 250-850 rpm, controle de oxigênio dissolvido em 10\% de saturação. Constatou-se que o lactato é a principal fonte de carbono limitante, embora somente se tem a hipótese de que o glicerol age como protetor mecânico. O ácido L-glutâmico é a principal fonte de nitrogênio consumida durante o cultivo. As OMV começaram a ser liberadas quantitativamente no início da fase estacionária de crescimento. Sendo que a melhor condição para a produção de OMV, valor 162,3 mg/L, é aquela em que as concentrações iniciais de lactato e aminoácidos foram duplicadas, 15,00 g/L e 2,93 g/L respectivamente. Através da análise do padrão eletroforético, confirmou-se a presença das principais proteínas de superfície, inclusive das IRPs. A integridade da OMV foi constatada por microscopia eletrônica. Assim, o antígeno obtido mostra-se passível de utilização na composição de vacina anti-meningocócica.

Palavras-chave: Neisseria meningitidis; vesícula de membrana externa; meio de cultura; vacinas; cultivo descontínuo. 


\begin{abstract}
SANTOS, S. Bioreactor cultivation kinetics of group B Neisseria meningitidis. 2007. 155 f. Masters Thesis (Biotecnology) - Instituto de Ciências Biomédicas, Universidade de São Paulo, São Paulo, 2007.

Neisseria meningitidis B liberates outer membrane vesicles known by the abbreviation OMV. These vesicles have the same components of the outer membrane of the bacteria and may be used as antigens in vaccines against meningitis B. The vesicles must also express outer membrane proteins (OMP) and iron regulated proteins (IRP). The aim of this paper is to study bacterial growth kinetics, carbon and nitrogen sources consumption - specially those which limit growth - and OMV production, seeking to improve the production of this antigen. Discontinuous bioreactor cultivations were carried out for a period of 20 hours in Catlin medium with iron restriction and modifications in lactate, amino acid, and glycerol concentrations. Cultivation conditions were: $4,2 \mathrm{~L}$ of medium, temperature at $36^{\circ} \mathrm{C}, 0,5 \mathrm{~atm}$, air flow rate of $1 \mathrm{~L} / \mathrm{min}$, agitation between $250-850 \mathrm{rpm}$, and dissolved oxygen control at $10 \%$ of saturation. It was verified that lactate is the main limiting carbon source, although there is just a hypothesis that glycerol acts as a mechanic protector. The L-glutamic acid is the main source of nitrogen consumed during the cultivation. The OMV started to be liberated quantitatively at the beginning of the stationary phase of growth. The best condition for production of $\mathrm{OMV}$, value $162,3 \mathrm{mg} / \mathrm{L}$, is that where the initial concentrations of lactate and amino acids were duplicated, 15,00 g/L and 2,93 g/L, respectively. Through an analysis of the electroforetic pattern, the presence of the main surface proteins was confirmed, including the IRPs. The integrity of the OMV was testified by electronic microscopy. So, the antigen thus obtained may be used in the antimeningococcal vaccine composition.
\end{abstract}

Key words: Neisseria meningitidis; outer membrane vesicle; culture medium; vaccines; discontinuous cultivation. 


\section{LISTAS DE ILUSTRAÇÕES}

Figura 1.1 - Processo inflamatório da meningite................................................... 26

Figura 1.2 - Neisseria meningitidis........................................................... 27

Figura 1.3 - Representação do envoltório celular da Neisseria meningitidis........... 28

Figura 1.4 - Vesículas de membrana externa (OMV) de Neisseria meningitidis (a) 32 e representação esquemática da liberação de OMV (b)

Figura 2.1 - Fluxograma do processo de cultivo de $N$. meningitidis.

Figura 2.2 - Desenho do Biorreator New Brunswick Scientific Bioflo 2000.......... $\quad 40$

Figura 2.3 - Fluxograma da purificação de OMV a partir do sobrenadante do 45 cultivo centrifugado e respectivas análises.

Figura 3.1 - Curvas de crescimento celular (DO ${ }_{540 \mathrm{~nm}}$ ) suavizadas dos ensaios 2 $(\diamond), 3(\square)$ e $4(\Delta)$

Figura 3.2 - Curvas de massa seca $(\mathrm{g} / \mathrm{L})$ dos ensaios $2(\bullet), 3(\square)$ e $4(\Delta) \ldots \ldots \ldots \ldots \ldots \ldots . .63$

Figura 3.3 - Curvas de viabilidade celular (UFC/mL) dos ensaios $3(\square)$ e $4(\Delta) \ldots . . \quad 64$

Figura 3.4 - Curvas de consumo de L-lactato (g/L) suavizadas dos ensaios $2(\diamond), \quad 64$ $3(\square)$ e $4(\Delta)$

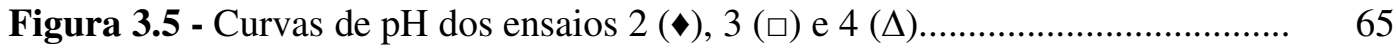

Figura 3.6 - Curvas de produção de OMV (mg/L) suavizadas dos ensaios $2(\bullet), 3 \quad 65$ () e $4(\Delta)$

Figura 3.7 - Curvas de consumo de ácido L-glutâmico (g/L) dos ensaios $2(\bullet), 3 \quad 66$ () e $4(\Delta)$.

Figura 3.8 - Curvas de crescimento celular (DO ${ }_{540 \mathrm{~nm}}$ ) suavizadas dos ensaios 5 $(\diamond)$ e $6(\square)$

Figura 3.9 - Curvas de massa seca (g/L) dos ensaios $5(\bullet)$ e $6(\square)$

Figura 3.10 - Curvas de viabilidade celular (UFC/mL) dos ensaios $5(\diamond)$ e $6(\square) \ldots \quad 70$

Figura 3.11 - Curva de consumo de L-lactato (g/L) suavizada do ensaio $5(\diamond) \ldots \ldots . \quad 70$

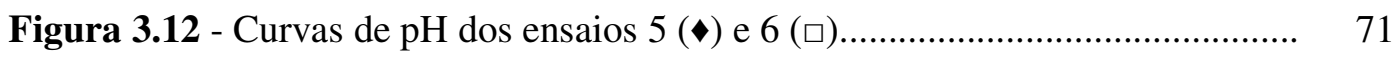

Figura 3.13 - Curvas de produção de OMV (mg/L) suavizadas dos ensaios $5(\bullet)$ e 71 $6(\square)$.. 
Figura 3.14 - Curvas de consumo de ácido L-glutâmico (g/L) dos ensaios 5 (४).... 72

Figura 3.15 - Curvas de crescimento celular (DO ${ }_{540 \mathrm{~nm}}$ ) suavizadas dos ensaios $7 \quad 75$ $(\diamond)$ e $8(\square)$

Figura 3.16 - Curvas de massa seca (g/L) ensaios 7 (४) e 8 ( ( $)$............................ 75

Figura 3.17 - Curvas de consumo de L-lactato (g/L) suavizadas dos ensaios 7 ( $\bullet \quad 76$ e $8(\square)$

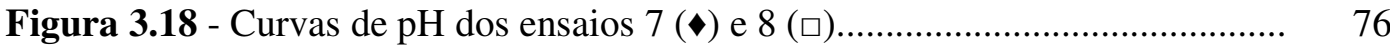

Figura 3.19 - Curvas de produção de OMV (mg/L) suavizadas dos ensaios 7 (४) e 77 $8(\square)$

Figura 3.20 - Curvas de consumo de ácido L-glutâmico (g/L) dos ensaios 7 (४) e 77 $8(\square)$

Figura 3.21 - Curvas de crescimento celular (DO ${ }_{540 \mathrm{~nm}}$ ) suavizadas dos ensaios $9 \quad 81$ $(\diamond), 10(\square)$ e $11(\circ)$

Figura 3.22 - Curvas de massa seca (g/L) ensaios $9(\diamond), 10(\square)$ e11 (०)................ 81

Figura 3.23 - Curvas de viabilidade celular (UFC/mL) dos ensaios 10 (口) e $11 \quad 82$ (०)

Figura 3.24 - Curvas de consumo de L-lactato (g/L) suavizadas dos ensaios $9(\bullet), \quad 82$ $10(\square)$ e $11(\circ)$

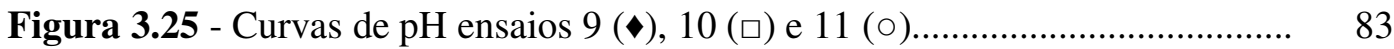

Figura 3.26 - Curvas de produção de OMV (mg/L) suavizadas dos ensaios $9(\diamond), \quad 83$ $10(\square)$ e $11(\circ)$

Figura 3.27 - Curvas de consumo de ácido L-glutâmico (g/L) dos ensaios $9(\diamond)$ e $\quad 84$ $10(\square)$

Figura 3.28 - Curva de crescimento celular (DO ${ }_{540 \mathrm{~nm}}$ ) suavizada do ensaio 12 ( $\square$ ).

Figura 3.29 - Curva de massa seca (g/L) do ensaio 12 ( $\square$ )..................................... 87

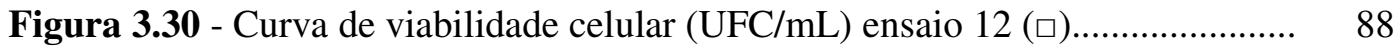

Figura 3.31 - Curva de consumo de L-lactato (g/L) suavizada do ensaio 12 ()..... 88

Figura 3.32 - Curva de pH do ensaio 12 ()..................................................... 89

Figura 3.33 - Curva de produção de OMV (mg/L) suavizada do ensaio 12 ()...... $\quad 89$ 
Figura 3.34 - Curva de consumo de ácido L-glutâmico (g/L) do ensaio 12 (ロ)......

Figura 3.35 - Gel de eletroforese SDS-PAGE (10\%) das amostras de OMV obtidas durante o cultivo. As colunas de 13 a 20, no ensaio 3, e 6 a 20, ensaio 4, correspondem ao extrato de OMV fracionados representando as respectivas horas de cultivos. As bandas representativas da expressão de IRP de OMV estão indicadas entre $(70-108 \mathrm{kDa})$ dos ensaios 3 e 4, respectivamente, do grupo $\underline{\mathbf{B}}$

Figura 3.36 - Gel de eletroforese SDS-PAGE (10\%) das amostras de OMV obtidas durante o cultivo. As colunas de 6 a 20 correspondem ao extrato de OMV fracionados representando as respectivas horas de cultivos. As bandas representativas da expressão de IRP de OMV estão indicadas entre (70 - 108 $\mathrm{kDa}$ ) dos ensaios 5 e 6 , respectivamente, do grupo C.

Figura 3.37 - Gel de eletroforese SDS-PAGE (10\%) das amostras de OMV obtidas durante o cultivo. As colunas de 6 a 20 correspondem ao extrato de OMV fracionados representando as respectivas horas de cultivos. As bandas representativas da expressão de IRP de OMV estão indicadas entre (70 - 108 $\mathrm{kDa})$ dos ensaios 7 e 8 , respectivamente, do grupo D.

Figura 3.38 - Gel de eletroforese SDS-PAGE (10\%) das amostras de OMV obtidas durante o cultivo. As colunas de 6 a 20 correspondem ao extrato de OMV fracionados representando as respectivas horas de cultivos. As bandas representativas da expressão de IRP de OMV estão indicadas entre (70 - 108 $\mathrm{kDa}$ ) dos ensaios 10 e 11 , respectivamente, do grupo E.

Figura 3.39 - Gel de eletroforese SDS-PAGE (10\%) das amostras de OMV obtidas durante o cultivo. As colunas de 6 a 20 correspondem ao extrato de OMV fracionados das respectivas horas de cultivos. As bandas representativas da expressão de IRP estão indicadas entre $(70-108 \mathrm{kDa})$ do ensaio 12 do grupo $\underline{\mathbf{F}}$

Figura 3.40 - Microscopia eletrônica das OMV do ensaio 4, em meio de Catlin 98 sem ferro: (A) $8 \mathrm{~h}$; (B) $14 \mathrm{~h}$ e (C) $20 \mathrm{~h}$.

Figura 3.41 - Microscopia eletrônica das OMV do ensaio 11, em meio de Catlin sem ferro, com concentrações iniciais de lactato e aminoácidos dobrados: (A) $8 \mathrm{~h}$; (B) $14 \mathrm{e} \mathrm{(C)} 20 \mathrm{~h}$

Figura 3.42 - Microscopia eletrônica das OMV do ensaio 12, em meio de Catlin sem ferro, com concentrações iniciais de aminoácidos e lactato dobrados e sem glicerol: (A) $8 \mathrm{~h}$; (B) $14 \mathrm{~h} \mathrm{e} \mathrm{(C)} 20 \mathrm{~h}$.

Figura 4.1 - Curvas experimentais suavizadas referentes à concentração de OMV no cultivo em biorreator no período de 20h: ( ) grupo B, ensaio 3; (o) grupo C, ensaio 6; grupo D, ensaio 7; (匹) grupo E, ensaio 9; ( $\square$ ) grupo F, ensaio 12. 
Figura 4.2 - Curvas experimentais referentes à concentração de L-lactato (g/L), 112 no cultivo em biorreator no período de 20h: (\$) grupo B, ensaio 3; (०) grupo C,

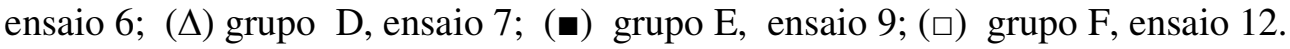

Figura 4.3 - Representação através de microscopia eletrônica das formas de OMV de Neisseria meningitidis sorogrupo B, cepa N.44/89 (Figura 4A) comparado com as OMV de Neisseria meningitidis sorogrupo B, cepa SD1C (Figura 4B) do artigo de Devoe e Gilchrist (1973).

Figura 7.2.1 Curvas de D.O. 540nm versus Massa seca (g/L), com as linhas de tendência, considerando: interseção no ponto zero, equação e coeficiente de correlação.

Figura 7.3.1 - Curvas de produção de amônia $\left(\mathrm{NH}_{4}\right)$ dos ensaios $3(\square), 5(\mathbf{\square}), 7$ $(\Delta), 10(\boldsymbol{\Delta})$ e 12(O), representando os grupos B, C, D, E e F, respectivamente........

Figura 7.4.1 - Curvas experimentais dos ensaios 2 (४), 3 (口) e $4(\Delta)$ representando $\mathrm{DO}_{540 \mathrm{~nm}}$, massa seca $(\mathrm{g} / \mathrm{L})$, lactato $(\mathrm{g} / \mathrm{L}), \mathrm{OMV}(\mathrm{mg} / \mathrm{L})$, glicerol $(\mathrm{g} / \mathrm{L}), \mathrm{pH}$, oxigênio dissolvido $(\%)$, rotação por minuto $(\mathrm{rpm})$, viabilidade celular (UFC/mL) e ácido L-glutâmico (g/L) e curvas suavizadas de $\mathrm{DO}_{540 \mathrm{~nm}}$, lactato $(\mathrm{g} / \mathrm{L})$ e OMV (mg/L). Os respectivos valores estão descrito nas tabelas 3.3 a 3.5 e tabelas 7.1.1 a 7.1.3 do anexo 7.1. Todos ocorrido no período de $20 \mathrm{~h}$ de cultivo em meio Catlin sem ferro, grupo B

Figura 7.4.2 - Curvas experimentais dos ensaios $5(\diamond)$ e $6(\square)$ representando DO

540nm, massa seca $(\mathrm{g} / \mathrm{L})$, lactato $(\mathrm{g} / \mathrm{L}), \mathrm{OMV}(\mathrm{mg} / \mathrm{L})$, glicerol $(\mathrm{g} / \mathrm{L}), \mathrm{pH}$, oxigênio dissolvid o (\%) e rotação por minuto (rpm) e curvas suavizadas de DO 540nm, Lactato $(\mathrm{g} / \mathrm{L})$ e OMV $(\mathrm{mg} / \mathrm{L})$. Os respectivos valores estão descrito nas tabelas 3.6 e 3.7 e tabelas 7.1.4 e 7.1.5 do anexo 7.1. Ambos ocorridos no período de $20 \mathrm{~h}$ de cultivo em meio Catlin sem ferro, com concentrações de lactato triplicado desde o inicio do cultivo, grupo C.

Figura 7.4.3 - Curvas experimentais dos ensaios 7 ( ) e 8 ( $\square$ ) representando DO 146 540nm, massa seca $(\mathrm{g} / \mathrm{L})$, lactato $(\mathrm{g} / \mathrm{L}), \mathrm{OMV}(\mathrm{mg} / \mathrm{L})$, glicerol $(\mathrm{g} / \mathrm{L}), \mathrm{pH}$, oxigênio dissolvido (\%) e rotação por minuto (rpm) e curvas suavizadas de DO 540nm, Lactato $(\mathrm{g} / \mathrm{L})$ e OMV $(\mathrm{mg} / \mathrm{L})$. Os respectivos valores estão descrito nas tabelas 3.8 e 3.9 e tabelas 7.1.6 e 7.1.7 do anexo 7.1. Ambos ocorrido durante $20 \mathrm{~h}$ de cultivo em meio Catlin sem ferro, com pulso de concentrações de aminoácidos e lactato na $6^{\mathrm{a}} \mathrm{h}$ de cultivo, grupo D.

Figura 7.4.4 - Curvas dos ensaios $9(\diamond), 10(\square)$ e11 (०) representando $\mathrm{DO}_{540 \mathrm{~nm}}$, massa seca $(\mathrm{g} / \mathrm{L})$, lactato $(\mathrm{g} / \mathrm{L})$, OMV $(\mathrm{mg} / \mathrm{L})$, glicerol $(\mathrm{g} / \mathrm{L}), \mathrm{pH}$, oxigênio dissolvido $(\%)$, rotação por minuto $(\mathrm{rpm})$, viabilidade celular $(\mathrm{UFC} / \mathrm{mL})$ e ácido L-glutâmico (g/L) e curvas suavizadas de $\mathrm{DO}_{540 \mathrm{~nm}}$, lactato $(\mathrm{g} / \mathrm{L})$ e $\mathrm{OMV}(\mathrm{mg} / \mathrm{L})$. Os respectivos valores estão descrito nas tabelas 3.10 a 3.12 e tabelas 7.1 .8 a 7.1.11 do anexo 7.1. Todos ocorridos durante $20 \mathrm{~h}$ de cultivo em meio Catlin sem ferro, com concentrações de aminoácidos e lactato dobrados desde inicio do cultivo, grupo E. 
Figura 7.4.5 - Curvas do ensaio 12 ( $\square$ ) representando DO $_{540 \mathrm{~nm}}$, massa seca $(\mathrm{g} / \mathrm{L})$, lactato $(\mathrm{g} / \mathrm{L}), \mathrm{OMV}(\mathrm{mg} / \mathrm{L}), \mathrm{pH}$, oxigênio dissolvido $(\%)$, rotação por minuto (rpm), viabilidade celular (UFC/mL) e ácido L-glutâmico e curvas suavizadas de $\mathrm{DO}_{540 \mathrm{~nm}}$, lactato $(\mathrm{g} / \mathrm{L})$ e $\mathrm{OMV}(\mathrm{mg} / \mathrm{L})$. Os seus respectivos valores estão descrito na tabela 3.13 e tabela 7.1.11 do anexo 7.1. Ensaio corrido no período de $20 \mathrm{~h}$ de cultivo em meio Catlin sem ferro, com concentrações iniciais de aminoácidos e lactato dobrados e glicerol ausente, grupo F. 


\section{LISTAS DE TABELAS}

Tabela 2.1 - Composição do meio sólido de ágar Müller-Hinton - contendo 2\% de soro.

Tabela 2.2 - Composição do meio sólido de ágar-soro em base TSB.................... 35

Tabela 2.3 - Composição do meio sólido de ágar-chocolate em base BHI............. 35

Tabela 2.4 - Composição do meio líquido de Catlin sem ferro.............................. 36

Tabela 2.5 - Massa de amostra (g) a ser pesada de acordo com a concentração 49

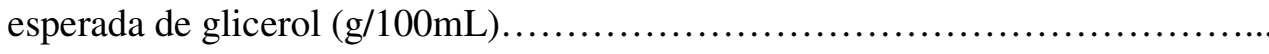

Tabela 3.1 - Resumo dos ensaios em meio de Catlin sem ferro realizados em $\quad 57$ agitador rotatório e biorreator.

Tabela 3.2 - Resultado das analises do planejamento fatorial celular e das analises preliminares do ensaio 1

Tabela 3.3 - Resultados experimentais do grupo B, ensaio 2............................. 61

Tabela 3.4 - Resultados experimentais do grupo B, ensaio 3............................. 61

Tabela 3.5 - Resultados experimentais do grupo B, ensaio 4............................. 62

Tabela 3.6 - Resultados experimentais do grupo C, ensaio 5............................. 68

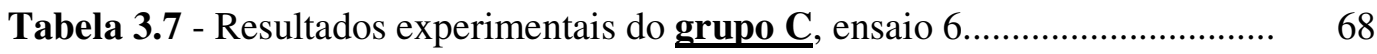

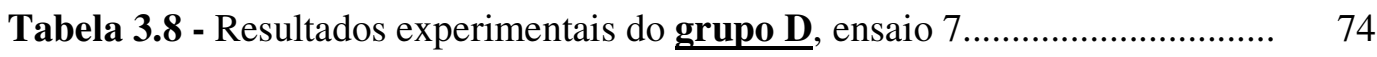

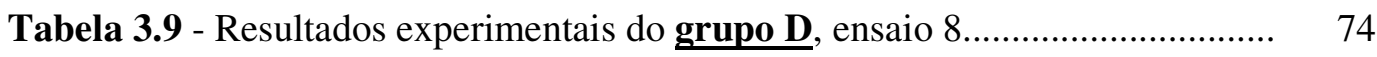

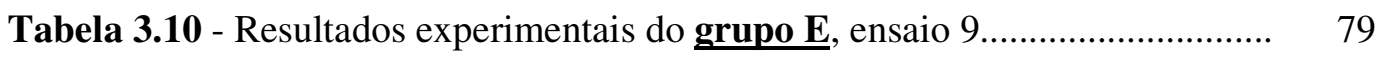

Tabela 3.11 - Resultados experimentais do grupo E, ensaio 10......................... 79

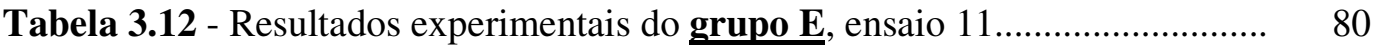

Tabela 3.13 - Resultados experimentais do grupo F, ensaio $12 \ldots \ldots \ldots \ldots \ldots \ldots \ldots \ldots \ldots . . . . . . . . . . . .66$

Tabela 4.1-Coeficientes de concentração celular dos ensaios com seus 103 respectivos coeficientes de correlação $\left(\mathrm{r}^{2}\right)$........

Tabela 4.2 - Valores de concentração celular máxima $\left(\mathrm{X}_{\text {máx }}\right)$, concentração de OMV máxima $\left(\mathrm{P}_{\text {máx }}\right)$, produtividade em biomassa $\left(\operatorname{Prod}_{\mathrm{x}}\right)$ e de vesículas da membrana externa $\left(\operatorname{Prod}_{\mathrm{p}}\right)$, fator de conversão biomassa/lactato $\left(\mathrm{Y}_{\mathrm{x} / \mathrm{s}}\right)$ e OMV/biomassa $\left(\mathrm{Y}_{\mathrm{p} / \mathrm{x}}\right)$ 
Tabela 4.3 - Representação dos valores das variações das concentrações (original, duplicada e triplicada) da mistura racêmica a 50\% de: lactato de sódio $(\mathrm{g} / \mathrm{L})$, D-L lactato $(\mathrm{g} / \mathrm{L})$, D-lactato $(\mathrm{g} / \mathrm{L})$ e L-lactato $(\mathrm{g} / \mathrm{L})$ respectivamente. Estas concentrações referem-se à composição do *meio de Catlin sem ferro (tabela 2.4), empregada em diferentes ensaios.

Tabela 4.4 - Valores da média da velocidade especifica de formação de produto $\left(\mu_{\mathrm{p}}\right)$ e da constante empírica não associada $\beta$.

Tabela 7.1.1 - Resultados suavizados do ensaio 2, em meio Catlin sem ferro, grupo B , durante $20 \mathrm{~h}$ de cultivo.

Tabela 7.1.2 - Resultados suavizados do ensaio 3, em meio Catlin sem ferro, grupo B , durante $20 \mathrm{~h}$ de cultivo.

Tabela 7.1.3 - Resultados suavizados do ensaio 4, em meio Catlin sem ferro, grupo B, durante $20 \mathrm{~h}$ de cultivo.

Tabela 7.1.4 Resultados suavizados do ensaio 5, durante $20 \mathrm{~h}$ de cultivo, em meio de Catlin com concentração de lactato triplicado desde o inicio, grupo $\mathbf{C}$, durante $20 \mathrm{~h}$ de cultivo.

Tabela 7.1.5 Resultados suavizados do ensaio 6, durante 20h de cultivo, em meio de Catlin com concentração de lactato triplicado desde o inicio, grupo $\mathbf{C}$, durante $20 \mathrm{~h}$ de cultivo

Tabela 7.1.6 Resultados suavizados do ensaio 7, em meio de Catlin com pulso de lactato e aminoácidos na $6^{\mathrm{a}} \mathrm{h}$ de cultivo, grupo D, durante $20 \mathrm{~h}$ de cultivo.

Tabela 7.1.7 Resultados suavizados do ensaio 8, em meio de Catlin com pulso de lactato e aminoácidos na $6^{\mathrm{a}} \mathrm{h}$ de cultivo (tabela 3.1), grupo D, durante $20 \mathrm{~h}$ de cultivo.

Tabela 7.1.8 Resultados suavizados do ensaio 9, durante 20h de cultivo, em meio de Catlin com concentrações iniciais de lactato e aminoácidos dobrados desde o inicio, grupo E, durante $20 \mathrm{~h}$ de cultivo.

Tabela 7.1.9 Resultados suavizados do ensaio 10, durante $20 \mathrm{~h}$ de cultivo, em meio de Catlin com concentrações iniciais de lactato e aminoácidos dobrados desde o inicio, grupo E, durante $20 \mathrm{~h}$ de cultivo.

Tabela 7.1.10 Resultados suavizados do ensaio 11, durante $20 \mathrm{~h}$ de cultivo, em meio de Catlin com concentrações iniciais de lactato e aminoácidos dobrados desde o inicio, grupo E, durante $20 \mathrm{~h}$ de cultivo.

Tabela 7.1.11 Resultados suavizados do ensaio 12, em meio de Catlin durante 20h de cultivo com concentrações iniciais de lactato, aminoácidos dobrados e sem glicerol desde o inicio grupo F , durante $20 \mathrm{~h}$ de cultivo 
Tabela 7.3.1 - Resultados experimentais de amônia nos cultivos em biorreator.... 


\section{LISTA DE ABREVIATURA E SIGLAS}

$\%$ - Porcentagem

${ }^{\circ} \mathrm{C}$ - Graus Celsius

$\mu \mathrm{g}-$ micrograma

$\mu \mathrm{L}-$ microlitro

$\mu \mathrm{m}-$ micrometro

a - área de interface (gás/líquido) por unidade de volume de líquido $\left(\mathrm{m}^{2}\right)$

AOCS - "America Oil Chemistry Society"

bar - unidade de pressão correspondente a aproximadamente 1 atm

BHI - "Brain Heart Infusion"

BSA - albumina sérica bovina

$\mathrm{CO}_{2}$ - dióxido de carbono

CVE - Centro de Vigilância Epidemiológica

dLOS - endotoxina detoxificada

DO - densidade óptica

$\mathrm{dP}$ - produto formado no intervalo de tempo " $\mathrm{dt}$ ” (g/L)

dP/dt - derivada dos valores de concentração de OMV (g/(L.h))

$\mathrm{dS}$ - substrato consumido no intervalo de tempo " $\mathrm{dt}$ " (g/L)

dS/dt - derivada dos valores de concentração de lactato ou substrato (g/(L.h))

$\mathrm{dt}$ - intervalo diferencial de tempo (h)

$\mathrm{dX}$ - biomassa formada no intervalo de tempo " $\mathrm{dt}$ ” $(\mathrm{g} / \mathrm{L})$

dX/dt - derivada dos valores de concentração celular (g/(L.h))

FDA - Food and Drug Administration

g - grama 


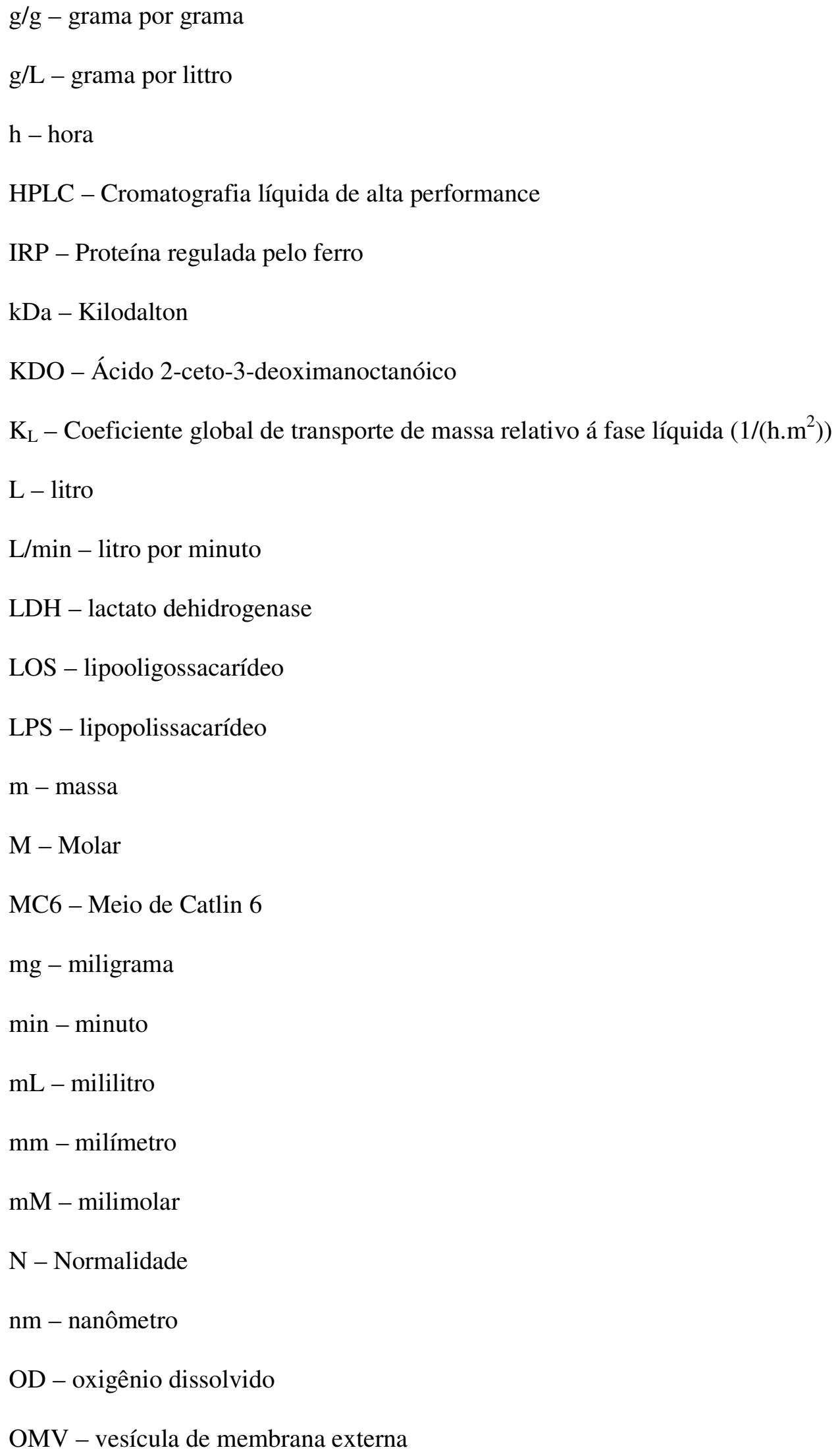


Opa - proteína de opacidade

$\mathrm{p} / \mathrm{p}-\mathrm{peso} / \mathrm{peso}$

$\mathrm{p} / \mathrm{v}$ - peso/volume

PBS - "Phosphate Buffered Saline"

$\mathrm{P}_{\mathrm{f}}$ - concentração máxima de $\mathrm{P}(\mathrm{g} / \mathrm{L})$

pH - potencial hidrogeniônico

PITC - fenilisotiocianato

$\mathrm{P}_{\mathrm{m}}$ - concentração máxima de produto $(\mathrm{g} / \mathrm{L})$

$\mathrm{P}_{\mathrm{o}}$ - concentração de inicial produto $(\mathrm{g} / \mathrm{L})$

$\mathrm{P}_{\mathrm{o}}$ - concentração de inicial produto $(\mathrm{g} / \mathrm{L})$

PorA - proteína porina tipo A ou de classe 1

PorB - Proteína porina tipo B ou de classe 2

Prod $_{. P}$ - produtividade de produto (g/(L.h))

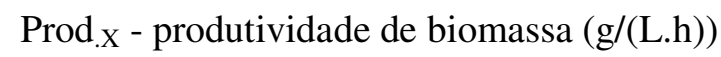

$\mathrm{P}_{\text {suav }}$ - valor ajustado e/ou calculado de $\mathrm{P}(\mathrm{g} / \mathrm{L})$

rpm - rotação por minuto

RQ - coeiciente de respiração

SDS - dodecil sulfato de sódio

SDS-PAGE - eletroforese em gel de poliacrilamida

$\mathrm{S}_{\mathrm{i}}$ - concentração inicial de substrato $(\mathrm{g} / \mathrm{L})$

$\mathrm{S}_{\min }$ - concentração de substrato quando a concentração celular é máxima (g/L)

$\mathrm{S}_{\text {suav }}$ - valor ajustado e/ou calculado de S (g/L)

$\mathrm{t}$ - tempo de fermentação (h)

Tbps - proteínas ligantes de transferrina

TCA - Ciclo do ácido tricarboxílico 
TEA - Trietilamina

$t_{f}$ - tempo de cultivo correspondente a $X_{f}(h)$

$t_{\mathrm{fP}}$ - tempo de cultivo correspondente a $\mathrm{P}_{\mathrm{f}}(\mathrm{h})$

$\mathrm{t}_{\mathrm{o}}$ - tempo inicial $(\mathrm{h})$

Tris - Tris(hidroximetil)aminometano

TSB - "Trypic Soy Broth"

UFC - Unidades formadoras de colônias

$\mathrm{V}$ - volume de meio no biorreator (L)

v/v - volume/volume

va - volume de $\mathrm{NaOH}$ consumido na titulação $(\mathrm{mL})$

$\mathrm{vb}$ - volume de $\mathrm{NaOH}$ consumido para titular o branco $(\mathrm{mL})$

$X$ - concentração celular expressa em biomassa seca $(\mathrm{g} / \mathrm{L})$

$\mathrm{X}_{\mathrm{f}}$ - concentração máxima de $\mathrm{X}(\mathrm{g} / \mathrm{L})$

$\mathrm{X}_{\mathrm{m}}$ - concentração celular máxima $(\mathrm{g} / \mathrm{L})$

$\mathrm{X}_{\mathrm{o}}$ - concentração celular inicial (g/L)

$\mathrm{X}_{\text {suav }}$ - valor ajustado e/ou calculado de $\mathrm{X}(\mathrm{g} / \mathrm{L})$

$\mathrm{Y}_{\mathrm{P} / \mathrm{S}}$ - fator de conversão substrato/produto (g produto/g substrato)

$\mathrm{Y}_{\mathrm{P} / \mathrm{X}}$ - fator de conversão célula/produto (g produto/g biomassa)

$\mathrm{Y}_{\mathrm{X} / \mathrm{S}}$ - fator de conversão substrato/célula (g biomassa/g substrato)

$\alpha$ - Constante empírica associada ao crescimento do microrganismo

$\beta$ - Constante empírica não associada

$\mu_{\mathrm{P}}$ - velocidade específica de formação de produto $\left(\mathrm{h}^{-1}\right)$

$\mu_{\mathrm{S}}$ - velocidade específica de consumo de substrato $\left(\mathrm{h}^{-1}\right)$

$\mu_{\mathrm{X}}$ - velocidade específica de geração de biomassa $\left(\mathrm{h}^{-1}\right)$ 


\section{SUMÁRIO}

1 INTRODUÇÃO

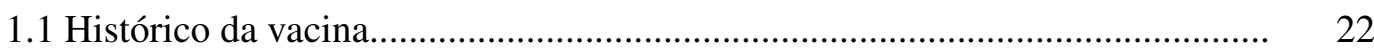

1.2 Doença meningocócica............................................................................ 25

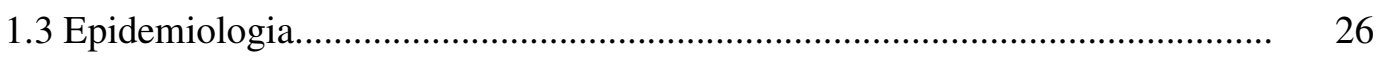

1.4 Neisseria meningitidis........................................................................... 27

$\begin{array}{llllllll}\text { 1.4.1Componentes não protéicos da superfície celular da } & N . & 29\end{array}$ meningitidis.

1.4.2 Componentes protéicos da superfície celular da $N$. meningitidis................... 29

1.5 Vesícula da membrana externa (OMV)........................................................... 32

1.6 Processo para o cultivo do meningococo........................................................ 33

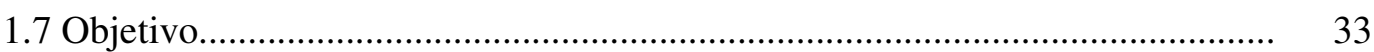

2 MATERIAIS E MÉTODOS................................................................. 34

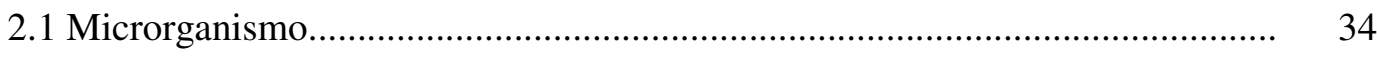

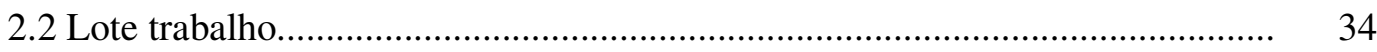

2.3 Meios de Cultura..................................................................................... 34

2.4 Ensaios preliminares em agitador rotativo...................................................... 36

2.5 Cultivo em biorreator............................................................................... 37

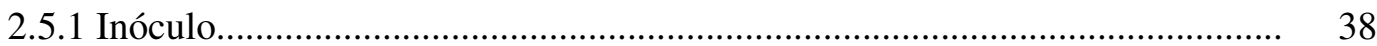

2.5.1.1 Preparo da $1^{\mathrm{a}}$. etapa do inóculo................................................................. 38

2.5.1.2 Preparo da $2^{\mathrm{a}}$. etapa do inóculo................................................................. 38

2.5.1.3 Determinação do volume do inóculo........................................................ 38

2.6 Descrição do biorreator..................................................................................... 39

2.6.1 Preparo do biorreator e filtração do meio.......................................................... 41

2.6.1.1 Condições dos cultivos.............................................................................. 41

2.6.1.2 Calibração do eletrodo de oxigênio dissolvido............................................ 42

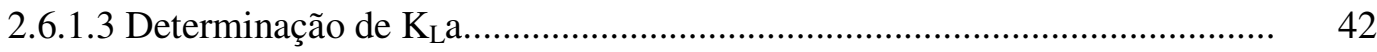

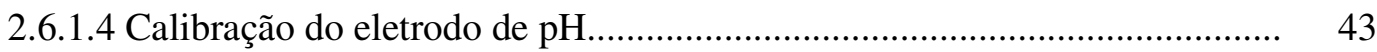

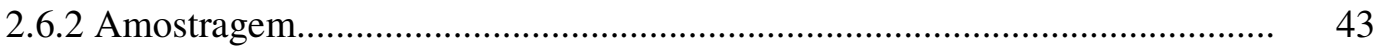

2.7 Metodologias Analíticas............................................................................. 44

2.7.1 Determinação da concentração celular.......................................................... 44

2.7.2 Viabilidade celular (UFC/mL) ............................................................ 44 
2.7.3 Análise do sobrenadante do cultivo.

2.7.3.1 Extração da membrana da vesícula externa (OMV)................................... 46

2.7.3.2 Dosagem de proteínas.............................................................................. 46

2.7.3.3 Eletroforese em gel de poliacrilamida - SDS.............................................. 46

2.7.3.4 Determinação da concentração de lactato................................................... 47

2.7.3.5 Determinação da concentração de glicerol................................................ 48

2.7.3.6 Determinação da concentração dos aminoácidos........................................ 50

2.7.4 Microscopia eletrônica................................................................................ 51

2.7.5 Determinação dos parâmetros cinéticos......................................................... 51

2.7.5.1 Modelo de Luedeking e Piret....................................................................... 53

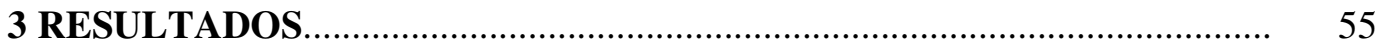

3.1 Ensaio do grupo A - Cultivo em agitador rotatório......................................... 58

3.1.1 Os resultados experimentais do ensaio do grupo A ……................................ 58

3.2 Ensaios do Grupo B - Meio Catlin sem ferro..................................................... 60

3.2.1 Resultados experimentais dos ensaios do grupo B........................................ 60

3.2.2 Curvas dos resultados dos ensaios do grupo B .............................................. 63

3.3 Ensaios do Grupo C - Meio Catlin sem ferro com concentração de L-lactato 67 triplicada.

3.3.1 Resultados experimentais dos ensaios do grupo C...........................................6 67

3.3.2 Curvas dos resultados dos ensaios do grupo C................................................. 69

3.4 Ensaios do Grupo D - Meio Catlin sem ferro com pulso de lactato e 73 aminoácidos

3.4.1 Resultados experimentais dos ensaios do grupo D...................................... 73

3.4.2 Curvas dos resultados dos ensaios do grupo D........................................... 75

3.5 Ensaios do Grupo E - Meio Catlin sem ferro com concentrações iniciais de 78 lactato e aminoácidos dobradas

3.5.1 Resultados experimentais dos ensaios do grupo E.......................................... 78

3.5.2 Curvas dos resultados dos ensaios do grupo E............................................ 81

3.6 Ensaios do grupo F - Meio Catlin sem ferro com concentrações iniciais de 85 lactato e aminoácidos dobradas e sem glicerol

3.6.1 Resultado experimental do ensaio do grupo F............................................ 85

3.6.2 Curvas do resultado do ensaio do grupo F................................................. 87

3.7 Perfil eletroforético de OMVs dos ensaios realizados em biorreator................ 91 
3.7.1 Géis de eletroforese, SDS-PAGE 10\%, dos ensaios do grupo B em meio de catlin sem ferro.

3.7.2 Géis de eletroforese, SDS-PAGE 10\%, dos ensaios do grupo C em meio de

Catlin sem ferro com concentração inicial de lactato triplicada.

3.7.3 Géis de eletroforese, SDS-PAGE 10\%, dos ensaios do grupo D em meio de

Catlin sem ferro com pulso de concentração de lactato e aminoácidos na $6^{\mathrm{a}} \mathrm{h}$ de cultivo.

3.7.4 Géis de eletroforese, SDS-PAGE 10\%, dos ensaios do grupo E em meio de

Catlin sem ferro com concentrações iniciais de lactato e aminoácidos dobradas.

3.7.5 Gel de eletroforese, SDS-PAGE 10\%, do ensaio do grupo F em meio de catlin sem ferro com concentrações iniciais de lactato e aminoácidos dobrados e sem glicerol.

3.8 Microscopia eletrônica das vesículas da membrana externa (OMV)

3.8.1 Microscopia eletrônica das OMV do ensaio 4 do grupo B............................ 98

3.8.2 Microscopia eletrônica das OMV do ensaio 11 do grupo E........................... 99

3.8.3 Microscopia eletrônica das OMV do ensaio 12 do grupo F............................ 100

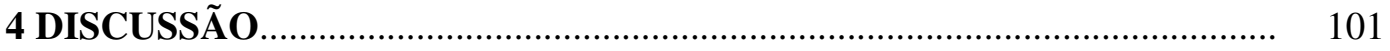

4.1 Análise dos efeitos das prováveis fontes de carbono no ensaio com 101 planejamento fatorial realizado em agitador rotatório.

4.2 Coeficiente de concentração celular entre Massa seca e $\mathrm{DO}_{540 \mathrm{~nm}}$.................... 102

4.3 Análise das produtividades e fatores de conversão.......................................... 103

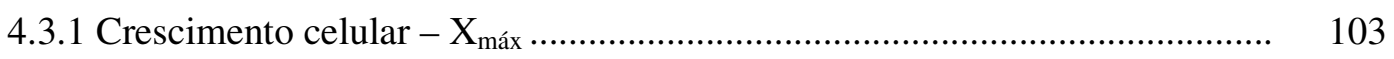

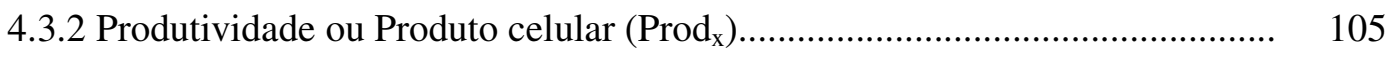

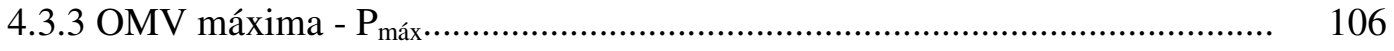

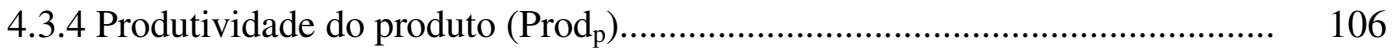

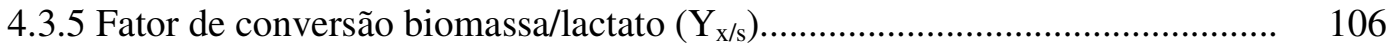

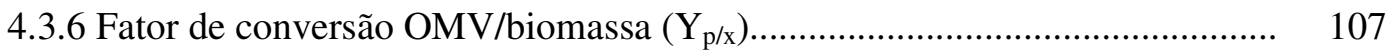

4.4 Fonte de carbono e nitrogênio....................................................................... 108

4.5 Efeito do glicerol................................................................................. 110

4.6 Liberação das vesículas de membrana externa (OMV).................................. 110

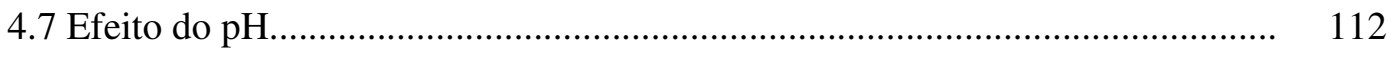

4.8 Modelo de Luedeking \& Piret na Formação de OMV ..................................... 113 
4.9 Presença de IRP e Proteínas nas OMV ............................................................ 114

4.10 Microscopia eletrônica …............................................................................ 115

5 CONCLUSÃO

5.1 Perspectivas futuras........................................................................ 116

REFERÊNCIAS BIBLIOGRÁFICAS...................................................... 117

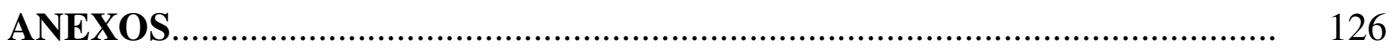

Anexo 7.1: Tabelas de resultados suavizados...................................................... 126

Anexo 7.2: Curvas de D.O. 540nm X Massa seca (g/L)....................................... 138

Anexo 7.3: Resultados e curvas de produção de amônia......................................... 140

Anexo 7.4: Curvas experimentais e suavizadas..................................... 143

Anexo 7.5: Artigo Publicado................................................................................... 149 


\section{INTRODUÇÃO}

\subsection{Histórico da vacina}

A doença meningocócica constitui um significante problema de saúde pública em países desenvolvidos e em desenvolvimento (CAUGANT et al., 1986; FRASCH, 1989). A doença meningocócica foi, no passado, causadora de grandes problemas epidemiológicos durante a primeira e segunda guerra mundial, na Europa e nos Estados Unidos (FRASCH, 1995).

No Brasil, a meningite meningocócica foi observada pela primeira vez em São Paulo no ano de 1906. Em 1945 houve uma epidemia de $N$. meningitidis sorogrupo A que se estendeu até 1951 (GOMES et al., 1950; IVERSSON, 1976; POOLMAN, 1990). Em 1971 ocorreram duas novas epidemias na grande São Paulo, uma causada por $N$. meningitidis $\mathrm{C}$ e outra pela $N$. meningitidis A (BARATA, 1988). Em 1988, iniciou-se uma nova epidemia causada por $N$. meningitidis B que se estendeu por vários anos.

As primeiras vacinas eficazes contra meningococos foram constituídas de polissacarídeos capsulares purificados. Tais vacinas foram produzidas contra os sorogrupos A, C, Y e W135. No entanto, para o sorogrupo B a vacina de polissacarídeo não foi possível. A cápsula do polissacarídeo do meningococo do sorogrupo B é um homopolímero de ácido siálico (ácidos $\mathrm{N}$-acetilneuramínicos), quimicamente idêntico ao polissacarídeo presente em tecidos humanos (POLLARD; MAXON, 2002; FRASCH, 1995; FRASCH; PEPPLER, 1982). Por essa razão, é pouco imunogênico ou o uso do polissacarídeo capsular B em vacina poderia induzir formação de anticorpos relacionados à autoimunidade. Assim, uma abordagem alternativa seria a vacina baseada em proteínas expostas na superfície da membrana externa ou, no caso, presentes na superfície de vesículas de membrana externa, OMV (BORROW et al., 2005; COMANDUCCI et al., 2002; FRASCH, 1995).

Todas as vacinas contra meningococos do sorogrupo B no mercado e em testes clínicos são baseadas em OMVs. Entre as comercializadas, encontra-se a vacina cubana, VAMENGOC-BC ${ }^{\circledR}$ extraída da cepa Cu385/83 e polissacarídeo do grupo C (PSC) (MILAGRES et al., 1998; MILAGRES et al., 1994), a vacina norueguesa, Folkehelsa ${ }^{\circledR}$, formulada com OMV extraídas da cepa 44/76 (FREDERIKSEN et al.,1991; JÓDAR et al.,2002; MORLEY; POLLARD, 2002; ZOLLINGER, 1997) e a vacina hexavalente holandesa Hexamen, composta de OMVs de duas cepas cada uma expressando três subtipos diferentes de porina A (CLAASSEN et al., 1996). 
Em função da situação epidemiológica no Brasil, no final dos anos 80, foi administrada a vacina VA-MENGOC-BC ${ }^{\circledR}$, em crianças e adolescentes, a maioria vacinada dos três meses aos nove anos de idade com duas doses. A eficácia da vacina foi avaliada pelo Instituto Adolfo Lutz, em São Paulo em iniciativa conjunta da Secretaria Estadual de Saúde de São Paulo e da Organização Panamericana de Saúde, em colaboração com a Food and Drug Administration (FDA), dos Estados Unidos. Concluíram que a vacina cubana era dependente da idade, sendo que nenhuma proteção foi conferida em crianças menores de 24 meses (JÓDAR et al., 2002; MORLEY; POLLARD, 2002; ZOLLINGER, 1997; MORAES et al., 1992; MILAGRES et al., 1994). Doze meses após a segunda dose a eficácia geral da vacina foi de 54-57\% com comprovação de ausência de resposta em crianças menores de 2 anos, que corresponde à faixa etária de maior risco para o desenvolvimento dessa doença (MORAES et al., 1992; MILAGRES et al., 1994; NORONHA et al., 1995). Esses resultados foram posteriormente confirmados em ensaios clínicos com a mesma vacina cubana, no Chile (BOSLEGO et al., 1995).

Frente à gravidade da doença meningocócica e a partir desses resultados, três instituições brasileiras, o Instituto Adolfo Lutz, Instituto Butantan e Fundação Oswaldo Cruz, estabeleceram um projeto cooperativo, chamado Projeto Meningite, em que estabeleceram metas independentes e/ou intercomplementares com o objetivo de desenvolver e produzir uma vacina contra a doença meningocócica $\mathrm{B}$ e $\mathrm{C}$.

O Instituto Adolfo Lutz, de São Paulo, como Centro de Referência Nacional em Neisseria meningitidis, foi responsável pela escolha das cepas vacinais, da padronização dos ensaios imunológicos e da avaliação da imunogenicidade dos antígenos vacinais em modelos animais.

O Instituto Butantan e Fundação Oswaldo Cruz, caracterizados como produtores, desenvolveram, a partir dos estudos preliminares realizados no Instituto Adolfo Lutz, alternativas distintas para o cultivo do meningococo e obtenção dos antígenos, em escala piloto de produção, para que pudessem ser analisados como vacinas num potencial estudo da fase I e II. A proposta de composição das vacinas experimentais do Projeto Meningite foi comum aos dois produtores devendo ser composta de vesículas de membrana externa, OMV, com cepas prevalentes no Brasil. Essas vesículas devem expressar, além das proteínas de classe (PorA, PorB, Rmp, Opa e Opc), as proteínas reguladas pelo íon ferro (IRP) e a endotoxina lipooligossacarídeos (LOS). O LOS constitutivo das vesículas deveria ser 
parcialmente removido, de forma a diminuir o nível de toxicidade da vacina conservando, porém, a integridade das vesículas.

Nos estudos realizados no Instituto Butantan, empregou-se o meio de Catlin com várias concentrações de ferro para os sucessivos experimentos relacionados à expressão de IRPs. No processo de produção da vacina do Instituto Butantan, as OMVs são obtidas a partir do meio de cultivo, para onde são liberadas durante o crescimento. Isso contribui para facilitar a extração e purificação das OMVs, pois praticamente não ocorre lise bacteriana e conseqüentemente não ocorre contaminação por material intracelular como proteínas e ácidos nucléicos, indesejáveis na vacina.

Durante o desenvolvimento do Projeto Meningite, muitas linhas de pesquisa se abriram no Centro de Biotecnologia do Instituto Butantan com várias abordagens, entre elas: "Influência da composição do meio de cultura sobre as produtividades em polissacarídeo, da Neisseria meningitidis sorogrupo C, cultivada em processo descontínuo submerso"(PAZ, 1999); “Obtenção e avaliação imunológica de vacina conjugada antiminingocócica sorogrupos B e C" (FUKASAWA, 2000); "Estudo comparativo entre os processos descontínuo e descontínuo alimentado na produção de polissacarídeo de Neisseria meningitidis sorogrupo C" (BARUQUE-RAMOS, 2000); "Estudo de formulação da vacina anti-meningocócica polissacarídeo $\mathrm{C}$, conjugada a vesícula de membrana externa $\mathrm{B}$ de Neisseria meningitidis" (CORRÊA, 2002); "Produção de polissacarídeo em processo de cultivo descontínuo de Neisseria meningitidis sorogrupo C comparando os meios de cultivo Frantz, Frantz modificado e Catlin 6" (PAZ et al., 2003); "Desenvolvimento de uma vacina conjugada antimeningocócica sorogrupos B/C" (FUKASAWA, 2004); e o presente trabalho "Cinética do cultivo em biorreator de Neisseria meningitidis sorogrupo B".

Com base nos bons resultados obtidos sobre o cultivo e a purificação do antígeno de N. meningitidis B, no Centro de Biotecnologia do Instituto Butantan, em 1996 foi decidida a criação do laboratório de vacina contra meningite junto à Divisão de Produção, de tal forma que o produto obtido estivesse em condições para ser utilizado em estudo de fase I e II em seres humanos.

O Laboratório de Meningite criado em 1996, tendo como responsável a $\operatorname{Dr}^{\mathrm{a}}$ Rocilda Perrazini Furtado Schenkman, passou por quatro etapas. Segundo Schenkman, 2007, a primeira etapa teve início em março/1998 com implantação e instalação dos equipamentos; a segunda, com início em outubro/1999, foi a fase da produção dos lotes sementes, lote trabalho 
e lote do produto concentrado a granel; a terceira etapa, com início em 2002, foi a fase de testes de controle de qualidade, escolhas dos lotes para formulação e envase da vacina e organização da documentação necessária. Foram produzidos dois lotes de vacina contra meningite B, um dos lotes com LOS detoxificado - dLOS e outro sem dLOS totalizando de 8.300 doses usáveis. A quarta etapa do Laboratório de Meningite foi a etapa da desativação e em março/2004 o laboratório foi totalmente desativado (SCHENKMAN et al., 2001; informação verbal) ${ }^{1}$.

\subsection{Doença meningocócica}

Meningite e septicemia causadas por Neisseria meningitidis do sorogrupo B são duas doenças severas de alto índice de letalidade (ZOLLINGER et al., 1997; GIULIANI et al., 2006). A doença meningocócica é conhecida desde 1805, quando Vieussex descreveu uma epidemia de febre cerebroespinhal em Genebra. No entanto, apenas em 1887 é que foi estabelecido por Weichselbaum que a Neisseria meningitidis era o agente etiológico dessa infecção (MAZZA et al., 1991). A meningite, segundo Focaccia (1996), é um processo inflamatório do espaço subaracnóideo e das membranas leptomeníngeas (pia - aracnóide) que envolvem o encéfalo e a medula espinhal (Figura 1.1).

\footnotetext{
${ }^{1}$ SCHENKMAN, R.P.F. São Paulo, 2007 (informação verbal).
} 


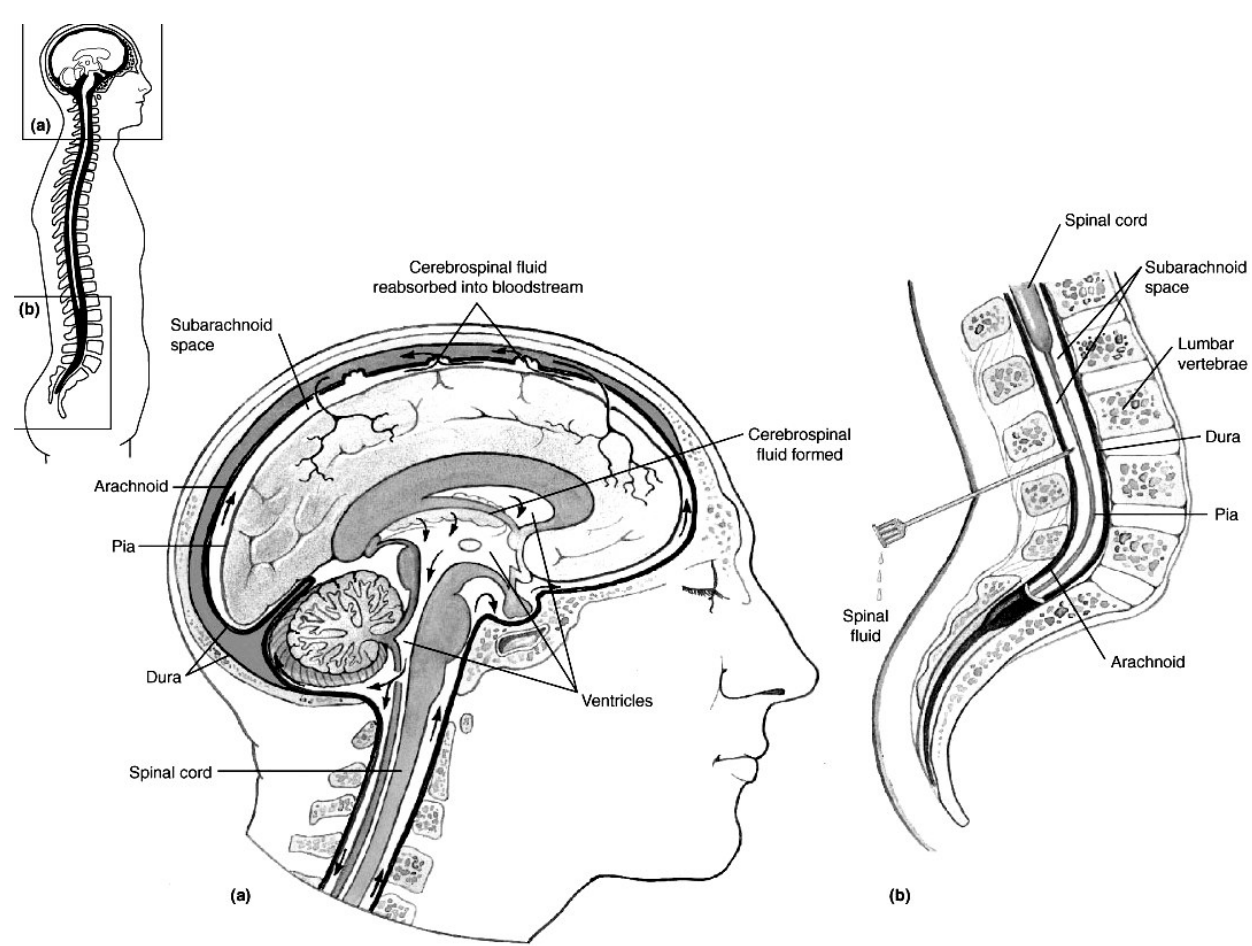

Figura 1.1 - Processo inflamatório da meningite.

FONTE: http://images.google.com.br/images?hl=pt-R\&q=n.+meningitidis\&gbv=2 Acesso em: jun. de 2006.

A doença é responsável por mortes e seqüelas graves, especialmente retardo mental, deficiência auditiva, convulsões, incapacidade permanente, disfunção e amputação de membros. O desenvolvimento dessa doença tem início repentino e sua evolução é rápida, podendo levar o indivíduo a óbito em menos de 24 horas. A meningite meningocócica resulta da disseminação da bactéria presente na nasofaringe para a corrente sanguínea e desta para as meninges. Caracteriza-se clinicamente por febre alta, cefaléia, vômitos, rigidez de nuca, alterações de reflexos e convulsões (CVE - Centro de Vigilância Epidemiológica, Estado de São Pauo, 2006; MAZZA et al., 1991).

\subsection{Epidemiologia}

A incidência e mortalidade mundial, causadas por $N$. meningitidis, estão estimadas em 500.000 casos, com pelo menos 50.000 mortes (GIRARD et al., 2006).

No Brasil, as duas primeiras epidemias, ocasionadas pelo sorogrupo A e C, foram combatidas com vacinas de polissacarídeos. A terceira epidemia, causada pelo sorogrupo B, 
ocorreu no final dos anos 80 e se estendeu por vários anos. A partir disso, foi introduzida campanha de vacinação em massa, com a vacina cubana VAMENGOC-BC. No entanto, esta apresentou proteção variável de acordo com o grupo etário vacinado (MORAES et al., 1992). Mas, mesmo assim, segundo Fletcher et al. (2004), a prevenção através da vacinação ainda parece ser o melhor caminho para diminuir o contágio da doença meningocócica.

No Brasil, segundo dados do Sinan/SVS/MS (Sistema Nacional de Agravos Notificáveis da Secretaria de Vigilância em Saúde do Ministério da Saúde) no período de 1994 a 2004, o coeficiente médio de incidência da doença meningocócica causada pela Neisseria meningitidis de todos os sorogrupos foi de 3,28/100.000 habitantes e a letalidade foi de 19,4\%. No Estado de São Paulo, a taxa média de incidência foi em torno de 4,59/100.000 habitantes no mesmo período. A letalidade oscilou entre $17 \%$ a $20 \%$ dos casos (CVE, 2006).

A partir de 2003, observou-se aumento da incidência do sorogrupo C em comparação com o sorogrupo B. Porém, a letalidade do sorogrupo B é maior do que a do sorogrupo C (CVE, 2006).

\subsection{Neisseria meningitidis}

Neisseria meningitidis é um diplococo aeróbico, gram-negativo da classe $\beta$ Proteobacterium (TETTELIN et al., 2000), popularmente conhecida como meningococo (Figura 1.2).

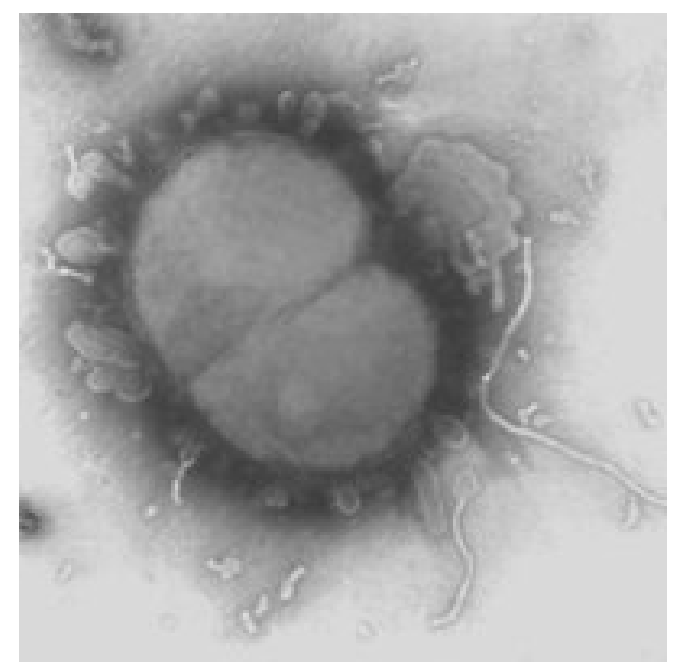

Figura 1.2 - Neisseria meningitidis.

FONTE: Extraída do site: www.kcl.ac.uk/.../nutritional/staff/revans.html acesso em: 21/04/2007. 
O habitat natural de N.meningitidis é o tecido subeptelial da nasofaringe (POOLMAN, 1995), ou seja, trato superior respiratório humano. Cerca de $10 \%$ da população humana têm sua nasofaringe colonizada pelo meningococo, sem que ocorra o desenvolvimento da doença (GUILIANI et al., 2006).

N. meningitidis apresenta um envoltório constituído por uma membrana interna (citoplasmática) e uma membrana externa, com um espaço periplasmático e uma camada de peptidoglicano entre elas (FRASCH; GOTSCHLICH, 1974). Externamente, há uma cápsula de polissacarídeo que envolve toda a bactéria. A membrana externa é constituída por proteínas, lipopolissacarídeos (LPS) e polissacarídeo capsular (PELCZAR et al., 1996; POOLMAN 1995; FRASCH; PEPPLER, 1982) (Figura 1.3).

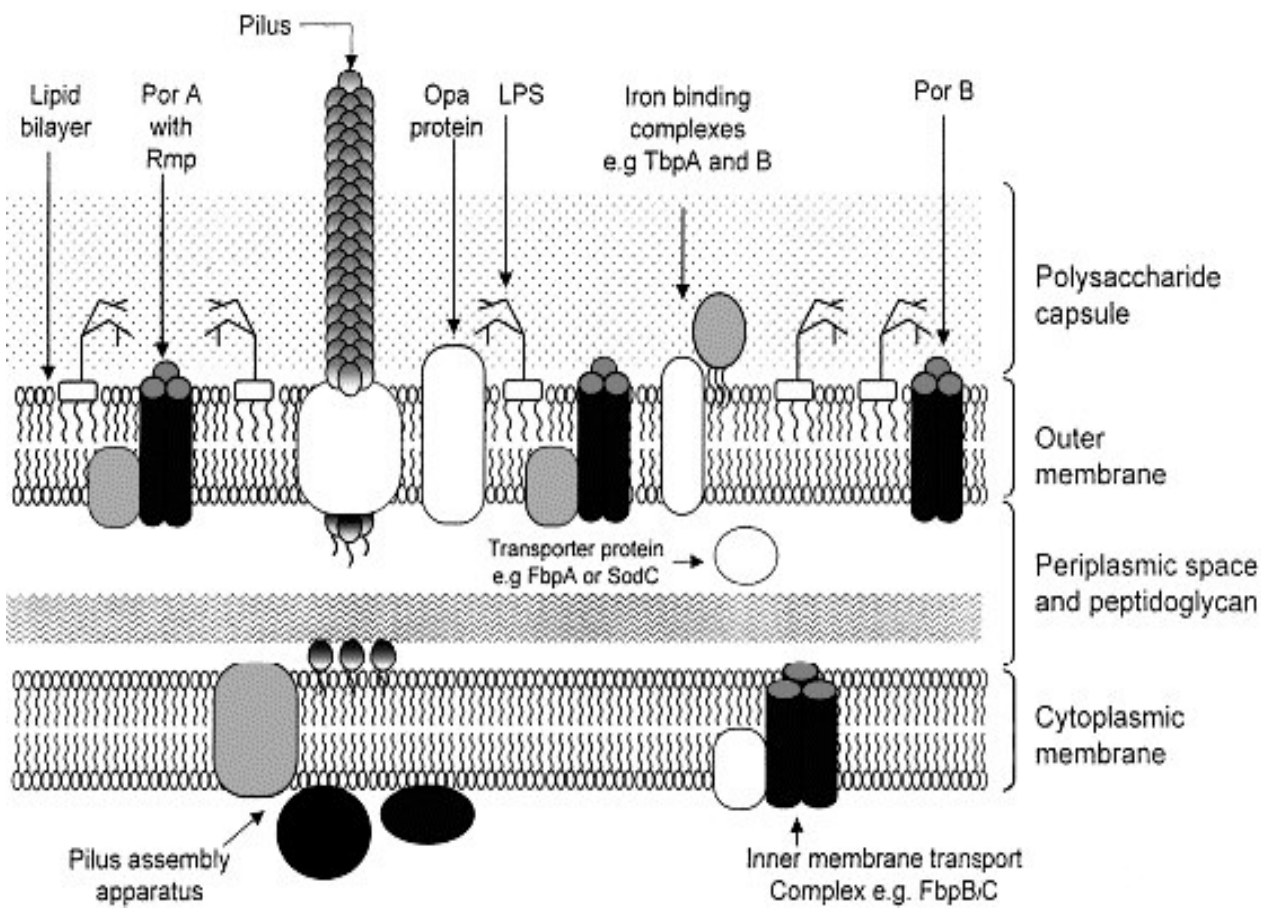

Figura 1.3 - Representação do envoltório celular da Neisseria meningitidis. FONTE: Extraída de MORLEY, S.L. e POLLARD, A.J. (2002).

Na figura 1.3 estão ilustrados os principais componentes presentes na superfície da $N$. meningitidis que serão descritos a seguir. 


\subsubsection{Componentes não protéicos da superfície celular da $N$. meningitidis}

\section{Cápsula polissacarídica}

Atualmente, são descritos 13 sorogrupos com base no polissacarídeo capsular (GIULIANI, 2006). Desses sorogrupos, somente cinco, A, B, C, Y e W135 são responsáveis pelo maior número de casos de doença meningocócica em todo mundo (GIRARD et al., 2006; POLLARD; MAXON, 2002).

As cápsulas dos diferentes sorogrupos diferenciam-se na composição química do polissacarídeo, resultando assim em diferentes propriedades antigênicas (MORLEY; POLLARD, 2002).

\section{Lipooligossacarídeos (LOS)}

O LOS é constituído de uma parte lipídica, o lipídeo A, responsável pela toxidade e uma cadeia constituída de moléculas de ácido 2-ceto-3-deoximanoctanóico (KDO), e de cadeias de polissacarídeos ou oligossacarídeos (ZOOLINGER, 1997), por isso na literatura o encontramos sob a denominação de LOS ou LPS (POLLARD e FRASCH, 2001). As diferenças antigênicas na cadeia de oligossacarídeos dos LOS são utilizadas para a classificação dos meningococos em imunotipos (ZOLLINGER, 1997). Nas vacinas que utilizam OMV como antígeno, retira-se o máximo possível de LOS, porém, tenta-se manter a integridade das vesículas. No entanto, durante esse procedimento ocorre lise de uma parte das OMVs. Por essa razão, neste trabalho as OMVs foram utilizadas e purificadas sem a extração do LOS, para que não houvesse lise ou perdas por meio do procedimento, pois o objetivo era encontrar condições para aumentar a produção de OMV nativa, "in natura”.

\subsubsection{Componentes protéicos da superfície celular da N. meningitidis}

\section{$\underline{\text { Pili }}$}

A presença de "pili" na superfície dos meningococos foi observada por Devoe e Gilchrist (1973). O pili é uma estrutura filamentosa proteinácea que promove a adesão dos meningococos com as células endoteliais e epiteliais humanas (POLLARD; FRASCH, 2001). Por sua enorme variação entre cepas e dentro de uma mesma cepa, essa estrutura não é considerada uma forte candidata vacinal (PETTERSSON-FERNHOLM, 1994). 


\section{Proteínas de classe}

Sâo proteínas majoritárias da membrana externa. Com base principalmente nos trabalhos de Poolman (1995) e Frasch (2001), será feita uma breve descrição das proteínas de classe presentes na superfície da membrana externa e conseqüentemente presentes nas OMVs.

\section{Proteínas de classe 1 (PorA)}

As proteínas de classe 1 são porinas cátion específicas sob a forma de trímeros, também denominadas de porina A (PorA). Apresentam massa molecular entre 44 a $47 \mathrm{kDa}$. A PorA apresenta 2 regiões com alto grau de variabilidade. As diferenças antigênicas nessas regiões classificam os meningococos em subtipos. Forte candidata a antígeno para a vacina meningocócica.

\section{Proteínas de classe 2 ou 3 (PorB)}

As proteínas de classe 2 ou 3 são porinas ânion específicas (POOLMAN, 1995), sob a forma de trímeros. Apresentam massa molecular entre 37 a $42 \mathrm{kDa}$. A PorB apresenta 4 regiões com alto grau de variabilidade na seqüiência dos aminoácidos. Essas regiões hipervariáveis compreendem a base para a classificação dos meningococos em sorotipos. As proteínas de classe 2 e de classe 3 são excludentes entre si, isto é, uma cepa só pode apresentar uma delas.

\section{Proteína de classe $4(\mathrm{Rmp})$}

A proteína de classe 4 , conhecida como proteína de redução modificável, Rmp, tem função desconhecida. Apresenta massa molecular de 33 a $34 \mathrm{kDa}$, possui estrutura altamente conservada.

\section{Proteínas de classe 5 (Opa e Opc)}

As proteínas de classe 5, conhecidas como proteínas de opacidade de adesão e invasão, Opa e Opc, possuem massa molecular que varia entre 25 a $30 \mathrm{kDa}$. Opa é uma proteína altamente variável na expressão. A estrutura da proteína é composta de três regiões variáveis, uma semi-variável e duas hipervariáveis.

\section{Neisseria Adesina A (NadA)}

A NadA é uma proteína, associada à adesão e à invasão celular, presente na superfície dos meningococos. Possui uma estrutura oligomérica com massa molecular de 170 a 190 kDa 
composta por 4 a 5 monômeros. Cada monômero apresenta 362 aminoácidos com massa molecular entre 35 a $40 \mathrm{kDa}$. Essa forma oligomérica é extremamente estável ao calor e não se dissocia na presença de dodecil sulfato de sódio (SDS) e nem em mercaptoetanol (CAPECCHI et al., 2005). Foi verificado que a NadA recombinante é capaz de induzir anticorpos com altas atividades bactericidas contra cepas do sorogrupo A, B e C e que conferiram proteção passiva em ratos neonatos desafiados com duas cepas de meningococos de grupo B (COMANDUCCI, 2002). Dessa maneira, a proteína NadA é uma forte candidata ao antígeno vacinal (CAPECCHI et al., 2005; COMANDUCCI et al., 2002).

\section{Proteínas reguladas pelo íon ferro (IRPs)}

As IRPs são glicoproteínas receptoras de ferro expressas na membrana externa quando os meningococos se encontram em meio com limitação de ferro (POLLARD; FRASCH, 2001). As proteínas reguladas pelo íon ferro têm a função de captar ferro de transferrinas, lactoferrinas e grupos heme do hospedeiro (ARCHIBALD; DEVOE, 1980). O íon ferro é um nutriente essencial para o crescimento bacteriano e no meio extracelular sua presença é muito reduzida, tornando-se um fator limitante para o seu crescimento. A capacidade que cada bactéria possui para adquirir ferro do meio define o seu potencial de virulência (BULLEN, 1981; FINKELSTEIN et al., 1983; HOLBEIN, 1981). Em situações de estresse de ferro, produzem IRPs, essas proteínas captam formas de ferro presentes no meio e o utilizam em benefício próprio (BRANDILEONE et al., 1994). Diferentemente de algumas bactérias, $N$. meningitidis é incapaz de sintetizar sideróforos, compostos de alto peso molecular envolvidos com a captação do ferro, porém ela sintetiza um número adicional de proteínas de membrana externa, receptores de ferro, chamadas genericamente de IRPs (PETTERSSON-FERNHOLM, 1994).

Recentemente, a importância do ferro na patogênese de $N$. meningitidis tem instigado inúmeras pesquisas no sentido de relacionar algumas proteínas reguladas pela disponibilidade do íon ferro, as IRPs, com imunidade humoral e como candidatas à produção de vacinas contra N. meningitidis B (BHATNAGAR; FRASCH, 19990; BLACK et al., 1986; FRASCH et al., 1988). 


\subsection{Vesícula da membrana externa (OMV)}

As vesículas da membrana externa têm de 10 a 100 nm de diâmetro, são liberadas no meio de cultura durante o crescimento bacteriano e são resultantes de evaginações da membrana externa (Figura 1.4) (DEVOE, 1973; POOLMAN, 1995). Essas vesículas apresentam interesse imunogênico porque são constituídas de todos os componentes presentes na superfície da membrana externa da bactéria, isto é, polissacarídeos, fosfolipídeos, lipoooligossacarídeos e principalmente proteínas (JOHNSTON; GOTSCHLICH, 1974), conforme descritas no item anterior.

Vale ressaltar que uma melhor compreensão do processo e obtenção dessas não é importante apenas porque as vesículas são utilizadas como antígenos na vacina contra meningite $\mathrm{B}$, mas porque, além disso, as OMVs também têm sido utilizadas como carregadores de polissacarídeos em vacinas conjugadas de hemofilos, produzidas pela Merck, em vacinas de pneumonia (AHONKHAI et al., 1991; FU et al., 1995) e experimentalmente como adjuvante oral da vacina contra o vírus respiratório sincicial (ETCHART et al., 2006).

a)

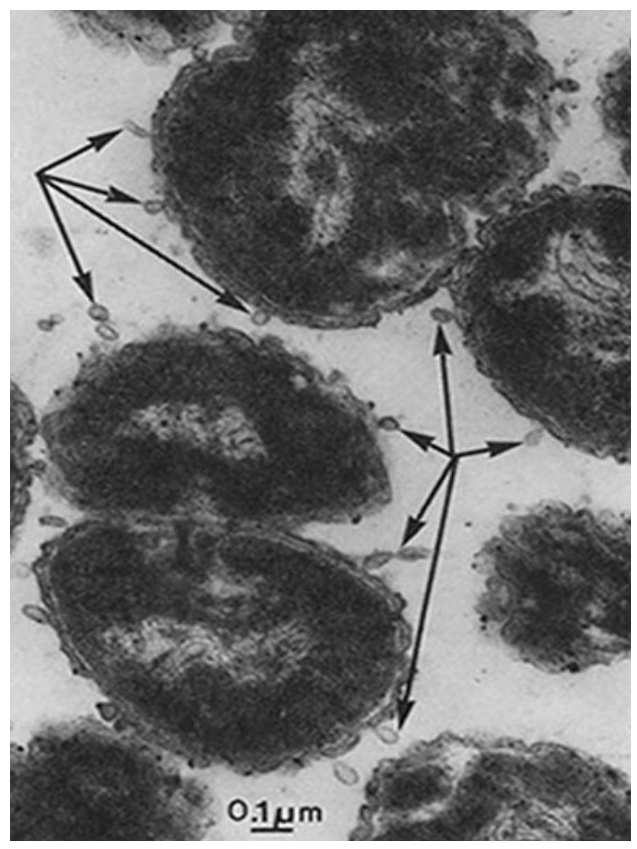

b)

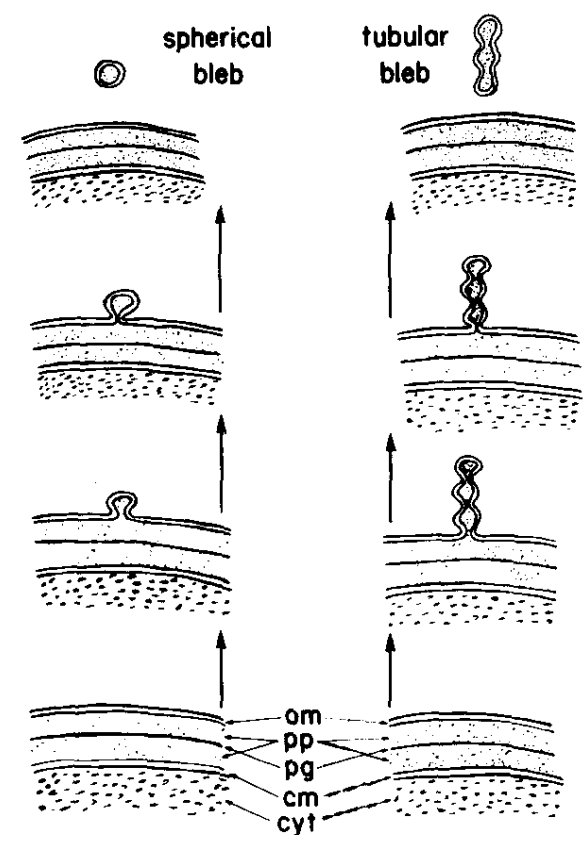

Figura 1.4 - Vesículas de membrana externa (OMV) de Neisseria meningitidis (a) e representação esquemática da liberação de OMV (b).

FONTE: Extraído do artigo DEVOE, I.W. e GILCHRIST, J.E. (1973). 


\subsection{Processo para o cultivo do meningococo}

A maior parte de cultivo de $N$. meningitidis ocorre em meio líquido de Catlin (CATLIN, 1973), após ativação em meio agar Muller-Hinton. O meio de Catlin é um meio quimicamente definido, o que permite rigoroso controle de formulação e análise distinta do efeito de cada componente. Esses meios foram utilizados por pesquisadores do Instituto Adolfo Lutz para escolha de cepa vacinal utilizada pelo Instituto Butantan.

Fu e colaboradores (1995) tiveram preocupação em estudar o meio de cultivo como estímulo para o aumento da biomassa. Deram ênfase na modificação do meio de Catlin e no aperfeiçoamento das técnicas de cultivo para obtenção de maior densidade celular. Utilizaram glicose como única fonte de carbono e concluíram que o catabolismo da glicose estava sendo realizado predominantemente pelo ciclo de triose-fosfato da via pentose-fosfato, uma vez que detectaram baixos níveis de acumulação de acetato no meio e não detectaram a formação de piruvato. Realizaram um estudo detalhado sobre os componentes do meio de cultivo, reportaram uma condição de cultivo e de meio modificado, utilizando glicose, que dizem ser ótima para a produção de biomassa, utilizaram uma cepa do sorotipo 2 , diferente da cepa prevalente no Brasil que é sorotipo 3, mas não apresentaram valores sobre as concentrações de OMVs, nem durante, nem no final do cultivo.

O crescimento de $N$. meningitidis, segundo Leighton et. al. (2001), requer piruvato, lactato ou glicose como fonte de carbono. O sistema piruvato desidrogenase presente em $N$. meningitidis converte piruvato em acetil-CoA e $\mathrm{CO}_{2}$. O lactato, como principal fonte de carbono, é utilizado convertendo-se em piruvato por pelo menos três enzimas lactato desidrogenase - as LDH (ERWIN e GOTSCHLICH 1996) que têm sua seqüência confirmada no genoma de $N$. meningitidis B cepa MC58 (TETTILIN et. al. 2000). Diante dessa perspectiva, torna-se interessante um estudo sobre a utilização do lactato, como principal fonte de carbono, e a produção de OMV.

\subsection{Objetivo}

O presente trabalho tem como objetivo estudar a cinética de geração de biomassa e de OMV de $N$. meningitidis sorogrupo B em cultivos descontínuo e descontínuo com pulso de lactato e aminoácidos realizados em biorreator, procurando melhorar o rendimento na obtenção desse antígeno vacinal. 


\section{MATERIAIS E MÉTODOS}

\subsection{Microrganismo}

Foi utilizada a cepa N.44/89 de Neisseria meningitidis sorogrupo B, prevalente no Brasil, proveniente do banco de cultura do Instituto Adolfo Lutz de São Paulo, Centro de Referência Nacional em Meningites.

\subsection{Lote trabalho}

O lote trabalho foi preparado em meio Müller-Hinton líquido contendo $2 \%$ de soro eqüino normal e 20 a $30 \%$ de glicerol. Foi aliquotado em vários criotubos e mantido em nitrogênio líquido.

\subsection{Meios de Cultura}

Foram utilizados o meio de ágar Müller-Hinton (tabela 2.1), contendo $2 \%$ de soro eqüino normal (MÜLLER, 1941), para o preparo do inóculo, o meio ágar-soro em base TSB, (Tryptic Soy Broth) (tabela 2.2) e ágar-chocolate em base BHI (Brain and Heart Infusion) (DIFCO LABORATORIES, 1984) (tabela 2.3) para estudos da viabilidade celular e o meio de Catlin (CATLIN, 1973) sem ferro (tabela 2.4) para cultivo em meio líquido utilizado em todos os ensaios. Modificações no meio de Catlin, no que diz respeito às concentrações de lactato, aminoácidos e glicerol, foram realizadas no decorrer deste trabalho. No entanto, esse meio sempre foi mantido sem ferro, porque só na ausência deste íon é possível a obtenção de OMVs que apresentam as proteínas reguladas pelo ferro, as IRPs, em sua superfície. 
Tabela 2.1 - Composição do meio sólido de ágar Müller-Hinton - contendo 2\% de soro.

\begin{tabular}{lr}
\hline Infusão de carne - Difco & $300,0 \mathrm{~g}$ \\
Ácidos casamínicos - Difco & $17,5 \mathrm{~g}$ \\
Amido & $1,5 \mathrm{~g}$ \\
Ágar & $17,0 \mathrm{~g}$ \\
Água destilada (q.s.p) & $1,0 \mathrm{~L}$ \\
Soro eqüino & $2 \%$ \\
\hline
\end{tabular}

Tabela 2.2 - Composição do meio sólido de ágar-soro em base TSB.

\begin{tabular}{ll}
\hline TSB - Difco & $30,0 \mathrm{~g}$ \\
Ágar & $15,0 \mathrm{~g}$ \\
Água Destilada (q.s.p) & $1,0 \mathrm{~L}$ \\
Soro eqüino & $2 \%$ \\
\hline
\end{tabular}

Tabela 2.3 - Composição do meio sólido de ágar-chocolate em base BHI.

\begin{tabular}{ll}
\hline BHI - Difco & $37 \mathrm{~g}$ \\
Ágar & $20 \mathrm{~g}$ \\
Água Destilada (q.s.p) & $1,0 \mathrm{~L}$ \\
Sangue eqüino & $10 \%$ \\
\hline
\end{tabular}


Tabela 2.4 - Composição do meio líquido de Catlin sem ferro*

\begin{tabular}{llr}
\hline Componentes & & g/L \\
\hline Cloreto de sódio & $\mathrm{NaCl}$ & 5,844 \\
Cloreto de amônia & $\mathrm{NH}{ }_{4} \mathrm{Cl}$ & 0,401 \\
Cloreto de potássio & $\mathrm{KCl}$ & 0,186 \\
Cloreto de cálcio & $\mathrm{CaCl}_{2} \cdot 2 \mathrm{H}_{2} \mathrm{O}$ & 0,037 \\
Citrato de sódio & $\mathrm{C}_{6} \mathrm{H}_{5} \mathrm{Na}_{3} \mathrm{O}_{7} \cdot 2 \mathrm{H}_{2} \mathrm{O}$ & 0,647 \\
Sulfato de magnésio & $\mathrm{MgSO}_{4} \cdot 7 \mathrm{H}_{2} \mathrm{O}$ & 0,616 \\
Sulfato de manganês & $\mathrm{MnSO}_{4} \cdot \mathrm{H}_{2} \mathrm{O}$ & 0,001 \\
Ácido L-glutâmico & $\mathrm{C}_{5} \mathrm{H}_{9} \mathrm{NO}_{4}$ & 1,18 \\
L-arginina.HCl & $\mathrm{C}_{6} \mathrm{H}_{14} \mathrm{~N}_{4} \mathrm{O}_{2} \cdot \mathrm{HCl}$ & 0,105 \\
Glicina & $\mathrm{NH}_{2} \mathrm{CH}_{2} \mathrm{COOH}$ & 0,151 \\
L-serina & $\mathrm{C}_{3} \mathrm{H}_{7} \mathrm{NO}_{3}$ & 0,021 \\
L-cisteína.HCl.H & $\mathrm{C}_{3} \mathrm{H}_{7} \mathrm{NO}_{2} \mathrm{~S} . \mathrm{HCl} \cdot \mathrm{H}_{2} \mathrm{O}$ & 0,011 \\
Glicerol & $\mathrm{C}_{3} \mathrm{H}_{8} \mathrm{O}_{6}$ & 5,01 \\
Lactato de Sódio & $\mathrm{C}_{3} \mathrm{H}_{5} \mathrm{O}_{3} \mathrm{Na}_{2}$ & 7,51 \\
Fosfato de Sódio & $\mathrm{Na}_{2} \mathrm{HPO}_{4}$ & 1,062 \\
Fosfato de Potássio & $\mathrm{KH}_{2} \mathrm{PO}_{4}$ & 0,171 \\
\hline
\end{tabular}

*O meio Catlin completo tem a mesma formulação, incluindo-se o $\mathrm{FeSO}_{4} .7 \mathrm{H}_{2} \mathrm{O}$.

\subsection{Ensaios preliminares em agitador rotatório}

Ensaios foram realizados de acordo com planejamento fatorial de 3 variáveis em 2 níveis conforme ilustrado na tabela 3.2. As variáveis utilizadas foram ácido L-glutâmico, glicerol e lactato. Os dois níveis considerados foram o de maior concentração e o de menor concentração de cada uma das variáveis. Foram utilizados oito erlenmeyers de $300 \mathrm{~mL}$ de capacidade, contendo $100 \mathrm{~mL}$ de meio Catlin sem ferro, incubados a $250 \mathrm{rpm}$ e $36{ }^{\circ} \mathrm{C}$. O inóculo foi preparado nas mesmas condições descritas no item 2.5.1. Os valores adotados para as concentrações iniciais do ácido L-glutâmico, glicerol e lactato estão listados na tabela 3.2. As análises dos resultados foram baseadas na leitura da densidade óptica a $540 \mathrm{~nm}$, realizadas de hora em hora e na determinação da quantidade de OMV após 8h de cultivo (tabela 3.2). 


\subsection{Cultivo em biorreator}

Na figura 2.1 observa-se um fluxograma que representa as várias etapas do processo de cultivo de $N$. meningitidis e análises das amostras dos ensaios realizados em biorreator.

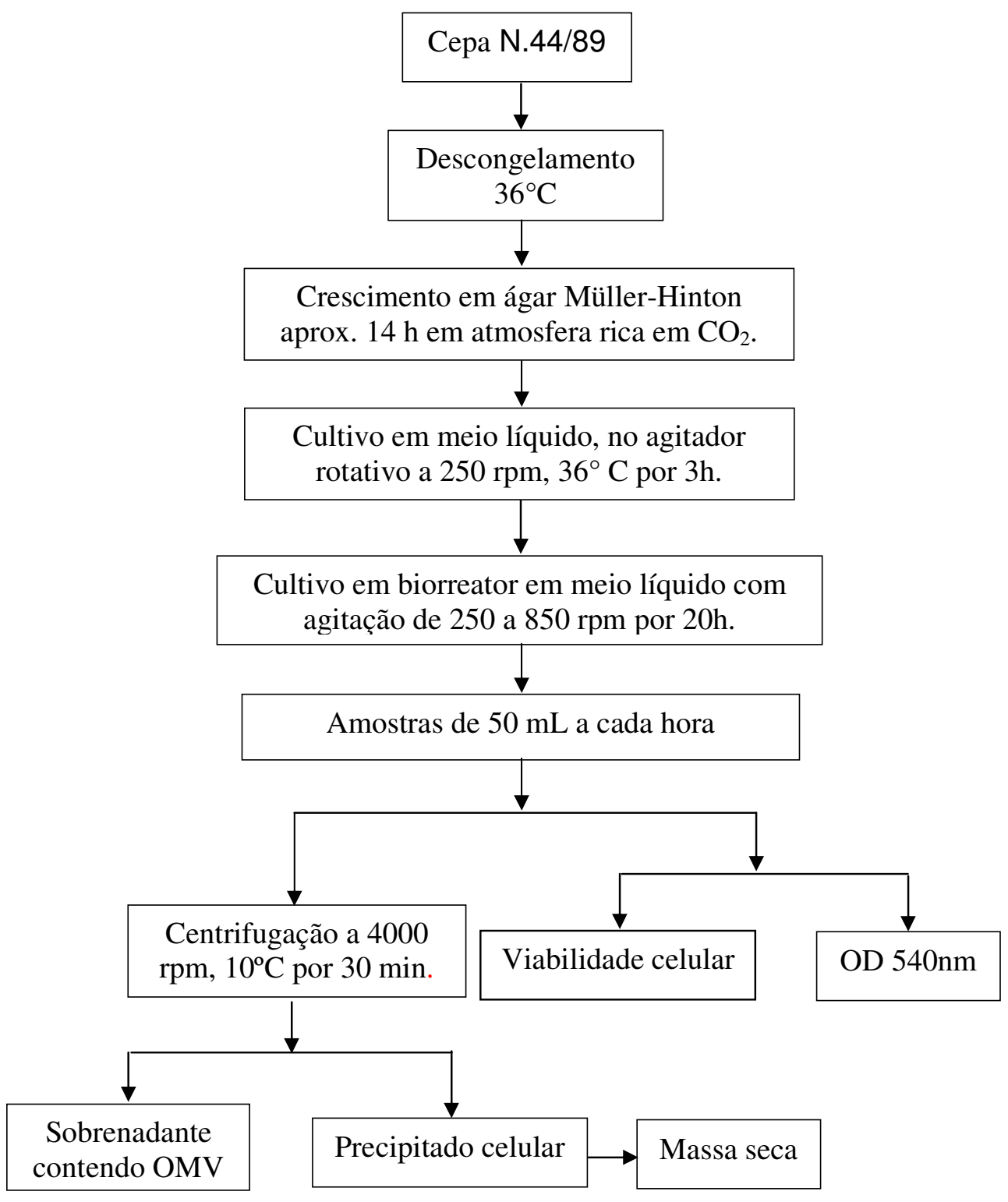

Figura 2.1 - Fluxograma do processo de cultivo de N. meningitidis. 


\subsubsection{Inóculo}

\subsubsection{Preparo da $\mathbf{1}^{\mathrm{a}}$. etapa do inóculo}

Um criotubo contendo $1 \mathrm{ml}$ de $N$. meningitidis cepa N.44/89 foi retirado do nitrogênio líquido e descongelado a $36^{\circ} \mathrm{C}$. Após o descongelamento, alíquota de $200 \mu \mathrm{L}$ da suspensão bacteriana do criotubo foi inoculada em cada um dos 5 tubos com tampa rosqueada, contendo meio inclinado de ágar Müller-Hinton (tabela 2.1) com $2 \%$ de soro eqüino normal. Esses tubos foram incubados em devido suporte por aproximadamente $14 \mathrm{~h}$ a $36^{\circ} \mathrm{C}$, em câmera úmida sob atmosfera de 6-8\% de $\mathrm{CO}_{2}$.

\subsubsection{Preparo da $2^{\mathrm{a}}$. etapa do inóculo}

Para ressuspender o tapete celular formado na superfície do meio de ágar MüllerHinton dos 5 tubos, utilizamos aproximadamente $3 \mathrm{~mL}$ de meio de Catlin sem ferro (tabela 2.4) por tubo. O material de cada tubo foi transferido com auxílio de uma pipeta para 5 erlenmeyers de $500 \mathrm{~mL}$ cada um, contendo $100 \mathrm{~mL}$ do meio Catlin sem ferro. Esses frascos foram mantidos em agitador rotativo, com freqüência rotativa de $250 \mathrm{rpm}$, a $36^{\circ} \mathrm{C}$, por 3 horas, período suficiente para que as células atingissem a fase exponencial de crescimento. Após esse período foram realizados coloração de Gram (BIER, 1985) e exame microscópico para verificar a pureza da cultura de cada frasco. Constatando-se que não havia contaminação, o conteúdo de todos os erlenmeyers foi reunido em um único frasco e foi feita a leitura da densidade óptica do inóculo a $540 \mathrm{~nm}$.

\subsubsection{Determinação do volume do inóculo}

Após a leitura da densidade óptica do inóculo, foi transferido ao biorreator um volume de inóculo que promovesse uma densidade óptica inicial de 0,1 a $540 \mathrm{~nm}$. Esse procedimento foi realizado para padronizar a concentração inicial de células em todos os ensaios. 
O volume do inóculo necessário para se obter essa densidade óptica no biorreator foi calculado por meio da equação 1:

$$
\text { Volume do inóculo }=\frac{\text { Volume do biorreator X 0,1 }}{\mathrm{DO}_{540} \text { inóculo }-0,1}
$$

\subsection{Descrição do biorreator}

O biorreator New Brunswick Scientific (modelo Bioflo 2000), com dorna de vidro de borossilicato, capacidade nominal total de 7L e tampa de aço inox, tem sua agitação garantida por um rotor composto por dois impelidores do tipo Rushton com aeração superficial (figura 2.2). Para medir oxigênio dissolvido durante o cultivo, o biorreator possui um eletrodo de vidro esterilizável (Ingold model 465-90, Mettler-Toledo, Alphaville-Barueri, Brazil) e um eletrodo polarográfico autoclavável (Ingold model 531, Mettler-Toledo, Alphaville-Barueri, Brasil).

Uma sonda de temperatura foi acoplada internamente ao biorreator. O conteúdo da dorna é aquecido com auxílio de uma manta elétrica localizada na base do biorreator e o controle ocorre por meio do resfriamento com circulação de água na serpentina de refrigeração localizada em seu interior.

A retirada de amostras foi realizada por uma saída própria composta por uma mangueira de silicone e em sua extremidade está conectada um amostrador. 

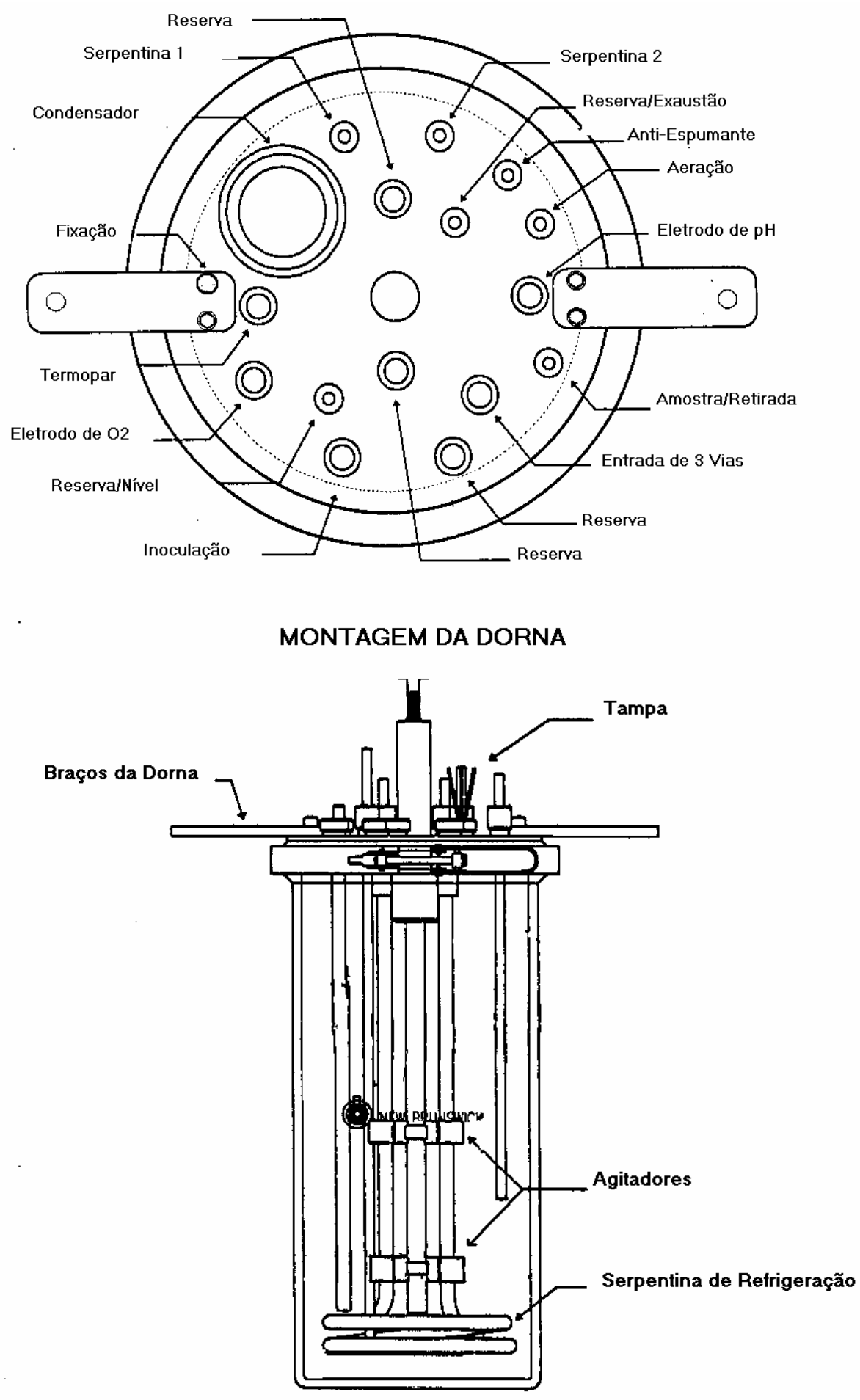

Figura 2.2 - Desenho do Biorreator New Brunswick Scientific Bioflo 2000.

FONTE: NEW BRUNSWICK, 1996. 


\subsubsection{Preparo do biorreator e filtração do meio}

A dorna, devidamente montada e contendo $3 \mathrm{~L}$ de água destilada no seu interior, foi esterilizada em autoclave a $121^{\circ} \mathrm{C}$, durante $40 \mathrm{~min}$, como descrito por Urenha, Pradella e Rodrigues (2001). Após o resfriamento, à temperatura ambiente, a água foi removida por meio de uma mangueira destinada à drenagem, de forma que a esterilidade da dorna fosse mantida. A seguir o meio foi filtrado para o interior da dorna pelo sistema de filtração esterilizante Opticap da Millipore, com membrana de porosidade média de 0,22 $\mu \mathrm{m}$. O meio foi introduzido para o interior da dorna passando pelo filtro esterilizado com o auxílio de uma bomba peristáltica. Aproximadamente 4,2 L de meio de Catlin sem ferro, modificado ou não, foram filtrados para o interior do biorreator e o 1,8 litro restante foi filtrado em cabine de fluxo laminar para o interior de frascos esterilizados, em sistema Millipak - Millipore, com membrana de porosidade média de $0,22 \mu \mathrm{m}$. Esse volume restante foi utilizado para cultivo em agitador rotativo, preparo do inóculo e para as diluições das amostras quando necessário.

\subsubsection{Condições dos cultivos}

As condições de cultivo utilizadas foram pré-estabelecidas no Laborátorio de Meningite do Instituto Butantan sob a Coordenação da Dra. Rocilda P. F. Schenkman.

Temperatura $=36^{\circ} \mathrm{C}$;

Duração = 20 h;

Vazão de ar = $1 \mathrm{~L} / \mathrm{min}$ (aeração superficial);

Volume inicial do meio sem inóculo $=4,2 \mathrm{~L}$;

Volume do inóculo $=0,4 \mathrm{~L}$;

$\mathrm{pH}$ do meio de cultura $=7,0$ a 7,4;

Pressão no biorreator $=0,5$ bar;

Agitação mínima $=250 \mathrm{rpm}$;

Agitação máxima $=850 \mathrm{rpm}$;

Oxigênio dissolvido $=10 \%$ da saturação;

$\mathrm{k}_{\mathrm{L}} \mathrm{a}=5,3 \mathrm{~h}^{-1}$. 


\subsubsection{Calibração do eletrodo de oxigênio dissolvido}

O monitoramento da concentração de oxigênio dissolvido foi realizado por meio de eletrodo polarográfico, descrito no item 2.6, durante um processo fermentativo.

A sonda de oxigênio foi calibrada antes do início de cada cultivo, em zero e $100 \%$.

Nos primeiros ensaios, a calibração da sonda de oxigênio em zero foi realizada com o ajuste da agitação a 400 rpm, seguida por borbulhamento do gás nitrogênio no meio de cultura até o oxigênio atingir zero. Em outros ensaios, a calibração foi feita pelo ajuste do zero eletrônico, com a desconexão do cabo do eletrodo até atingir zero.

A calibração da sonda em $100 \%$ foi realizada, no meio de cultura, sob a agitação mantida em 400 rpm e borbulhando ar comprimido por cerca de 10 minutos ou até que o valor de oxigênio dissolvido ficasse constante e, quando necessário, o ajuste em 100\% foi feito manualmente. Para a calibração desse eletrodo utilizou-se o "Guia de Operações” Bioflo 3000 Bench - TOP. Fermentor manual no M1227-0050/D - New Brunswick Scientific.

\subsubsection{Determinação de $K_{L} a$}

Para determinar o produto entre coeficiente global de transporte de massa relativo à fase líquida ("K $\mathrm{K}_{\mathrm{L}}$ ) e a área de interfase (gás-liquido) por unidade de volume ("a"), foi utilizada a técnica do "gassing-out" (PIRT, 1975). Esse método consiste na eliminação do oxigênio dissolvido no meio de cultura por meio da introdução do nitrogênio. Após certo tempo, foi introduzido ar comprimido ao biorreator e os valores crescentes da concentração de oxigênio dissolvido no decorrer do tempo foram anotados. A determinações de $\mathrm{K}_{\mathrm{L}} \mathrm{a}$ foram realizadas antes do ensaio, no meio de cultura, sob as mesmas condições de cultivo no biorreator (item 2.6.1.1). 


\subsubsection{Calibração do eletrodo de pH}

O eletrodo autoclavável descrito no item 2.6, foi calibrado por meio da solução tampão de $\mathrm{pH}=7,0$ e tampão de $\mathrm{pH}=4,0$. A calibração do eletrodo de $\mathrm{pH}$ foi realizada antes da dorna ser autoclavada para que ambos fossem esterilizados em conjunto (dorna e eletrodo de $\mathrm{pH})$.

\subsubsection{Amostragem}

Parâmetros como temperatura, $\mathrm{pH}$, agitação e oxigênio dissolvido (\%OD) foram anotados antes de cada coleta de amostra. Um volume de aproximadamente $50 \mathrm{~mL}$ de suspensão bacteriana foi coletado de hora em hora. Com a amostra 'in natura', foi medida a densidade óptica no comprimento de onda de $540 \mathrm{~nm}$ (item 2.7.1) para acompanhar o crescimento celular. A seguir, a suspensão bacteriana foi centrifugada por $30 \mathrm{~min}$, a 4.000 rpm e a $10^{\circ} \mathrm{C}$, em dois tubos contendo $25 \mathrm{~mL}$ cada um.

O precipitado contendo a massa bacteriana foi utilizado para determinação da biomassa seca conforme descrito no item 2.7.1. Ao sobrenadante do centrifugado adicionouse azida sódica na concentração final de 0,02\%. E, em seguida, essa amostra foi distribuída em tubos de ultracentrífuga que foram devidamente equilibrados e armazenados a $4^{\circ} \mathrm{C}$. Posteriormente esse material foi ultracentrifugado por 3 horas a $30.000 \mathrm{rpm}$ e a $12^{\circ} \mathrm{C}$ na ultracentrífuga Beckman (modelo L8-M, CA, USA). O sobrenadante da ultracentrifugação foi armazenado a $-20{ }^{\circ} \mathrm{C}$ e posteriormente utilizado para determinação das concentrações de lactato, glicerol e aminoácidos.

O precipitado da ultracentrifugação contendo as OMVs purificadas foi ressuspendido em $500 \mu \mathrm{l}$ de azida $0,02 \%$ e armazenado a $4^{\circ} \mathrm{C}$. Para a dosagem de proteína total desse precipitado, foi utilizado o método de Lowry (LOWRY et al., 1951), uma forma indireta para se quantificar as OMVs. Foram realizadas eletroforeses para análise do padrão protéico das amostras de OMVs e foram preparadas amostras para observações em microscópio eletrônico para constatação da integridade das vesículas e morfologia. 


\subsection{Metodologias Analíticas}

\subsubsection{Determinação da concentração celular}

Densidade óptica - A determinação de concentração celular por densidade óptica foi realizada em espectrofotômetro nas amostras retiradas de hora em hora. Para calibração do espectrofotômetro foi utilizado como branco, o meio de cultura. Quando necessário, as amostras foram previamente diluídas com o próprio meio de cultura até que o valor ficasse na faixa aceitável de leitura, entre 0,10 e 0,90. O valor de densidade óptica diluída obtida era multiplicado pelo fator de sua diluição.

Biomassa seca - A determinação de massa seca foi realizada pelo método do peso seco de acordo com Baruque-Ramos (2000). Tubos de centrífuga vazios, de polipropileno de $50 \mathrm{~mL}$ de capacidade, foram submetidos à secagem prévia, em estufa, na temperatura de $60^{\circ} \mathrm{C}$ por $24 \mathrm{~h}$. Depois foram deixados em dessecador até atingir temperatura ambiente e pesados. As amostras de $50 \mathrm{~mL}$ retiradas do biorreator, subdivididas em duplicatas de $25 \mathrm{~mL}$ e centrifugadas, foram colocadas nestes tubos previamente pesados. Esses contendo o precipitado úmido foram levados à estufa a $60^{\circ} \mathrm{C}$ por $48 \mathrm{~h}$, colocados em dessecador até atingir a temperatura ambiente e pesados novamente. A massa seca foi calculada com base na diferença entre o peso dos tubos contendo o precipitado seco e os tubos vazios.

\subsubsection{Viabilidade celular (UFC/mL)}

O número de células viáveis por unidades formadoras de colônias (UFC) foi determinado pelo método direto que quantifica o crescimento bacteriano por meio da diluição seriada (SOMASEGRARAN; HODBEN, 1985). Alíquotas de 100 $\mu \mathrm{L}$ do cultivo bacteriano foram diluídas em $900 \mu \mathrm{L}$ de meio de cultura. A partir dessa amostra fora feita diluição seriada de $10^{-1}$ a $10^{-8}$. A placa de Petri contendo ágar-chocolate ou ágar-soro foi subdividida em oito regiões e cada uma dessas regiões recebia a duplicata de cada diluição, sob a forma de gotas de $10 \mu \mathrm{L}$. A contagem do número de colônias foi realizada após 24 horas de incubação em estufa a $36^{\circ} \mathrm{C}$, em atmosfera de $6-8 \%$ de $\mathrm{CO}_{2}$. 


\subsubsection{Análise do sobrenadante do cultivo}

O sobrenadante proveniente da centrifugação do cultivo foi ultracentrifugado e utilizado para a purificação das OMVs e para as diversas análises, como pode ser observado na figura 2.3.

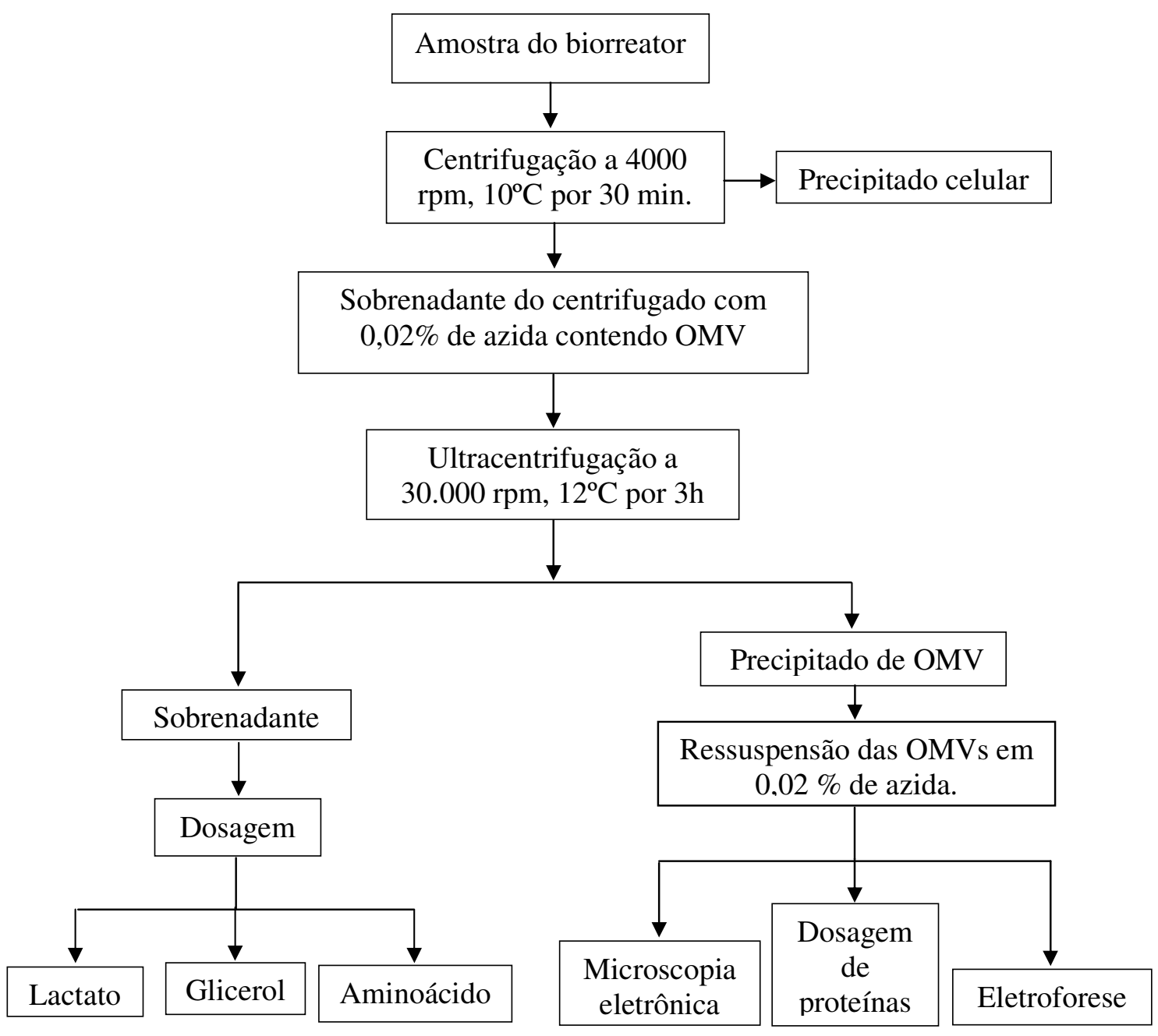

Figura 2.3 - Fluxograma da purificação de OMV a partir do sobrenadante do cultivo centrifugado e respectivas análises. 


\subsubsection{Extração da membrana da vesícula externa (OMV)}

As OMVs purificadas foram obtidas diretamente do precipitado resultante da ultracentrifugação. Esse precipitado foi ressuspendido em $500 \mu \mathrm{L}$ de azida $0,02 \%$.

\subsubsection{Dosagem de proteínas}

Utilizou-se a dosagem de proteínas como um método de quantificação de OMVs. A dosagem de proteína total foi determinada pelo método descrito por Lowry et al. (1951). Nestes ensaios foram utilizados 50-200 $\mu 1$ da suspensão de OMVs e completados com água destilada para um volume final de $1 \mathrm{~mL}$ em tubos de ensaio. Posteriormente adicionaram-se 3 $\mathrm{mL}$ do reagente, constituído de $1 \mathrm{~mL}$ de tartarato de sódio 2,0 \% (p/v) e $1 \mathrm{~mL}$ de sulfato de cobre 1,0 \% (p/v) diluídos 1:100 em solução de carbonato de sódio 2,0 \% (p/v) e hidróxido de sódio $0,1 \mathrm{M}$, que foram incubados durante 10 minutos à temperatura ambiente. A seguir, foram adicionados $300 \mu \mathrm{L}$ do reagente fenol de Folin-Ciocalteu $2 \mathrm{~N}$, da Sigma, deixando-se em repouso por 30 minutos à temperatura ambiente. $\mathrm{O}$ conteúdo foi transferido para uma cubeta de vidro e a absorbância foi lida em espectrofotômetro a $750 \mathrm{~nm}$.

Para determinação da curva padrão, utilizou-se solução de albumina de soro bovino (BSA) em concentrações variando de 25 a $250 \mu \mathrm{g}$ onde foram lidas as absorbâncias a $750 \mathrm{~nm}$. Com base nesses dados foram calculadas a regressão linear e a equação da reta. A concentração de proteína nas amostras foi calculada por meio da leitura da absorbância e do fator encontrado na equação da reta. Os valores da concentração de proteína total, isto é, das OMVs, foram expressos em mg de OMV por litro de cultivo, levando-se em consideração as respectivas diluições.

\subsubsection{Eletroforese em gel de poliacrilamida - SDS}

Para a análise do perfil eletroforético (SAMBROOK et al., 1989) foram utilizadas amostras de OMV a partir da quinta ou sexta hora de cultivo em biorreator. Com base no resultado de quantidade de proteína obtido por meio do método de Lowry, utilizamos em cada pocinho do gel cerca de $40 \mu \mathrm{g}$ de OMV em $10 \mu \mathrm{l}$ de tampão de amostra. O tampão de amostra 
continha 5\% de mercaptoetanol e $4 \mathrm{M}$ de uréia. Após a corrida das amostras o gel foi corado em azul de Coomassie. A eletroforese foi realizada em gel 10\% de acrilamida/bisacrilamida.

\subsubsection{Determinação da concentração de lactato}

O método consiste na leitura direta da solução de ácido L-lactato em g/L, com sensor enzimático. A enzima L-lactato oxidase é imobilizada na membrana L-lactato do Yelow Spring (YSI).

$$
\text { L-lactato }+\mathrm{O}_{2} \underset{\text { L-lac. Oxidase }}{\longrightarrow} \mathrm{H}_{2} \mathrm{O}_{2}+\text { Piruvato }
$$

Esse método utiliza um analisador enzimático automático (Yelow Spring, modelo YSI 2700 Select, Yelow Springs, Ohio, USA). O sensor enzimático YSI emprega uma ou mais reações de enzima catalisadora para depois produzir peróxido de hidrogênio (reação 1). Esse é eletroquimicamente oxidado na platina (anodo da sonda eletroquímica). O mesmo também produz um sinal elétrico na sonda, o qual é utilizado para determinação da concentração de lactato.

O sistema Yelow Spring mede apenas o L-lactato. No caso de mistura racêmica, o valor da concentração do D-lactato é suposto ser igual ao do L-lactato (tabela 4.3). Deste modo, o valor da concentração de lactato total pode ser estimado multiplicando-se por 2 o valor determinado pelo analisador. Nesse trabalho, todos os dados referentes ao lactato de sódio foram baseados apenas no L-lactato $(\mathrm{g} / \mathrm{L})$, não considerando o D-lactato $(\mathrm{g} / \mathrm{L})$ e os valores de concentrações utilizadas estão de acordo com as concentrações do meio de Catlin sem ferro (tabela 2.4). 


\subsubsection{Determinação da concentração de glicerol}

A concentração do glicerol foi determinada pelos métodos de oxidação do periodato de sódio e com leitura em cromatografia líquida de alta performance (HPLC).

Método da oxidação do periodato de sódio - O método consiste na determinação do glicerol (AMÉRICA OIL CHEMISTRY SOCIETY, 1982) por oxidação do periodato de sódio aplicável também na determinação do poliálcoois contendo três ou mais grupos hidroxilas adjacentes. O glicerol reage com o periodato de sódio em solução ácida formando aldeído e ácido fórmico. O ácido fórmico é titulado com uma solução de hidróxido de sódio padronizado $(0,125 \mathrm{~N})$ e o volume gasto corresponde ao valor da concentração de glicerol na amostra, para tal foi utilizada a seguinte equação:

$\%$ glicerol $(\mathrm{w} / \mathrm{w})=\underline{(\mathrm{va}-\mathrm{vb}) * \mathrm{~N} * 9,2095}$

$\mathrm{m}$

em que:

va $=$ Volume de $\mathrm{NaOH}$ consumido na titulação $(\mathrm{mL}) ;$

$\mathrm{vb}=$ Volume de $\mathrm{NaOH}$ consumido para titular o branco $(\mathrm{mL})$;

$\mathrm{N}=$ Normalidade exata do $\mathrm{NaOH}$;

$\mathrm{m}=$ Massa da amostra $(\mathrm{g})$.

Foram pesadas quantidades das amostras $(\mathrm{g} / 100 \mathrm{~mL})$ do centrifugado (sobrenadante), em béquer pequeno, de acordo tabela 2.2 . 
Tabela 2.5 - Massa de amostra (g) a ser pesada de acordo com a concentração esperada de glicerol $(\mathrm{g} / 100 \mathrm{~mL})$.

\begin{tabular}{cc}
\hline $\begin{array}{c}\text { Concentração esperada de glicerol } \\
(\mathbf{g} / \mathbf{1 0 0} \mathbf{m L})\end{array}$ & Massa da amostra $(\mathbf{g})$ \\
\hline 8 a 10 & 0,5 \\
5 a 8 & 1,0 \\
2 a 5 & 1,5 \\
Menor que 2 & 2,0 \\
\hline
\end{tabular}

Dados de acordo a American Oil Chemistry Society - AOCS.

A amostra foi transferida para um béquer de $250 \mathrm{~mL}$ previamente lavado com água destilada. Adicionou ácido sulfúrico $\left(\mathrm{H}_{2} \mathrm{SO}_{4}\right)$ de concentração $0,2 \mathrm{~N}$ até o pH atingir valor inferior a 3,0, a seguir foi adicionado hidróxido de sódio $(\mathrm{NaOH})$ na concentração $0,05 \mathrm{~N}$ até o $\mathrm{pH}$ atingir um valor entre $8,1 \pm 0,1$. Como branco foi utilizado $50 \mathrm{~mL}$ de água destilada e o procedimento foi repetido até o $\mathrm{pH}$ atingir $8,1 \pm 0,1$. Em seguida foi adicionado $10 \mathrm{~mL}$ de solução de periodato de sódio (60 $\mathrm{g}$ de $\mathrm{NaIO}_{4}$ dissolvido em água destilada acrescido de 120 $\mathrm{mL}$ de $\mathrm{H}_{2} \mathrm{SO}_{4}$ 0,1 $\mathrm{N}$ e com posterior diluição para $1 \mathrm{~L}$ com água destilada), a solução foi homogeneizada e incubada no escuro durante 30 minutos, coberta com vidro de relógio em temperatura ambiente nunca superior a $35^{\circ} \mathrm{C}$. A seguir foram adicionados $2 \mathrm{~mL}$ de etilenoglicol a $50 \%(\mathrm{p} / \mathrm{v})$ mantendo a solução em repouso e no escuro durante 20 minutos. Após este tempo foi adicionado água até atingir $100 \mathrm{~mL}$. Essa solução foi titulada com hidróxido de sódio $(\mathrm{NaOH})$ na concentração de $0,125 \mathrm{~N}$, padronizada, até atingir um $\mathrm{pH}$ de $6,5 \pm 0,1$, para o branco (AOCS 1982).

Cromatografia líquida de alta performace (HPLC) - A concentração do glicerol foi determinada por meio da cromatografia líquida de alta performace (HPLC), modelo 10AVP (Shimadzu, Kyoto, Japan), acoplado a um detector de índice de refração e usando a coluna HPX-87H (Bio Rad, Hercules, CA, USA) com diluição de 1:5 de amostra de cultivo com solução de ácido sulfúrico $5 \mathrm{mM}$ e filtrado em membrana de $0,22 \mu \mathrm{m}$ de poro. Foi injetado na coluna um padrão de glicerol em diferentes diluições para a curva padrão. Foi usado fluxo de 0,6 mL/min de solução 5,0 $\mathrm{mM}$ de ácido sulfúrico como fase móvel a $35^{\circ} \mathrm{C}$. A integração dos 
picos cromatográficos e determinação da concentração do glicerol foram realizadas por meio do uso do software Class VP-Versions 6.2.

\subsubsection{Determinação da concentração dos aminoácidos}

Para a análise de aminoácidos utilizou-se a técnica de cromatografia líquida de alta performance, HPLC - Shimadzu CLASS- VP (Shimadzu, Kyoto, Japan), em coluna C18 $\mu$ Bondapak, (Waters Milford-Massachusset, USA) de 4,6 mm de diâmetro por $250 \mathrm{~mm}$ de altura. Foi utilizado gradiente com duas fases, A e B. A fase A era constituída de $470 \mathrm{~mL}$ de solução estoque onde foram adicionados $30 \mathrm{~mL}$ de acetonitrila. A fase $\mathrm{B}$, utilizada como solvente de gradiente, era constituída de $400 \mathrm{~mL}$ de acetonitrila, $100 \mathrm{~mL} \mathrm{de} \mathrm{H}_{2} \mathrm{O}$ e $100 \mu \mathrm{L}$ de EDTA $1 \mathrm{M}$.

A solução estoque utilizada para o preparo da fase A é constituída de $19 \mathrm{~g}$ de acetato de sódio, 0,5 mL de TFA (trifluoressigsaure), $200 \mu \mathrm{L}$ de EDTA (solução $100 \mathrm{mg} / 100 \mathrm{~mL}$ ) pH 8,0 e $1 \mathrm{~L}$ de $\mathrm{H}_{2} \mathrm{O}$. O pH final era acertado para 6,4.

Foi realizado um gradiente de $50 \mathrm{~min}$, com fluxo de $1 \mathrm{~mL} / \mathrm{min}$ para a eluição dos aminoácidos. Aos $38 \mathrm{~min}$ era iniciada a lavagem com fluxo de 1,5 mL/min durante $6 \mathrm{~min}$. A seguir o fluxo era regulado novamente para $1 \mathrm{~mL} / \mathrm{min}$ para o início de um novo ciclo de eluição.

Para análise dos aminoácidos foram utilizados $50 \mu \mathrm{L}$ do sobrenadante do ultracentrifugado ao qual foram acrescentados $50 \mu \mathrm{L}$ da solução de derivatização. A solução de derivatização é constituída de $300 \mu \mathrm{L}$ de etanol, $50 \mu \mathrm{L}$ de PITC (fenilisotiocianato), $50 \mu \mathrm{L}$ de TEA (trietilamina) e $50 \mu \mathrm{L}$ de $\mathrm{H}_{2} \mathrm{O}$. Essa solução era deixada em repouso por 15 min até se obter uma coloração amarelada. Só então $50 \mu \mathrm{L}$ desta solução eram adicionados a $50 \mu \mathrm{L}$ da amostra. Aguardavam-se 10-12 min para ocorrer a reação com o grupo amina dos aminoácidos, após esse período acrescentavam-se $100 \mu \mathrm{L}$ de $\mathrm{H}_{2} \mathrm{O}$ totalizando $200 \mu \mathrm{L}$. Apenas $100 \mu \mathrm{L}$ desta solução contendo amostra eram injetados no HPLC.

A integração dos picos cromatográficos e determinação da concentração dos aminoácidos foram realizadas por meio do uso do software Class VP-Versions 6.2. 


\subsubsection{Microscopia eletrônica}

Para microscopia eletrônica utilizou-se a técnica de contrastação negativa. Uma suspensão de OMV de $15 \mu \mathrm{l}$ em PBS pH 7,2 foi aplicada sobre grades de cobre de 300 meshes recobertas por película de palódio / carbono, durante cerca de 3 minutos, para a adsorção das partículas sobre a película. Em seguida, o excesso de líquido foi retirado com auxílio de papel de filtro e colocaram-se imediatamente $15 \mu \mathrm{l}$ de ácido fosfotúngstico $2 \%, \mathrm{pH}$ 7,2 durante 10 segundos. Retirou-se todo o líquido com o papel de filtro e deixou-se secar totalmente. As grades foram examinadas no microscópio eletrônico de transmissão LEO 906E (Zeiss, Alemanha), operando a 80kV. As imagens foram capturadas por uma câmera de TV VarioCam, PCO, através do software KS 300, e foram salvas em extensão TIF.

\subsection{5 - Determinação dos parâmetros cinéticos}

Foram efetuados ajustes de curva dos resultados experimentais, com o programa de computador Logiciel du Lissage (SIMÕES et al., 1992), para o cálculo das velocidades de crescimento, consumo de substrato e formação de produto. Esse programa se refere a uma variante do método Spline (KAHANER et al., 1989) que utiliza o ajuste de um polinômio de grau " $x$ " a um intervalo de dois pontos incorporando um número de pontos à frente a ser definido; além disso, o método exige que a derivada do polinômio ajustado no intervalo anterior seja igual à derivada do polinômio ajustado no intervalo seguinte (FERRAZ et al., 1995 apud GOMBERT, 1996) ${ }^{2}$.

As curvas foram suavizadas para determinação de parâmetros cinéticos, de acordo Hiss (2001), como velocidade específica de crescimento $(\mu x)$, velocidade específica de consumo de substrato $(\mu \mathrm{s})$ e velocidade específica de formação do produto $(\mu \mathrm{p})$ representadas pelas seguintes equações:

\footnotetext{
${ }^{2}$ FERRAZ et al., 1995
} 


$$
\begin{aligned}
& \mu_{\mathrm{X}}=\frac{1}{\mathrm{X}} \cdot \frac{\mathrm{dX}}{\mathrm{dt}} \\
& \mu_{\mathrm{P}}=\frac{1}{\mathrm{X}} \cdot \frac{\mathrm{dP}}{\mathrm{dt}} \\
& \mu_{\mathrm{S}}=\frac{1}{\mathrm{X}} \cdot \frac{\mathrm{dS}}{\mathrm{dt}}
\end{aligned}
$$

Onde:

$\mathrm{X}$ - concentração celular no meio de fermentação;

$\mathrm{S}$ - concentração de substrato no meio de fermentação;

$\mathrm{P}$ - concentração de produto no meio de fermentação;

$\mathrm{dX}$ - biomassa formada em $\mathrm{dt}$;

$\mathrm{dS}$ - substrato consumido em dt;

$\mathrm{dP}$ - produto formado em dt;

$\mathrm{dt}$ - intervalo de tempo.

Os fatores globais de conversão são definidos pelas seguintes expressões:

$$
\begin{gathered}
Y_{X / S}=\frac{X_{m}-X_{o}}{S_{i}-S_{\text {min }}} \\
Y_{P / X}=\frac{P_{m}-P_{o}}{X_{m}-X_{o}}
\end{gathered}
$$

Onde:

$\mathrm{X}_{\mathrm{m}}$ - concentração celular máxima;

$\mathrm{X}_{\mathrm{o}}$ - concentração celular inicial;

$\mathrm{S}_{\mathrm{i}}$ - concentração de substrato inicial;

$\mathrm{S}_{\min }$ - concentração de substrato quando a concentração celular é máxima;

$\mathrm{P}_{\mathrm{m}}$ - concentração de produto máximo;

$\mathrm{P}_{\mathrm{o}}$ - concentração de produto inicial. 
A produtividade em biomassa e produtividade em produto foram calculadas segundo as expressões:

$$
\begin{aligned}
& \operatorname{Prod}_{{ }_{X}}=\frac{X_{f}-X_{o}}{t_{f}-t_{o}} \\
& \text { Prod. }_{P}=\frac{P_{f}-P_{o}}{t_{f P}-t_{o}}
\end{aligned}
$$

Onde:

$\mathrm{X}_{\mathrm{f}}$ - concentração maxima de $\mathrm{X}$;

$X_{o}$ - concentração inicial de $X$;

$\mathrm{P}_{\mathrm{f}}$ - concentração máxima de $\mathrm{P}$;

$\mathrm{P}_{\mathrm{o}}$ - concentração inicial de $\mathrm{P}$;

$\mathrm{t}_{\mathrm{f}}$ - tempo de cultivo correspondente a $\mathrm{X}_{\mathrm{f}}$;

$\mathrm{t}_{\mathrm{fP}}$ - tempo de cultivo correspondente a $\mathrm{P}_{\mathrm{f}}$;

$\mathrm{t}_{\mathrm{o}}$ - tempo inicial igual a zero.

\subsubsection{Modelo de Luedeking e Piret}

Para análise do produto de fermentação foi utilizada a expressão empírica proposta por Luedeking e Piret (1959) que relaciona velocidade específica de formação de produto $\left(\mu_{\mathrm{P}}\right)$ com velocidade específica de crescimento do microrganismo $\left(\mu_{\mathrm{X}}\right)$.

$$
\mu_{P}=\alpha \cdot \mu_{X}+\beta
$$

Onde:

$\mu_{\mathrm{P}}=$ velocidade especifica do produto;

$\mu_{\mathrm{X}}=$ velocidade especifica de crescimento do microrganismo;

$\alpha=$ constante empírica associada ao crescimento do microrganismo;

$\beta=$ constante empírica não associada. 
Essa equação, onde $\alpha$ e $\beta$ são constantes empíricas funções do $\mathrm{pH}$, indica a existência de dois mecanismos de produção de vesículas de membrana externa: um deles associado à reprodução de bactérias (representado pela parcela $\alpha . \mu_{\mathrm{X}}$ ) e outro independente do crescimento do microrganismo (representado pelo termo $\beta$ ) (HISS, 2001). 


\section{RESULTADOS}

Foram realizados 12 ensaios de cultivos de Neisseria meningitidis sorogrupo B, cepa N.44/89, sendo um destes em agitador rotatório com duração de $8 \mathrm{~h}$ e onze ensaios em biorreator com duração de $20 \mathrm{~h}$.

Os ensaios foram realizados com o propósito de conhecer o microorganismo em função das variações das concentrações fonte de carbono (lactato), fonte de nitrogênio (aminoácidos) e glicerol (função desconhecida até então) e que resulte no maior crescimento celular, formação e liberação da membrana da vesícula externa.

Abaixo seguem as descrições dos ensaios realizados:

Ensaio 1: Cultivo em agitador rotatório de acordo o planejamento fatorial $2^{3}$. Nesse foram alterados valores das concentrações iniciais do ácido L-glutâmico, glicerol e lactato para possível conhecimento da principal fonte de carbono e/ou comportamento desses no meio do cultivo. As concentrações alteradas do meio de Catlin sem ferro nesse ensaio estão descritas na tabela 3.2.

Ensaio 2, 3 e 4: Cultivo descontínuo com duração de 20h, em meio de Catlin sem ferro nas concentrações descritas na tabela 2.4. Sem controles de $\mathrm{pH}$ e oxigênio dissolvido.

Ensaio 5 e 6: Cultivo descontínuo com duração de 20h, em meio de Catlin sem ferro com concentração de lactato de sódio, triplicado, igual 22,5 g/L correspondendo a 8,94 $\mathrm{g} / \mathrm{L}$ de L-lactato triplicado. Os demais componentes mantiveram suas concentrações de acordo com a tabela 2.4 e sem controles de $\mathrm{pH}$.

Ensaio 7 e 8: Cultivo descontínuo alimentado com duração de 20h, em meio de Catlin sem ferro. O pulso de concentrações de lactato de sódio igual a 7,5 g/L correspondendo a 2,98 g/L de L-lactato e aminoácidos: L-glutâmico 1,18 g/L, Larginina $0,11 \mathrm{~g} / \mathrm{L}$, glicina $0,15 \mathrm{~g} / \mathrm{L}$, L-serina $0,02 \mathrm{~g} / \mathrm{L}$ e L-cisteína $0,01 \mathrm{~g} / \mathrm{L}$, ocorreram na $\left(6^{a} h\right)$ sexta hora de cultivo. Os demais componentes mantiveram suas concentrações de acordo com a tabela 2.4 e sem controle de $\mathrm{pH}$. 
Ensaio 9, 10 e 11: Cultivo descontínuo com duração de 20h, em meio de Catlin sem ferro, sem controle de pH. Nesses ensaios as concentrações de lactato de sódio e aminoácidos foram dobradas: lactato de sódio $15,00 \mathrm{~g} / \mathrm{L}$ correspondendo a $5.96 \mathrm{~g} / \mathrm{L}$ de L-lactato, L-glutâmico 2,36 g/L, L-arginina 0,21 g/L, glicina 0,30 g/L, L-serina 0,04 g/L e L-cisteína 0,02 g/L. Os demais componentes mantiveram suas concentrações de acordo com a tabela 2.4.

Ensaio 12: Cultivo descontínuo com duração de 20h, em meio de Catlin sem ferro, sem controle de $\mathrm{pH}$. Nesses ensaios as concentrações de lactato de sódio e aminoácidos foram dobradas: lactato de sódio $15,00 \mathrm{~g} / \mathrm{L}$ correspondendo a $5.96 \mathrm{~g} / \mathrm{L}$ de L-lactato, L-glutâmico 2,36 g/L, L-arginina 0,21 g/L, glicina 0,30 g/L, L-serina 0,04 g/L e L-cisteína 0,02 g/L e a concentração de glicerol ausente. Os demais componentes mantiveram suas concentrações de acordo com a tabela 2.4. 
Tabela 3.1 - Resumo dos ensaios em meio de Catlin sem ferro realizados em rotatório e biorreator.

\begin{tabular}{|c|c|c|c|c|c|c|c|}
\hline Grupo & Ensaio & $\begin{array}{l}\text { Agitador } \\
\text { rotatório }^{\mathrm{x}}\end{array}$ & $\begin{array}{c}\text { Catlin sem } \\
\text { ferro }^{\mathbf{y}}\end{array}$ & $\begin{array}{c}\text { Conc. } \\
\text { Inicial } \\
\text { Lactato } \\
\text { triplicada }^{\mathbf{z}}\end{array}$ & $\begin{array}{l}\text { Pulso } \\
6^{\mathrm{a}} \mathrm{h}^{\mathrm{w}}\end{array}$ & $\begin{array}{l}\text { Conc. Inicial } \\
\text { Lac. e aas. } \\
\text { duplicada }^{\mathbf{t}}\end{array}$ & $\begin{array}{l}\text { Conc. Inicial } \\
\text { Lac. e aas. } \\
\text { duplicada sem } \\
\text { glicerol }^{\mathbf{v}}\end{array}$ \\
\hline $\mathbf{A}$ & 1 & $\mathrm{X}$ & $\ldots \ldots$. & $\ldots \ldots$. & $\ldots \ldots$. & ....... & $\ldots \ldots$. \\
\hline \multirow{3}{*}{ B } & 2 & ........ & $X$ & ........ & $\ldots \ldots$ & ........ & ........ \\
\hline & 3 & ........ & $X$ & ........ & $\ldots \ldots$ & ........ & ....... \\
\hline & 4 & $\ldots \ldots$. & $X$ & $\ldots \ldots$ & $\ldots \ldots$ & $\ldots \ldots$ & $\ldots \ldots$ \\
\hline \multirow[t]{2}{*}{ C } & 5 & ....... & $\ldots \ldots$ & $\bar{X}$ & $\ldots \ldots$ & ....... & $\ldots \ldots$ \\
\hline & 6 & ........ & ........ & $X$ & $\ldots \ldots$ & ........ & ........ \\
\hline \multirow[t]{3}{*}{ D } & 7 & ........ & ........ & ........ & $X$ & ........ & ........ \\
\hline & 8 & ........ & ........ & ........ & X & ........ & ........ \\
\hline & 9 & $\ldots \ldots$. & ........ & ........ & $\ldots \ldots$. & $X$ & ........ \\
\hline \multirow[t]{2}{*}{$\mathbf{E}$} & 10 & $\ldots \ldots$. & ....... & ....... & $\ldots \ldots$ & $X$ & $\ldots \ldots$. \\
\hline & 11 & $\ldots \ldots$. & $\ldots \ldots$ & $\ldots \ldots$. & $\ldots \ldots$ & $X$ & $\ldots \ldots$. \\
\hline $\mathbf{F}$ & 12 & $\ldots \ldots$ & $\ldots \ldots$ & ....... & $\ldots \ldots$ & ....... & $X$ \\
\hline
\end{tabular}

${ }^{\mathrm{x}}$ Concentração original do meio Catlin sem ferro: 5,00, 1,18 e 7,500 g/L de glicerol, ácido L-glutâmico e lactato de sódio respectivamente.

${ }^{\mathrm{y}}$ Catlin sem ferro nas concentrações descritas na tabela 2.4.

${ }^{\mathrm{z}}$ Concentração, desde o inicio, de lactato de sódio igual 22,50 g/L, correspondendo a 8,94 g/L de L-lactato

"Pulso com concentrações de lactato de sódio igual a 7,50 g/L, correspondendo a 2,98 g/L de L-lactato, Lglutâmico $1,18 \mathrm{~g} / \mathrm{L}$, L-arginina $0,11 \mathrm{~g} / \mathrm{L}$, glicina $0,15 \mathrm{~g} / \mathrm{L}$, L-serina $0,02 \mathrm{~g} / \mathrm{L}$ e L-cisteína $0,01 \mathrm{~g} / \mathrm{L}$ na $6^{\mathrm{a}} \mathrm{h}$ de cultivo.

tConcentração de lactato de sódio 15,00 g/L, correspondendo a 5,98 g/L de L-lactato, L-glutâmico 2,36 g/L, Larginina $0,21 \mathrm{~g} / \mathrm{L}$, glicina $0,30 \mathrm{~g} / \mathrm{L}$, L-serina $0,04 \mathrm{~g} / \mathrm{L}$ e L-cisteína $0,02 \mathrm{~g} / \mathrm{L}$ desde inicio do cultivo.

`concentração de lactato de sódio 15,00 g/L, correspondendo a 5,98 g/L de L-lactato, L-glutâmico 2,36 g/L, Larginina $0,21 \mathrm{~g} / \mathrm{L}$, glicina $0,30 \mathrm{~g} / \mathrm{L}$, L-serina $0,04 \mathrm{~g} / \mathrm{L}$, L-cisteína $0,02 \mathrm{~g} / \mathrm{L}$ e ausência de glicerol durante todo cultivo. 


\subsection{Ensaio do grupo A - Cultivo em agitador rotatório}

O ensaio de planejamento fatorial $\left(2^{3}\right)$ foi realizado para estabelecer as condições de cultivo que foram posteriormente realizadas no biorreator.

As variáveis independentes consideradas nesses ensaios foram: Glicerol, Ácido Lglutâmico e L-lactato, os níveis foram o de maior e o de menor concentração de cada uma das variáveis e as variáveis dependentes foram: a densidade óptica $\left(\mathrm{DO}_{540 \mathrm{~nm}}\right)$ e a produção da OMV.

\subsubsection{Os resultados experimentais do ensaio do grupo A}

Os valores experimentais do ensaio do grupo A estão ilustrados na tabela 3.2. O resultado do efeito e interação dos componentes - lactato, glicerol e ácido L-glutâmico determinou as alterações que deverão ser promovidas nos demais ensaios para um maior produção de OMV (tabela 3.2). 
Tabela 3.2 - Resultado das análises do planejamento fatorial celular e das análises preliminares do ensaio 1.

(X1) Glicerol (g/L): $0(-) / 5,00(+)^{1}$

(X2) Ácido L-glutâmico (g/L): 1,18 (-)/2,36 (+) ${ }^{1}$

(X3) Lactato (g/L): 2,61 (-)/5,22 (+) ${ }^{1}$

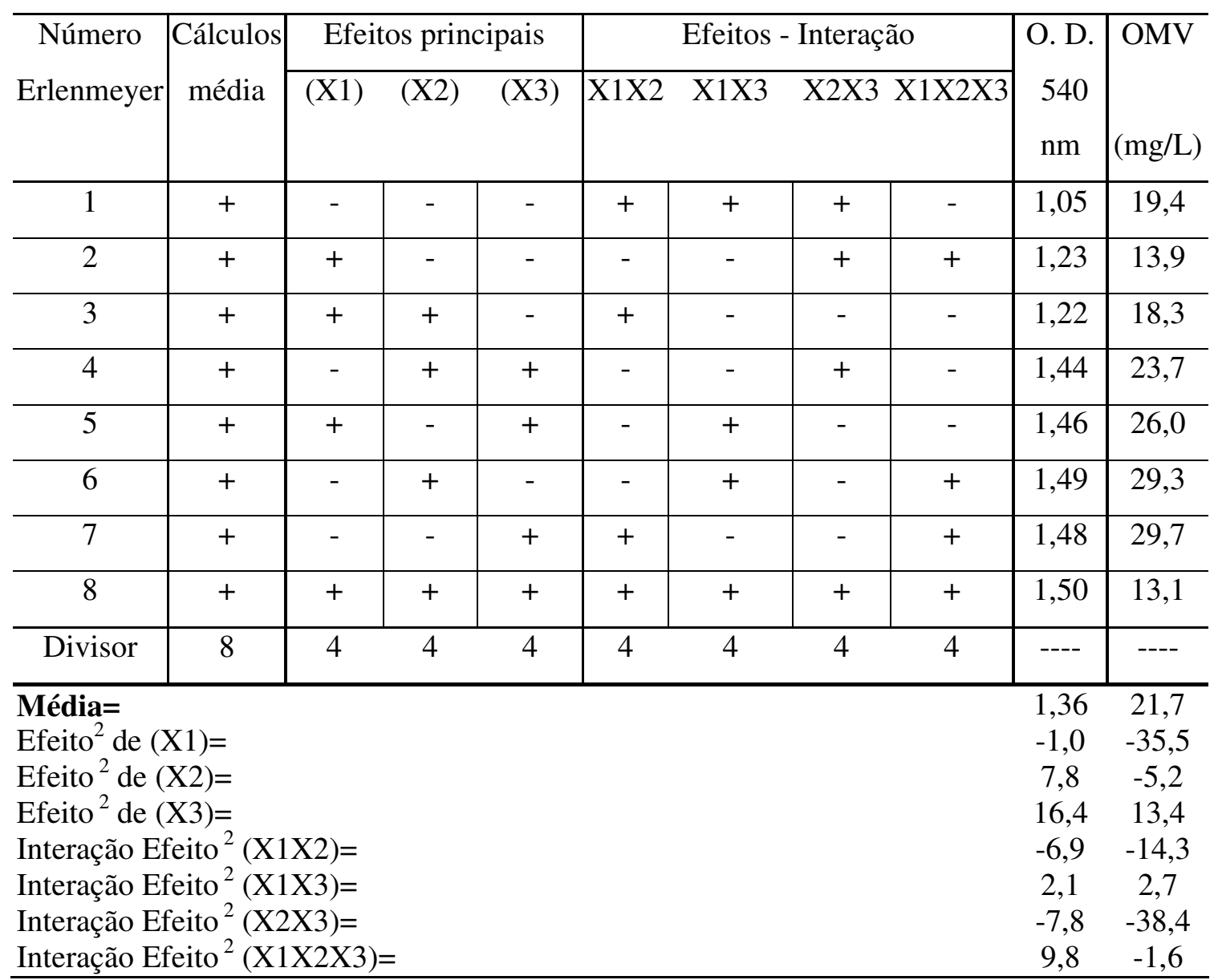

${ }^{1}$ Concentração original do meio Catlin sem ferro: 5, 00, 1,18 e 7,500 g/L de glicerol, ácido L-glutâmico e lactato de sódio (50\% concentração da solução) respectivamente.

${ }^{2}$ Cálculos em termos percentuais em relação às respectivas médias. 


\subsection{Ensaios do Grupo B - Meio Catlin sem ferro}

Os ensaios do grupo B foram realizados em cultivo descontínuo em meio de Catlin sem ferro. As figuras 3.1 e 3.2 ilustram as curvas de crescimento celular medidas por densidade óptica a $540 \mathrm{~nm}\left(\mathrm{DO}_{540 \mathrm{~nm}}\right)$ e massa seca realizadas em triplicatas. A fase estacionária inicia-se na sexta hora de cultivo com densidade óptica ao redor de 1,0-1,5 e massa seca de 0,6 g/L permanecendo até a décima segunda hora. $\mathrm{O}$ perfil de viabilidade celular é ilustrado na figura 3.3 , onde se observa que na fase estacionária atingiu o valor de $1,0 \times 10^{9} \mathrm{UFC} / \mathrm{mL}$ e permaneceu neste valor até a $16^{\mathrm{a}}$ hora de cultivo.

O lactato foi completamente consumido na $10^{\mathrm{a}}$ hora (Figura 3.4) e neste momento é possível verificar o aumento do $\mathrm{pH}$ (Figura 3.5) indicando que o microorganismo começou a utilizar os aminoácidos. A figura 3.6 ilustra a formação de OMV que se inicia na $4^{\mathrm{a}}$ hora de cultivo, mas sua formação se destaca a partir da $10^{\mathrm{a}}$ hora atingindo valor médio em torno de $40 \mathrm{mg} / \mathrm{L}$.

Nesse grupo o crescimento celular $\left(\mathrm{DO}_{540 \mathrm{~nm}}\right)$ apresentou variabilidade entre os ensaios, acredita-se que as condições pré-estabelecidas tenham saído da faixa estipulada como oxigênio dissolvido, que os ensaios 3 e 4 não tiveram valores registrados, porém o cultivo permaneceu baseando-se nas determinações da densidade óptica $\left(\mathrm{DO}_{540 \mathrm{~nm}}\right)$. A viabilidade celular (UFC/mL) foi analisada apenas nos ensaios 3 e 4, apresentando um perfil que acompanha o do crescimento celular (Figura 3.2). As curvas do ácido L-glutâmico mostram o consumo total entre a $6^{\mathrm{a}}$ e $8^{\mathrm{a}}$ hora (Figura 3.7).

\subsubsection{Resultados experimentais dos ensaios do grupo B}

Os valores experimentais da cinética dos ensaios do grupo B estão ilustrados na tabela 3.3 a 3.5 e os valores suavizados, calculados por meio do programa de Lissage, na tabela 7.1.1 a 7.1.3 do anexo 7.1. 
Tabela 3.3 - Resultados experimentais do grupo B, ensaio 2.

\begin{tabular}{cccccccccc}
\hline Tempo & $\mathbf{p H}$ & $\begin{array}{c}\text { Oxig.Diss. } \\
(\mathbf{\%})\end{array}$ & $\begin{array}{c}\text { Agitação } \\
(\mathbf{r p m})\end{array}$ & $\mathbf{D O}_{\mathbf{5 4 0 n m}}$ & $\begin{array}{c}\text { M. Seca } \\
(\mathbf{g} / \mathbf{L})\end{array}$ & $\begin{array}{c}\text { Glicerol } \\
(\mathbf{g} / \mathbf{L})\end{array}$ & $\begin{array}{c}\text { L-lactato } \\
(\mathbf{g} / \mathbf{L})\end{array}$ & $\begin{array}{c}\text { OMV } \\
(\mathbf{m g} / \mathbf{L})\end{array}$ & $\begin{array}{c}\text { Ác. L- glutâmico } \\
(\mathbf{g} / \mathbf{L})\end{array}$ \\
\hline $\mathbf{0}$ & 7,08 & $\ldots \ldots \ldots$ & 250 & 0,10 & $\ldots \ldots \ldots$ & 5,31 & 2,83 & $\ldots \ldots \ldots$ & 1,18 \\
$\mathbf{1}$ & 7,00 & 8,8 & 441 & 0,18 & 0,07 & 5,31 & 2,78 & $\ldots \ldots \ldots$ & 1,18 \\
$\mathbf{2}$ & 6,93 & 8,9 & 475 & 0,46 & 0,22 & 5,31 & 2,60 & $\ldots \ldots \ldots$ & 1,18 \\
$\mathbf{3}$ & 6,98 & 7,5 & 587 & 1,03 & 0,34 & 5,31 & 1,94 & $\ldots \ldots \ldots$ & 0,99 \\
$\mathbf{4}$ & 7,26 & 9,0 & 599 & 1,10 & 0,43 & 5,31 & 1,23 & $\ldots \ldots \ldots$ & 0,92 \\
$\mathbf{5}$ & 7,40 & 9,9 & 587 & 1,16 & 0,46 & 5,31 & 0,83 & $\ldots \ldots \ldots$ & $\ldots \ldots \ldots$ \\
$\mathbf{6}$ & 7,48 & 9,2 & 583 & 1,42 & 0,51 & 5,31 & 0,54 & $\ldots \ldots \ldots$ & $\ldots \ldots \ldots$ \\
$\mathbf{7}$ & 7,56 & 9,1 & 601 & 2,02 & 0,57 & 5,31 & 0,23 & 4,20 & $\ldots \ldots \ldots$ \\
$\mathbf{8}$ & 7,56 & 13,6 & 575 & 1,53 & 0,60 & 5,31 & 0,00 & 4,20 & $\ldots \ldots \ldots$ \\
$\mathbf{9}$ & 7,56 & 6,5 & 604 & 1,54 & 0,60 & 5,31 & 0,00 & 5,10 & $\ldots \ldots \ldots$ \\
$\mathbf{1 0}$ & 7,53 & 5,5 & 466 & 1,54 & 0,60 & 5,31 & 0,00 & 6,50 & $\ldots \ldots \ldots$ \\
$\mathbf{1 1}$ & 7,77 & 11,6 & 503 & 1,54 & 0,67 & 5,31 & 0,00 & 5,20 & $\ldots \ldots \ldots$ \\
$\mathbf{1 2}$ & 8,07 & 10,3 & 452 & 1,90 & 0,67 & 5,31 & 0,00 & 8,20 & $\ldots \ldots \ldots$ \\
$\mathbf{1 3}$ & 8,44 & 8,7 & 352 & 1,66 & 0,61 & 5,31 & 0,00 & 10,80 & 0,03 \\
$\mathbf{1 4}$ & 8,62 & 10,3 & 356 & 1,72 & 0,60 & 5,31 & 0,00 & 10,80 & 0,07 \\
$\mathbf{1 5}$ & 8,61 & 10,7 & 364 & 1,70 & 0,59 & 5,31 & 0,00 & 17,70 & 0,07 \\
$\mathbf{1 6}$ & 8,60 & 20,3 & 435 & 1,33 & 0,58 & 5,31 & 0,00 & 17,10 & 0,04 \\
$\mathbf{1 7}$ & 8,52 & 10,2 & 502 & 1,45 & 0,58 & 5,31 & 0,00 & 27,40 & 0,05 \\
$\mathbf{1 8}$ & 8,56 & 10,1 & 475 & 1,39 & 0,57 & 5,31 & 0,00 & 25,00 & 0,07 \\
$\mathbf{1 9}$ & 8,49 & 10,1 & 457 & 1,31 & 0,58 & 5,31 & 0,00 & 23,40 & 0,03 \\
$\mathbf{2 0}$ & 8,44 & 10,0 & 442 & 1,28 & 0,56 & 5,31 & 0,00 & $\ldots \ldots \ldots$ & 0,06 \\
\hline
\end{tabular}

Tabela 3.4 - Resultados experimentais do grupo B, ensaio 3.

\begin{tabular}{cccccccccc}
\hline $\begin{array}{c}\text { Tempo } \\
(\mathbf{h})\end{array}$ & $\mathbf{p H}$ & $\begin{array}{c}\text { Agitação } \\
(\mathbf{r p m})\end{array}$ & $\mathbf{D O}_{\mathbf{5 4 0 n m}}$ & $\begin{array}{c}\text { Viab. Cel. } \\
(\mathbf{U F C} \mathbf{m L})\end{array}$ & $\begin{array}{c}\text { M. Seca } \\
(\mathbf{g} / \mathbf{L})\end{array}$ & $\begin{array}{c}\text { Glicerol } \\
(\mathbf{g} / \mathbf{L})\end{array}$ & $\begin{array}{c}\text { L-lactato } \\
(\mathbf{g} / \mathbf{L})\end{array}$ & $\begin{array}{c}\text { OMV } \\
(\mathbf{m g} / \mathbf{L})\end{array}$ & $\begin{array}{c}\text { Ác. L-glutâmico } \\
(\mathbf{g} / \mathbf{L})\end{array}$ \\
\hline $\mathbf{0}$ & 6,92 & 250 & 0,09 & $9,00 \mathrm{E}+07$ & 0,20 & 5,47 & 2,40 & 0,53 & 1,18 \\
$\mathbf{1}$ & 6,92 & 381 & 0,16 & & 0,14 & 5,47 & 2,35 & 1,06 & 1,18 \\
$\mathbf{2}$ & 6,90 & 441 & 0,33 & $3,08 \mathrm{E}+08$ & 0,20 & 5,47 & 2,20 & 1,93 & 1,18 \\
$\mathbf{3}$ & 6,91 & 528 & 0,97 & & 0,33 & 5,47 & 1,97 & 2,21 & 1,18 \\
$\mathbf{4}$ & 7,05 & 571 & 1,38 & $2,33 \mathrm{E}+09$ & 0,59 & 5,47 & 1,47 & 3,28 & 1,09 \\
$\mathbf{5}$ & 7,29 & 565 & 1,26 & & 0,57 & 5,47 & 0,92 & 5,31 & $\ldots \ldots .$. \\
$\mathbf{6}$ & 7,42 & 566 & 1,20 & $1,50 \mathrm{E}+10$ & 0,66 & 5,47 & 0,48 & 7,09 & 0,98 \\
$\mathbf{7}$ & 7,48 & 537 & 1,26 & & 0,65 & 5,47 & 0,21 & 8,15 & 0,19 \\
$\mathbf{8}$ & 7,52 & 507 & 1,17 & $1,40 \mathrm{E}+09$ & 0,78 & 5,47 & 0,04 & 8,68 & 0,02 \\
$\mathbf{9}$ & 7,45 & 429 & 1,27 & & 0,72 & 5,47 & 0,00 & 7,00 & 0,04 \\
$\mathbf{1 0}$ & 7,50 & 250 & 1,18 & $7,00 \mathrm{E}+08$ & 0,69 & 5,47 & 0,00 & 8,33 & 0,05 \\
$\mathbf{1 1}$ & 7,54 & 250 & 1,12 & & 0,64 & 5,47 & 0,00 & 9,65 & 0,04 \\
$\mathbf{1 2}$ & 7,45 & 250 & 1,13 & $2,70 \mathrm{E}+08$ & 0,66 & 5,47 & 0,00 & 13,46 & 0,05 \\
$\mathbf{1 3}$ & 7,56 & 250 & 0,96 & & 0,52 & 5,47 & 0,00 & 19,57 & 0,04 \\
$\mathbf{1 4}$ & 7,54 & 250 & 0,86 & $3,75 \mathrm{E}+08$ & 0,47 & 5,47 & 0,00 & 26,13 & 0,07 \\
$\mathbf{1 5}$ & 7,66 & 250 & 0,68 & & 0,42 & 5,47 & 0,00 & 29,23 & 0,06 \\
$\mathbf{1 6}$ & 7,67 & 250 & 0,36 & $2,60 \mathrm{E}+07$ & 0,28 & 5,47 & 0,00 & 50,13 & 0,04 \\
$\mathbf{1 7}$ & 7,73 & 250 & 0,24 & & 0,36 & 5,47 & 0,00 & 54,29 & 0,08 \\
$\mathbf{1 8}$ & 7,84 & 250 & 0,13 & $2,85 \mathrm{E}+05$ & 0,25 & 5,47 & 0,00 & 54,56 & $\ldots \ldots .$. \\
$\mathbf{1 9}$ & 7,93 & 250 & 0,18 & & 0,28 & 5,47 & 0,00 & 54,65 & 0,02 \\
$\mathbf{2 0}$ & 8,00 & 250 & 0,16 & $2,15 \mathrm{E}+04$ & 0,26 & 5,47 & 0,00 & 52,08 & 0,07 \\
\hline
\end{tabular}


Tabela 3.5 - Resultados experimentais do grupo B, ensaio 4.

\begin{tabular}{cccccccccc}
\hline $\begin{array}{c}\text { Tempo } \\
\text { (h) }\end{array}$ & $\mathbf{p H}$ & $\begin{array}{c}\text { Rotação } \\
(\mathbf{r p m})\end{array}$ & $\mathbf{D O}_{\mathbf{5 4 0 n m}}$ & $\begin{array}{c}\text { Viab. Cel. } \\
(\mathbf{U F C} \mathbf{m L})\end{array}$ & $\begin{array}{c}\text { M. Seca } \\
(\mathbf{g} / \mathbf{L})\end{array}$ & $\begin{array}{c}\text { Glicerol } \\
(\mathbf{g} / \mathbf{L})\end{array}$ & $\begin{array}{c}\text { L-lactato } \\
(\mathbf{g} / \mathbf{L})\end{array}$ & $\begin{array}{c}\text { OMV } \\
(\mathbf{m g} / \mathbf{L})\end{array}$ & $\begin{array}{c}\text { Ác. L-glutâmico } \\
(\mathbf{g} / \mathbf{L})\end{array}$ \\
\hline $\mathbf{0}$ & 6,94 & 250 & 0,11 & $1,10 \mathrm{E}+08$ & 0,13 & 4,59 & 2,49 & 2,47 & 1,18 \\
$\mathbf{1}$ & 6,92 & 312 & 0,17 & & 0,04 & 4,59 & 2,49 & 1,34 & 1,18 \\
$\mathbf{2}$ & 6,87 & 447 & 0,29 & $2,40 \mathrm{E}+08$ & 0,25 & 4,59 & 2,47 & 4,84 & $\mathbf{1 , 1 8}$ \\
$\mathbf{3}$ & 6,91 & 541 & 0,88 & & 0,35 & 4,59 & 2,24 & 2,26 & 0,86 \\
$\mathbf{4}$ & 6,99 & 584 & 1,20 & $3,35 \mathrm{E}+09$ & 0,82 & 4,59 & 1,83 & 2,78 & 0,39 \\
$\mathbf{5}$ & 7,28 & 569 & 1,14 & & 1,27 & 4,59 & 1,34 & 5,04 & 0,10 \\
$\mathbf{6}$ & 7,35 & 569 & 1,23 & $2,35 \mathrm{E}+09$ & 2,60 & 4,59 & 0,89 & 6,07 & 0,04 \\
$\mathbf{7}$ & 7,46 & 503 & 1,19 & & 0,74 & 4,59 & 0,50 & 9,26 & 0,07 \\
$\mathbf{8}$ & 7,53 & 515 & 1,21 & $5,00 \mathrm{E}+08$ & 1,61 & 4,59 & 0,29 & 8,23 & 0,03 \\
$\mathbf{9}$ & 7,63 & 436 & 1,20 & & 2,57 & 4,59 & 0,08 & 9,67 & 0,02 \\
$\mathbf{1 0}$ & 7,63 & 250 & 1,13 & $\ldots \ldots \ldots$ & 0,63 & 4,59 & 0,02 & 8,03 & 0,02 \\
$\mathbf{1 1}$ & 7,63 & 250 & 1,24 & & 0,62 & 4,59 & 0,00 & 10,29 & 0,01 \\
$\mathbf{1 2}$ & 7,63 & 250 & 1,20 & $3,10 \mathrm{E}+08$ & 0,73 & 4,59 & 0,00 & 12,45 & 0,02 \\
$\mathbf{1 3}$ & 7,64 & 250 & 1,19 & & 0,79 & 4,59 & 0,00 & 14,61 & 0,02 \\
$\mathbf{1 4}$ & 7,56 & 250 & 1,12 & $2,35 \mathrm{E}+08$ & 0,40 & 4,59 & 0,00 & 13,79 & 0,02 \\
$\mathbf{1 5}$ & 7,49 & 250 & 1,12 & & 0,60 & 4,59 & 0,00 & 17,29 & 0,03 \\
$\mathbf{1 6}$ & 7,49 & 250 & 1,06 & $1,35 \mathrm{E}+08$ & 0,44 & 4,59 & 0,00 & 20,68 & 0,02 \\
$\mathbf{1 7}$ & 7,51 & 250 & 0,90 & & 0,49 & 4,59 & 0,00 & 30,76 & 0,02 \\
$\mathbf{1 8}$ & 7,51 & 250 & 0,93 & $3,50 \mathrm{E}+07$ & 0,29 & 4,59 & 0,00 & 26,34 & 0,01 \\
$\mathbf{1 9}$ & 7,57 & 250 & 0,32 & & 0,40 & 4,59 & 0,00 & 32,72 & 0,02 \\
$\mathbf{2 0}$ & 7,61 & 250 & 0,54 & \multirow{2}{*}{$1,75 \mathrm{E}+06$} & 0,25 & 4,59 & 0,00 & 44,24 & 0,02 \\
\hline
\end{tabular}


3.2.2 Curvas dos resultados dos ensaios do grupo B

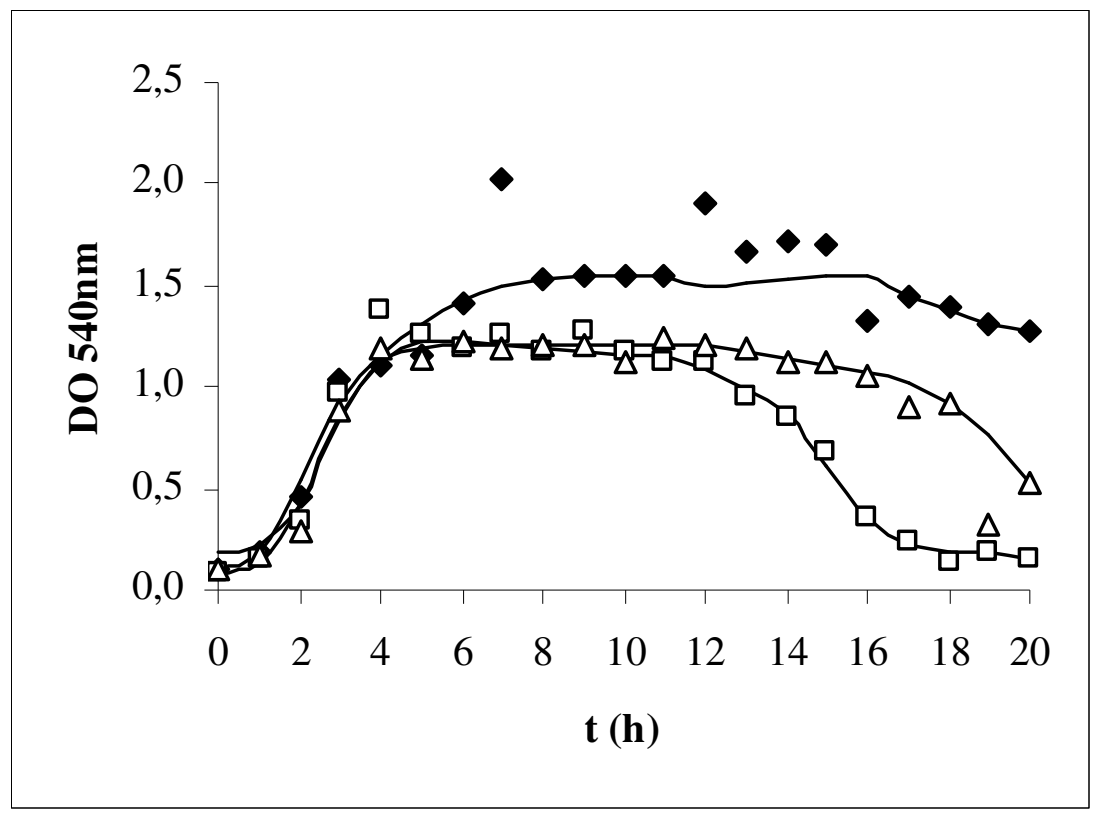

Figura 3.1 - Curvas de crescimento celular ( DO $\left._{540 \mathrm{~nm}}\right)$ suavizadas dos ensaios $2(\diamond), 3(\square)$ e 4 $(\Delta)$.

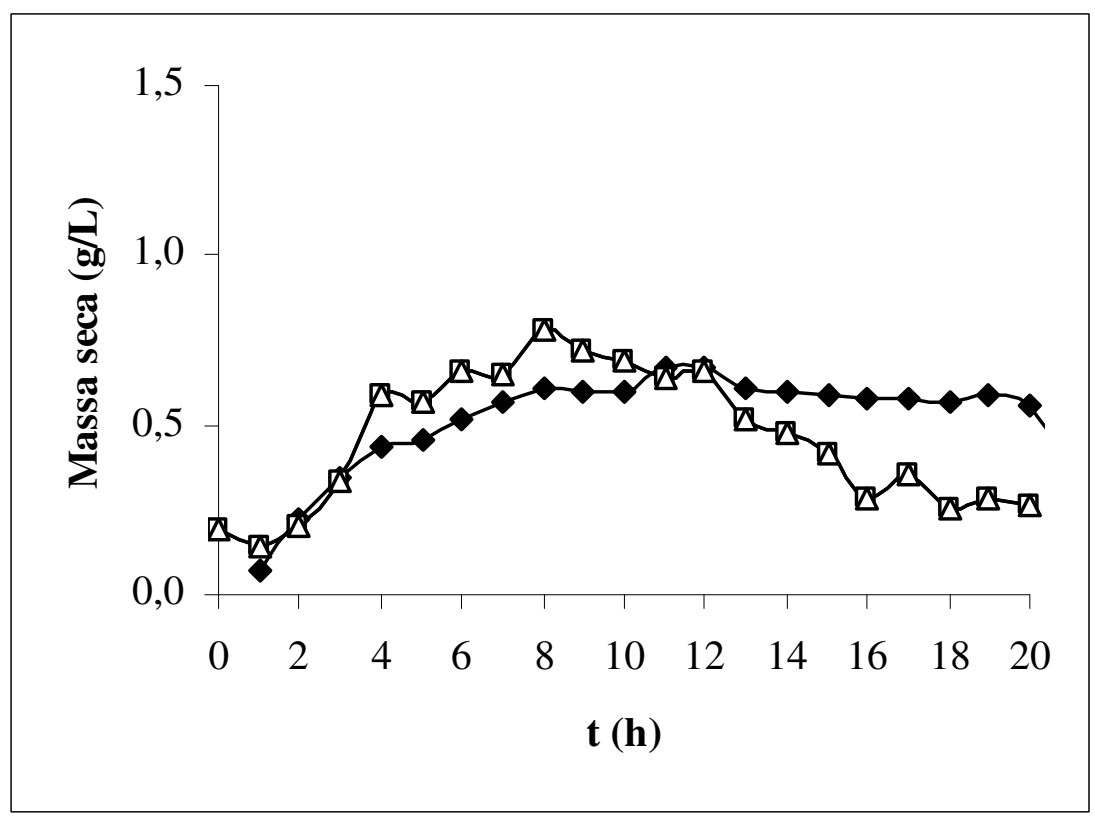

Figura 3.2 - Curvas de massa seca (g/L) dos ensaios $2(\bullet), 3(\square)$ e $4(\Delta)$. 


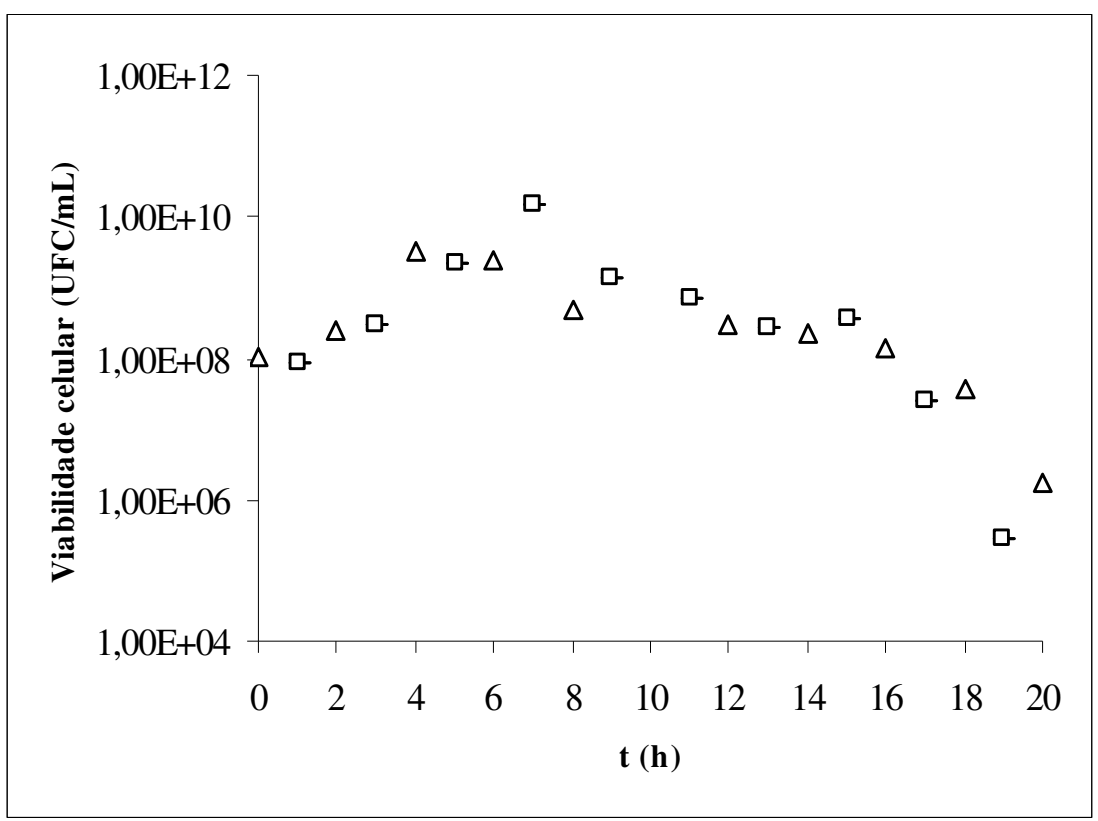

Figura 3.3 - Curvas de viabilidade celular (UFC/mL) dos ensaios $3(\square)$ e $4(\Delta)$.

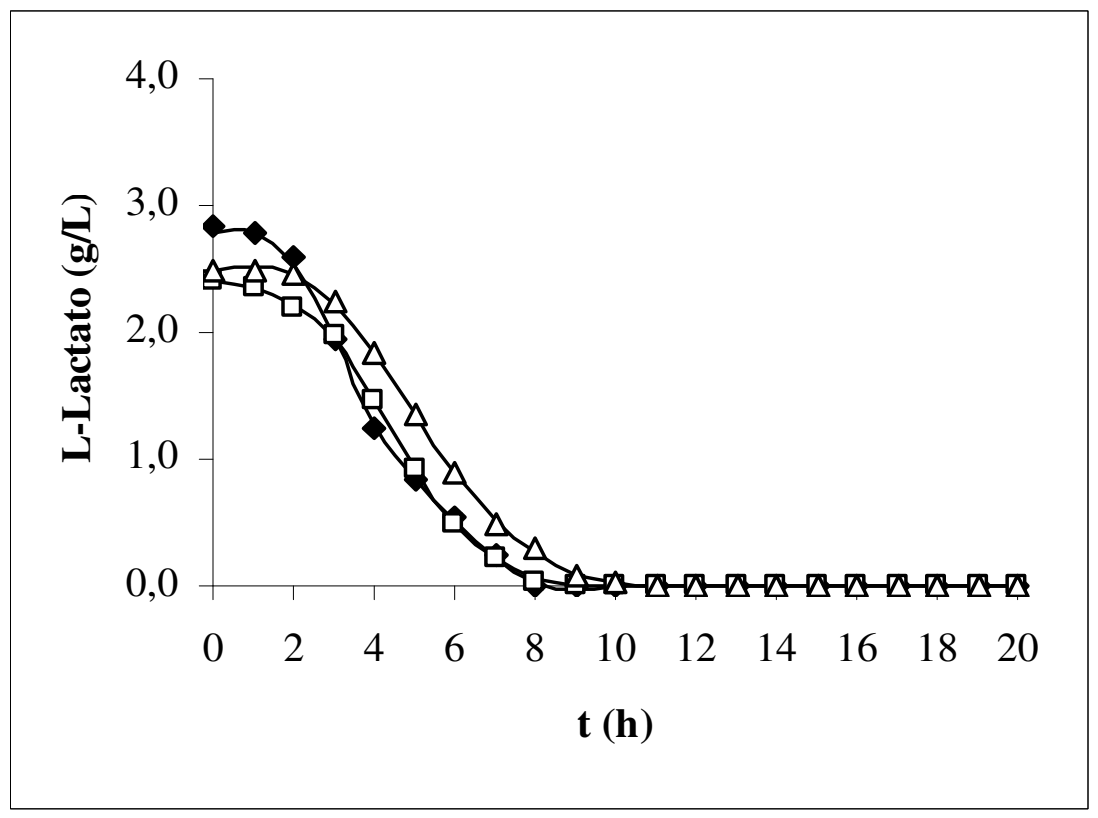

Figura 3.4 - Curvas de consumo de L-lactato (g/L) suavizadas dos ensaios $2(\diamond), 3(\square)$ e 4 $(\Delta)$. 


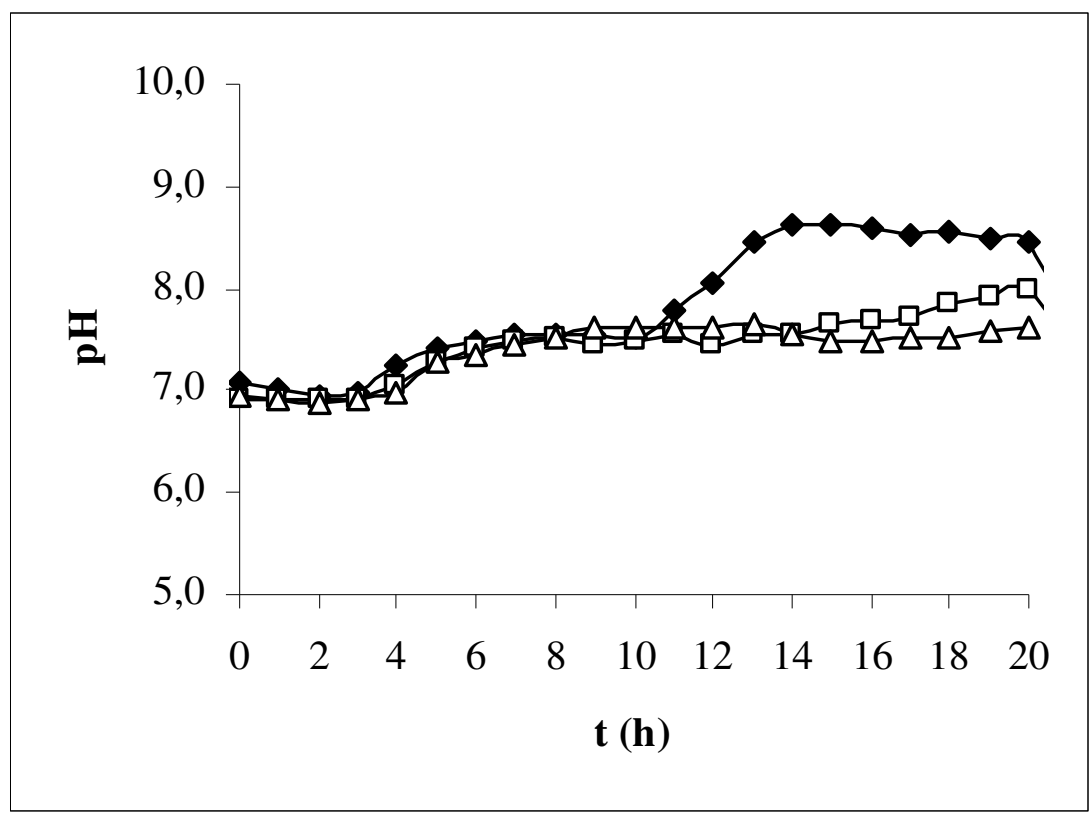

Figura 3.5 - Curvas de pH dos ensaios $2(\diamond), 3(\square)$ e $4(\Delta)$.

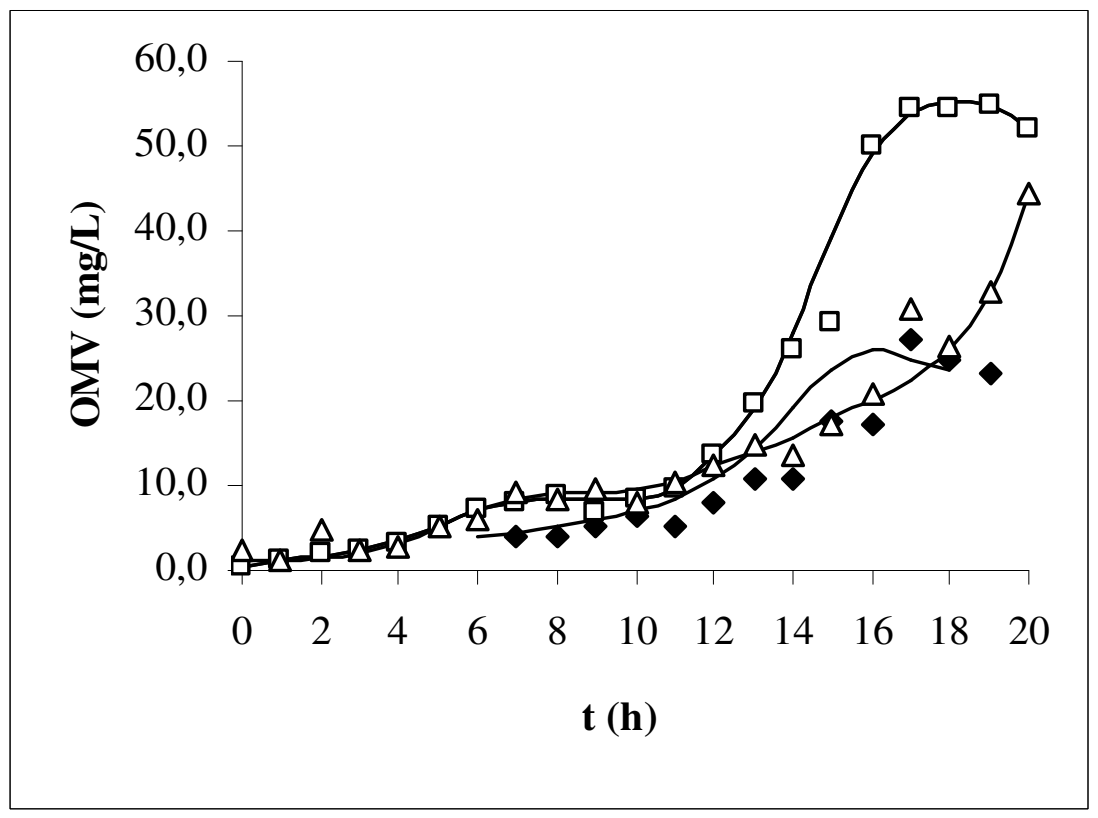

Figura 3.6 - Curvas de produção de OMV (mg/L) suavizadas dos ensaios $2(\diamond), 3(\square)$ e $4(\Delta)$. 


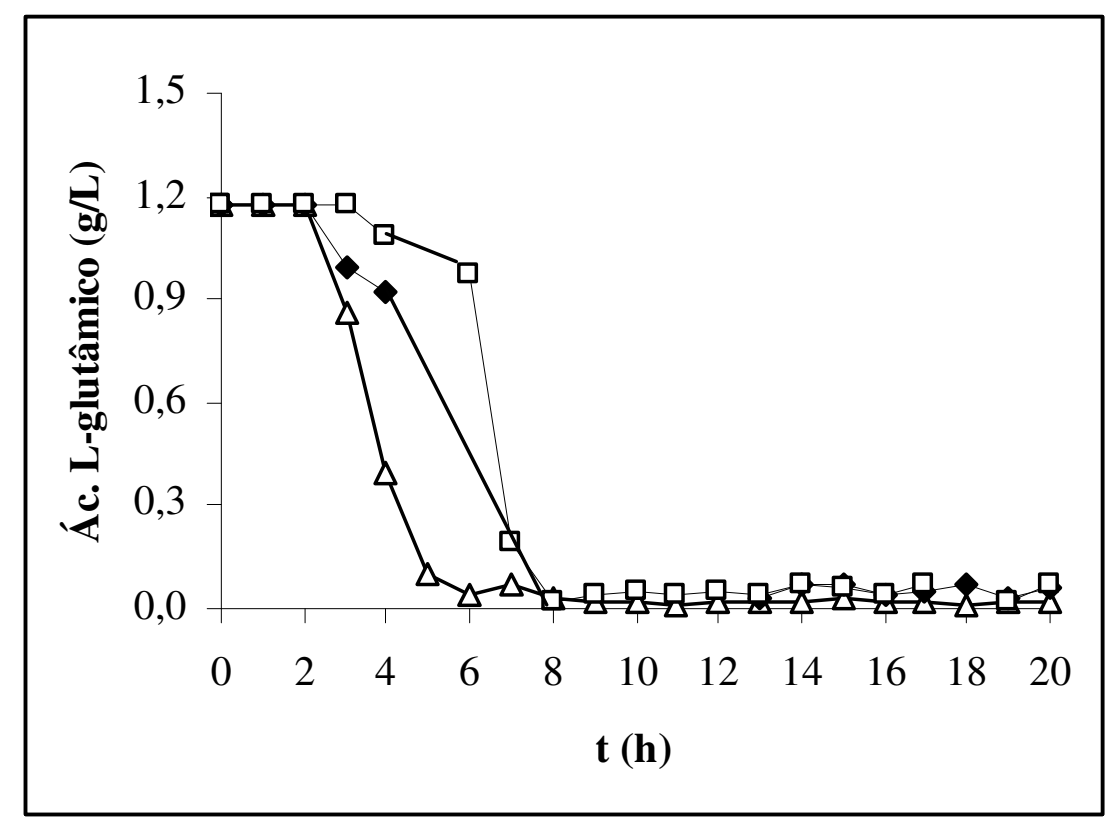

Figura 3.7 - Curvas de consumo de ácido L-glutâmico (g/L) dos ensaios $2(\bullet), 3(\square)$ e $4(\Delta)$. 


\subsection{Ensaios do Grupo C - Meio Catlin sem ferro com concentração de L-lactato triplicada}

Com intuito de aumentar o crescimento celular e consequentemente a produção de OMV, os ensaios do grupo $\mathrm{C}$ foram realizados em cultivo descontínuo no meio de Catlin sem ferro, com concentração inicial de lactato, ou seja, L-lactato triplicada.

As figuras 3.8 e 3.9 ilustram as curvas de crescimento celular medidas por densidade óptica a $540 \mathrm{~nm}\left(\mathrm{DO}_{540 \mathrm{~nm}}\right)$ e massa seca realizada em duplicatas. A fase estacionária inicia-se na $9^{\text {a }}$ hora de cultivo com densidade óptica ao redor de 2,06 e 4,1 permanecendo até a $15^{\text {a }}$ hora e massa seca de aproximadamente 1,0 e $2,8 \mathrm{mg} / \mathrm{L}$. O perfil de viabilidade celular é ilustra

na do figura 3.10 , onde se observa que na fase estacionária atingiu o valor de $1,5 \times 10^{11}$ $\mathrm{UFC} / \mathrm{mL}$.

No ensaio 5, o lactato não foi completamente consumido até o final do cultivo, apresentando resíduo de 2,34 g/L na $20^{\text {a }}$ hora de cultivo (Figura 3.11). Mesmo apresentando um residual de lactato é possível verificar o aumento do pH (Figura 3.12), indicando que o microorganismo utiliza os aminoácidos independentes do lactato. A figura 3.13 ilustra a formação de OMV que se inicia na $6^{\mathrm{a}}$ hora, porém se destaca a partir da $11^{\mathrm{a}}$ hora de cultivo e no final da $20^{\mathrm{a}}$ hora atinge valor médio em torno de $80 \mathrm{mg} / \mathrm{L}$.

Nesse grupo, o crescimento celular $\left(\mathrm{DO}_{540 \mathrm{~nm}}\right)$ apresentou variedade entre os ensaios. A viabilidade celular (UFC/mL) foi analisada nos dois ensaios (Figura 3.10) e apresentou perfil que acompanha o do crescimento celular do ensaio 5 (Figura 3.8). As curvas do ácido Lglutâmico mostram o consumo total (Figura 3.14).

\subsubsection{Resultados experimentais dos ensaios do grupo C}

Os valores experimentais da cinética dos ensaios do grupo $\mathrm{C}$ estão ilustrados na tabela 3.6 e 3.7 e os valores suavizados, calculados por meio do programa de Lissage, na tabela 7.1.4 a 7.1.5 do anexo 7.1. 
Tabela 3.6 - Resultados experimentais do grupo C, ensaio 5.

\begin{tabular}{ccccccccccc}
\hline $\begin{array}{c}\text { Tempo } \\
(\mathbf{h})\end{array}$ & $\mathbf{p H}$ & $\begin{array}{c}\text { Oxig.Diss. } \\
(\mathbf{\%})\end{array}$ & $\begin{array}{c}\text { Agitação } \\
(\mathbf{r p m})\end{array}$ & $\mathbf{D O}_{\mathbf{5 4 0 n m}}$ & $\begin{array}{c}\text { Viab. Cel. } \\
(\mathbf{U F C} \mathbf{m L})\end{array}$ & $\begin{array}{c}\text { M.Seca } \\
(\mathbf{g} / \mathbf{L})\end{array}$ & $\begin{array}{c}\text { Glicerol } \\
(\mathbf{g} / \mathbf{L})\end{array}$ & $\begin{array}{c}\text { L-lactato } \\
(\mathbf{g} / \mathbf{L})\end{array}$ & $\begin{array}{c}\text { OMV } \\
(\mathbf{m g} / \mathbf{L})\end{array}$ & $\begin{array}{c}\text { Ác. L-glutâmico } \\
(\mathbf{g} / \mathbf{L})\end{array}$ \\
\hline $\mathbf{0}$ & 6,92 & $\ldots \ldots$. & 250 & 0,13 & $1,15 \mathrm{E}+08$ & 0,11 & 6,30 & 7,25 & 0,00 & 1,18 \\
$\mathbf{1}$ & 6,89 & 6,9 & 454 & 0,20 & & 0,12 & 6,30 & 7,40 & 0,00 & 1,18 \\
$\mathbf{2}$ & 6,84 & 9,8 & 521 & 0,43 & $2,80 \mathrm{E}+08$ & 0,24 & 6,30 & 7,25 & 0,08 & 1,18 \\
$\mathbf{3}$ & 6,89 & 9,0 & 582 & 1,03 & & 0,37 & 6,30 & 6,95 & 2,37 & 0,12 \\
$\mathbf{4}$ & 7,17 & 9,6 & 629 & 1,22 & $1,40 \mathrm{E}+09$ & 0,59 & 6,30 & 6,45 & 2,05 & 0,04 \\
$\mathbf{5}$ & 7,38 & 9,0 & 679 & 1,35 & & 0,65 & 6,30 & 5,80 & 2,88 & 0,16 \\
$\mathbf{6}$ & 7,36 & 9,5 & 712 & 1,53 & $2,40 \mathrm{E}+09$ & 0,64 & 6,30 & 5,45 & 5,05 & 0,11 \\
$\mathbf{7}$ & 7,40 & 9,4 & 748 & 1,90 & & 0,86 & 6,30 & 4,95 & 8,21 & 0,15 \\
$\mathbf{8}$ & 7,53 & 9,6 & 694 & 2,18 & $2,40 \mathrm{E}+10$ & 0,95 & 6,30 & 4,69 & 9,71 & 0,06 \\
$\mathbf{9}$ & 7,55 & 9,1 & 841 & 2,34 & & 1,02 & 6,30 & 4,32 & 15,23 & 0,04 \\
$\mathbf{1 0}$ & 7,63 & 2,6 & 850 & 2,19 & $1,55 \mathrm{E}+11$ & 0,93 & 6,30 & 4,16 & 14,76 & 0,04 \\
$\mathbf{1 1}$ & 7,66 & 0,0 & 850 & 2,35 & & 0,89 & 6,30 & 3,95 & 15,63 & 0,02 \\
$\mathbf{1 2}$ & 7,68 & 0,0 & 850 & 2,33 & $3,00 \mathrm{E}+10$ & 0,96 & 6,30 & 3,45 & $\ldots \ldots \ldots$ & 0,01 \\
$\mathbf{1 3}$ & 7,75 & 0,0 & 850 & 2,29 & & 1,07 & 6,30 & 3,42 & 20,05 & 0,03 \\
$\mathbf{1 4}$ & 7,79 & 0,0 & 850 & 2,21 & $2,65 \mathrm{E}+09$ & 0,90 & 6,30 & 3,38 & 29,44 & $\ldots \ldots .$. \\
$\mathbf{1 5}$ & 7,83 & 0,0 & 850 & 2,06 & & 0,96 & 6,30 & 3,06 & 30,94 & 0,03 \\
$\mathbf{1 6}$ & 7,92 & 0,0 & 850 & 1,97 & $3,55 \mathrm{E}+08$ & 0,99 & 6,30 & 2,96 & 43,96 & 0,03 \\
$\mathbf{1 7}$ & 7,98 & 0,0 & 850 & 1,76 & & 0,88 & 6,30 & 2,88 & 53,82 & 0,05 \\
$\mathbf{1 8}$ & 8,12 & 0,0 & 850 & 1,64 & $3,20 \mathrm{E}+08$ & 0,80 & 6,30 & 2,55 & 66,61 & 0,02 \\
$\mathbf{1 9}$ & 8,20 & 0,0 & 850 & 1,46 & & 1,54 & 6,30 & 2,37 & $\ldots \ldots \ldots$ & 0,04 \\
$\mathbf{2 0}$ & 8,32 & 0,0 & 850 & 1,36 & $1,40 \mathrm{E}+07$ & 1,34 & 6,30 & 2,34 & 79,43 & 0,04 \\
\hline
\end{tabular}

Tabela 3.7 - Resultados experimentais do grupo C, ensaio 6.

\begin{tabular}{|c|c|c|c|c|c|c|c|c|}
\hline $\begin{array}{c}\text { Tempo } \\
\text { (h) }\end{array}$ & pH & $\begin{array}{c}\text { Oxig.Diss. } \\
(\%) \\
\end{array}$ & $\begin{array}{c}\text { Rotação } \\
(\mathbf{r p m})\end{array}$ & DO $_{540 \mathrm{~nm}}$ & $\begin{array}{l}\text { Viab. Cel. } \\
\text { (UFC/mL) }\end{array}$ & $\begin{array}{c}\text { M.Seca } \\
(\mathrm{g} / \mathrm{L}) \\
\end{array}$ & $\begin{array}{c}\text { Glicerol } \\
(\mathrm{g} / \mathrm{L})\end{array}$ & $\begin{array}{c}\text { OMV } \\
(\mathrm{mg} / \mathrm{L})\end{array}$ \\
\hline $\mathbf{0}$ & 7,32 & 14,30 & 250 & 0,11 & $1,60 \mathrm{E}+08$ & 0,23 & 5,43 & 1,03 \\
\hline 1 & 7,24 & 9,80 & 426 & 0,18 & & 0,33 & ......... & 2,17 \\
\hline 2 & 7,09 & 10,60 & 532 & 0,41 & $1,90 \mathrm{E}+09$ & 0,41 & ......... & 0,72 \\
\hline 3 & 7,04 & 9,20 & 624 & 0,88 & & 0,70 & $\ldots \ldots \ldots$ & 1,14 \\
\hline 4 & 7,28 & 8,20 & 679 & 1,29 & $2,70 \mathrm{E}+09$ & 0,92 & ......... & 2,89 \\
\hline 5 & 7,28 & 7,30 & 850 & 2,58 & & 1,36 & ........ & 5,06 \\
\hline 6 & 7,32 & 1,40 & 850 & 3,67 & ........ & 1,80 & ........ & 13,43 \\
\hline 7 & 7,48 & 1,10 & 851 & 3,87 & & 1,88 & ........ & 20,25 \\
\hline 8 & 7,59 & 1,00 & 850 & 4,10 & $4,78 \mathrm{E}+09$ & 1,92 & ......... & 23,14 \\
\hline 9 & 7,92 & 0,80 & 849 & 4,15 & & 2,00 & ......... & 24,18 \\
\hline 10 & 7,96 & 0,80 & 850 & 3,99 & $6,20 \mathrm{E}+09$ & ......... & ........ & 24,59 \\
\hline 11 & 7,96 & 0,70 & 834 & 3,76 & & $\ldots \ldots \ldots$ & ......... & 26,86 \\
\hline 12 & 7,94 & 0,60 & 850 & 3,78 & $4,10 \mathrm{E}+10$ & $\ldots \ldots .$. & ........ & 24,18 \\
\hline 13 & 7,86 & 0,60 & 850 & 4,16 & & 2,88 & ........ & 26,86 \\
\hline 14 & 7,70 & 0,60 & 850 & 4,01 & $\ldots \ldots \ldots$ & 3,32 & ......... & 24,59 \\
\hline 15 & 7,71 & 0,60 & 850 & 4,24 & & 3,30 & ........ & 27,07 \\
\hline 16 & 7,76 & 0,50 & 852 & 4,68 & $\ldots \ldots \ldots$ & 3,41 & ......... & 35,75 \\
\hline 17 & 8,13 & $\ldots \ldots \ldots$ & ........ & 4,53 & & 3,24 & $\ldots \ldots \ldots$ & 79,76 \\
\hline 18 & 8,33 & ........ & ......... & 4,89 & ........ & 2,09 & ......... & 70,26 \\
\hline 19 & 8,42 & …..... & ......... & 4,76 & & 1,96 & ......... & 88,03 \\
\hline 20 & 8,49 & ......... & ........ & 4,01 & ......... & 2,40 & 5,29 & 89,27 \\
\hline
\end{tabular}


3.3.2 Curvas dos resultados dos ensaios do grupo C.

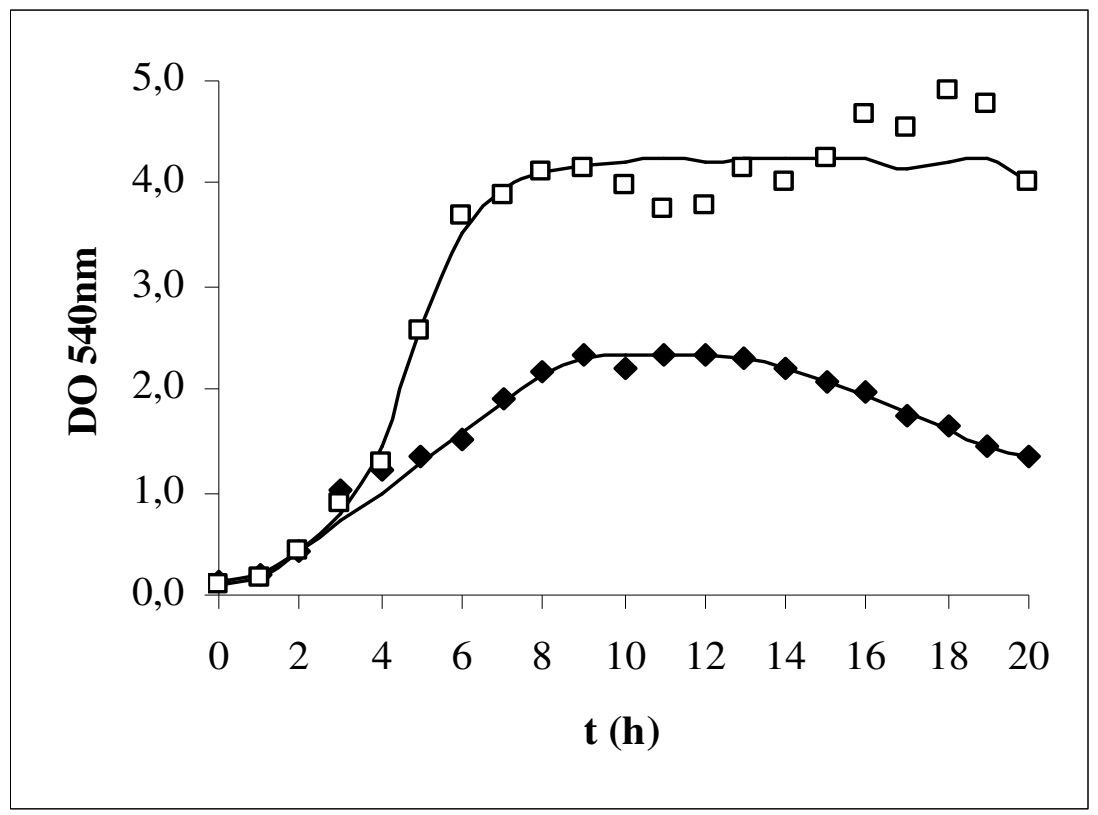

Figura 3.8 - Curvas de crescimento celular (DO $540 \mathrm{~nm}$ ) suavizadas dos ensaios 5 (४) e 6 ( $\square$ ).

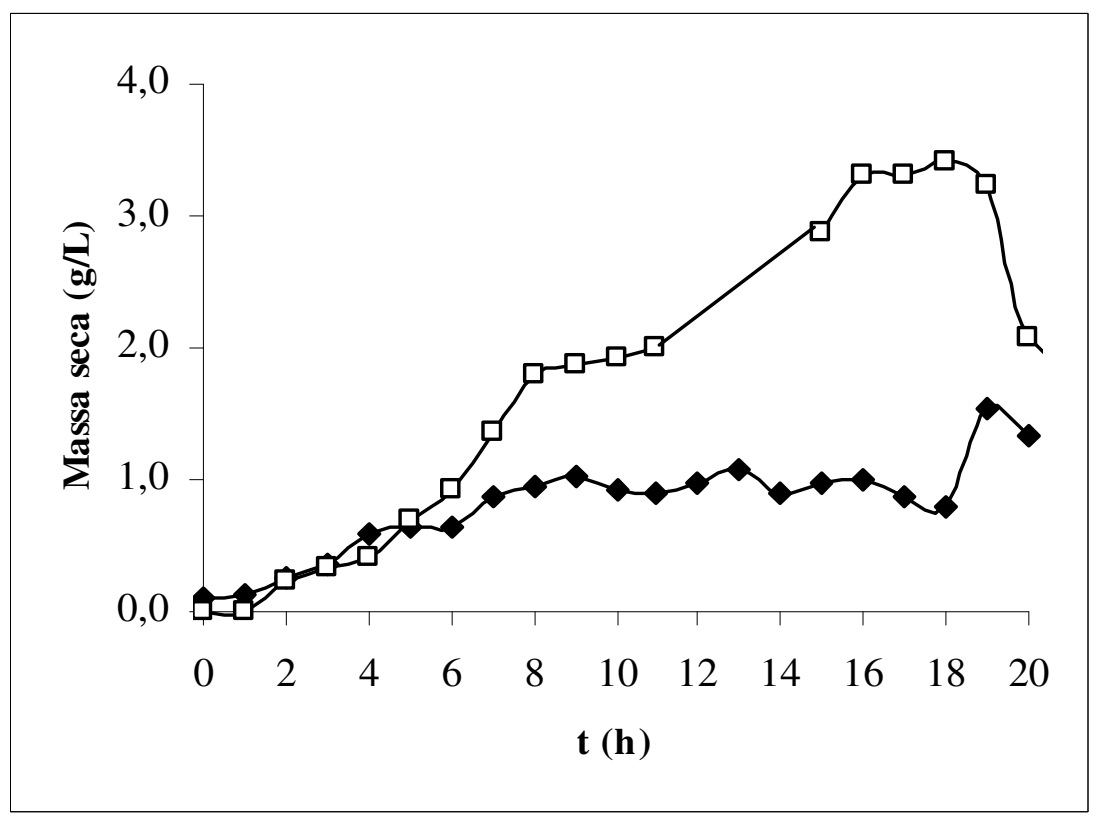

Figura 3.9 - Curvas de massa seca (g/L) dos ensaios $5(\diamond)$ e $6(\square)$. 


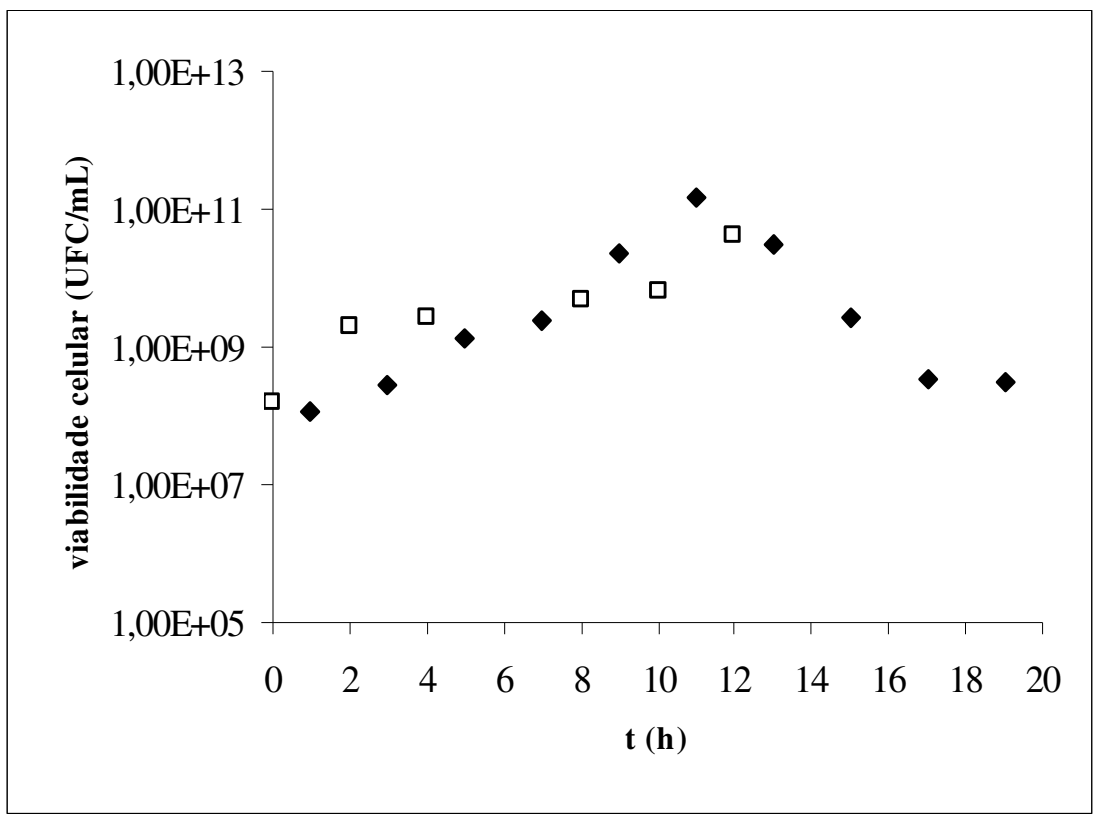

Figura 3.10 - Curvas de viabilidade celular (UFC/mL) dos ensaios $5(\diamond)$ e $6(\square)$.

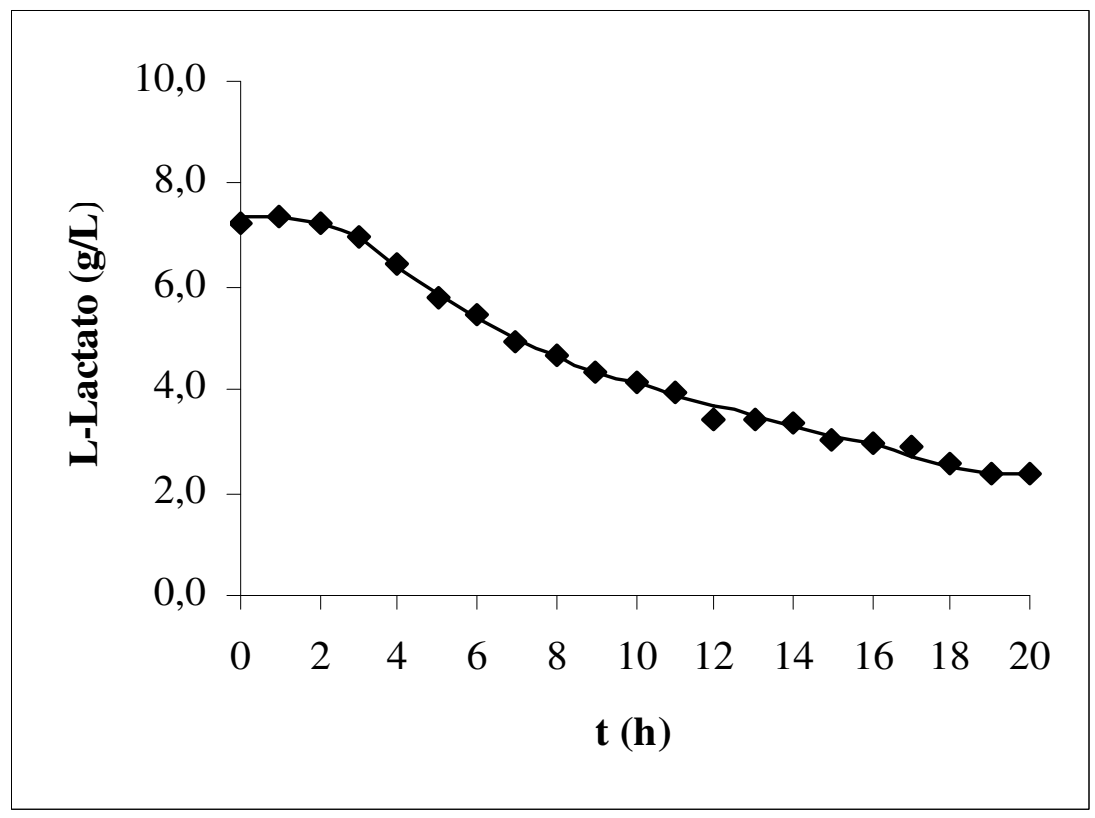

Figura 3.11 - Curva de consumo de L-lactato (g/L) suavizada do ensaio 5 ( $\bullet$ ). 


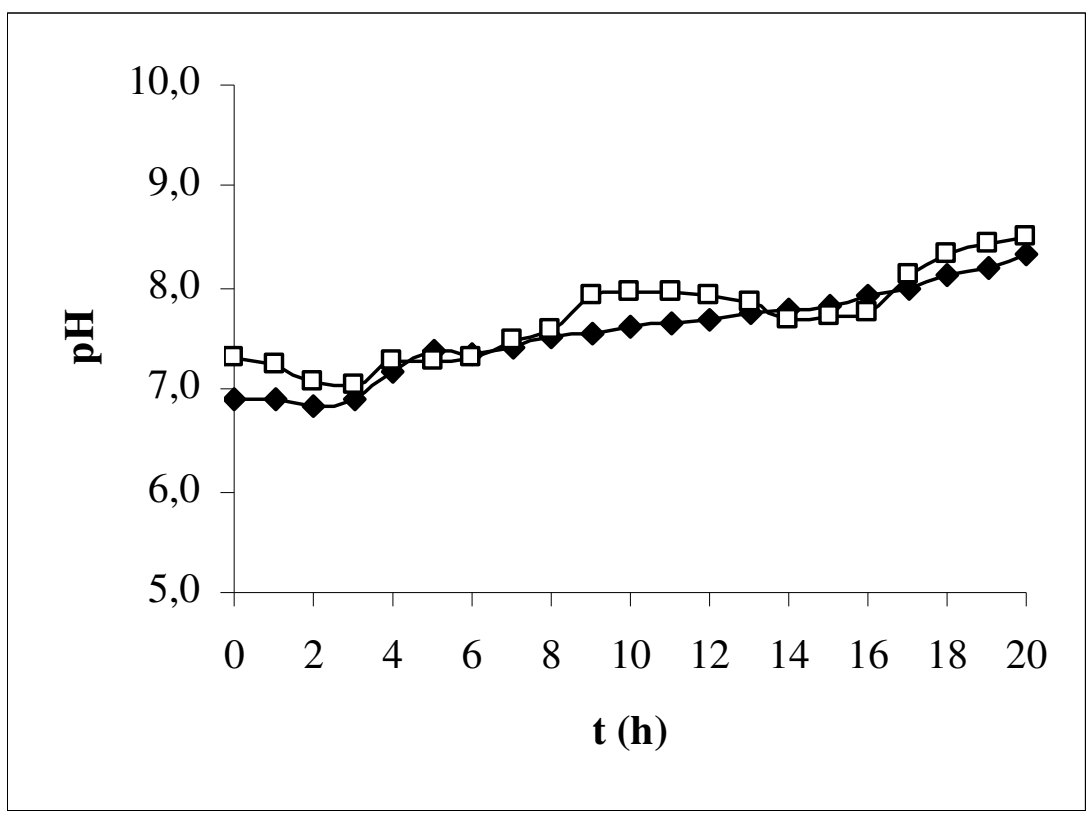

Figura 3.12 - Curvas de pH dos ensaios $5(\diamond)$ e $6(\square)$.

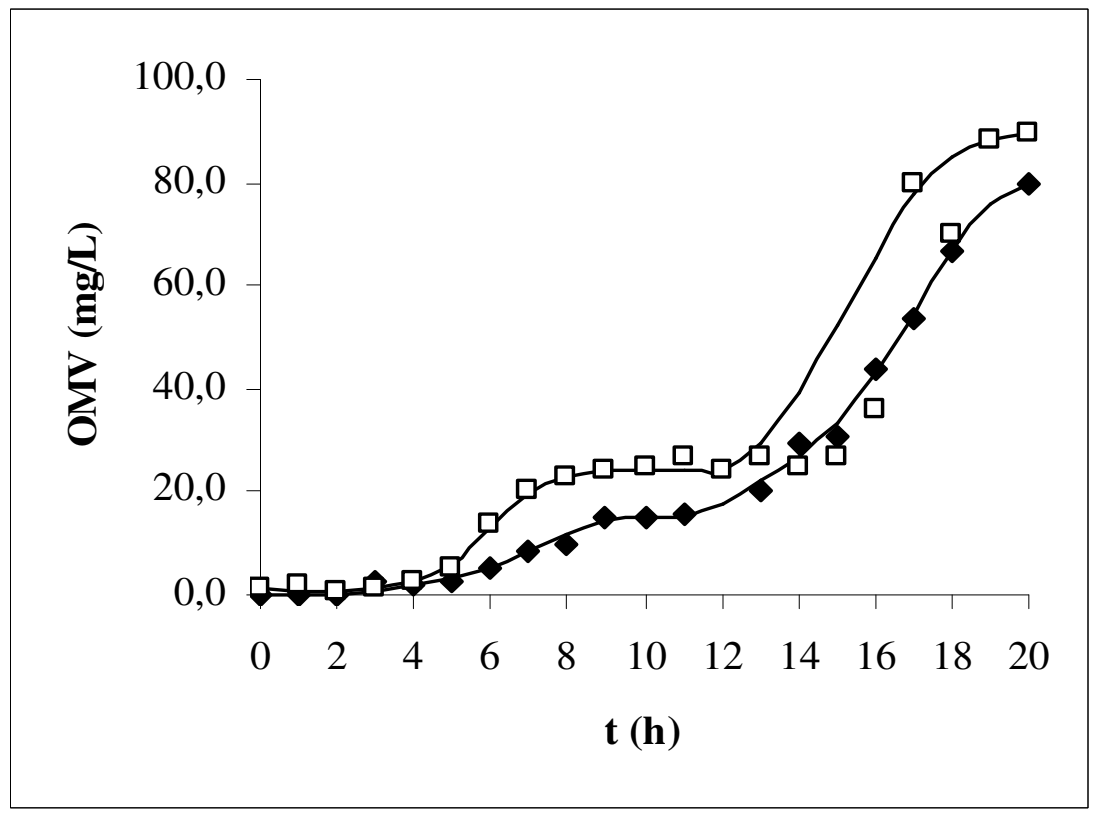

Figura 3.13 - Curvas de produção de OMV (mg/L) suavizadas dos ensaios $5(\diamond)$ e 6 ( $\square$ ). 


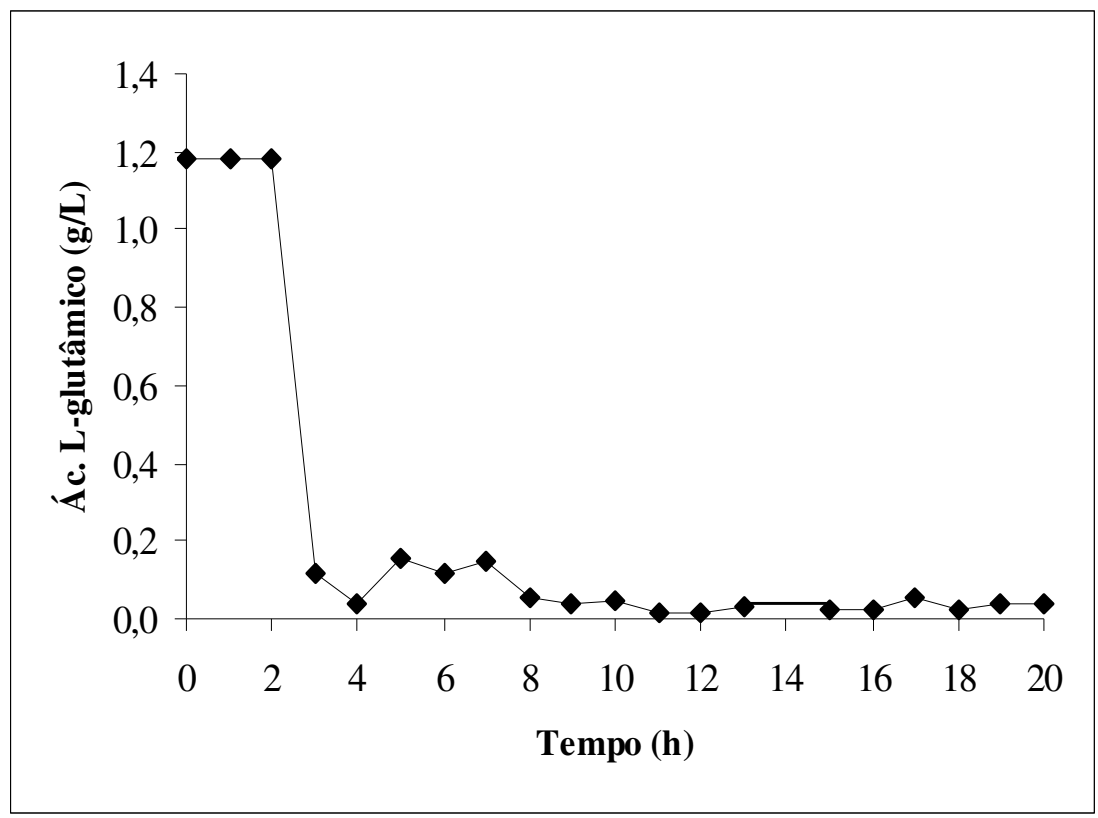

Figura 3.14 - Curvas de consumo de ácido L-glutâmico (g/L) dos ensaios 5 (»). 


\subsection{Ensaios do Grupo D - Meio Catlin sem ferro com pulso de lactato e aminoácidos}

Com objetivo de prolongar a fase de crescimento e aumentar a produção de OMV, os ensaios do grupo D foram realizados em cultivo descontínuo alimentado no meio de Catlin sem ferro com pulso de lactato e aminoácidos na $6^{\mathrm{a}} \mathrm{h}$ de cultivo, momento em que o microorganismo parece querer iniciar a fase estacionária.

As figuras 3.15 e 3.16 ilustram as curvas de crescimento celular medidas por densidade óptica $\left(\mathrm{DO}_{540 \mathrm{~nm}}\right)$ e massa seca realizadas em duplicatas. A fase estacionária iniciase na décima hora de cultivo com densidade óptica ao redor de 2,0-2,69 e massa seca de 1,0 $\mathrm{g} / \mathrm{L}$ até a $12^{\mathrm{a}}$ hora.

O lactato foi consumido até a sexta hora apresentando média no valor de resíduo de 0,6 g/L, com adição do pulso de lactato e aminoácidos nesse instante o valor em média foi elevado para 3,0 g/L sendo totalmente consumido na $16^{\mathrm{a}}$ hora (Figura 3.17). No primeiro instante de consumo de lactato ( $6^{\mathrm{a}}$ hora) o $\mathrm{pH}$ se elevou até 8,0 , com o pulso de lactato e aminoácidos ele declina para 7,5 iniciando uma nova elevação do valor até atingir pH de 8,3 (Figura 3.18), indicando a utilização dos aminoácidos pela Neisseria.

A figura 3.19 ilustra a formação de OMV que se inicia na segunda hora de cultivo, porém sua formação se destaca a partir da $9^{\text {a }}$ hora, atingindo valor médio em torno de 49 $\mathrm{mg} / \mathrm{L}$ no final do cultivo. As curvas do ácido L-glutâmico mostram o consumo total (Figura $3.20)$.

\subsubsection{Resultados experimentais dos ensaios do grupo D}

Os valores experimentais da cinética dos ensaios do grupo D estão ilustrados na tabela 3.8 e 3.9 e os valores suavizados, calculados por meio do programa de Lissage, apresentados na tabela 7.1.6 à 7.1.7 do anexo 7.1. 
Tabela 3.8 - Resultados experimentais do grupo D, ensaio 7.

\begin{tabular}{|c|c|c|c|c|c|c|c|c|c|}
\hline $\begin{array}{c}\text { Tempo } \\
\text { (h) } \\
\end{array}$ & pH & $\begin{array}{c}\text { Oxig.Diss. } \\
(\%) \\
\end{array}$ & $\begin{array}{c}\text { Agitação } \\
(\mathbf{r p m})\end{array}$ & DO $_{540 \mathrm{~nm}}$ & $\begin{array}{c}\text { M.Seca } \\
(\mathrm{g} / \mathrm{L}) \\
\end{array}$ & $\begin{array}{c}\text { Glicerol } \\
(\mathrm{g} / \mathrm{L}) \\
\end{array}$ & $\begin{array}{c}\text { L-lactato } \\
(\mathrm{g} / \mathrm{L})\end{array}$ & $\begin{array}{c}\text { OMV } \\
(\mathrm{mg} / \mathrm{L})\end{array}$ & $\begin{array}{c}\text { Ác. L-glutâmico } \\
(\mathrm{g} / \mathrm{L})\end{array}$ \\
\hline 0 & 7,00 & $\ldots \ldots .$. & 250 & 0,14 & 0,05 & 5,23 & 2,29 & 0,00 & 1,18 \\
\hline 1 & 7,21 & $\ldots \ldots .$. & 250 & 0,24 & 0,10 & ......... & 2,23 & 0,00 & 1,18 \\
\hline 2 & 7,24 & 6,28 & 251 & 0,56 & 0,24 & ........ & 2,06 & 0,55 & 1,18 \\
\hline 3 & 7,57 & 11,30 & 365 & 1,09 & 0,46 & $\ldots \ldots \ldots$ & 1,64 & 2,03 & 1,18 \\
\hline 4 & 7,90 & 10,90 & 350 & 0,98 & 0,43 & ......... & 1,16 & 3,97 & 1,13 \\
\hline 5 & 8,04 & 10,40 & 319 & 1,08 & 0,51 & ........ & 0,78 & 4,02 & 1,01 \\
\hline \multirow[t]{2}{*}{6} & 8,09 & 9,80 & 298 & 1,13 & 0,53 & ........ & 0,50 & 6,88 & 0,82 \\
\hline & & & & & & & 2,80 & & 3,00 \\
\hline 7 & 7,51 & 3,40 & 708 & 1,30 & 0,65 & $\ldots \ldots \ldots$ & 2,87 & 9,18 & ......... \\
\hline 8 & 7,52 & 8,70 & 800 & 1,81 & 0,79 & ........ & 2,25 & 13,66 & 3,82 \\
\hline 9 & 7,60 & 3,00 & 850 & 1,84 & 0,86 & ........ & 1,55 & 21,10 & 4,46 \\
\hline 10 & 7,66 & 2,60 & 850 & 2,11 & 0,90 & ........ & 1,26 & 24,82 & 3,46 \\
\hline 11 & 7,83 & 10,20 & 719 & 1,85 & 1,00 & ........ & 0,84 & 30,19 & 3,56 \\
\hline 12 & 7,90 & 8,80 & 749 & 1,82 & 1,24 & ........ & 0,44 & 28,52 & 0,32 \\
\hline 13 & 7,90 & 9,00 & 724 & 1,53 & 1,33 & ......... & 0,34 & 29,93 & 0,38 \\
\hline 14 & 8,04 & 10,10 & 725 & 2,53 & 1,29 & ......... & 0,05 & 36,36 & 0,31 \\
\hline 15 & 8,15 & 10,60 & 686 & 2,55 & ......... & ......... & 0,03 & 32,14 & 0,30 \\
\hline 16 & 8,14 & 9,80 & 661 & 2,65 & 1,44 & ........ & 0,02 & 49,19 & 0,76 \\
\hline 17 & 8,20 & 10,00 & 599 & 2,66 & 1,72 & $\ldots \ldots \ldots$ & 0,02 & 38,67 & 0,81 \\
\hline 18 & 8,20 & 9,40 & 633 & 2,14 & ......... & ......... & 0,03 & 51,77 & ......... \\
\hline 19 & 8,20 & 9,10 & 627 & 2,62 & 1,70 & ........ & 0,02 & 59,42 & 0,34 \\
\hline 20 & 8,30 & ........ & 850 & 2,32 & $\ldots \ldots \ldots$ & 5,03 & 0,01 & 50,94 & 1,18 \\
\hline
\end{tabular}

Tabela 3.9 - Resultados experimentais do grupo D, ensaio 8.

\begin{tabular}{cccccccccc}
\hline Tempo $(\mathbf{h})$ & $\mathbf{p H}$ & $\begin{array}{c}\text { Oxig.Diss. } \\
(\mathbf{\%})\end{array}$ & $\begin{array}{c}\text { Agitação } \\
(\mathbf{r p m})\end{array}$ & $\mathbf{D O}_{\mathbf{5 4 0 n m}}$ & $\begin{array}{c}\text { M.Seca } \\
(\mathbf{g} / \mathbf{L})\end{array}$ & $\begin{array}{c}\text { Glicerol } \\
(\mathbf{g} / \mathbf{L})\end{array}$ & $\begin{array}{c}\text { L-lactato } \\
(\mathbf{g} / \mathbf{L})\end{array}$ & $\begin{array}{c}\text { OMV } \\
(\mathbf{m g} / \mathbf{L})\end{array}$ & $\begin{array}{c}\text { Ác. L-glutâmico } \\
(\mathbf{g} / \mathbf{L})\end{array}$ \\
$\mathbf{0}$ & 7,00 & $\ldots \ldots \ldots$ & 250 & 0,12 & 0,12 & 5,34 & 2,29 & 0,00 & 1,180 \\
$\mathbf{1}$ & 7,23 & $\ldots \ldots \ldots$ & 250 & 0,23 & 0,09 & $\ldots \ldots \ldots$ & 2,36 & 0,00 & 1,180 \\
$\mathbf{2}$ & 7,26 & 8,7 & 250 & 0,55 & 0,19 & $\ldots \ldots \ldots$ & 2,11 & 0,28 & 1,180 \\
$\mathbf{3}$ & 7,43 & 10,3 & 250 & 1,25 & 0,87 & $\ldots \ldots \ldots$ & 1,89 & 1,63 & 1,180 \\
$\mathbf{4}$ & 7,80 & 10,1 & 388 & 1,20 & 0,53 & $\ldots \ldots \ldots$ & 1,40 & 3,05 & 0,842 \\
$\mathbf{5}$ & 7,99 & 10,0 & 361 & 1,12 & 0,86 & $\ldots \ldots \ldots$ & 0,95 & 4,50 & 0,949 \\
$\mathbf{6}$ & 8,08 & 9,7 & 380 & 1,00 & 0,93 & $\ldots \ldots \ldots$ & 0,71 & 5,44 & 0,983 \\
& & & & & & & 3,10 & & 1,733 \\
$\mathbf{7}$ & 7,43 & 6,7 & 732 & 1,35 & 0,58 & $\ldots \ldots \ldots$ & 3,17 & 5,96 & 1,724 \\
$\mathbf{8}$ & 7,50 & 8,5 & 850 & 2,08 & 0,88 & $\ldots \ldots \ldots$ & 2,26 & 12,87 & 1,009 \\
$\mathbf{9}$ & 7,48 & 5,7 & 850 & 2,59 & $\ldots \ldots \ldots$ & $\ldots \ldots \ldots$ & 0,95 & 17,48 & 0,224 \\
$\mathbf{1 0}$ & 7,52 & 5,6 & 850 & 3,10 & 1,19 & $\ldots \ldots \ldots$ & 0,98 & 26,21 & 0,400 \\
$\mathbf{1 1}$ & 7,59 & 5,1 & 850 & 1,26 & 1,31 & $\ldots \ldots \ldots$ & 0,71 & 32,58 & 0,504 \\
$\mathbf{1 2}$ & 7,68 & 4,7 & 850 & 1,86 & 1,64 & $\ldots \ldots \ldots$ & 0,48 & 47,25 & \\
$\mathbf{1 3}$ & 7,76 & 4,5 & 850 & 2,69 & 1,82 & $\ldots \ldots \ldots$ & 0,22 & 23,04 & 0,057 \\
$\mathbf{1 4}$ & 7,80 & 4,6 & 850 & 3,59 & 1,72 & $\ldots \ldots \ldots$ & 0,21 & 48,91 & 0,048 \\
$\mathbf{1 5}$ & 7,84 & 4,6 & 850 & 3,58 & 2,45 & $\ldots \ldots \ldots$ & 0,11 & 38,05 & 0,030 \\
$\mathbf{1 6}$ & 7,86 & 4,6 & 850 & 3,72 & $\ldots \ldots \ldots$ & $\ldots \ldots \ldots$ & 0,01 & 58,97 & 0,015 \\
$\mathbf{1 7}$ & 7,80 & 5,3 & 850 & 3,51 & 1,82 & $\ldots \ldots \ldots$ & 0,02 & 65,60 & 0,048 \\
$\mathbf{1 8}$ & 7,80 & 11,8 & 850 & 3,39 & $\ldots \ldots \ldots$ & $\ldots \ldots \ldots$ & 0,01 & 55,37 & 0,069 \\
$\mathbf{1 9}$ & 8,02 & 11,3 & 732 & 3,38 & 1,66 & $\ldots \ldots \ldots$ & 0,02 & 58,53 & 0,018 \\
$\mathbf{2 0}$ & 8,30 & 11,7 & 550 & 2,72 & 1,93 & 5,21 & 0,03 & 46,79 & 1,180 \\
\hline
\end{tabular}


3.4.2 Curvas dos resultados dos ensaios do grupo D

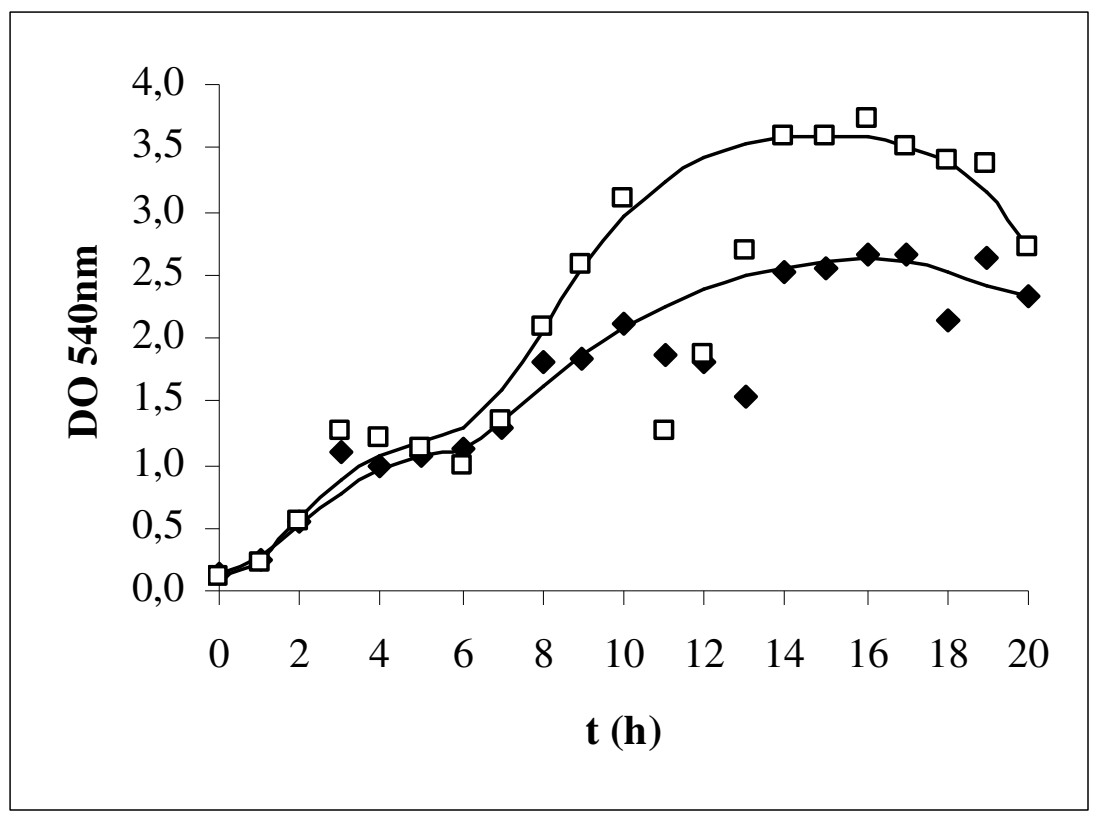

Figura 3.15 - Curvas de crescimento celular (DO ${ }_{540 \mathrm{~nm}}$ ) suavizadas dos ensaios 7 ( $\bullet$ e 8 (口).

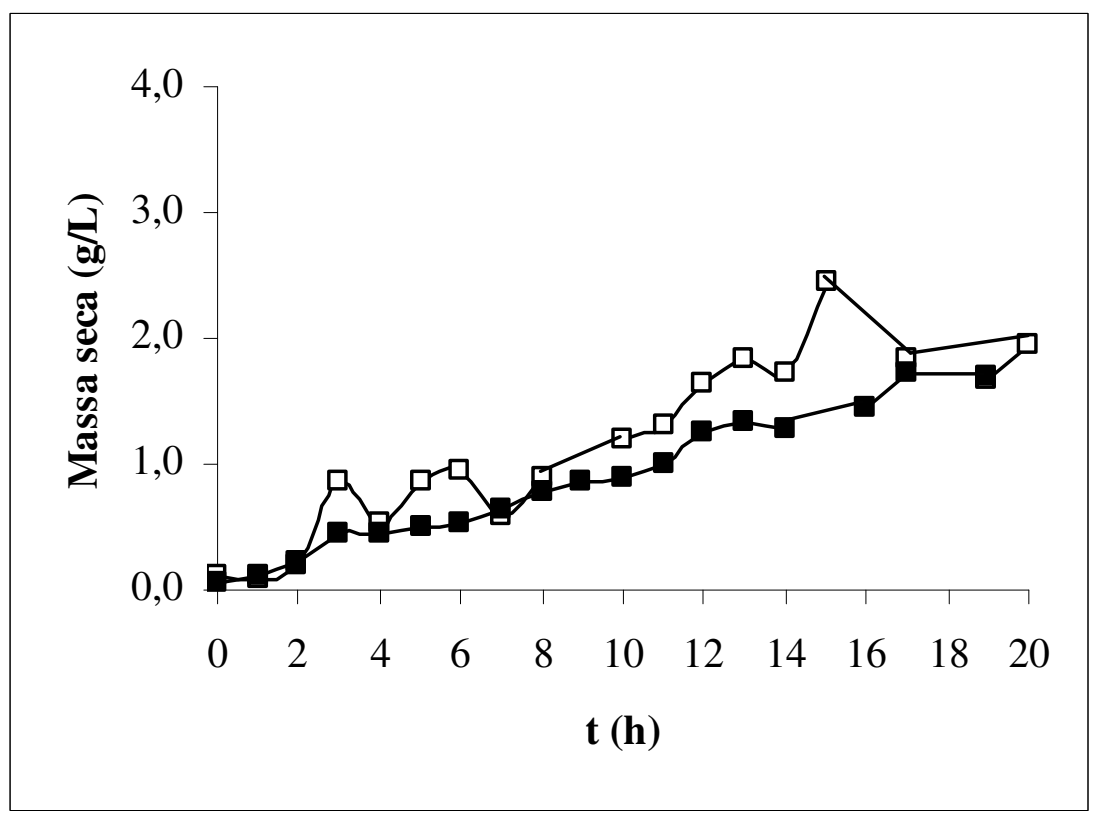

Figura 3.16 - Curvas de massa seca (g/L) ensaios 7 (४) e 8 ( $\square)$. 


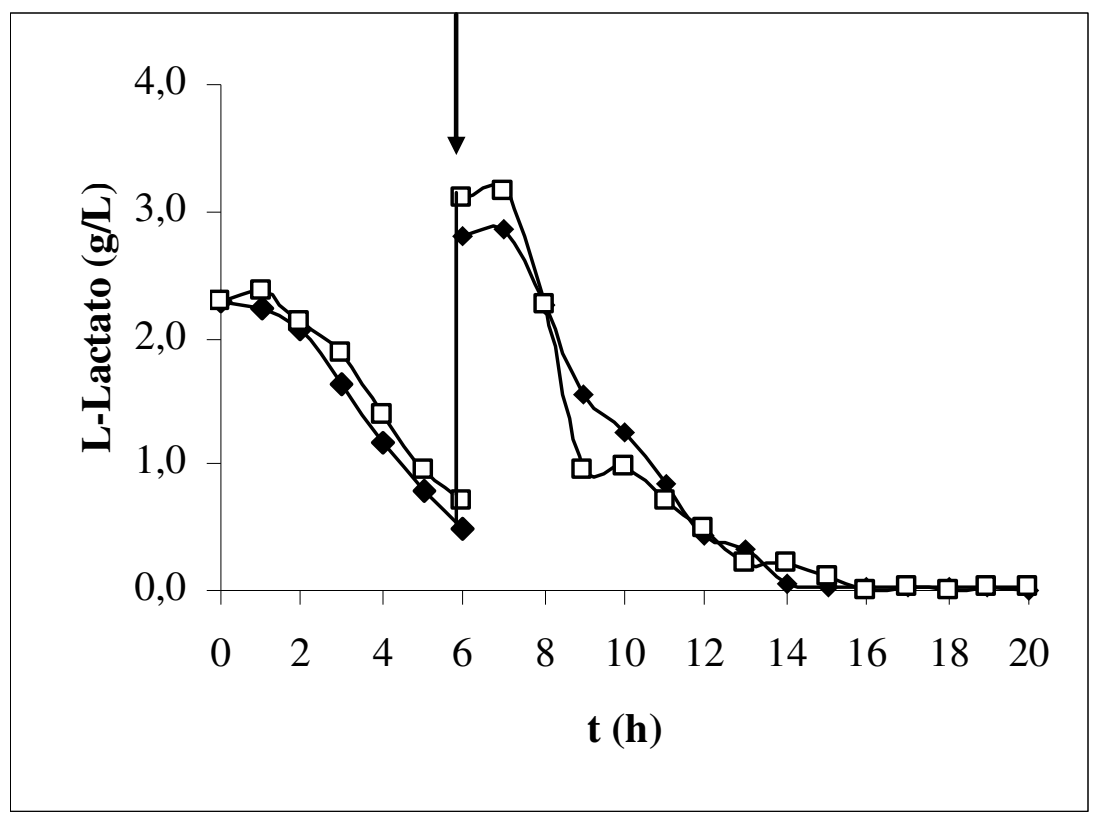

Figura 3.17 - Curvas de consumo de L-lactato (g/L) suavizadas dos ensaios 7 (४) e 8 ( $\square)$.

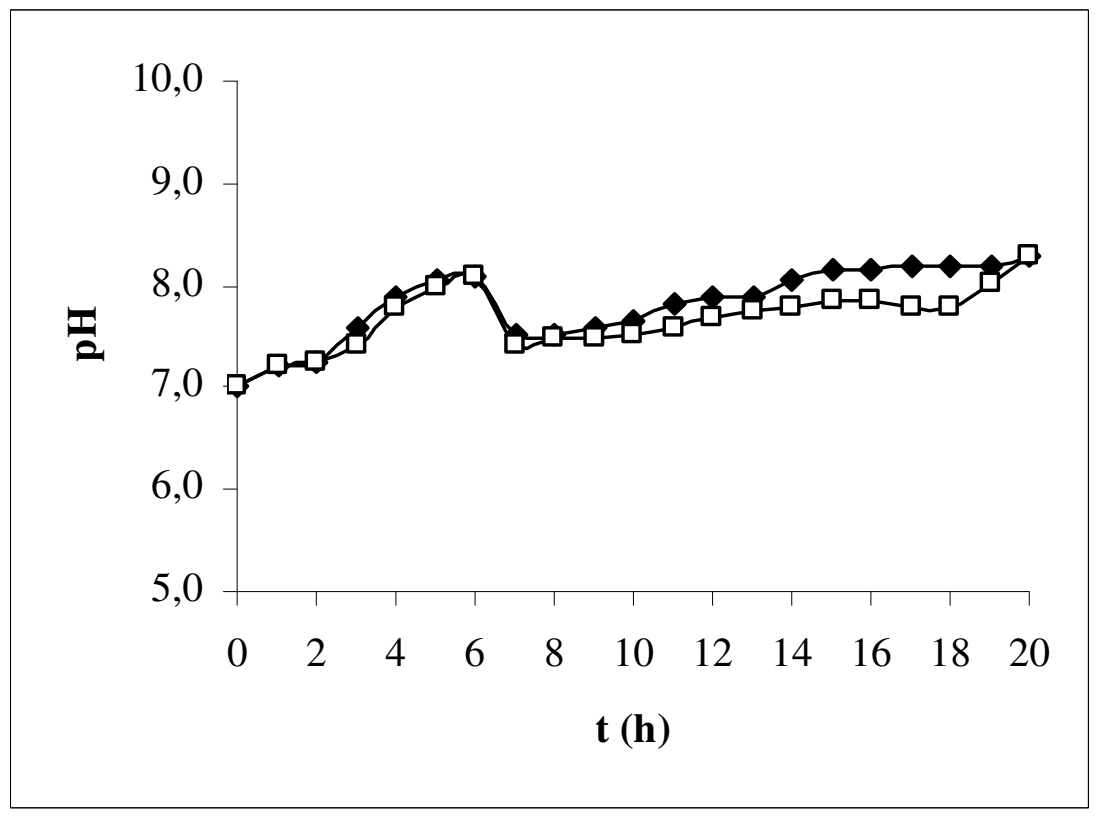

Figura 3.18 - Curvas de pH dos ensaios $7(\diamond)$ e $8(\square)$. 


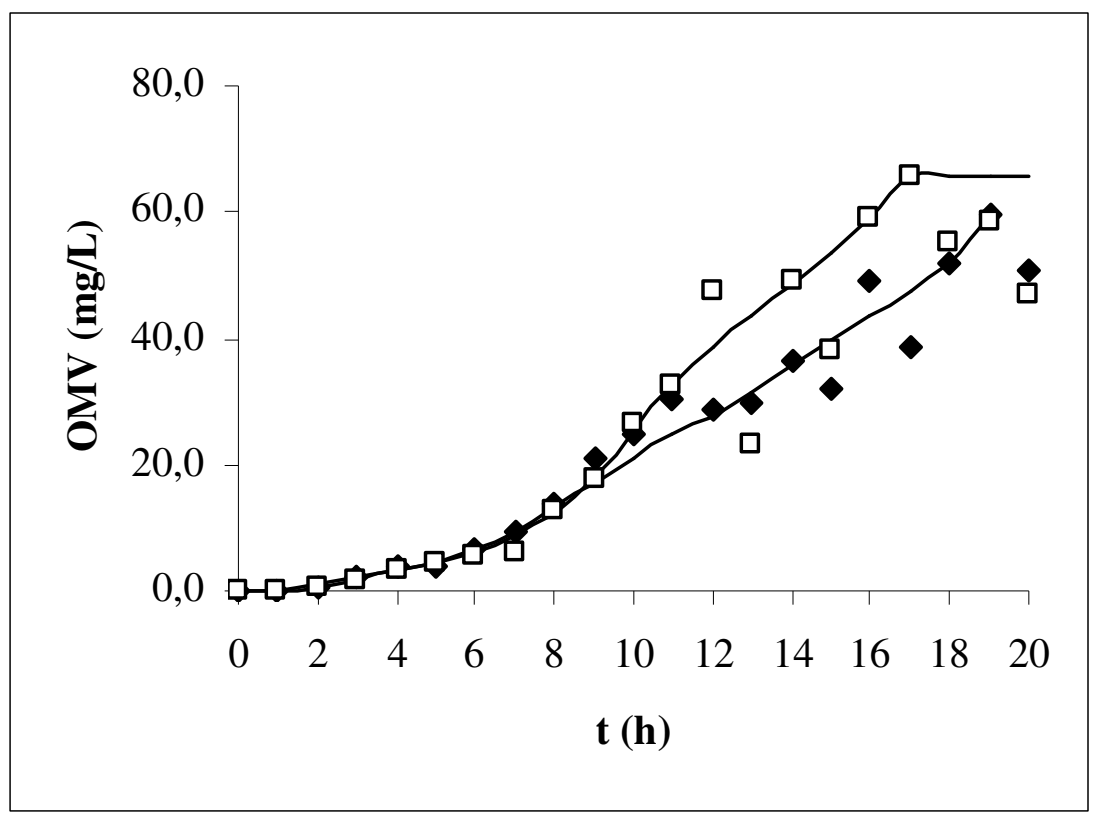

Figura 3.19 - Curvas de produção de OMV (mg/L) suavizadas dos ensaios 7 (४) e 8 (ロ).

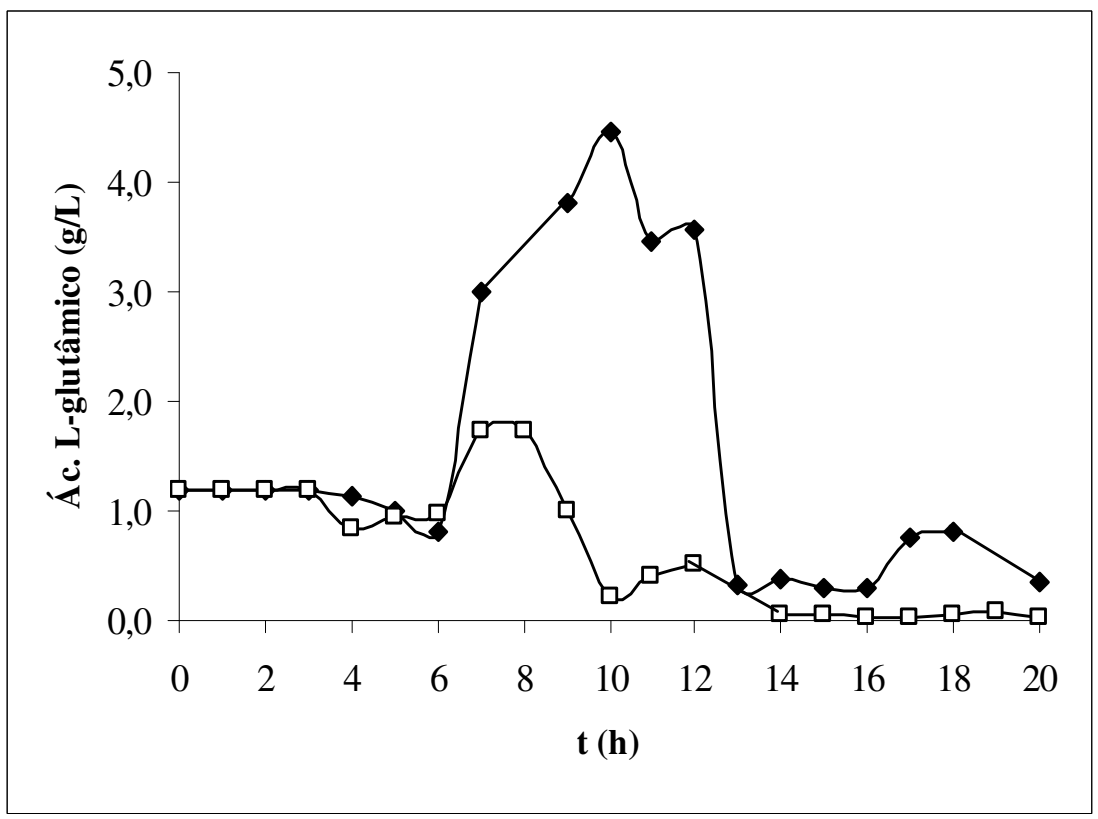

Figura 3.20 - Curvas de consumo de ácido L-glutâmico (g/L) dos ensaios 7 ( ) e 8 (ロ). 


\subsection{Ensaios do grupo E - Meio Catlin sem ferro com concentrações iniciais de lactato e aminoácidos dobradas}

Baseado no dados do grupo anterior, os ensaios do grupo $\mathrm{E}$ foram realizados em cultivo descontínuo no meio de Catlin sem ferro com concentrações iniciais de lactato e aminoácidos dobradas. As curvas de crescimento celular medidas por densidade óptica a $540 \mathrm{~nm}\left(\mathrm{DO}_{540 \mathrm{~nm}}\right)$ estão ilustradas nas figuras 3.21, e massa seca realizadas em triplicatas (Figura 3.22). A fase estacionária tem início na quinta hora de cultivo com densidade óptica ao redor de 2,0-4,7 e massa seca ao redor de 1,5-2,0 $\mathrm{mg} / \mathrm{L}$ permanecendo nessa faixa até a vigésima hora de cultivo. A figura 3.23 ilustra o perfil da viabilidade celular onde se observa o valor de $1,0 \times 10^{12}$ no início da fase estacionária do ensaio 10 , entretanto, no ensaio $11 \mathrm{o}$ valor observado foi de $2,0 \times 10^{9}$ fora do descrito.

O lactato foi consumido na $11^{\text {a }}$ hora (Figura 3.24), nesse instante é possível verificar o aumento do pH (Figura 3.25), indicando o consumo de aminoácidos por parte da Neisseria. A A figura 3.26 ilustra a formação de OMV, que se inícia na terceira hora do cultivo, entretanto sua formação se destaca a partir da $8^{\text {a }}$ hora, atingindo valor médio ao redor de $145 \mathrm{mg} / \mathrm{L}$.

Nesse grupo o crescimento celular $\left(\mathrm{DO}_{540 \mathrm{~nm}}\right)$ apresentou variabilidade celular entre os ensaios, no entanto, as condições pré-estabelecidas como agitação e oxigênio dissolvido foram mantidos. A viabilidade celular $(\mathrm{UFC} / \mathrm{mL})$ foi analisada apenas nos ensaios 10 e 11 , onde apresentaram perfil que acompanha o crescimento celular $\left(\mathrm{DO}_{540 \mathrm{~nm}}\right)$. As curvas do ácido L-glutâmico mostram o consumo total a partir da 10a de cultivo (Figura 3.27).

\subsubsection{Resultados experimentais dos ensaios do grupo $\mathbf{E}$}

Os valores experimentais da cinética dos ensaios do grupo E estão ilustrados na tabela 3.10 à 3.12 e os valores suavizados, calculados por meio do programa de Lissage, na tabela 7.1.8 à 7.1.10 do anexo 7.1. 
Tabela 3.10 - Resultados experimentais do grupo E, ensaio 9.

\begin{tabular}{cccccccccc}
\hline $\begin{array}{c}\text { Tempo } \\
\text { (h) }\end{array}$ & $\mathbf{p H}$ & $\begin{array}{c}\text { Oxig.Diss. } \\
(\mathbf{\%})\end{array}$ & $\begin{array}{c}\text { Agitação } \\
(\mathbf{r p m})\end{array}$ & $\mathbf{D O}_{\mathbf{5 4 0 n m}}$ & $\begin{array}{c}\text { M.Seca } \\
(\mathbf{g} / \mathbf{L})\end{array}$ & $\begin{array}{c}\text { Glicerol } \\
(\mathbf{g} / \mathbf{L})\end{array}$ & $\begin{array}{c}\text { L-lactato } \\
(\mathbf{g} / \mathbf{L})\end{array}$ & $\begin{array}{c}\text { OMV } \\
(\mathbf{m g} / \mathbf{L})\end{array}$ & $\begin{array}{c}\text { Ác. L-glutâmico } \\
(\mathbf{g} / \mathbf{L})\end{array}$ \\
\hline $\mathbf{0}$ & 7,36 & 9,50 & 250 & 0,15 & 0,08 & 5,62 & 3,80 & 0,74 & 2,36 \\
$\mathbf{1}$ & 7,28 & 9,00 & 416 & 0,22 & 0,08 & 5,62 & 3,86 & 0,30 & 2,36 \\
$\mathbf{2}$ & 7,13 & 10,10 & 492 & 0,50 & 0,25 & 5,62 & 3,84 & 2,52 & 1,77 \\
$\mathbf{3}$ & 7,14 & 8,30 & 659 & 1,21 & 0,55 & 5,62 & 3,31 & 5,48 & 1,45 \\
$\mathbf{4}$ & 7,50 & 10,40 & 764 & 2,28 & 0,99 & 5,62 & 2,37 & 11,41 & $\ldots \ldots \ldots$ \\
$\mathbf{5}$ & 7,68 & 10,30 & 771 & 2,64 & 1,10 & 5,62 & 1,24 & 17,18 & 1,10 \\
$\mathbf{6}$ & 7,77 & 12,10 & 750 & 2,62 & 1,27 & 5,62 & 0,47 & 15,11 & $\ldots \ldots \ldots$ \\
$\mathbf{7}$ & 7,59 & 11,70 & 704 & 3,02 & $\ldots \ldots \ldots$ & 5,62 & 0,36 & 16,59 & $\ldots \ldots .$. \\
$\mathbf{8}$ & 7,65 & 11,80 & 761 & 3,31 & 1,35 & 5,62 & 0,41 & 26,07 & $\ldots \ldots .$. \\
$\mathbf{9}$ & 7,75 & 10,30 & 847 & 3,58 & 1,41 & 5,62 & 0,48 & 27,55 & $\ldots \ldots .$. \\
$\mathbf{1 0}$ & 8,05 & 8,20 & 850 & 3,84 & 1,70 & 5,62 & 0,49 & 42,66 & 0,00 \\
$\mathbf{1 1}$ & 8,25 & 10,20 & 850 & 3,48 & $\ldots \ldots \ldots$ & 5,62 & 0,49 & 39,40 & 0,00 \\
$\mathbf{1 2}$ & 8,31 & 10,10 & 774 & 3,59 & 1,74 & 5,62 & 0,50 & 52,43 & 0,00 \\
$\mathbf{1 3}$ & 8,38 & 11,10 & 640 & 3,56 & 1,64 & 5,62 & 0,49 & 75,84 & 0,00 \\
$\mathbf{1 4}$ & 8,49 & 10,00 & 564 & 3,51 & 1,61 & 5,62 & 0,51 & 109,61 & 0,00 \\
$\mathbf{1 5}$ & 8,57 & 6,40 & 609 & 3,32 & 1,64 & 5,62 & 0,50 & 106,05 & 0,00 \\
$\mathbf{1 6}$ & 8,67 & 8,80 & 604 & 3,05 & 1,53 & 5,62 & 0,52 & 112,57 & 0,00 \\
$\mathbf{1 7}$ & 8,76 & 10,70 & 597 & 2,88 & 1,46 & 5,62 & 0,50 & 125,01 & 0,00 \\
$\mathbf{1 8}$ & 8,81 & 11,30 & 550 & 2,70 & 1,46 & 5,62 & 0,85 & 141,01 & 0,00 \\
$\mathbf{1 9}$ & 8,82 & 13,40 & 505 & 2,57 & 1,38 & 5,62 & 0,55 & 148,71 & 0,00 \\
$\mathbf{2 0}$ & 8,79 & 11,90 & 447 & 2,49 & 1,24 & 5,62 & 0,53 & 162,34 & 0,00 \\
\hline
\end{tabular}

Tabela 3.11 - Resultados experimentais do grupo E, ensaio 10.

\begin{tabular}{|c|c|c|c|c|c|c|c|c|c|c|}
\hline $\begin{array}{c}\text { Tempo } \\
\text { (h) }\end{array}$ & pH & $\begin{array}{c}\text { Oxig.Diss. } \\
(\%)\end{array}$ & $\begin{array}{c}\text { Agitação } \\
(\mathbf{r p m})\end{array}$ & $\mathrm{DO}_{540 \mathrm{~nm}}$ & $\begin{array}{l}\text { Viab. Cel. } \\
(\mathrm{UFC} / \mathrm{mL})\end{array}$ & $\begin{array}{c}\text { M. Seca } \\
(\mathrm{g} / \mathrm{L}) \\
\end{array}$ & $\begin{array}{c}\text { Glicerol } \\
(\mathrm{g} / \mathrm{L}) \\
\end{array}$ & $\begin{array}{c}\text { L-lactato } \\
(\mathrm{g} / \mathrm{L})\end{array}$ & $\begin{array}{l}\text { OMV } \\
(\mathrm{mg} / \mathrm{L})\end{array}$ & $\begin{array}{c}\text { Ác. L-glutâmico } \\
(\mathrm{g} / \mathrm{L})\end{array}$ \\
\hline $\mathbf{0}$ & 7,30 & $\ldots \ldots .$. & 250 & 0,14 & $2,0 \mathrm{E}+08$ & 0,33 & 4,18 & 4,18 & 0,83 & 2,36 \\
\hline 1 & 7,30 & 5,00 & 411 & 0,21 & & 0,36 & 4,18 & 4,38 & 1,36 & 2,36 \\
\hline 2 & 7,30 & 9,00 & 454 & 0,45 & $8,5 \mathrm{E}+08$ & 0,31 & 4,18 & 4,49 & 1,89 & 2,36 \\
\hline 3 & 7,30 & 7,90 & 594 & 0,94 & & 0,52 & 4,18 & 3,89 & 4,38 & 2,36 \\
\hline 4 & 7,70 & 10,00 & 732 & 2,27 & $\ldots \ldots \ldots$ & 1,03 & 4,18 & 0,07 & 6,11 & 1,99 \\
\hline 5 & 7,70 & 9,30 & 777 & 2,47 & & 1,29 & 4,18 & 0,05 & 8,15 & 1,46 \\
\hline 6 & 7,70 & 9,30 & 810 & 2,85 & $2,1 \mathrm{E}+10$ & 1,52 & 4,18 & 0,77 & 9,81 & ......... \\
\hline 7 & 7,70 & 8,70 & 788 & 3,63 & & 1,76 & 4,18 & 0,38 & 12,83 & ......... \\
\hline 8 & 8,00 & 8,40 & 852 & 4,33 & $1,0 \mathrm{E}+12$ & 2,09 & 4,18 & 0,01 & 19,62 & 0,67 \\
\hline 9 & 8,00 & 8,10 & 850 & 4,72 & & 2,11 & 4,18 & 0,39 & 37,74 & 0,60 \\
\hline 10 & 8,00 & 6,00 & 850 & 4,79 & ......... & ........ & 4,18 & 0,43 & 62,19 & ......... \\
\hline 11 & 8,30 & 4,80 & 850 & 4,95 & & 2,14 & 4,18 & 0,45 & 51,62 & …..... \\
\hline 12 & 8,50 & 5,70 & 850 & 4,59 & $\ldots \ldots \ldots$ & ........ & 4,18 & 0,46 & 65,81 & ......... \\
\hline 13 & 8,50 & 5,80 & 717 & 4,88 & & ......... & 4,18 & 0,54 & 91,78 & ........ \\
\hline 14 & 8,70 & 9,80 & 584 & 4,78 & $3,4 \mathrm{E}+11$ & 2,11 & 4,18 & 0,47 & 91,78 & ......... \\
\hline 15 & 9,00 & 8,80 & 594 & 4,58 & & 2,02 & 4,18 & 0,49 & 106,27 & ........ \\
\hline 16 & 9,00 & 7,80 & 540 & 4,19 & $2,2 \mathrm{E}+10$ & 2,02 & 4,18 & 0,49 & 118,95 & …..... \\
\hline 17 & 9,00 & 9,70 & 566 & 3,88 & & 2,01 & 4,18 & 0,53 & 121,36 & $\ldots \ldots \ldots$ \\
\hline 18 & 9,00 & 11,80 & 540 & 3,62 & ........ & 1,94 & 4,18 & 0,50 & 126,19 & 0,00 \\
\hline 19 & 9,00 & 11,20 & ......... & 0,34 & & 1,99 & 4,18 & 0,49 & 135,86 & 0,01 \\
\hline 20 & 9,00 & 10,50 & ........ & 0,34 & $3,0 \mathrm{E}+08$ & 1,91 & 4,18 & 0,50 & 142,50 & 0,00 \\
\hline
\end{tabular}


Tabela 3.12 - Resultados experimentais do grupo E, ensaio 11.

\begin{tabular}{|c|c|c|c|c|c|c|c|c|c|}
\hline $\begin{array}{c}\text { Tempo } \\
\text { (h) }\end{array}$ & pH & $\begin{array}{c}\text { Oxig.Diss. } \\
(\%)\end{array}$ & $\begin{array}{c}\text { Agitação } \\
(\mathbf{r p m})\end{array}$ & $\mathrm{DO}_{540 \mathrm{~nm}}$ & $\begin{array}{l}\text { Viab. Cel. } \\
\text { (UFC/mL) }\end{array}$ & $\begin{array}{c}\text { M.Seca } \\
(\mathrm{g} / \mathrm{L})\end{array}$ & $\begin{array}{c}\text { Glicerol } \\
\text { (g/L) }\end{array}$ & $\begin{array}{c}\text { L-lactato } \\
(\mathrm{g} / \mathrm{L})\end{array}$ & $\begin{array}{c}\text { OMV } \\
(\mathrm{mg} / \mathrm{L})\end{array}$ \\
\hline $\mathbf{0}$ & 7,31 & .............. & 250 & 0,12 & $1,83 \mathrm{E}+08$ & 0,31 & 5,25 & 2,28 & 1,22 \\
\hline 1 & 7,27 & ......... & 250 & 0,23 & & 0,37 & ......... & 2,61 & 2,07 \\
\hline 2 & 7,33 & 9,20 & 278 & 0,54 & $1,25 \mathrm{E}+08$ & 0,56 & ......... & 1,91 & 1,74 \\
\hline 3 & 7,63 & 7,80 & 451 & 1,56 & & 0,71 & ......... & 1,48 & 3,44 \\
\hline 4 & 7,95 & 9,90 & 590 & 2,23 & $2,00 \mathrm{E}+09$ & 1,38 & ......... & 1,12 & 8,71 \\
\hline 5 & 8,05 & 5,20 & 567 & 2,24 & & 1,33 & .......... & 0,84 & 12,53 \\
\hline 6 & 8,10 & 10,30 & 555 & 2,30 & ......... & 1,60 & .......... & 0,52 & 14,84 \\
\hline 7 & 8,15 & 12,30 & 737 & 2,49 & & 1,37 & .......... & 0,35 & 20,91 \\
\hline 8 & 8,10 & 10,70 & 765 & 2,49 & ......... & 1,56 & .......... & 0,90 & 22,42 \\
\hline 9 & 8,04 & 6,20 & 823 & 2,64 & & 1,39 & .......... & 0,36 & 20,91 \\
\hline 10 & 7,90 & 14,80 & 850 & 2,58 & $3,25 \mathrm{E}+08$ & 1,58 & .......... & 0,55 & 26,38 \\
\hline 11 & 7,82 & 8,50 & 825 & 2,62 & & 1,63 & .......... & 0,02 & 27,22 \\
\hline 12 & 7,72 & 14,00 & 740 & 2,42 & $9,25 \mathrm{E}+08$ & 1,58 & .......... & 0,00 & 49,45 \\
\hline 13 & 7,78 & 13,70 & 650 & 2,55 & & 1,53 & .......... & 0,00 & 49,08 \\
\hline 14 & 7,78 & 9,00 & 603 & 2,38 & $9,50 \mathrm{E}+08$ & 1,56 & .......... & 0,00 & 58,78 \\
\hline 15 & 7,78 & 14,30 & 542 & 2,32 & & 1,51 & .......... & 0,00 & 114,92 \\
\hline 16 & 8,00 & 13,40 & 552 & 2,05 & $3,43 \mathrm{E}+09$ & 1,36 & .......... & 0,00 & 139,98 \\
\hline 17 & 8,09 & 13,30 & 531 & 2,09 & & 1,37 & ......... & 0,00 & 138,75 \\
\hline 18 & 8,15 & 10,20 & 528 & 2,11 & $2,28 \mathrm{E}+08$ & 1,33 & .......... & 0,00 & 137,53 \\
\hline 19 & 8,22 & 11,00 & 519 & 2,21 & & 1,36 & ......... & 0,00 & 156,93 \\
\hline 20 & 8,29 & …..... & ........ & 2,19 & 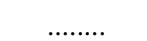 & 1,36 & 4,96 & 0,00 & 130,56 \\
\hline
\end{tabular}


3.5.2 - Curvas dos resultados dos ensaios do grupo $\mathrm{E}$

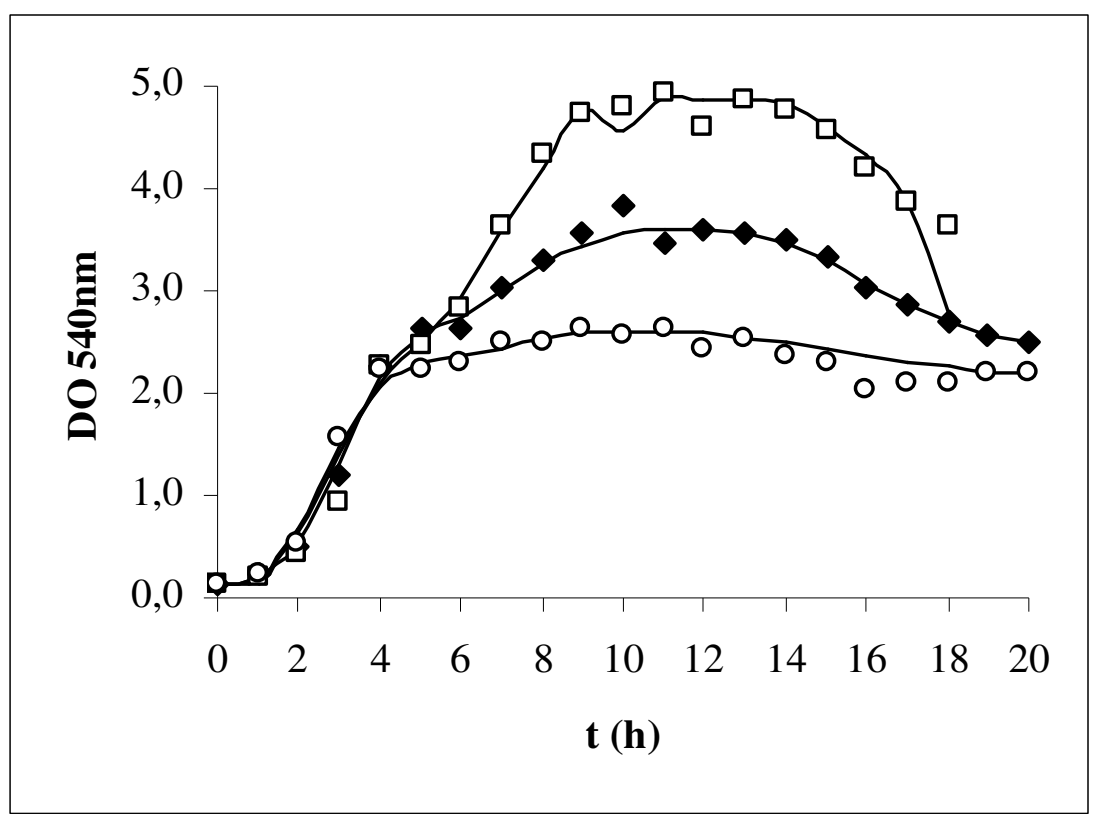

Figura 3.21 - Curvas de crescimento celular (DO 540nm) suavizadas dos ensaios $9(\diamond), 10(\square)$ e $11(0)$.

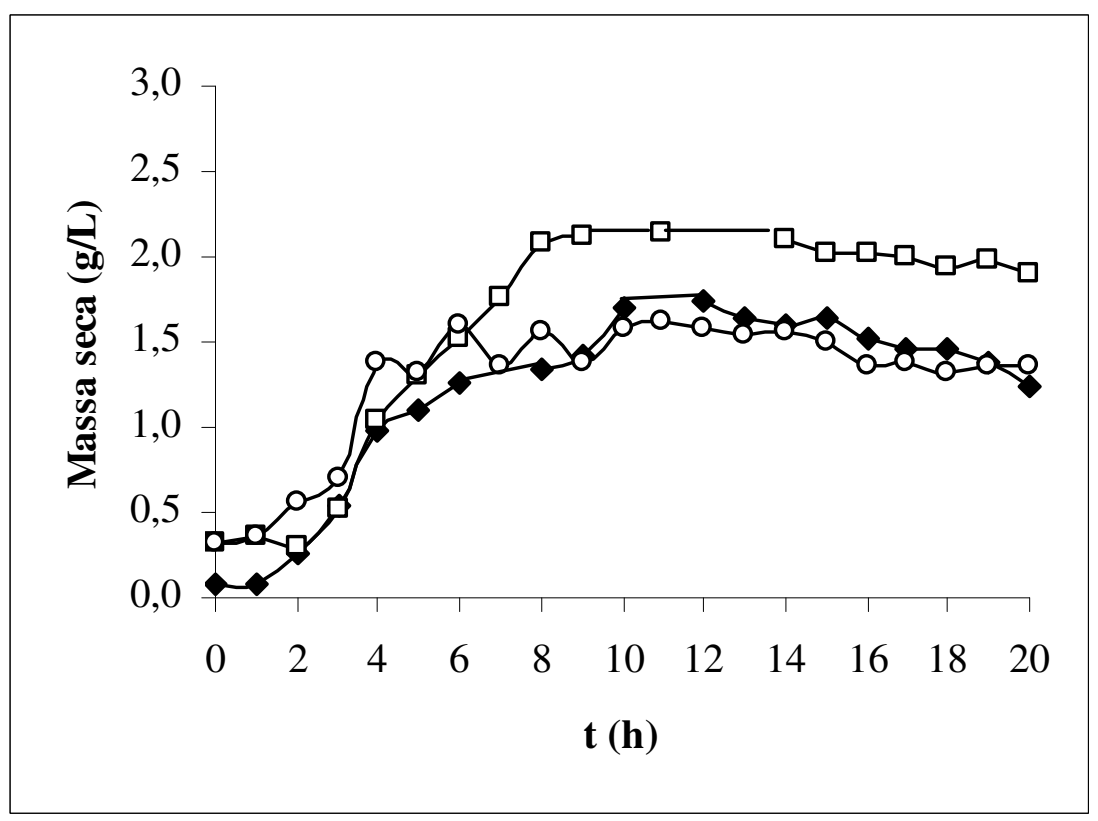

Figura 3.22 - Curvas de massa seca (g/L) ensaios $9(\diamond), 10$ ( $\square)$ e11 (०). 


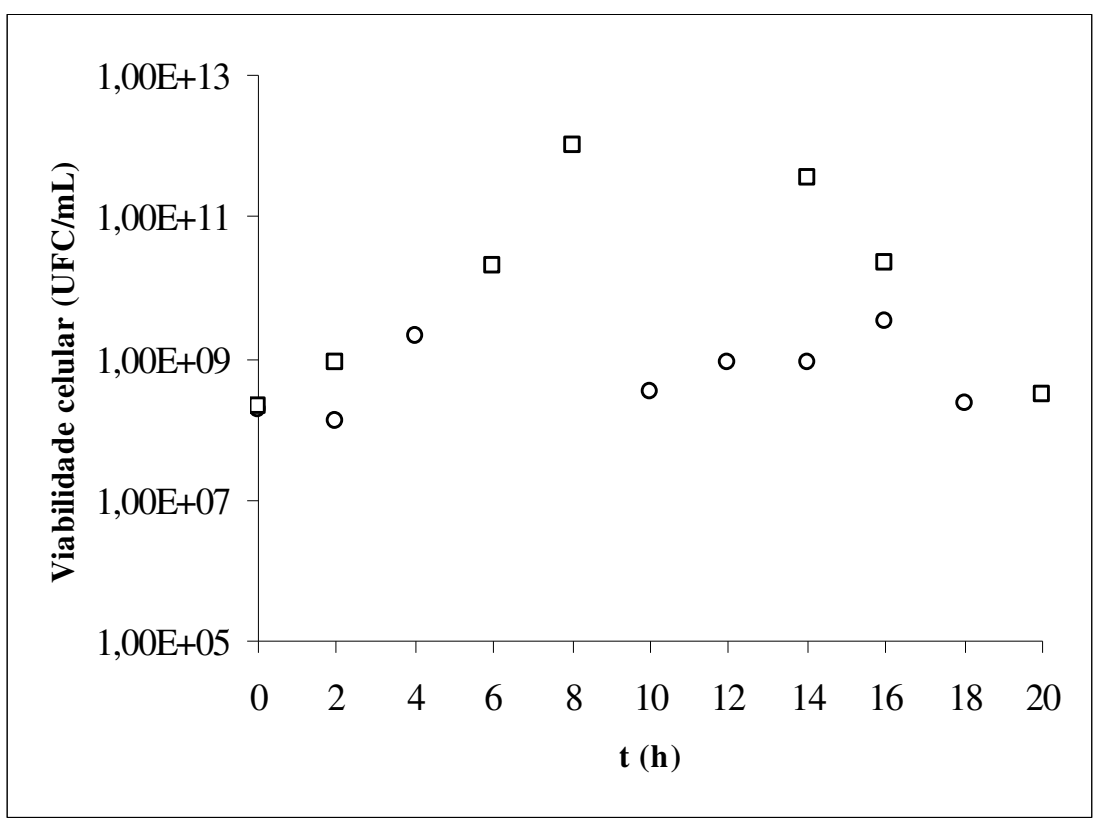

Figura 3.23 - Curvas de viabilidade celular (UFC/mL) dos ensaios 10 ( $\square)$ e 11 (०).

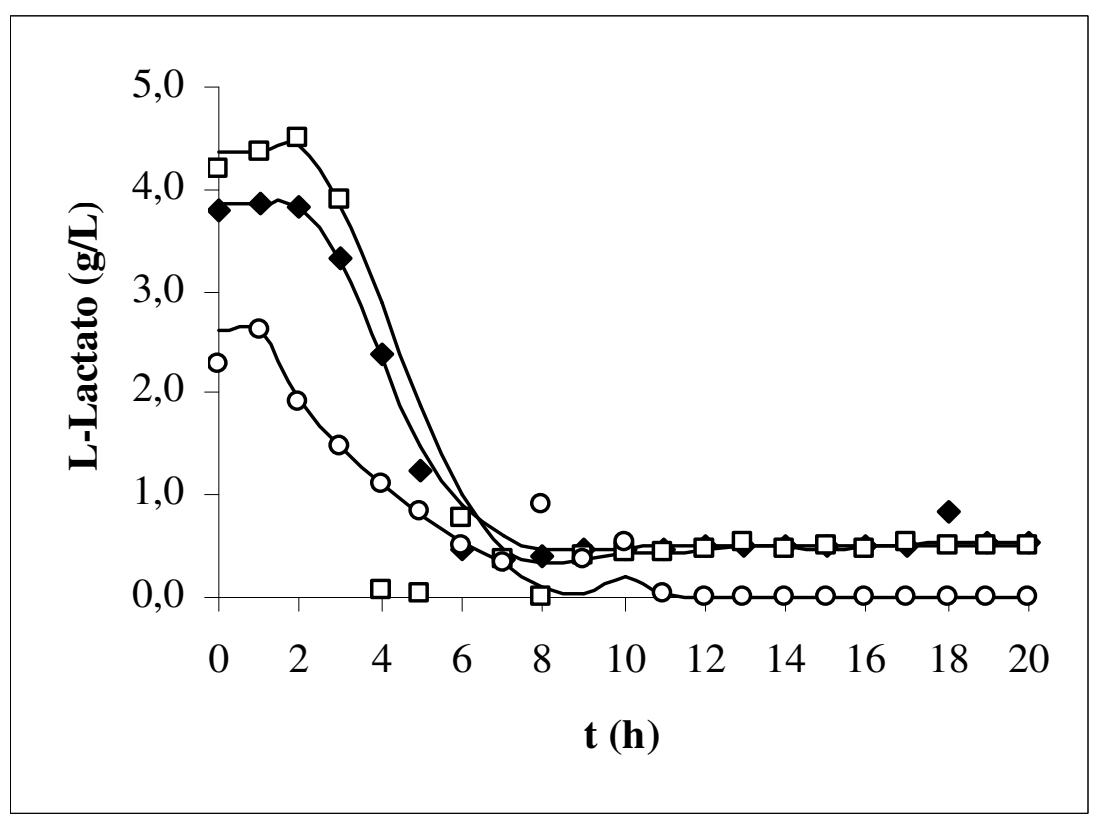

Figura 3.24 - Curvas de consumo de L-lactato (g/L) suavizadas dos ensaios $9(\bullet), 10(\square)$ e 11 (O). 


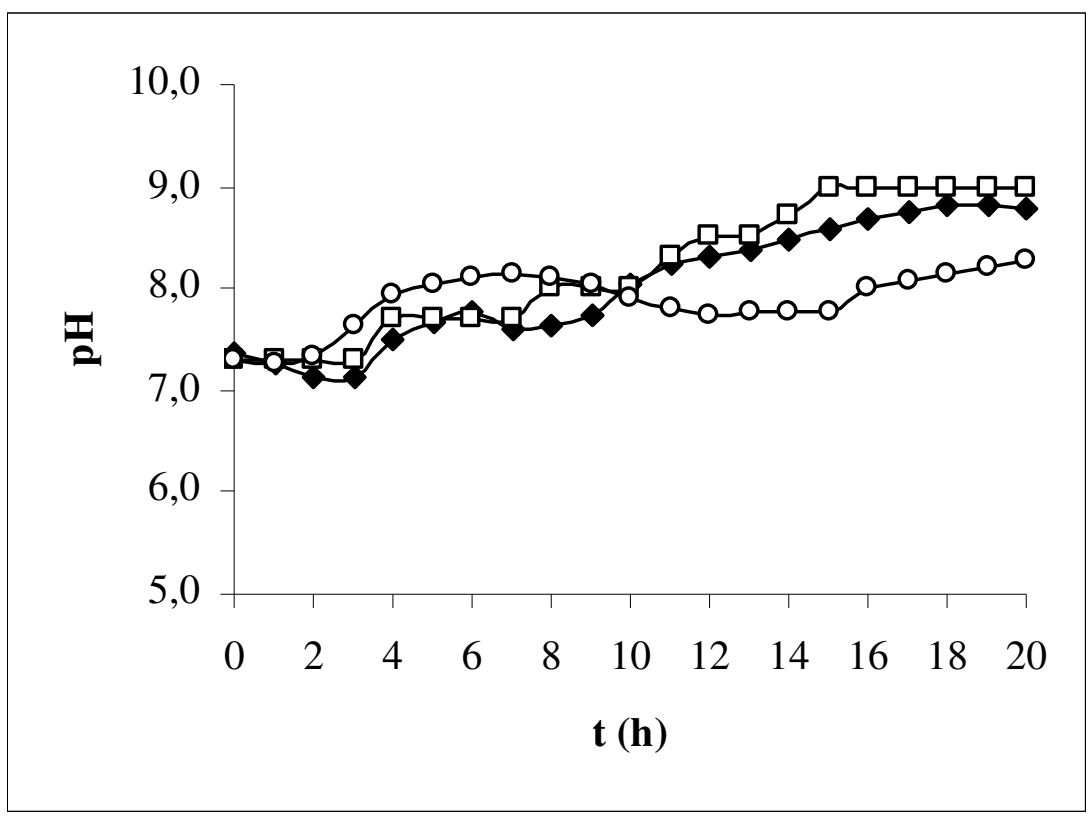

Figura 3.25 - Curvas de pH ensaios $9(\diamond), 10(\square)$ e 11 (०).

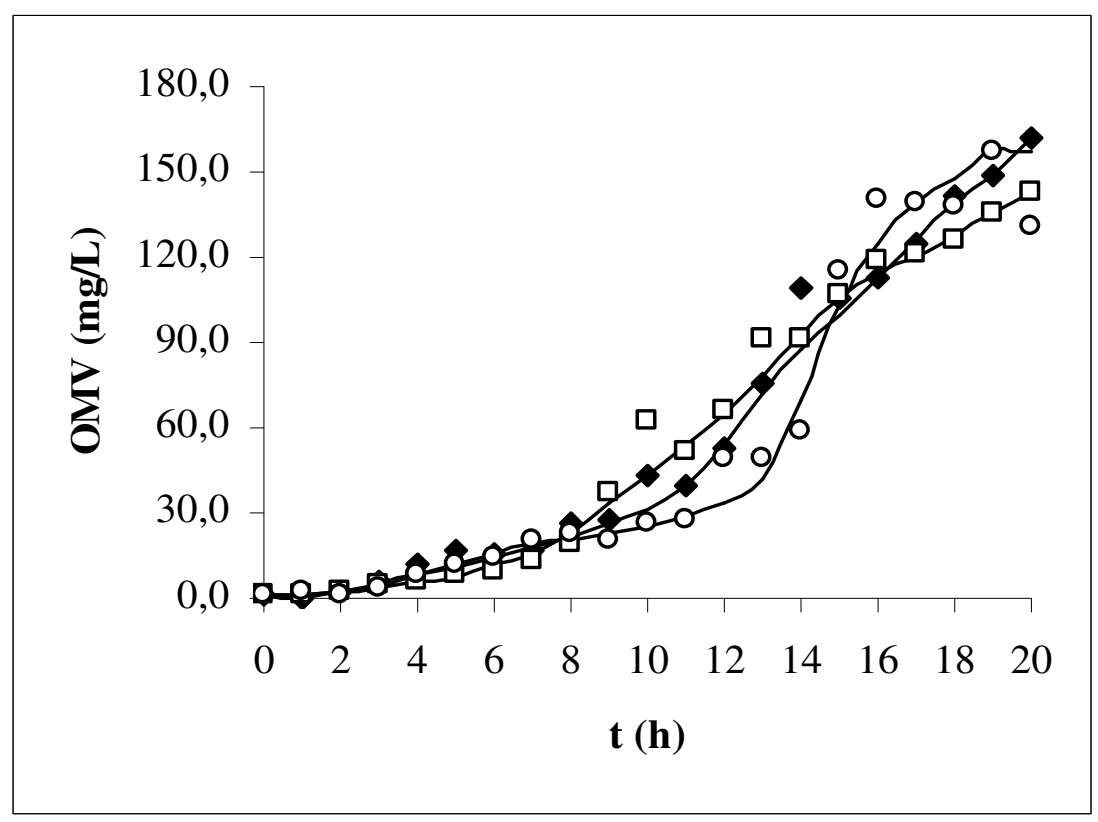

Figura 3.26 - Curvas de produção de OMV (mg/L) suavizadas dos ensaios $9(\diamond), 10(\square)$ e 11 (O). 


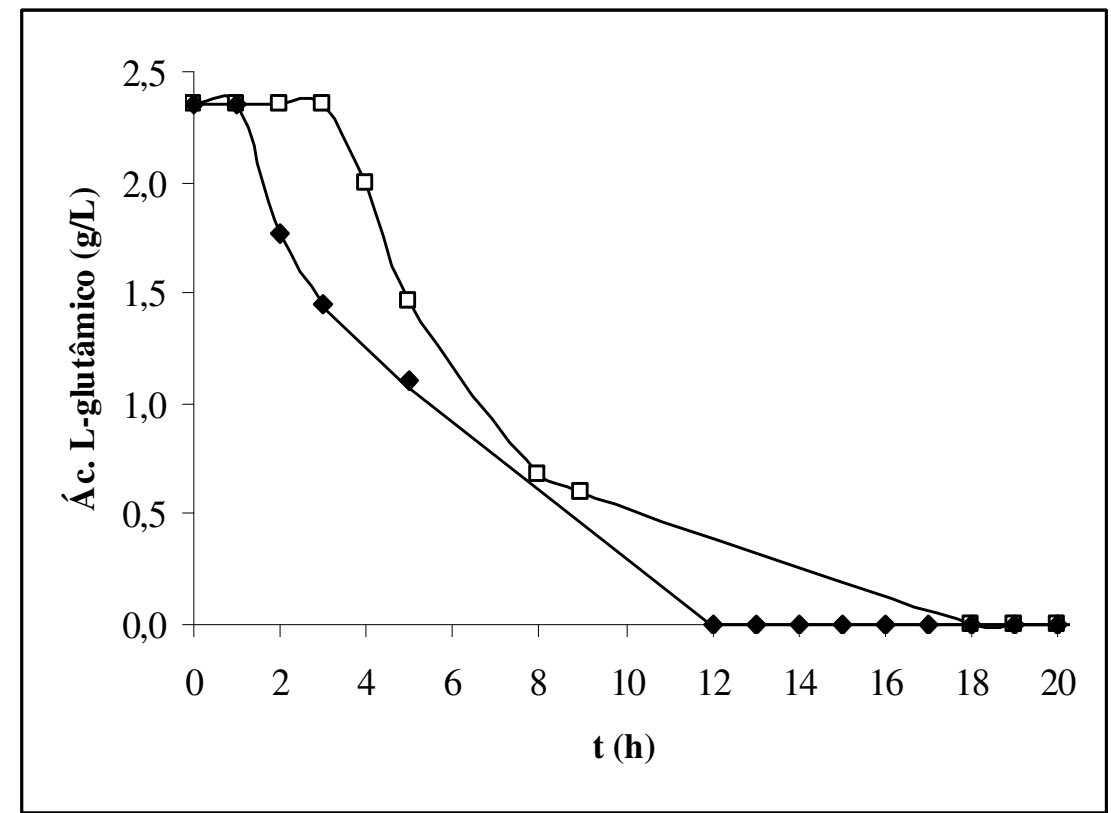

Figura 3.27 - Curvas de consumo de ácido L-glutâmico (g/L) dos ensaios 9 (४) e10 (口). 


\subsection{Ensaios do grupo F - Meio Catlin sem ferro com concentrações iniciais de lactato e aminoácidos dobradas e sem glicerol}

O ensaio do grupo F foi realizado em cultivo descontínuo no meio de Catlin sem ferro com concentrações iniciais de lactato e aminoácidos dobradas e sem glicerol. As curvas de crescimento celular medidas por densidade óptica $540 \mathrm{~nm}\left(\mathrm{DO}_{540 \mathrm{~nm}}\right)$ e massa seca estão ilustradas nas figuras 3.28 e 3.29 respectivamente.

O início da fase estacionária ocorre na oitava hora de cultivo com densidade óptica em torno de 4,0-4,7 e massa seca em redor de 2,0 g/L. O perfil da viabilidade celular $(\mathrm{UFC} / \mathrm{mL})$ está ilustrada na figura 3.30, observa-se que na fase estacionária o valor de 1,0x10 $\mathrm{UFC} / \mathrm{mL}$, esse perfil acompanha o do crescimento celular (Figura 3.28).

O lactato foi totalmente consumido a partir da sétima hora de cultivo (Figura 3.31), nesse instante pode ser observada a elevação do pH (Figura 3.32) indicando que a Neisseria começou a utilizar os aminoácidos. A ilustração da formação de OMV está representada na figura 3.33, que se inicia durante as primeiras horas de cultivo, porém sua formação tem destaque a partir da $9^{\mathrm{a}}$ hora, atingindo valor de $121 \mathrm{mg} / \mathrm{L}$. A curva do ácido L-glutâmico

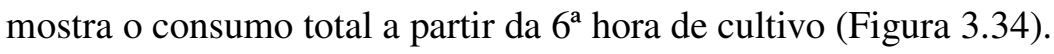

\subsubsection{Resultado experimental do ensaio do grupo F}

Os valores experimentais da cinética do ensaio do grupo F estão ilustrados na tabela 3.13 e os valores suavizados, calculados por meio do programa de Lissage, na tabela 7.1.11 do anexo 7.1. 
Tabela 3.13 - Resultados experimentais do grupo F, ensaio 12.

\begin{tabular}{cccccccccc}
\hline $\begin{array}{c}\text { Tempo } \\
\text { (h) }\end{array}$ & $\mathbf{p H}$ & $\begin{array}{c}\text { Oxig.Diss. } \\
(\mathbf{\%})\end{array}$ & $\begin{array}{c}\text { Agitação } \\
(\mathbf{r p m})\end{array}$ & $\mathbf{D O}_{\mathbf{5 4 0 n m}}$ & $\begin{array}{c}\text { Viab. Cel. } \\
(\mathbf{U F C} / \mathbf{m L})\end{array}$ & $\begin{array}{c}\text { M.Seca } \\
(\mathbf{g} / \mathbf{L})\end{array}$ & $\begin{array}{c}\text { L-lactato } \\
(\mathbf{g} / \mathbf{L})\end{array}$ & $\begin{array}{c}\text { OMV } \\
(\mathbf{m g} / \mathbf{L})\end{array}$ & $\begin{array}{c}\text { Ác. L-glutâmico } \\
\text { (g/L) }\end{array}$ \\
\hline $\mathbf{0}$ & 7,35 & $\ldots \ldots \ldots$ & 250 & 0,12 & $2,60 \mathrm{E}+07$ & 0,16 & 4,77 & 0,67 & 2,36 \\
$\mathbf{1}$ & 7,25 & 3,70 & 415 & 0,17 & & 0,24 & 6,20 & 0,77 & 2,36 \\
$\mathbf{2}$ & 7,09 & 8,70 & 456 & 0,40 & $4,30 \mathrm{E}+07$ & 0,30 & 4,78 & 0,72 & 2,36 \\
$\mathbf{3}$ & 7,03 & 9,30 & 554 & 0,95 & & 0,53 & 6,00 & 3,00 & 2,36 \\
$\mathbf{4}$ & 7,17 & 11,30 & 802 & 2,44 & $\ldots \ldots \ldots$ & 1,03 & 4,49 & 5,32 & 1,85 \\
$\mathbf{5}$ & 7,43 & 5,40 & 850 & 2,66 & & 1,28 & 3,00 & 6,77 & 1,10 \\
$\mathbf{6}$ & 7,50 & 1,30 & 850 & 3,14 & $\ldots \ldots \ldots$ & 1,51 & 1,06 & 10,23 & 0,02 \\
$\mathbf{7}$ & 7,53 & 1,10 & 849 & 3,75 & & 1,72 & 0,01 & 15,81 & 0,01 \\
$\mathbf{8}$ & 7,54 & 0,90 & 850 & 4,09 & $\ldots \ldots \ldots$ & 1,80 & 0,01 & 18,08 & 0,00 \\
$\mathbf{9}$ & 7,69 & 0,90 & 849 & 4,40 & & 2,09 & 0,01 & 22,11 & 0,03 \\
$\mathbf{1 0}$ & 7,76 & 0,70 & 850 & 4,63 & $4,15 \mathrm{E}+07$ & 2,09 & 0,01 & 36,16 & 0,03 \\
$\mathbf{1 1}$ & 7,87 & 0,60 & 850 & 4,78 & & 2,08 & 0,01 & 43,81 & 0,01 \\
$\mathbf{1 2}$ & 8,17 & 0,80 & 849 & 4,71 & $1,15 \mathrm{E}+07$ & 2,02 & 0,01 & 44,63 & 0,01 \\
$\mathbf{1 3}$ & 8,30 & 6,80 & 850 & 4,97 & & 1,86 & 0,02 & 47,53 & 0,02 \\
$\mathbf{1 4}$ & 8,40 & 12,90 & 533 & 4,59 & $\ldots \ldots \ldots$ & 2,14 & 0,01 & 50,83 & 0,01 \\
$\mathbf{1 5}$ & 8,39 & 9,00 & 614 & 4,65 & & 2,42 & 0,00 & 52,28 & 0,00 \\
$\mathbf{1 6}$ & 8,42 & 8,00 & 520 & 4,70 & $5,00 \mathrm{E}+05$ & 2,73 & 0,01 & 56,00 & 0,01 \\
$\mathbf{1 7}$ & 8,50 & 10,60 & 419 & 4,48 & & 1,51 & 0,01 & 76,04 & 0,00 \\
$\mathbf{1 8}$ & 8,53 & 12,90 & 468 & 3,78 & $8,00 \mathrm{E}+03$ & 1,86 & 0,01 & 83,48 & 0,01 \\
$\mathbf{1 9}$ & 8,50 & 10,90 & 345 & 3,66 & & 1,85 & 0,01 & 93,81 & 0,00 \\
$\mathbf{2 0}$ & 8,48 & 12,00 & 285 & 3,29 & $4,03 \mathrm{E}+07$ & 1,68 & 0,01 & 121,09 & 0,02 \\
\hline
\end{tabular}


3.6.2 Curvas do resultado do ensaio do grupo F

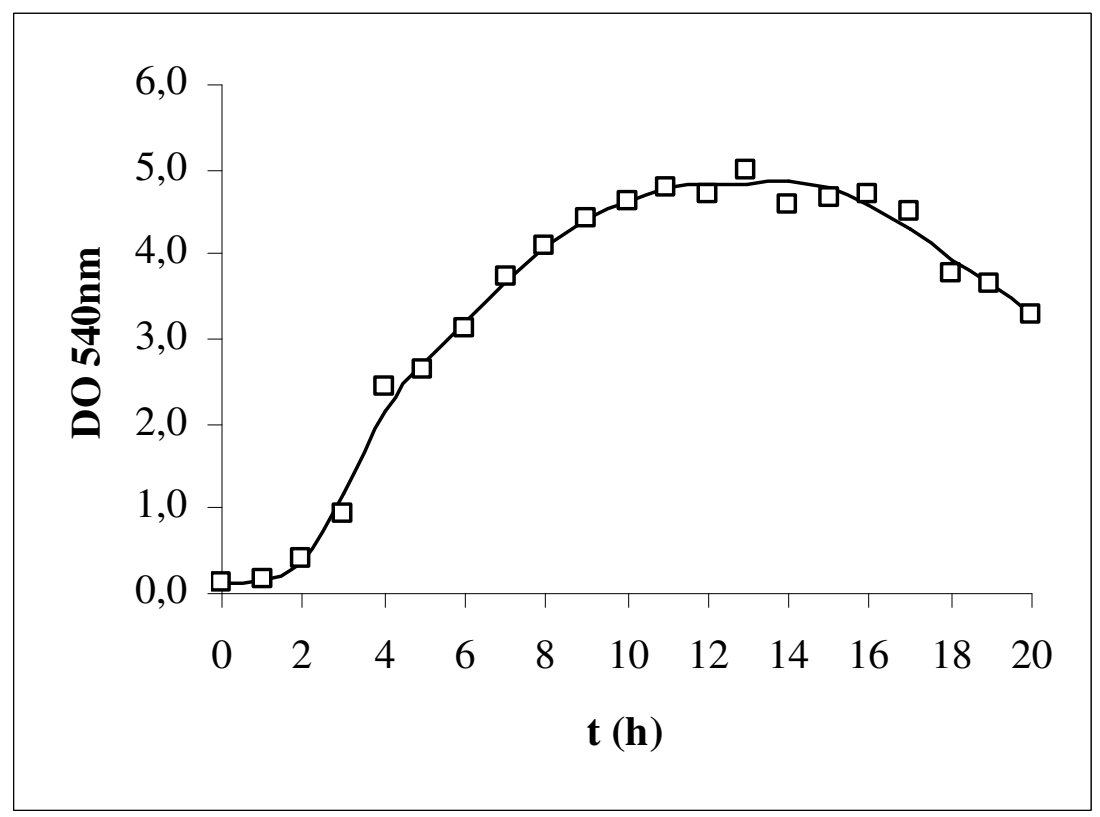

Figura 3.28 - Curva de crescimento celular ( $\left.\mathrm{DO}_{540 \mathrm{~nm}}\right)$ suavizada do ensaio 12 (口).

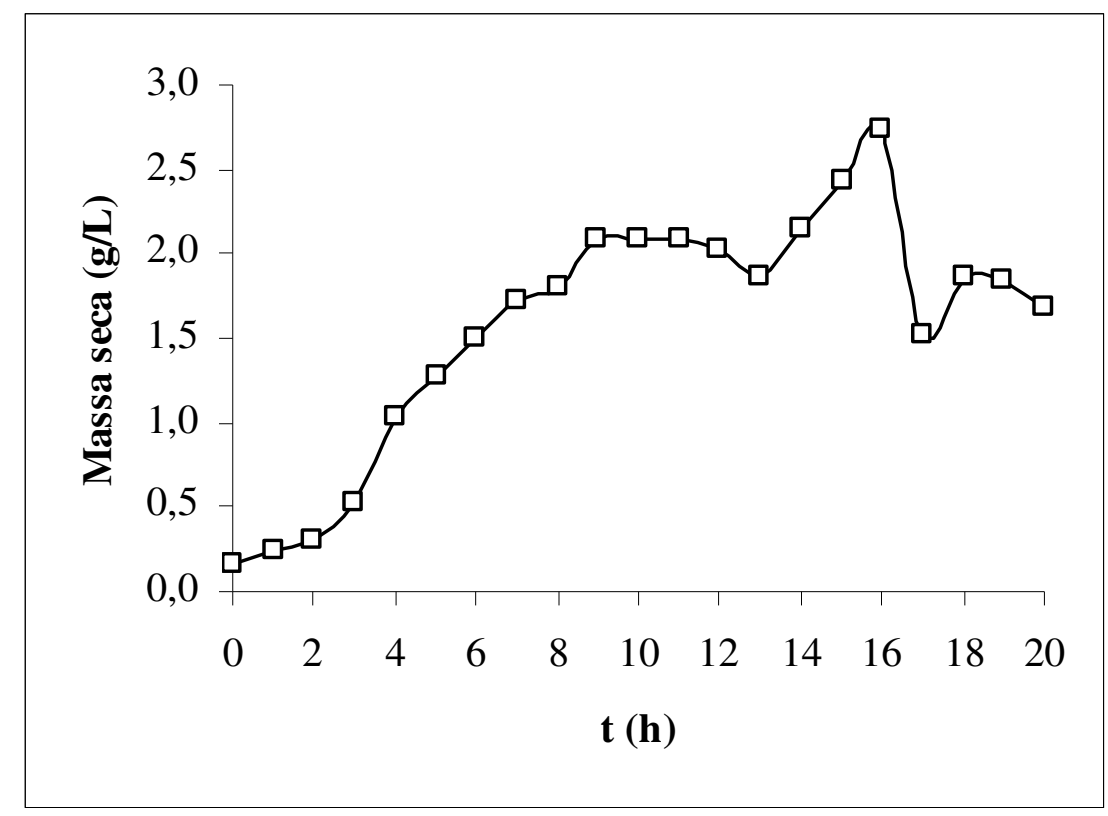

Figura 3.29 - Curva de massa seca (g/L) do ensaio 12 ( $\square$ ). 


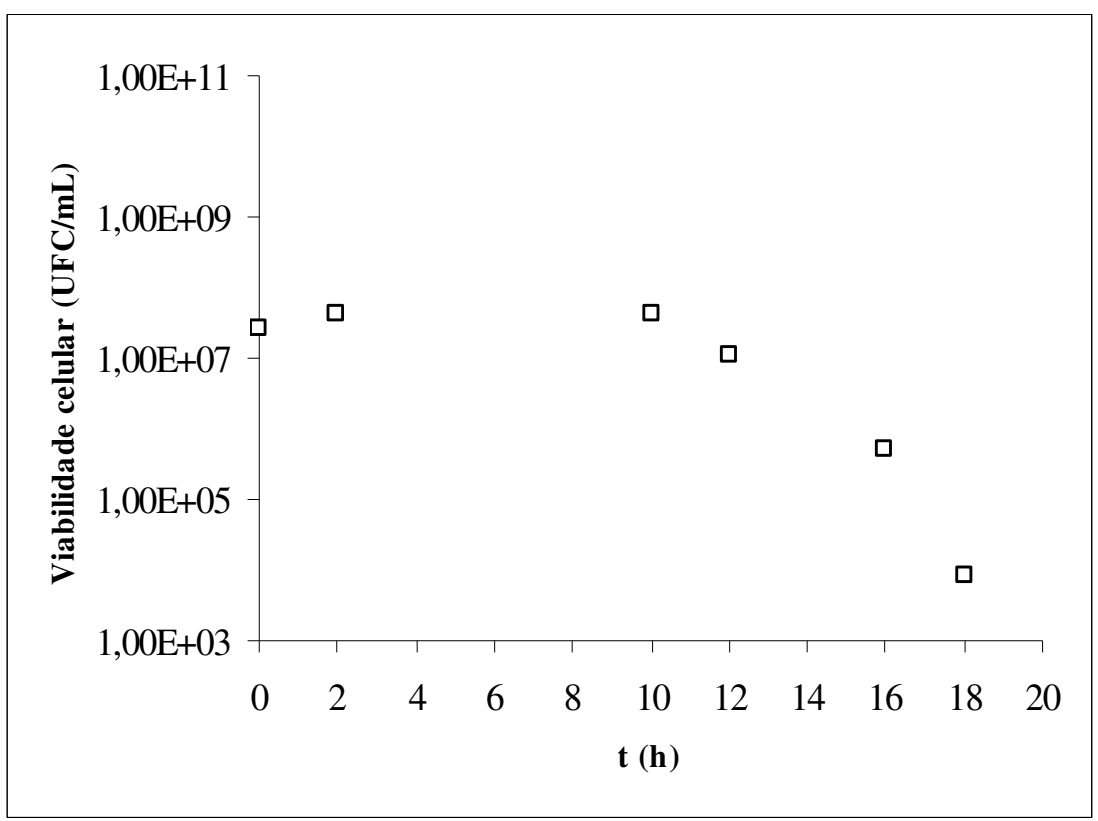

Figura 3.30 - Curva de viabilidade celular (UFC/mL) ensaio 12 ( $\square)$.

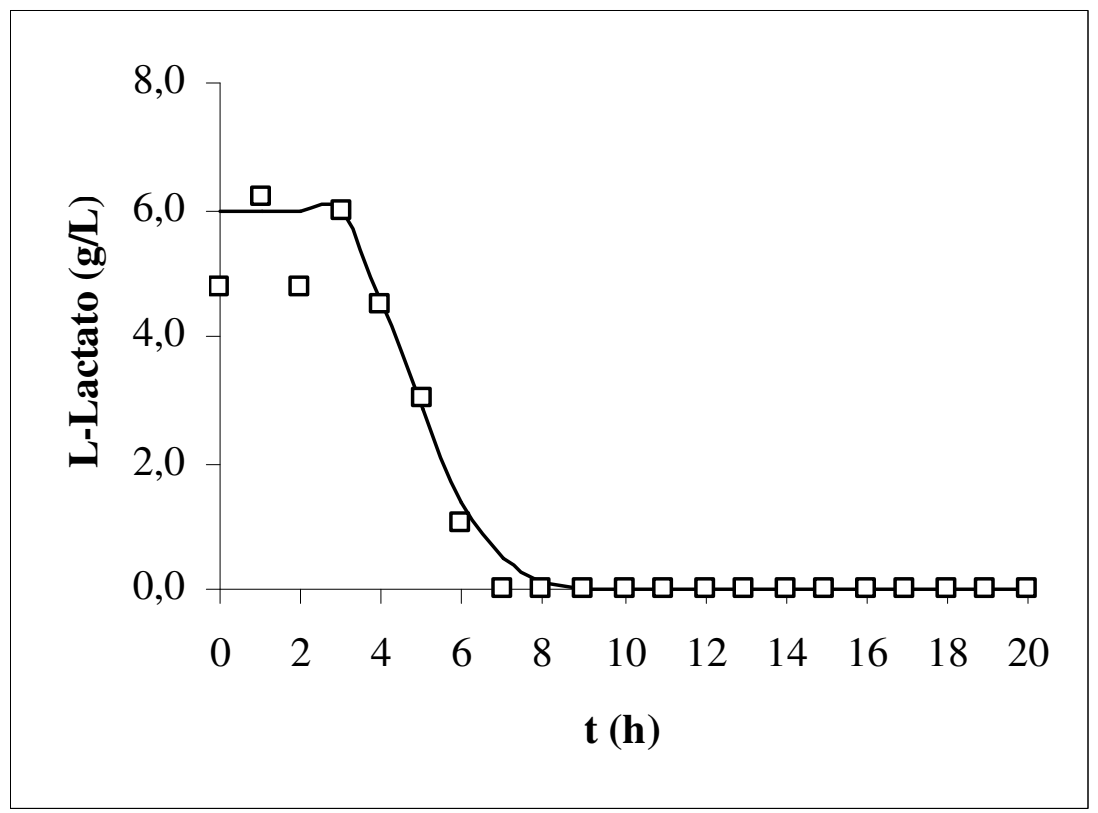

Figura 3.31 - Curva de consumo de L-lactato (g/L) suavizada do ensaio $12(\square)$. 


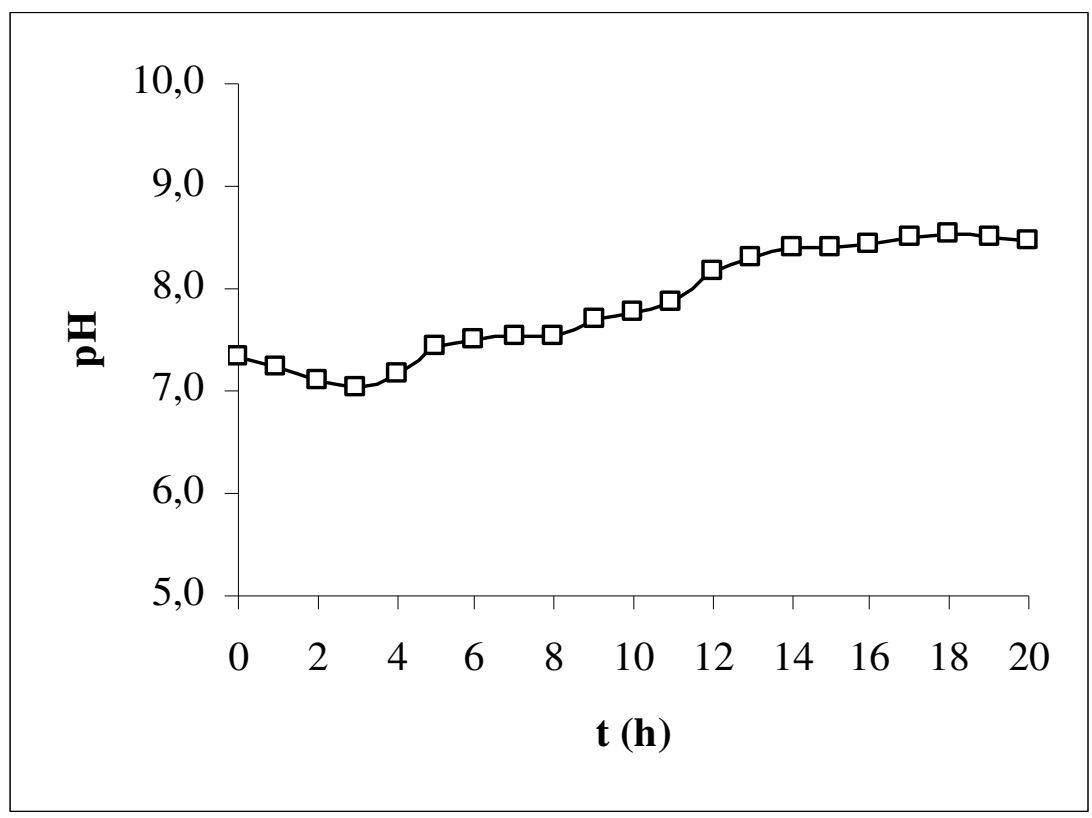

Figura 3.32 - Curva de pH do ensaio 12 ( $\square)$.

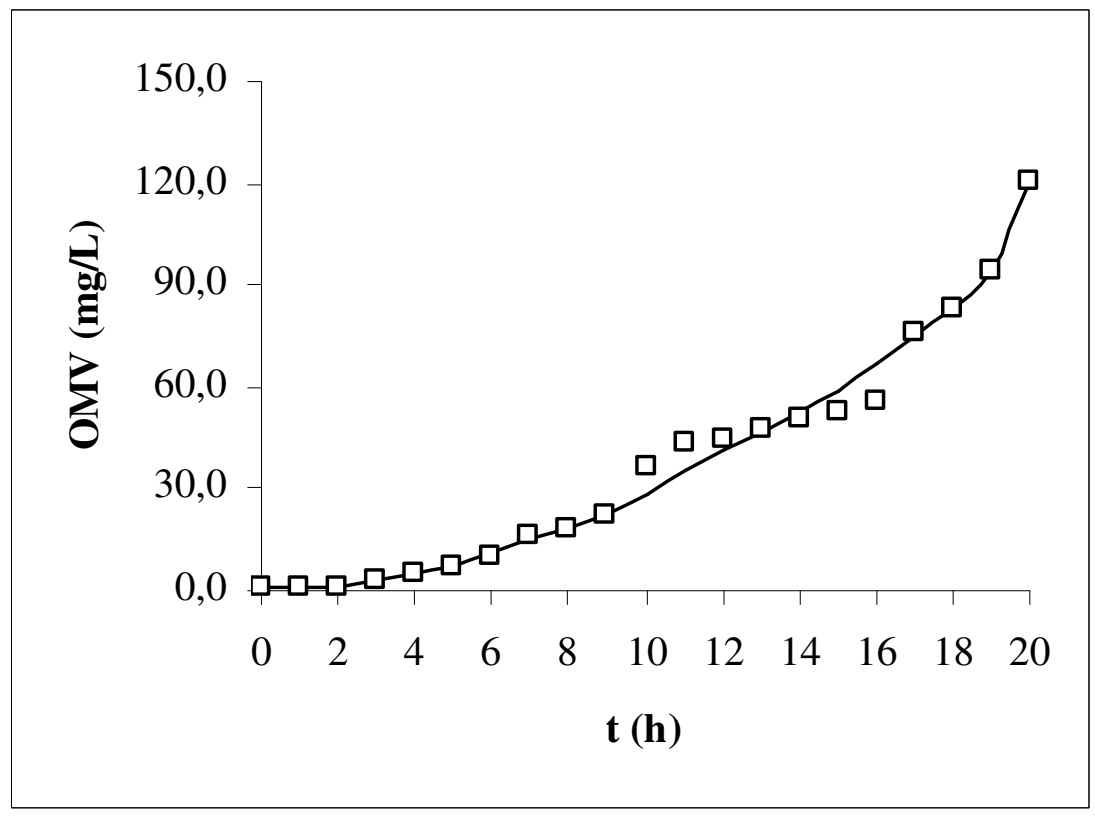

Figura 3.33 - Curva de produção de OMV (mg/L) suavizada do ensaio 12 ( $\square$ ). 


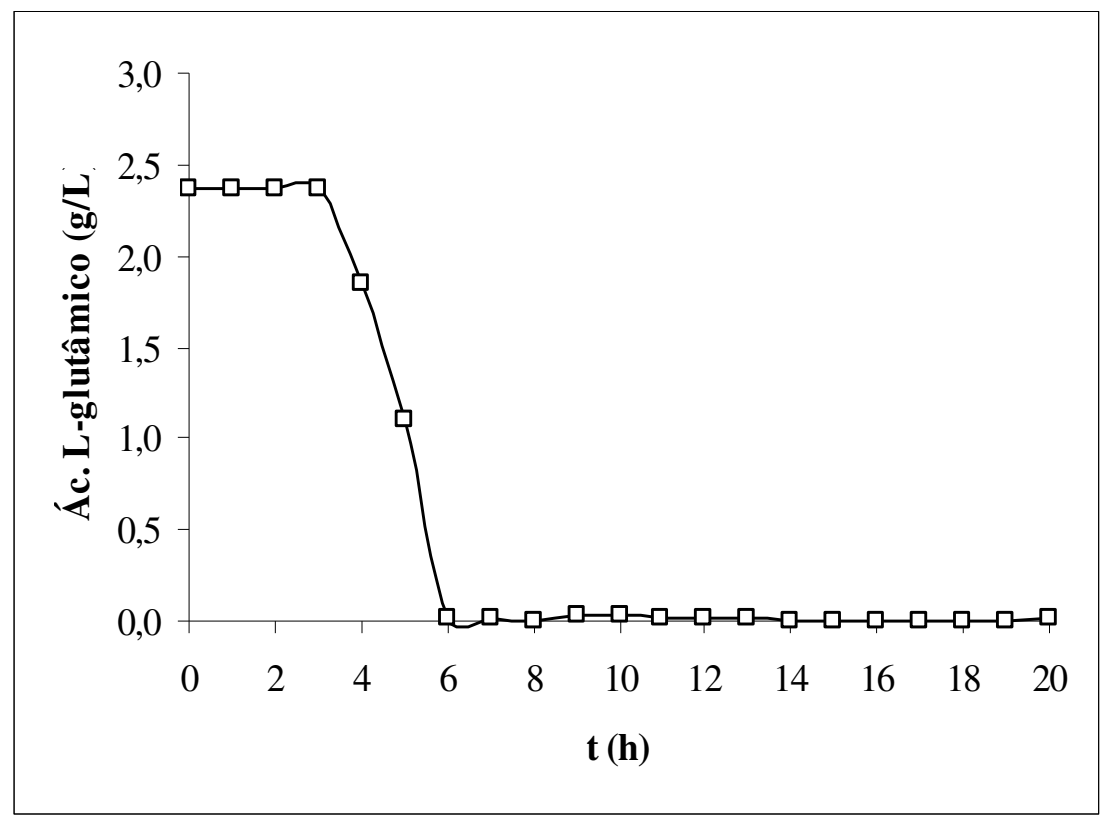

Figura 3.34 - Curva de consumo de ácido L-glutâmico (g/L) do ensaio 12 (ロ). 


\subsection{Perfil eletroforético de OMVs dos ensaios realizados em biorreator}

O perfil eletroforético de OMVs dos ensaios oriundos em biorreator, em meio de Catlin sem ferro foi realizado em gel SDS-PAGE $12 \%$ de poliacrilamida. As OMVs são formadas durante a fase de crescimento quando liberadas para o meio de cultivo, entretanto sua formação apresenta destaque quantitativo a partir da sexta hora de cultivo. Observa-se que as bandas ficam intensas no final do cultivo, $20^{\mathrm{a}}$ hora, onde a quantidade de OMV é maior. As figuras 3.30 a 3.34 ilustram a presença de proteínas que compõem as OMVs, entre elas encontram-se as proteínas de classe, presentes na faixa de 25 a $47 \mathrm{kDa}$; as IRPs presentes na faixa de 70 a $108 \mathrm{kDa}$ e a NadA, proteína de alto peso molecular, presente na faixa entre 170 a $190 \mathrm{kDa}$. Os ensaios 3, 4, 5 e 10 fizeram uso do padrão de médio peso molecular e os demais utilizaram padrão de alto peso molecular. 
3.7.1 Géis de eletroforese, SDS-PAGE 10\%, dos ensaios do grupo B em meio de Catlin sem ferro
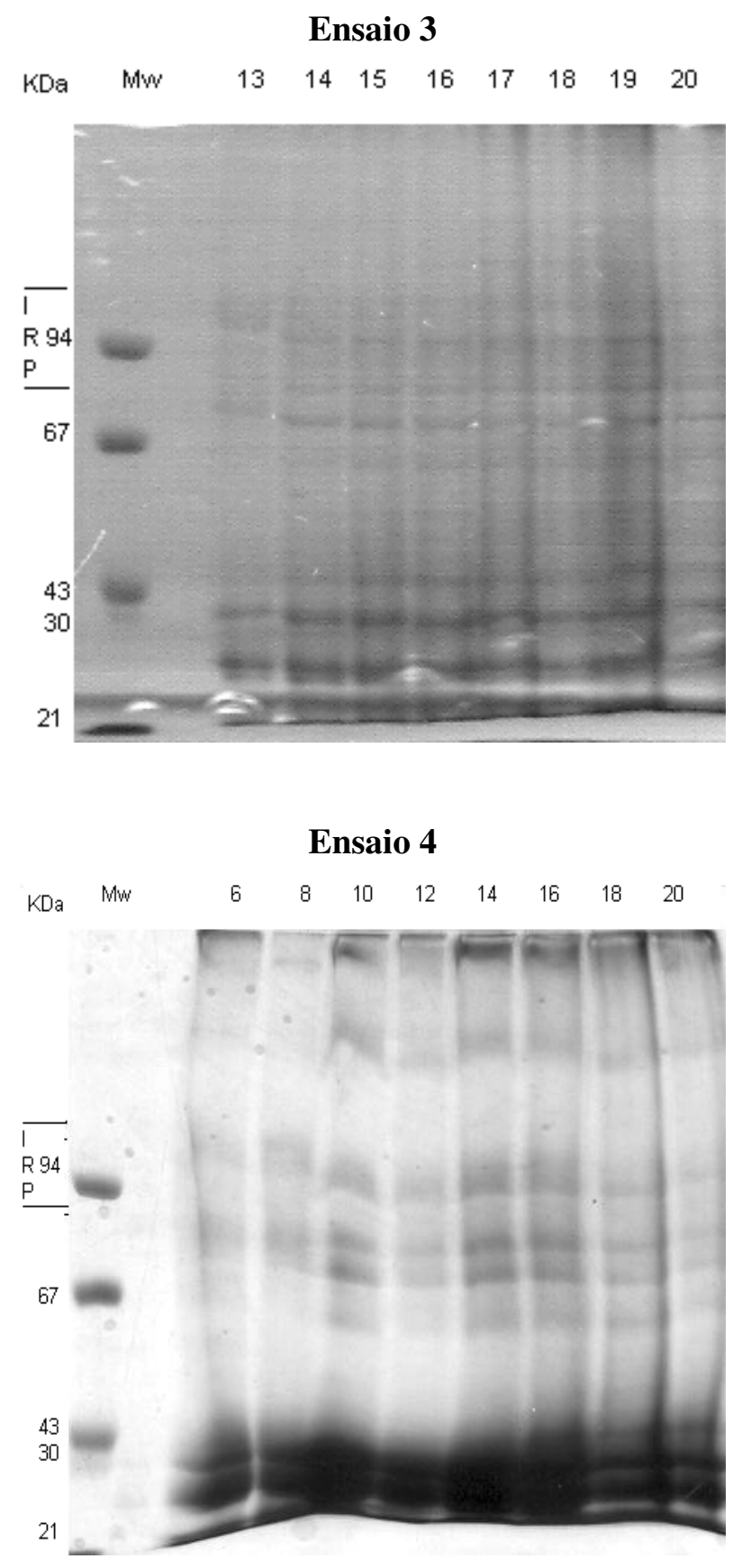

Figura 3.35 - Gel de eletroforese SDS-PAGE (10\%) das amostras de OMV obtidas durante o cultivo. As colunas de 13 a 20, no ensaio 3, e 6 a 20, ensaio 4, correspondem ao extrato de OMV fracionados representando as respectivas horas de cultivos. As bandas representativas da expressão de IRP de OMV estão indicadas entre $(70-108 \mathrm{kDa})$ dos ensaios 3 e 4, respectivamente, do grupo B. 
3.7.2 Géis de eletroforese, SDS-PAGE 10\%, dos ensaios do grupo C em meio de Catlin sem ferro com concentração inicial de lactato triplicada
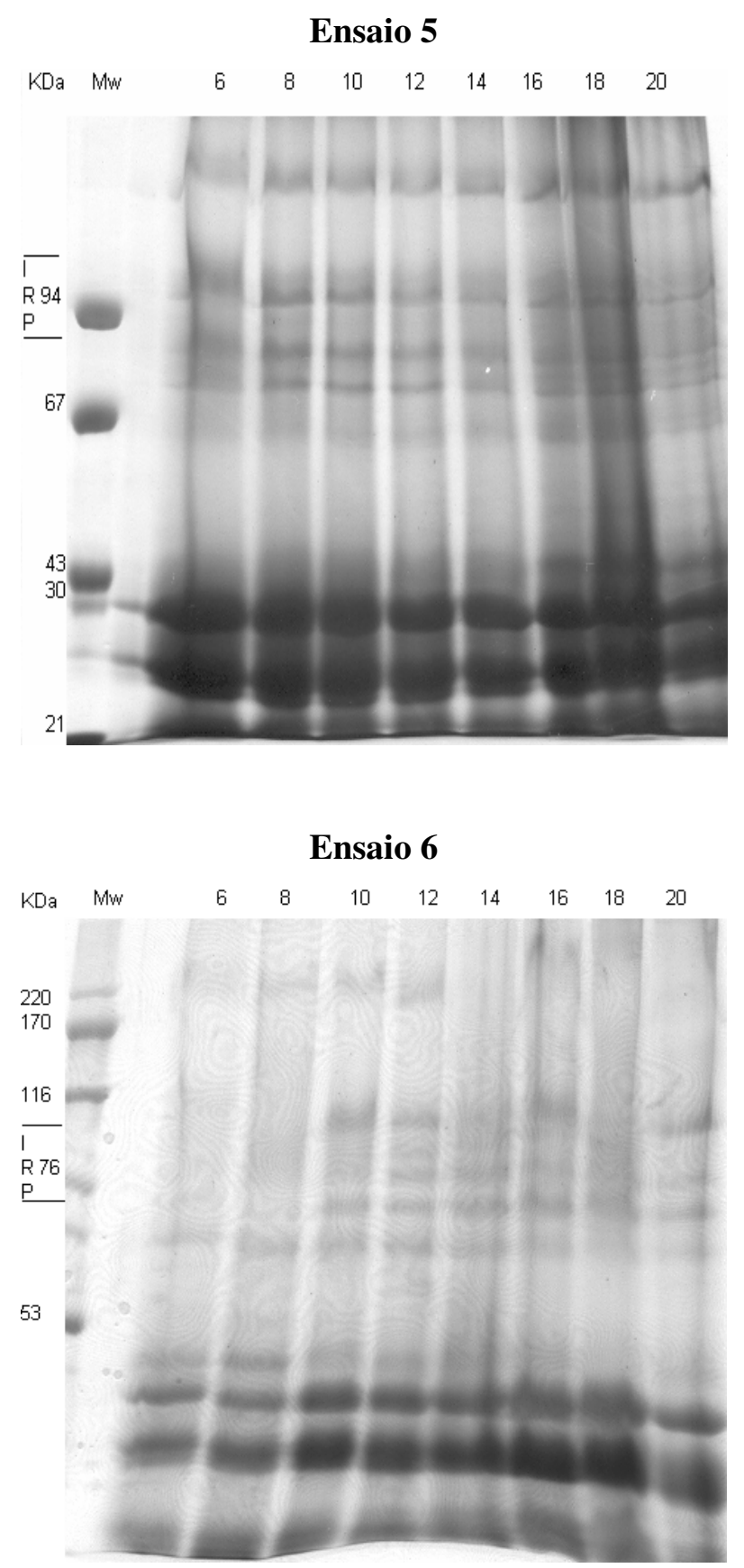

Figura 3.36 - Gel de eletroforese SDS-PAGE (10\%) das amostras de OMV obtidas durante o cultivo. A colunas de 6 a 20 correspondem ao extrato de OMV fracionados representando as respectiva horas de cultivos. As bandas representativas da expressão de IRP de OMV estão indicadas entre (70 - $108 \mathrm{kDa}$ ) dos ensaios 5 e 6 , respectivamente, do grupo C. 
3.7.3 Géis de eletroforese, SDS-PAGE 10\%, dos ensaios do grupo D em meio de Catlin sem ferro com pulso de concentração de lactato e aminoácidos na $6^{\mathrm{a}} \mathrm{h}$ de cultivo
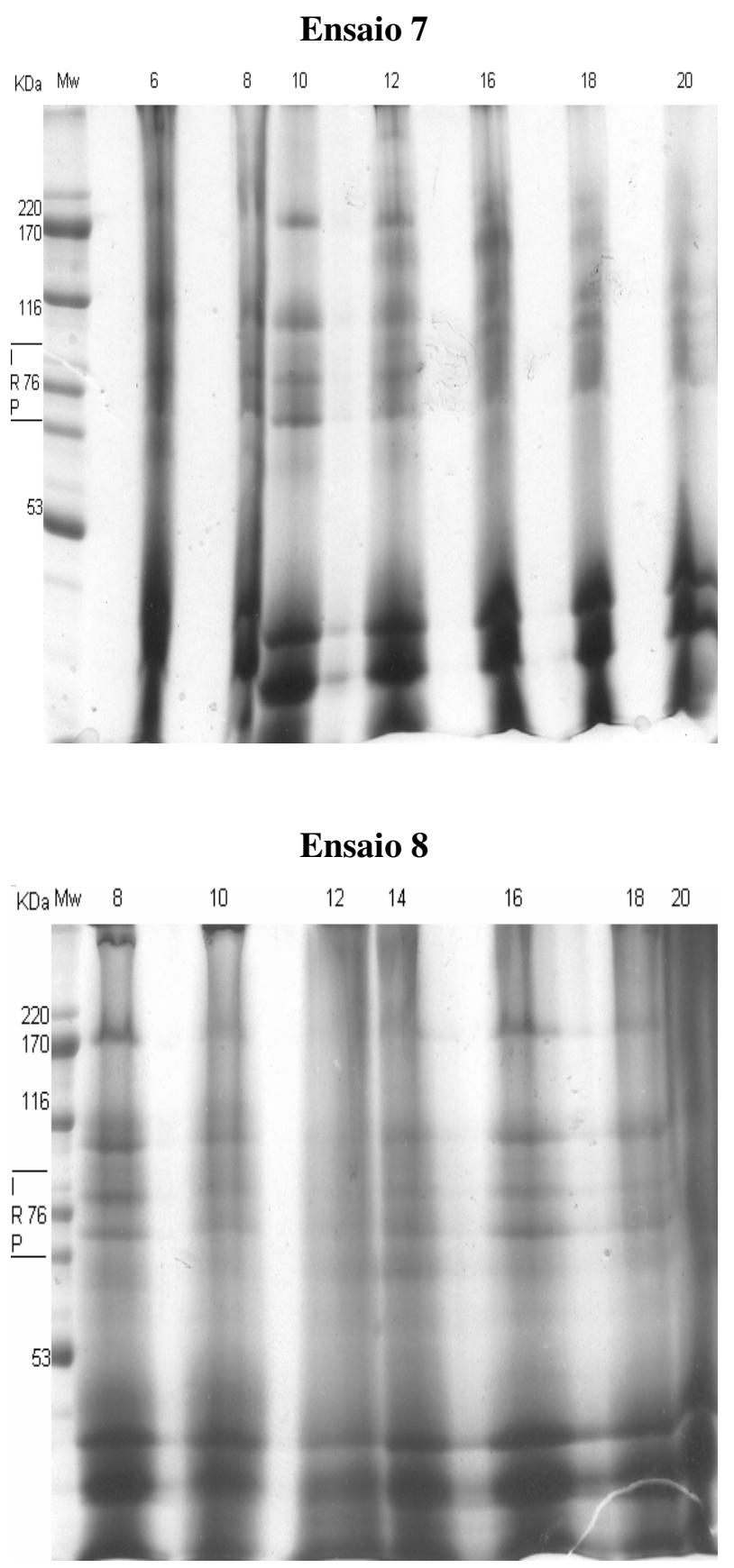

Figura 3.37 - Gel de eletroforese SDS-PAGE (10\%) das amostras de OMV obtidas durante o cultivo. As colunas de 6 a 20 correspondem ao extrato OMV fracionados representando as respectivas horas de cultivos. As bandas representativas da expressão de IRP de OMV estão indicadas entre (70 $-108 \mathrm{kDa}$ ) dos ensaios 7 e 8 , respectivamente, do grupo D. 
3.7.4 Gel de eletroforese, SDS-PAGE 10\%, dos ensaios do grupo E em meio de Catlin sem ferro com concentrações iniciais de lactato e aminoácidos dobradas
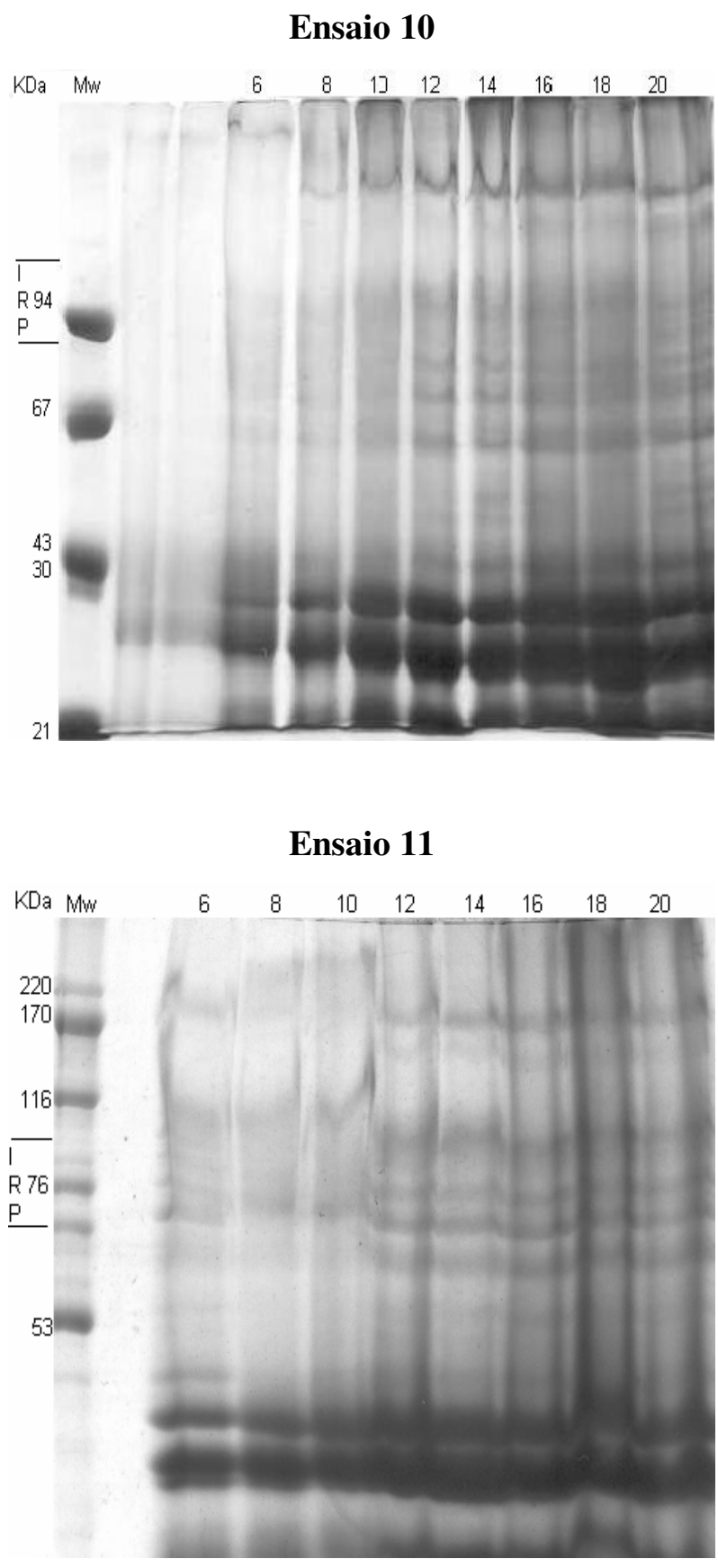

Figura 3.38 - Gel de eletroforese SDS-PAGE (10\%) das amostras de OMV obtidas durante o cultivo. As colunas de 6 a 20 correspondem ao extrato de OMV fracionados representando as respectivas horas de cultivos. As bandas representativas da expressão de IRP de OMV estão indicadas entre (70 - $108 \mathrm{kDa}$ ) dos ensaios 10 e 11, respectivamente, do grupo E. 
3.7.5 Gel de eletroforese, SDS-PAGE 10\%, do ensaio do grupo F em meio de Catlin sem ferro com concentrações iniciais de lactato e aminoácidos dobrados e sem glicerol

\section{Ensaio 12}

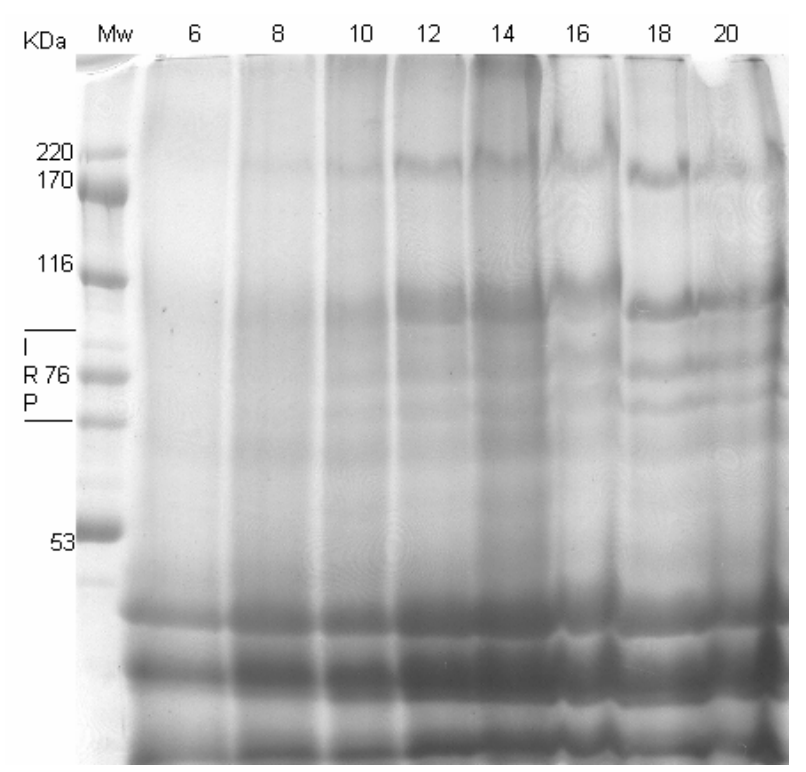

Figura 3.39 - Gel de eletroforese SDS-PAGE (10\%) das amostras de OMV obtidas durante o cultivo. As colunas de 6 a 20 correspondem ao extrato de OMV fracionados das respectivas horas de cultivos. As bandas representativas da expressão de IRP estão indicadas entre $(70-108 \mathrm{kDa})$ do ensaio 12 do grupo F. 


\subsection{Microscopia eletrônica das vesículas da membrana externa (OMV)}

A microscopia eletrônica das OMVs produzidas em biorreator em meio de Catlin sem ferro, variando as concentrações de alguns componentes do meio, apresenta uma grande importância para observação da integridade das vesículas. No ensaio do grupo B, as concentrações dos componentes do meio foram mantidas, no grupo $\mathrm{E}$ as concentrações iniciais de lactato e aminoácidos foram dobradas e no grupo $\mathrm{F}$, além de dobrar as concentrações iniciais de lactato e aminoácidos retirou-se o glicerol do meio.

A microscopia foi realizada por meio de amostras retiradas durante a oitava, décima quarta e vigésima hora de cultivo. Foram selecionados primeiramente os grupos $\mathrm{E}$ e F, considerados os de melhores condições para produção de OMV e o grupo B, considerado “padrão", por não apresentar nenhuma alteração nas concentrações dos componentes do meio.

As figuras 3.40 a 3.42 ilustram as três amostras de cada grupo. Nelas podem ser observadas as formas tubulares e esféricas, citada por Devoe e Gilchrist (1973), a integridade das vesículas. além do contorno. 
3.8.1 Microscopia eletrônica das OMV do ensaio 4 do grupo B

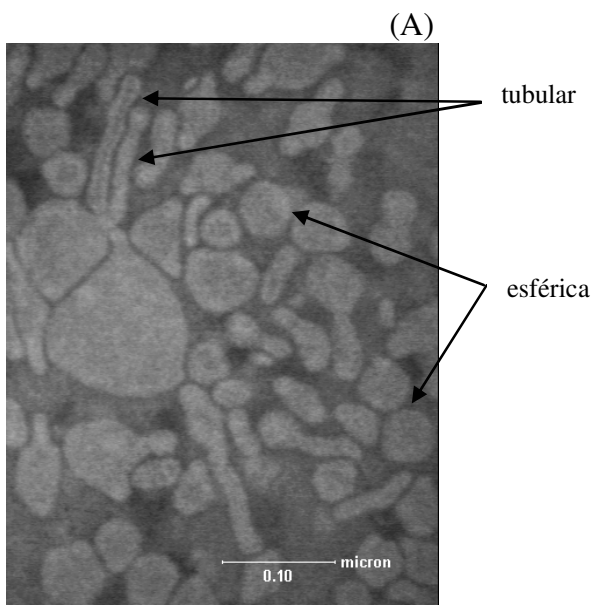

(B)
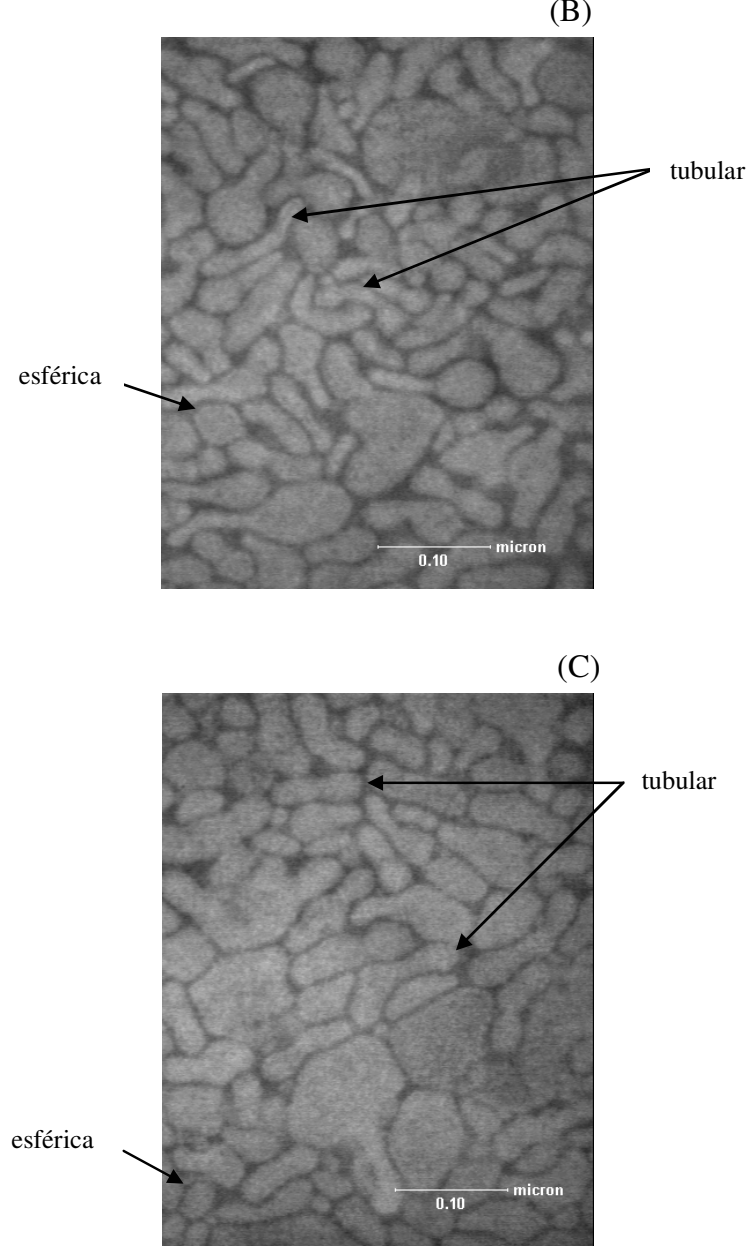

Figura 3.40 - Microscopia eletrônica das OMV do ensaio 4, em meio de Catlin sem ferro: (A) $8 \mathrm{~h}$; (B) $14 \mathrm{~h} \mathrm{e} \mathrm{(C)} 20 \mathrm{~h}$. 


\subsubsection{Microscopia eletrônica das OMV do ensaio 11 do grupo E}
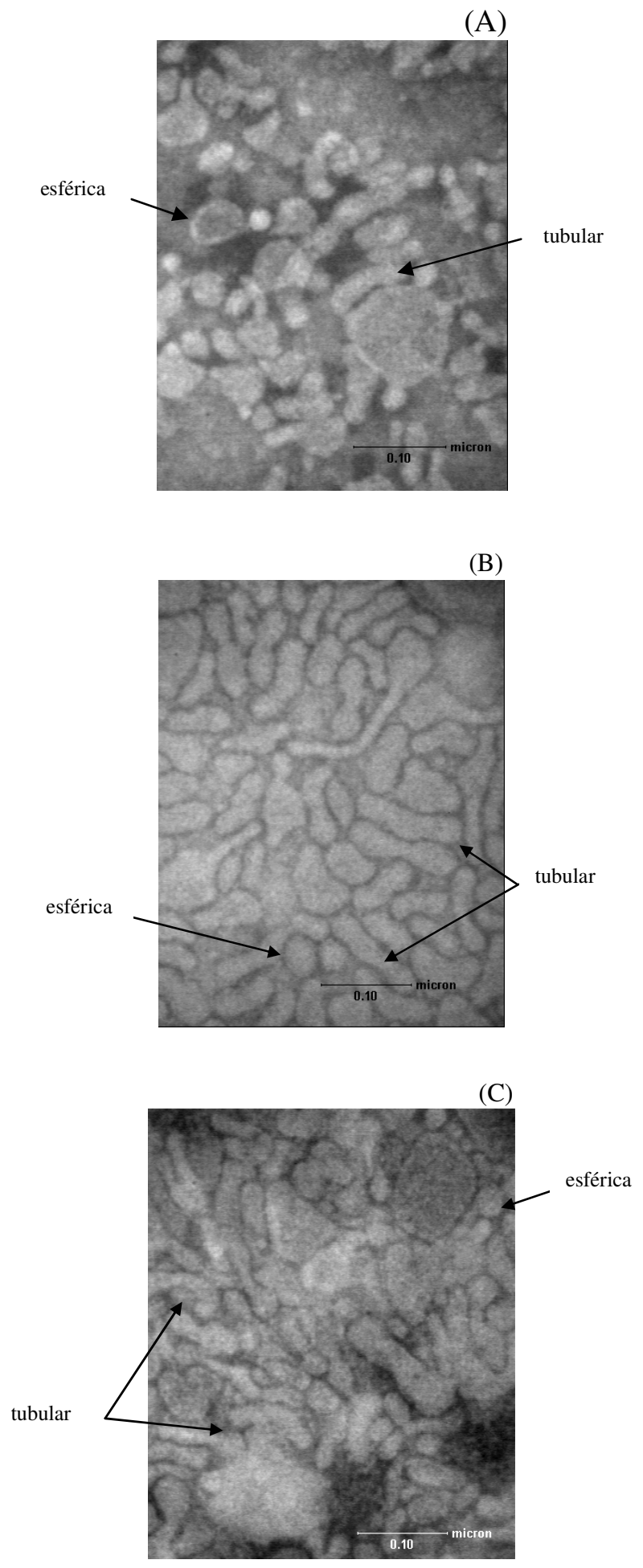

Figura 3.41 - Microscopia eletrônica das OMV do ensaio 11, em meio de Catlin sem ferro, com concentrações iniciais de lactato e aminoácidos dobrados: (A) $8 \mathrm{~h}$; (B) 14 e (C) $20 \mathrm{~h}$. 


\subsubsection{Microscopia eletrônica das OMV do ensaio 12 do grupo F}
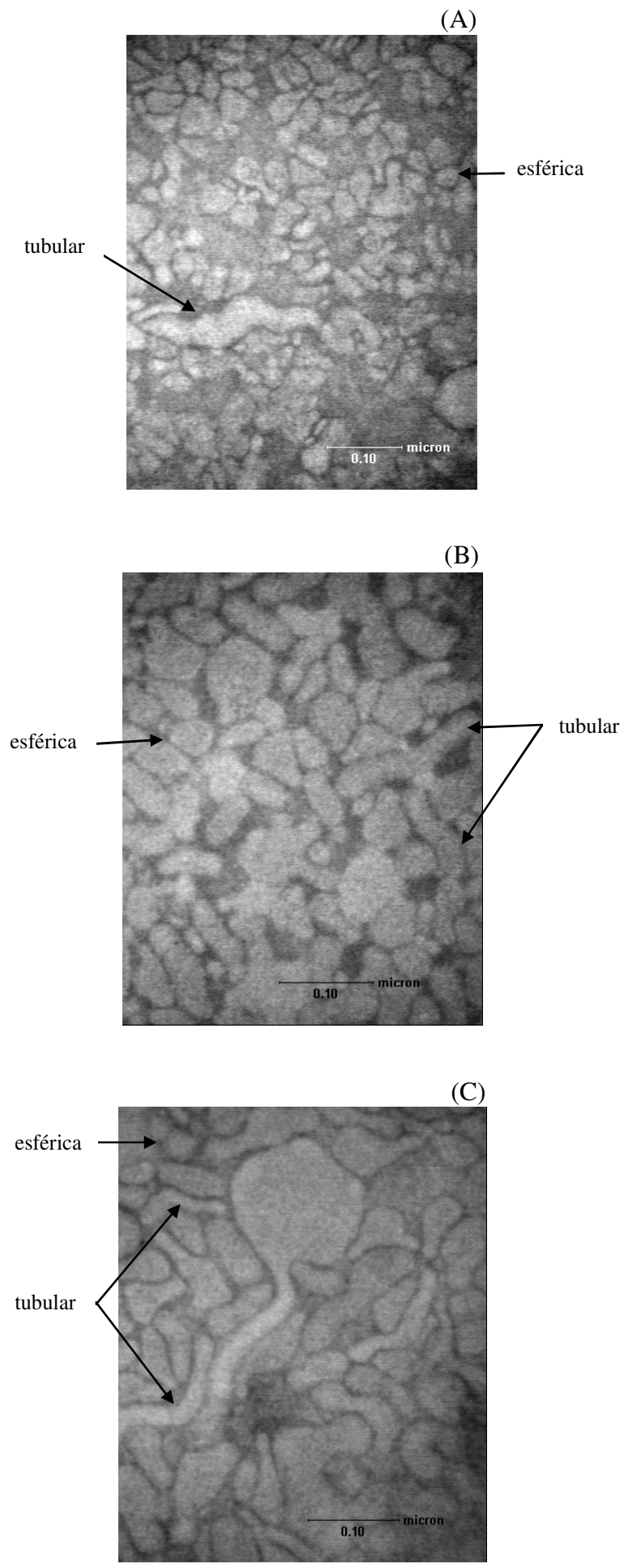

Figura 3.42 - Microscopia eletrônica das OMV do ensaio 12, em meio de Catlin sem ferro, com concentrações iniciais de aminoácidos e lactato dobrados e sem glicerol: (A) $8 \mathrm{~h}$; (B) $14 \mathrm{~h} \mathrm{e} \mathrm{(C)} 20 \mathrm{~h}$. 


\section{DISCUSSÃO}

\subsection{Análise dos efeitos das prováveis fontes de carbono no ensaio com planejamento fatorial realizado em agitador rotatório.}

De acordo com os resultados do ensaio 1 (tabela 3.2), grupo A, o resultado final da densidade óptica 540nm teve seu principal efeito devido ao aumento da concentração de lactato no meio de cultivo. A variação da concentração de glicerol, outra possível fonte de carbono para a bactéria, não provocou qualquer efeito nos valores finais de concentração celular. Além disso, os valores de concentração inicial e final do glicerol mostraram que este não é consumido durante o cultivo. Entretanto, analisando os resultados da concentração de OMV, apesar da concentração de lactato promover um efeito positivo, o principal efeito foi promovido pela variação da concentração do glicerol e interações com o ácido L- glutâmico e lactato de sódio. Desta maneira, apesar do aumento da concentração de glicerol no meio de cultivo parecer não promover crescimento celular, pode possivelmente promover algum efeito significativo na produção de OMV nos níveis de concentração empregados. Em hipótese, esse elemento poderia exercer algum efeito protetor sobre a geração de OMV. A variação da concentração do ácido L-glutâmico não promoveu nenhum efeito significativo nos níveis de concentração empregados.

As conclusões preliminares deste ensaio com planejamento fatorial implicaram nas condições de cultivo que foram escolhidas para os ensaios em biorreator (tabela 3.1).

Os primeiros ensaios em biorreator, denominados grupo $\mathrm{B}$, foram realizados nas condições pré-estabelecidas no Projeto Meningite, em meio de Catlin sem ferro, e com as observações do ensaio do grupo A. Após resultados obtidos da produção de OMV, nos ensaios do grupo B, foi feita a suposição que aumentando em três vezes à concentração de lactato, por acreditar ser este a principal fonte de carbono, a cinética de crescimento seria maior e consequentemente aumentaria a produção de OMV. Com este intuito os ensaios do grupo $\mathrm{C}$ foram realizados triplicando a concentração inicial de lactato. Estas modificações causaram crescimento celular que apresentaram mudança de fase na $6^{\mathrm{a}}$ hora de cultivo. Em hipótese baseada nos ensaios do grupo $\mathrm{C}$ e ensaios do grupo $\mathrm{A}$, a inserção pulso de lactato e aminoácidos na $6^{\mathrm{a}}$ hora de cultivo, provocaria um prolongamento na fase de crescimento celular e consequentemente elevação na produção de OMV. Está condição foi atribuída aos ensaios do grupo D. Entretanto, houve aumento do crescimento celular e diminuição da produção de OMV. 
Uma nova hipótese, baseada nos resultados do grupo A em agitador rotatório, seria provocar modificações nas concentrações iniciais de lactato e aminoácidos, surgindo assim os ensaios do grupo E, que por sua vez, apresentaram resultados favoráveis ao crescimento celular e a produção de OMV. Contudo, precisaria entender o comportamento do glicerol no que se refere à produção de OMV. Inicia neste instante um novo grupo de ensaio intitulado grupo $\mathrm{F}$, mantendo as condições do grupo anterior, concentrações iniciais de lactato e aminoácidos dobradas, no entanto retirando totalmente a concentração de glicerol do meio. Neste grupo o crescimento celular e a produção de OMV mostraram-se próximo aos valores encontrados nos ensaios do grupo E.

\subsection{Coeficiente de concentração celular entre Massa seca e DO $540 \mathrm{~nm}$}

A medida da concentração celular normalmente é realizada através de determinação da biomassa seca. No entanto, nos ensaios realizados em biorreator, com objetivo de melhorar os efeitos da variabilidade que ocorreu nas medidas de massa seca ao longo dos processos (tabelas 3.3 a 3.13), foram feitos gráficos correlacionando $\mathrm{DO}_{540 \mathrm{~nm}}$ e massa seca e traçadas as linhas de tendência (Figura 7.2.1 do anexo 7.2). Foi assumida a interseção no ponto zero e calculadas a equação da reta e valor do coeficiente de correlação $\left(\mathrm{r}^{2}\right)$ utilizando o programa Excel Microsoft. Dentre os valores de coeficiente de concentração, o valor de coeficiente de correlação $\left(\mathrm{r}^{2}\right)$ estabeleceu qual destes seriam considerados para o cálculo da média, uma vez que aqueles inferiores a 0,7 foram desconsiderados (tabela 4.1). Foram eles: ensaios 4 e 8 dos grupos B e D, respectivamente. A média dos valores do coeficiente de concentração foi de 0,46 (g/L) e o desvio padrão de 0,06. Este coeficiente foi utilizado para estimar valores de massa seca a partir de valores de $\mathrm{DO}_{540 \mathrm{~nm}}$ e para cálculo de $\mu_{\mathrm{S}}$ e $\mu_{\mathrm{P}}$ (item 2.7.5).

Com relação à viabilidade celular foi observado que o número de células viáveis, expressos por unidades formadoras de colônia (UFC/mL), apresenta perfil que acompanha o crescimento celular dos respectivos ensaios (Figuras 3.1, 3.3, 3.9 e 3.20). 
Tabela 4.1 - Coeficientes de concentração celular dos ensaios com seus respectivos coeficientes de correlação $\left(\mathrm{r}^{2}\right)$

\begin{tabular}{cccc}
\hline Grupo & Ensaio & $\begin{array}{c}\text { Coeficiente } \\
\text { M.seca x D.O. } \\
(\mathbf{g} / \mathbf{L})\end{array}$ & $\mathbf{r}^{\mathbf{2}}$ \\
\hline $\mathbf{A}$ & 1 & $\cdots \cdots \cdots$ & $\cdots \cdots$ \\
\hline $\mathbf{B}$ & 2 & 0,3366 & 0,8559 \\
& 3 & 0,4256 & 0,9050 \\
\hline $\mathbf{C}$ & 4 & 1,1722 & 0,5101 \\
\hline $\mathbf{D}$ & 5 & 0,4417 & 0,9416 \\
& 6 & 0,4959 & 0,9355 \\
\hline $\mathbf{E}$ & 7 & 0,4488 & 0,9870 \\
& 8 & 0,5475 & 0,6274 \\
\hline $\mathbf{F}$ & 9 & 0,4683 & 0,7976 \\
& 10 & 0,4793 & 0,9620 \\
& 11 & 0,5935 & 0,8614 \\
\hline
\end{tabular}

\subsection{Análise das produtividades e fatores de conversão}

\subsubsection{Crescimento celular $-X_{\text {máx }}$}

Os ensaios 2 a 12 tiveram suas curvas suavizadas (tabela 7.1.1 a 7.1.11 do anexo 7.1) para os dados experimentais de concentração celular, concentração de lactato e de OMV, utilizando o programa Logiciel du Lissage (item 2.7.5.). Posteriormente foram calculados os valores de produtividade celular e de OMV, assim como os fatores de conversão $Y_{x / s}$ e $Y_{p / x}$ de acordo com as equações inseridas no item 2.7.5 Os resultados obtidos estão expressos na tabela 4.2.

Na tabela 4.2 observa-se que a concentração celular máxima $\left(X_{\text {máx }}=2,27 \mathrm{~g} / \mathrm{L}\right)$ ocorreu no grupo F, grupo no qual as concentrações iniciais de lactato e aminoácidos foram o dobro das concentrações normais do meio de Catlin sem ferro (tabela 2.4) e o glicerol não foi utilizado. No grupo B, onde as concentrações permaneceram como as descritas por Catlin (1973), a média de $X_{\text {máx }}$ foi de 0,62 g/L. Estes resultados sugerem que as alterações nas 
concentrações dos componentes do meio de Catlin, desde o início, favorecem o crescimento celular. No grupo D, em que o meio sofreu alteração na $6^{\text {a }}$ hora através da inserção de pulso de aminoácidos e lactato, a média de $\mathrm{X}_{\text {máx }}$ foi de $1,19 \mathrm{~g} / \mathrm{L}$. Comparando-se os resultados dos grupos B, D e F, quando as concentrações de nutrientes foram alteradas desde o início ou durante o processo, houve em todos os ensaios aumento do crescimento celular em relação àquelas onde a concentração de nutrientes não foi alterada.

Com relação aos grupos de ensaio que apresentaram valores intermediários, no grupo E, o qual teve a concentração de lactato e aminoácidos dobrados desde o inicio, a média de $\mathrm{X}_{\text {máx }}$ foi de 1,56 g/L. Já no grupo C, que apresentou apenas concentração de lactato triplicado desde o início, obteve uma média de 1,52 g/L.

Assim, com base nos resultados obtidos na tabela 4.2, levando-se em consideração as alterações das concentrações dos componentes do meio de Catlin sem ferro e o tempo em que estas ocorreram, os dados demonstram que o grupo F, C e E, apresentaram os melhores resultados de crescimento celular máximo (Figura 3.28, 3.8 e 3.21) respectivamente. Os grupos D e B, respectivamente, apresentaram os mais baixos crescimentos celulares (Figura 3.15 e 3.1$)$. 
Tabela 4.2 - Valores de concentração celular máxima $\left(\mathrm{X}_{\text {máx }}\right)$, concentração de OMV máxima $\left(\mathrm{P}_{\text {máx }}\right)$, produtividade em biomassa $\left(\operatorname{Prod}_{\mathrm{x}}\right)$ e de vesículas da membrana externa $\left(\operatorname{Prod}_{\mathrm{p}}\right)$, fator de conversão biomassa/lactato $\left(\mathrm{Y}_{\mathrm{x} / \mathrm{s}}\right)$ e OMV/biomassa $\left(\mathrm{Y}_{\mathrm{p} / \mathrm{x}}\right)$.

\begin{tabular}{|c|c|c|c|c|c|c|c|c|}
\hline Grupos & Ensaios & $\begin{array}{l}\text { Inicio da fase } \\
\text { estacionária (h) }\end{array}$ & $\begin{array}{l}X_{\text {máx }} \\
(g / L)\end{array}$ & $\begin{array}{r}\mathbf{P}_{\text {máx }} \\
(\mathrm{mg} / \mathrm{L})\end{array}$ & $\begin{array}{l}\text { Prod.x } \\
\text { (g/L.h) }\end{array}$ & $\begin{array}{r}\text { Prod.p } \\
\text { (mg/L.h) }\end{array}$ & $\begin{array}{r}Y_{\mathrm{x} / \mathrm{s}} \\
(\mathrm{g} / \mathrm{g})\end{array}$ & $\begin{array}{c}Y_{p / x} \\
(\mathrm{mg} / \mathrm{g})\end{array}$ \\
\hline$\overline{\mathbf{A}}$ & 1 & $\ldots \ldots$ & …... & ....... & …... & $\ldots \ldots$ & $\ldots \ldots$ & $\ldots \ldots$ \\
\hline \multirow{3}{*}{ B } & 2 & 7 & 0,70 & 26,1 & 0,10 & 2,37 & 0,25 & 37,2 \\
\hline & 3 & 6 & 0,58 & 55,2 & 0,10 & 3,06 & 0,24 & 95,4 \\
\hline & 4 & 6 & 0,57 & 44,2 & 0,09 & 2,21 & 0,23 & 78,1 \\
\hline \multirow[t]{2}{*}{$\bar{C}$} & 5 & 9 & 1,08 & $\begin{array}{l}79,4 \\
\end{array}$ & 0,12 & 3,97 & 0,15 & 73,9 \\
\hline & 6 & 9 & 1,96 & 89,3 & 0,22 & 4,46 & 0,24 & 45,6 \\
\hline \multirow[t]{3}{*}{$\bar{D}$} & 7 & 10 & 0,98 & $\overline{59,4}$ & 0,10 & 2,97 & 0,43 & $\overline{60,8}$ \\
\hline & 8 & 10 & 1,39 & 65,9 & 0,14 & 3,86 & 0,61 & 47,3 \\
\hline & 9 & 10 & 1,67 & 162,3 & 0,17 & 8,12 & 0,78 & 97,3 \\
\hline \multirow[t]{2}{*}{$\mathbf{E}$} & 10 & 9 & 2,24 & 142,5 & 0,25 & 7,12 & 0,51 & 63,5 \\
\hline & 11 & 9 & 1,22 & 156,9 & 0,14 & 7,85 & 0,47 & 128,8 \\
\hline $\bar{F}$ & 12 & 12 & 2,27 & 121,1 & 0,19 & 6,05 & 0,38 & $\overline{53,3}$ \\
\hline
\end{tabular}

\subsubsection{Produtividade ou Produto celular $\left(\operatorname{Prod}_{\mathrm{x}}\right)$}

De acordo com dados expressos na tabela 4.2, a biomassa geradas em cada hora $\left(\operatorname{Prod}_{\mathrm{x}}\right)$ foi em média: 0,10; 0,17; 0,12; 0,18 e 0,19 g/L.h, valores dos grupos B, C, D, E, F, respectivamente. Assim com base, nos dados acima, sugere-se que o grupo C, E e F, realizados em meio de Catlin sem ferro com concentrações de lactato alteradas, apresentaram maior média de produtividade de biomassa por hora de cultivo, o que reafirma a influência da alteração na concentração de lactato no meio. No grupo B e D, a média de produtividade de biomassa por hora de cultivo foi menor, nestes a concentração de lactato e aminoácidos do meio foram de acordo ao estabelecido por Catlin (1973), sendo que no grupo D, houve pulso desses componentes na $6^{\mathrm{a}}$ hora de cultivo. 


\subsubsection{OMV máxima - Pmáx}

Na tabela 4.2, o grupo B apresentou a menor média de valores de concentração de OMV máxima $\left(\mathrm{P}_{\text {máx }}\right)$ de 41,8 mg/L, seguido pelo grupo $\mathrm{D}$, com $\mathrm{P}_{\text {máx }}$ de 62,7 mg/L em relação aos demais grupos. Em ambos os casos, esses grupos de ensaios (B e D) apresentaram baixo crescimento celular, o que pode ser atribuído à baixa concentração de lactato e aminoácidos (tabelas 3.3 a 3.5 e 3.8 a 3.9). O grupo $E$ apresentou a maior média de $P_{\text {máx }}$, que foi de 153,9 $\mathrm{mg} / \mathrm{L}$. Neste grupo de ensaios, as concentrações iniciais de lactato e aminoácidos foram o dobro daquelas dispostas no meio de Catlin sem ferro (tabela 2.4). Em seguida encontra-se o resultado do grupo $\mathrm{C}$, com média de $\mathrm{P}_{\text {máx }}=84,4 \mathrm{mg} / \mathrm{L}$, o qual teve em seu meio, três vezes a concentração de lactato em relação ao meio de Catlin sem ferro, sendo as demais concentrações dos outros nutrientes mantidas. No grupo F, ensaio 12, em meio de Catlin sem ferro com concentrações iniciais de lactato e aminoácidos dobradas e sem glicerol, o valor de $\mathrm{P}_{\text {máx }}$ foi de $121,1 \mathrm{mg} / \mathrm{L}$.

\subsubsection{Produtividade do produto $\left(\operatorname{Prod}_{\mathrm{p}}\right)$}

O grupo E continua apresentando os melhores resultados. Considerando a produtividade do produto $\left(\operatorname{Prod}_{\mathrm{P}}\right)$, realizou-se a média dos ensaios, a qual apresentou valor de $\operatorname{Prod}_{\mathrm{p}}=7,70 \mathrm{mg} / \mathrm{L} . \mathrm{h}$. O grupo F, em meio de Catlin sem ferro com concentrações iniciais de lactato e aminoácidos dobradas e sem glicerol, apresentou valor de $\operatorname{Prod}_{\mathrm{p}}=6,05 \mathrm{mg} / \mathrm{L} . \mathrm{h}$, apresentando resultados próximos ao do grupo E. Com relação às menores média, temos o

grupo C, com Prod igual a 4,21 mg/L.h, seguido do grupo D, com média de 3,41 mg/L.h e grupo B que apresentou valor igual a 2,55 mg/L.h (tabela 4.2).

Os grupos de melhor produtividade de produto, $\operatorname{Prod}_{\mathrm{p}}(\mathrm{E}, \mathrm{C}$ e F), são os que tiveram as concentrações iniciais de lactato alteradas de duas a três vezes em relação ao meio de Catlin sem ferro (tabela 2.4).

\subsubsection{Fator de conversão biomassa/lactato $\left(\mathrm{Y}_{\mathrm{x} / \mathrm{s}}\right)$}

Dados da tabela 4.2, mostram os valores de biomassa gerada a partir do consumo de lactato de sódio. No grupo $\mathrm{C}$, a média entre os valores de biomassa/lactato foi de $0,20 \mathrm{~g}$ de 
biomassa formada por $\mathrm{g}$ de lactato no meio, $\left(\mathrm{Y}_{\mathrm{x} / \mathrm{s}}=0,20 \mathrm{~g} / \mathrm{g}\right)$, neste a concentração inicial de lactato foi a maior em relação a todos os outros grupos, triplicada. $\mathrm{O}$ grupo $\mathrm{B}$, apresentou valor semelhante ao grupo anterior $0,22 \mathrm{~g} / \mathrm{g}$; a composição do meio neste grupo teve sua concentração de lactato de acordo descrito por Catlin (1973). O grupo F, com o meio de cultivo alterado para concentrações iniciais de lactato e aminoácidos dobradas, porém sem glicerol, apresentou valor de 0,38 g/g. No grupo D, o cultivo teve um pulso de lactato e aminoácidos na $6^{\mathrm{a}} \mathrm{h}$, tendo a média de biomassa por lactato igual a 0,52 g/g. O grupo E, apresentando concentrações iniciais de lactato e aminoácidos dobradas em relação à formulação do meio de Catlin, foi o que mostrou maior média de valor de $Y_{p / x}=0,59 \mathrm{~g} / \mathrm{g}$ (tabela 4.2), ficando evidente que este grupo, possui uma formação maior de biomassa por lactato.

\subsubsection{Fator de conversão OMV/biomassa $\left(Y_{\mathrm{p} / \mathbf{x}}\right)$}

Na conversão de OMV por biomassa, o grupo E apresentou valores superiores aos demais grupos, com valores para os ensaios 9, 10, $11 \mathrm{de} \mathrm{Y}_{\mathrm{p} / \mathrm{x}}=97,3 \mathrm{mg} / \mathrm{g}, \mathrm{Y}_{\mathrm{p} / \mathrm{x}}=63,5 \mathrm{mg} / \mathrm{g} \mathrm{e}$ $\mathrm{Y}_{\mathrm{p} / \mathrm{x}}=128,8 \mathrm{mg} / \mathrm{g}$ respectivamente. Neste grupo, as concentrações iniciais de lactato e aminoácidos foram dobradas em relação à formulação do meio de Catlin sem ferro. Nos demais grupos de ensaios, ocorreram variações. No grupo B, o ensaio 2 apresentou valor de OMV por biomassa igual a 37,2 mg/g e os ensaios 3 e 4 tiveram valores de 95,4 mg/g e 79,1 $\mathrm{mg} / \mathrm{g}$, respectivamente. $\mathrm{O}$ grupo $\mathrm{C}$, apresentou valores de $\mathrm{OMV}$ por biomassa igual a 73,9 $\mathrm{mg} / \mathrm{g}$ para o ensaio 5 e 45, $6 \mathrm{mg} / \mathrm{g}$ para o ensaio 6. Nos ensaios do grupo D, os quais tiveram em sua condição de cultivo um pulso de lactato e aminoácidos na $6^{\mathrm{a}}$ hora, apresentaram valores de OMV por biomassa igual a $60,3 \mathrm{mg} / \mathrm{g}$ (ensaio 7) e 47,3 mg/g (ensaio 8). No grupo F, em que o meio apresentou concentração inicial de lactato e aminoácidos dobradas e com ausência de glicerol, valor de OMV por biomassa foi 1 a 53,3 mg/g (Tabela 4.2).

Deste modo, de acordo dados gerados na tabela 4.2, o grupo E apresentou melhor produção de $\mathrm{OMV}$ por biomassa $\left(\mathrm{Y}_{\mathrm{p} / \mathrm{X}}\right)$ e também os valores mais altos de concentração de produto final (OMV). Isto pode indicar que a melhor concentração para o meio de cultivo seria aquela onde se manteve a concentração inicial de glicerol naquela indicada no meio de Catlin, mas que, no entanto, apresenta concentrações iniciais de lactato e aminoácidos dobradas. 


\subsection{Fonte de carbono e nitrogênio}

A Neisseria meningitidis requer piruvato, lactato ou glicose como únicas fontes de carbono (CHAPIN, 1918 apud LEIGHTON et al., 2001)³ . São poucos os trabalhos sobre metabolismo de Neisseria na literatura mas a publicação da seqüência completa do genoma de N. meningitidis B, cepa MC58 (TETTELIN et al., 2000), sugere a presença completa do ciclo do ácido cítrico.

No atual trabalho, o meio de cultura utilizado foi o descrito por Catlin (1973) sem ferro (tabela 2.4). Foi usada uma mistura racêmica de lactato de sódio a 50\%, ou seja, o valor da concentração do D-lactato é suposto ser igual ao do L-lactato. Entretanto, valores dos resultados experimentais (tabelas 3.3 a 3.13), referem-se apenas ao L-lactato (g/L), visto que nesta condição o sistema enzimático Yelow Spring (item 2.7.3.4) mede apenas o L-lactato. A tabela 4.3 apresenta os valores das variações das concentrações em meio de Catlin: lactato de sódio (g/L); D-L lactato (g/L); D-lactato (g/L); L-lactato (g/L).

Tabela 4.3 - Representação dos valores das variações das concentrações (original, duplicada e triplicada) da mistura racêmica a $50 \%$ de: lactato de sódio $(\mathrm{g} / \mathrm{L})$, D-L lactato $(\mathrm{g} / \mathrm{L})$, D-lactato $(\mathrm{g} / \mathrm{L})$ e L-lactato $(\mathrm{g} / \mathrm{L})$ respectivamente. Estas concentrações referem-se à composição do *meio de Catlin sem ferro (tabela 2.4), empregada em diferentes ensaios.

\begin{tabular}{ccccc}
\hline $\begin{array}{c}\text { Concentração de lactato de } \\
\text { sódio no meio de cultura* }\end{array}$ & $\begin{array}{c}\text { Lactato de } \\
\text { sódio }(\mathbf{g} / \mathbf{L})\end{array}$ & $\begin{array}{c}\text { D-L lactato } \\
(\mathbf{g} / \mathbf{L})\end{array}$ & $\begin{array}{c}\text { D-lactato } \\
(\mathbf{g} / \mathbf{L})\end{array}$ & $\begin{array}{c}\text { L-lactato } \\
(\mathbf{g} / \mathbf{L})\end{array}$ \\
\hline original & 7,5 & 5,96 & 2,98 & 2,98 \\
duplicada & 15 & 11,92 & 5,96 & 5,96 \\
triplicada & 22,5 & 17,88 & 8,94 & 8,94 \\
\hline
\end{tabular}

Nos ensaios do grupo B, em meio de Catlin sem ferro, houve consumo total de lactato entre a $7^{\mathrm{a}}$ e $8^{\mathrm{a}}$ hora. No grupo $\mathrm{C}$, em meio de Catlin sem ferro com concentrações de lactato triplicada, o consumo não foi completo, restando no final do processo concentração de lactato de 2,34 g/L. Em ensaios do grupo D, em meio de Catlin sem ferro com pulso de lactato e aminoácidos na $6^{\mathrm{a}}$ hora, o lactato atingiu baixa concentração no meio, em torno de $0,61 \mathrm{~g} / \mathrm{L} \mathrm{e}$ neste momento foi dado um pulso, e o consumo total de lactato ocorreu entre a $15^{\mathrm{a}}$ e $16^{\mathrm{a}}$ hora. 
Ensaios do grupo E, em meio de Catlin sem ferro, com concentrações iniciais de lactato e aminoácidos dobradas, apresentaram consumo quase total entre a $8^{\mathrm{a}}$ e $11^{\mathrm{a}}$ hora do cultivo. No grupo $\mathrm{F}$, também houve consumo total entre a $7^{\mathrm{a}}$ e $8^{\mathrm{a}}$ hora.

A maioria dos estudos, envolvendo metabolismo de carbono em Neisseria, está relacionada com a utilização da glicose como única fonte de carbono. Entretanto, a maior parte deles analisa a relação entre o consumo da fonte de carbono e a geração de polissacarídeo, principal produto do cultivo de Neisseria meningitidis do sorogrupo C (PAZ et al., 2003; BARUQUE-RAMOS et al., 2006).

O uso de glicose, ao invés de lactato, pode propiciar uma maior produtividade celular, conforme foi observado no trabalho de Fu e colaboradores (1995). O foco do trabalho destes autores foi a geração de biomassa e estes não estudaram a cinética de formação das OMVs produzidas a partir desses cultivos, não é feita a purificação e, conseqüentemente, nem a dosagem de OMVs. Analisaram o uso do meio de Catlin, alteraram o meio original, obtiveram melhor crescimento celular, para N.meningitidis B11, porém, sempre utilizaram a glicose como fonte de carbono e meio contendo ferro. Observaram o predomínio da via metabólica do ciclo das triose-fosfato sobre a via do ciclo das pentose-fosfato.

O gênero Neisseria produz 3 tipos de lactato-dehidrogenase (LDH) responsáveis pela captação e incorporação do lactato, através da transformação do lactato em piruvato na presença de $\mathrm{NAD}^{+}$. Erwin e Gotschlich (1996) demonstraram a presença de pelo menos duas LDH L-lactato específicas e uma LDH D-lactato específica. Essas três enzimas foram confirmadas através do genoma (TETTELIN et al., 2000). Erwin e Gotschlich (1993) mostraram que $N$. meningitidis é capaz de crescer tão bem em lactato quanto em glicose. Por outro lado, Leighton et al. (2001) mostram que o crescimento de $N$. meningitidis em lactato é claramente menos favorável do que o crescimento em piruvato.

O ácido L-glutâmico é a principal fonte de nitrogênio consumido durante as 20 horas de cultivo (tabelas 3.3 a 3.13), contribuindo para a formação de amônia (Tabela 7.3.1 no anexo 7.3) e elevação do pH. Resultados obtidos no grupo A demonstraram que apesar da concentração de lactato promover um efeito positivo na concentração de OMV, a variação da concentração do glicerol e interações com o ácido L- glutâmico e lactato de sódio, juntos, apresentam uma influência significativa na produção de OMV. No entanto de acordo com Santos et al. (2006) nos ensaios preliminares em agitador rotatório o ácido L-glutâmico separadamente não promoveu efeito significativo na produção de OMV.

${ }^{3}$ CHAPIN, C.W. Carbon dioxide inthe primary cultivation of the gonococcus. Journal of Infectious Diseases, v.19, p. 342-343, 1918. 


\subsection{Efeito do glicerol}

A determinação de glicerol - em suas concentrações iniciais e finais - foi realizada através da técnica de oxidação do periodato de sódio, e utilizando HPLC (item 2.7.3.5). Os valores experimentais obtidos se encontram na tabela 3.3 a 3.13 .

Dados experimentais obtidos em ensaio em agitador rotatório (tabela 3.2) demonstraram que a presença de glicerol no meio de cultivo parece não promover crescimento celular, mas poderia ter algum efeito significativo sobre as OMVs.

Quando comparados os resultados dos ensaios em biorreator, do grupo E e F (tabela 4.2), observa-se que a produtividade de OMV (Prod.p), é de 6,05 para o grupo F, sem glicerol, e em torno de 7,69 para o grupo E, com glicerol. Convém lembrar que em ambos o lactato e os aminoácidos estão duplicados e a única diferença entre estes grupos é a presença ou ausência de glicerol no meio. Estes resultados, bem como os obtidos em agitador rotatório, demonstram que o glicerol, embora não seja consumido durante o cultivo (tabela 3.10 a 3.12), parece exercer algum efeito sobre as OMVs. Talvez tenha algum efeito de proteção mecânica, ou osmótica, sobre as OMVs formadas e liberadas no meio. Nada a esse respeito foi encontrado na literatura, mas é de conhecimento corrente em laboratórios o uso de glicerol como crioprotetor, por exemplo, no processo de congelamento de bactérias.

Uma outra hipótese para a importância do glicerol no meio de cultura (ERWIN e GOTSCHLICH, 1993) seria que o glicerol poderia ser necessário para manutenção de atividade enzimática das LDHs, enzimas relacionadas com metabolismo de lactato, reduzindo o envenenamento destas por traços de matais.

\subsection{Liberação das vesículas de membrana externa (OMV)}

As vesículas de membrana externa, OMVs, tiveram o início de sua liberação durante a fase lag de crescimento celular, como descrito por Devoe e Gilchrist (1973). Os resultados das curvas representativas de cada grupo estão expressas na figura 4.1.

De acordo com as figuras 3.4 e 3.6, tabelas 3.3 a 3.5 do grupo B, em meio de Catlin sem ferro, é possível observar que a principal liberação de OMV, ocorre quando o lactato se esgota. No grupo C, em meio de Catlin sem ferro com concentração inicial de lactato triplicada, quando ao fim do processo de cultivo ainda há resíduos do lactato, a quantidade de OMV liberada é maior que no grupo B, (Figuras 3.11 e 3.13, tabelas 3.6 a 3.7). No grupo D, 
em meio de Catlin sem ferro, após esgotamento do lactato e aminoácidos, fez-se o pulso com lactato e aminoácidos na $6^{\text {a }}$ hora de cultivo e o valor de OMV liberada ao meio, foi menor que o grupo C, (Figuras 3.17 e 3.19, tabelas 3.8 a 3.9). Já no grupo E, em meio de Catlin sem ferro com concentrações iniciais de lactato e aminoácidos dobradas, os ensaios apresentaram aumento quantitativo de OMV, quando esgotamento total do lactato, (Figuras 3.24 e 3.26, tabelas 3.10 a 3.12). O grupo F, em meio de Catlin sem ferro com concentrações iniciais de lactato e aminoácidos dobradas e sem glicerol, apresentou valor quantitativo de OMV após consumo total do lactato, próximo, porém inferiores ao encontrado no grupo E, (Figuras 3.31 e 3.33 e tabela 3.13 ).

Desde modo, os dados mostram que a liberação de OMV é relevante após início da fase estacionária de crescimento (Figura 4.1) na maior parte dos experimentos, quando o lactato foi exaurido (Figura 4.2).

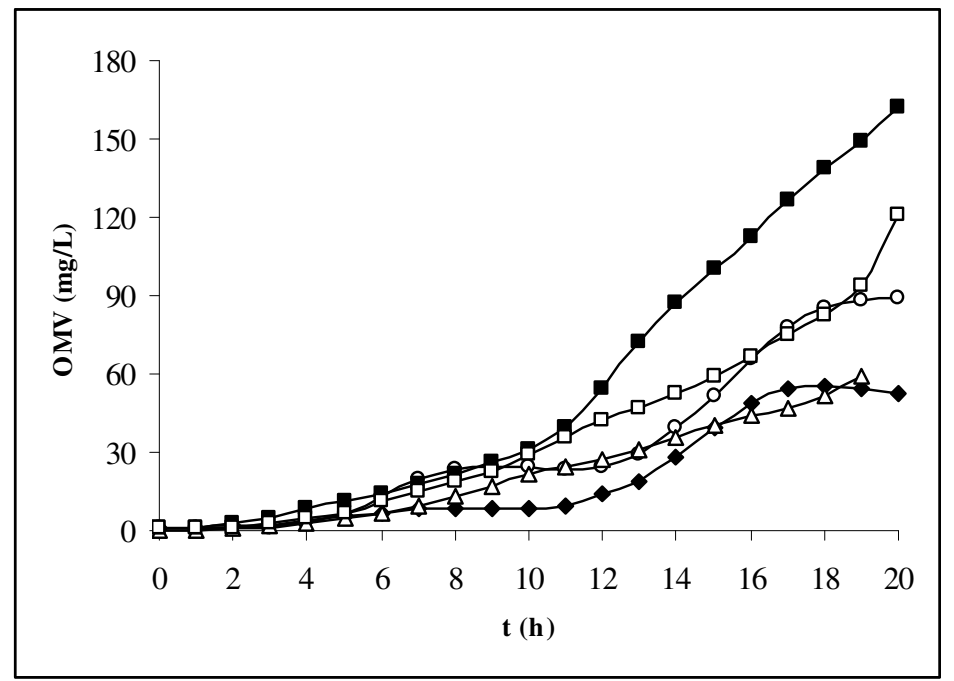

Figura 4.1 - Curvas experimentais suavizadas referentes à concentração de OMV no cultivo em biorreator no período de 20h: $(\diamond)$ grupo B, ensaio 3; ( $)$ grupo C, ensaio 6; grupo D, ensaio 7; (匹) grupo E, ensaio 9; ( $\square$ ) grupo F, ensaio 12. 


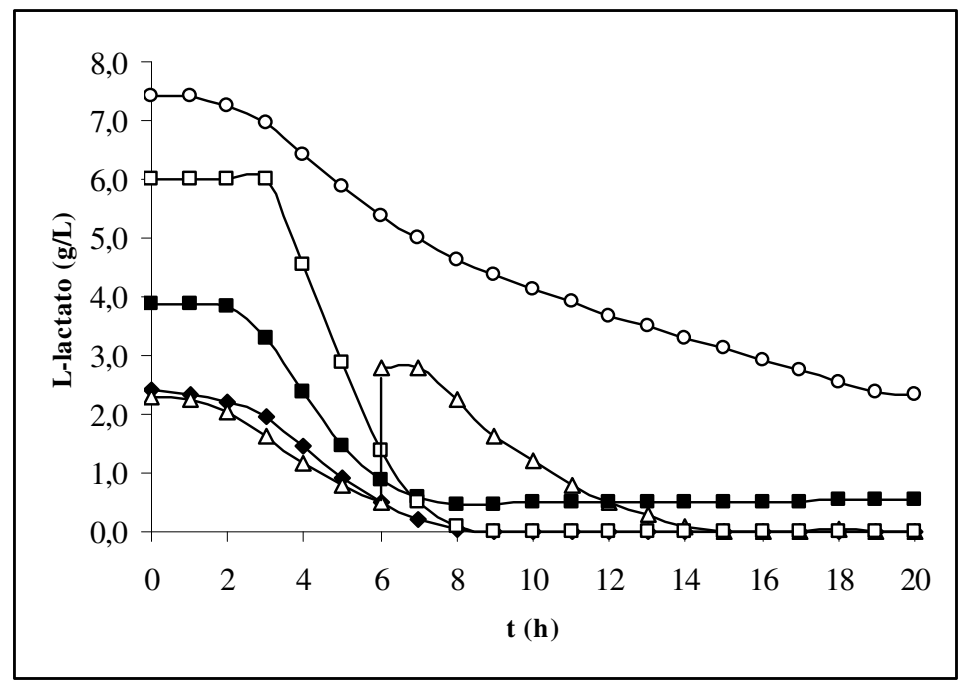

Figura 4.2 - Curvas experimentais referentes à concentração de L-lactato (g/L), no cultivo em biorreator no período de 20h: $(\diamond)$ grupo B, ensaio 3; ( $)$ grupo

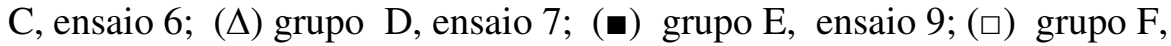
ensaio 12.

\subsection{Efeito do pH}

$\mathrm{O}$ pH do meio é um importante parâmetro no crescimento bacteriano. Segundo Pelczar, Chan e Krieg (1996) a maioria dos microrganismos cresce melhor em valores de $\mathrm{pH}$ entre 6,5 e 7,5. Entretanto muitos microrganismos excretam substâncias ácidas ou alcalinas que podem alterar o pH de seu ambiente, tornando-o desfavorável ao crescimento. Neste caso para manter o pH desejável, normalmente adiciona-se um tampão ao meio de crescimento. Há varias probabilidades de como o $\mathrm{pH}$ pode regular a atividade das vias de Entner-Doudoroff e pentose-fosfato. $\mathrm{O}$ valor do $\mathrm{pH}$ intracelular pode ser influenciado pela concentração externa do $\mathrm{H}^{+}$(MORSE; HEBELER, 1978). Neste trabalho, o $\mathrm{pH}$ do meio em todos os cultivos iniciou-se em 7,4 e elevou-se em média para 8,4 (Tabelas 3.3 a 3.13). A elevação do pH no meio de cultura pode ser atribuída à formação de amônia, determinada através da técnica de cromatografia líquida de alta performance, HPLC. Os valores experimentais de amônia comprovam o aumento quantitativo da formação deste íon no decorrer do cultivo (Tabela 7.3.1 e figura 7.3.1 do anexo 7.3). 


\subsection{Modelo de Luedeking \& Piret na Formação de OMV}

A liberação das vesículas de membrana externa OMVs iniciou durante a fase lag de crescimento celular e a liberação aumenta após o início da fase estacionária, (Tabela 3.3 a 3.13), momento quando se inicia a limitação da principal fonte de carbono (lactato) ou fator limitante de crescimento (Figuras 4.1 e 4.2).

Considerando que somente ocorre formação de produto não-associado ao crescimento, fez-se uma primeira estimativa da constante empírica não-associada $(\beta)$ através da média dos valores das velocidades específicas de formação de produto $\left(\mu_{\mathrm{P}}\right)$ tomadas a partir do início da fase estacionária (HISS, 2001). Os valores obtidos para $\beta$ em cada ensaio estão expressos na tabela 4.4

Tabela 4.4 - Valores da média da velocidade especifica de formação de produto $\left(\mu_{\mathrm{p}}\right)$ e da constante empírica não associada $\beta$.

\begin{tabular}{|c|c|c|c|}
\hline Grupo & Ensaio & $\mathrm{N}^{\circ}$ de pontos & Média de $\mu_{p}=\beta$ \\
\hline \multirow[t]{2}{*}{$\mathbf{A}$} & 1 & ............. & .......... \\
\hline & 2 & 5 & 0,78 \\
\hline \multirow[t]{2}{*}{ B } & 3 & 6 & 2,63 \\
\hline & 4 & 6 & 1,11 \\
\hline \multirow[t]{2}{*}{$\mathrm{C}$} & 5 & 5 & 6,50 \\
\hline & 6 & 5 & 22,85 \\
\hline \multirow[t]{3}{*}{ D } & 7 & 9 & 4,28 \\
\hline & 8 & 6 & 8,99 \\
\hline & 9 & 7 & 22,41 \\
\hline \multirow[t]{2}{*}{$\mathbf{E}$} & 10 & 8 & 25,81 \\
\hline & 11 & 5 & 24,51 \\
\hline $\mathbf{F}$ & 12 & 5 & 16,06 \\
\hline
\end{tabular}

Da mesma forma como já observado na análise dos valores de $\mathrm{P}_{\max }$ e $\mathrm{Y}_{\mathrm{p} / \mathrm{x}}$, observou-se em alguns grupos (especialmente no C) uma grande discrepância entre os valores de $\beta$ obtidos. Deste modo, de acordo dados gerados na tabela 4.2, o grupo E apresentou melhor 
produção de OMV por biomassa e os valores mais altos de concentração de produto final. Além disso, apresentou os maiores valores de $\beta$. Todos os parâmetros calculados indicam que a melhor condição para o meio de cultivo seria aquela onde se manteve a concentração inicial de glicerol, de acordo a indicada no meio de Catlin sem ferro (tabela 2.4), mas que, no entanto, apresenta concentrações iniciais de lactato e aminoácidos dobradas.

\subsection{Presença de IRP e Proteínas nas OMV}

A utilização da técnica de eletroforese SDS-PAGE (item 2.7.3.3) mostrou o padrão protéico das OMVs obtidas ao longo do tempo de cultivo.

Em todos os ensaios, as proteínas de classe, que são proteínas majoritárias das OMVs, estão presentes desde as primeiras horas de cultivo. As proteínas reguladas pelo íon ferro (IRP) e a proteína de alto peso molecular (NadA) são observadas no gel, em geral, após a décima hora de cultivo (Figuras 3.35 a 3.39). A observação das IRPs tardiamente no cultivo é geral para todos os meios de cultura utilizados.

Desta forma, as OMVs obtidas, em todos os meios utilizados, possuem o padrão protéico requerido para sua utilização na vacinas, após a décima hora de cultivo. 


\subsection{Microscopia eletrônica}

A integridade das vesículas foi comprovada através da microscopia eletrônica (Figuras 3.49 a 3.51). Há predominância de vesículas com formas tubulares e também foram observadas vesículas em forma de raquete (Figura 4.3), independentemente das modificações realizadas nas concentrações de alguns componentes do meio de cultura como: lactato de sódio; aminoácidos; glicerol. Este resultado demonstra coerência com os resultados encontrados por Devoe e Gilchrist (1973). Segundo esses autores, Neisseria meningitidis B formam OMVs tubulares com maior freqüência do que as forma esférica (Figura 3.40 a 3.42).

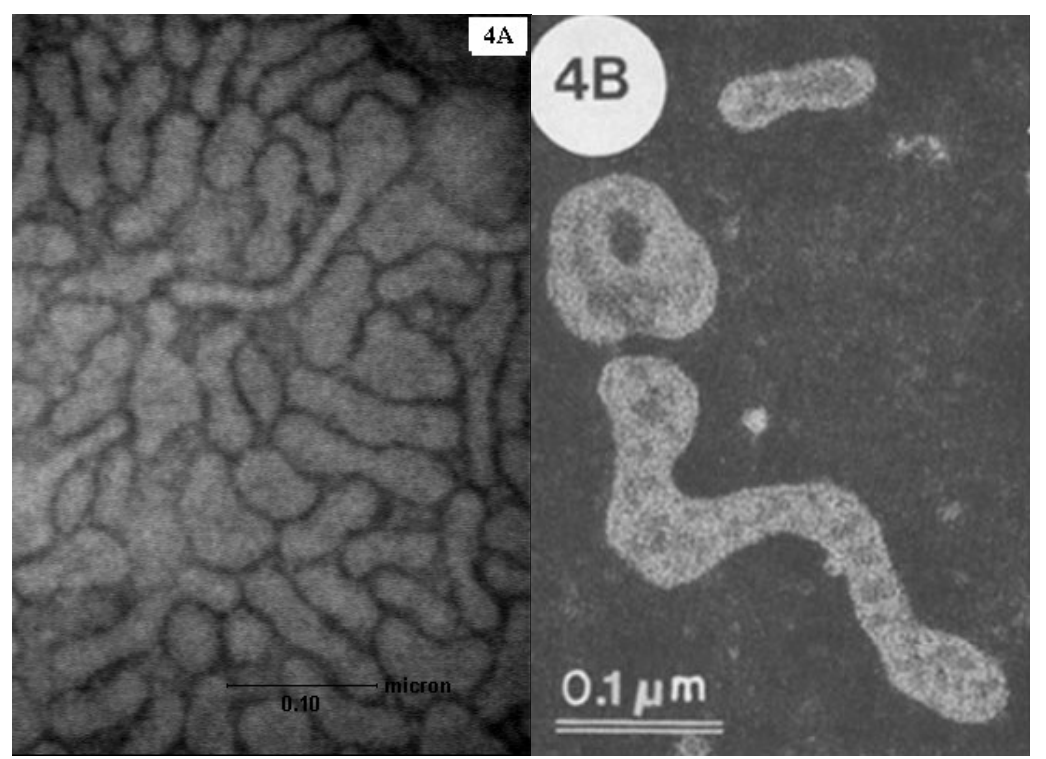

Figura 4.3 - Representação através de microscopia eletrônica das formas de OMV de Neisseria meningitidis sorogrupo B, cepa N.44/89 (Figura 4A) comparado com as OMV de Neisseria meningitidis sorogrupo B, cepa SD1C (Figura 4B) do artigo de Devoe e Gilchrist (1973). 


\section{CONCLUSÃO}

- Com o meio de cultura utilizado foi constatado que o lactato é a principal fonte de carbono;

- O glicerol não foi consumido e sua função no meio de cultura parece ser a de proteção mecânica das OMVs.

- Com o meio de cultura utilizado foi constatado que o ácido L-glutâmico é a principal fonte de nitrogênio;

- A liberação de OMV, em todos os ensaios, ocorre durante a fase lag e durante a fase exponencial, porém, é maior durante a fase estacionária;

- O padrão protéico das OMVs indica que elas possuem todas as proteínas desejáveis para serem utilizadas como antígeno vacinal;

- A melhor condição de rendimento de antígeno, OMV, é representada pelo grupo E, onde o meio de Catlin sem ferro possui o dobro das concentrações de lactato de sódio e aminoácidos em relação ao meio de Catlin original.

\subsection{Perspectivas futuras}

- Estudos para compreensão do comportamento metabólico relacionado ao consumo dos aminoácidos, geração de amônia e produção de OMV.

- Estudo sobre as condições de aeração e importância da concentração de oxigênio, uma vez que todos os experimentos foram realizados sob a mesma concentração de oxigênio no meio. 


\section{REFERÊNCIAS BIBLIOGRÁFICAS}

American Oil Chemistry Society glycerol. Method Ea 6-51. In: OFFICIAL METHODS AND RECOMMENDED PRACTICES OF THE AMERICAN OIL CHEMISTRY SOCIETY. Illinois, 1987, p.6-51.

ARCHIBALD, F.S.; DEVOE, I.N. Expression of Neisseria meningitidis in vitro. Infection and Immunity, v. 27, p. 322-334, 1980.

BARATA, R.C.B. Epidemia de doença meningocócica, 1970/1977. Aparecimento e disseminação do processo epidêmico. Revista de Saúde Pública, v. 22, p.16-24, 1988.

BARUQUE-RAMOS, J. Estudo comparative entre processos descontínuo e descontínuo alimentado na produção de polissacarídeo de Neisseria meningitidis sorogrupo C. 274 f. Tese (Doutorado em Engenharia) - Escola Politécnica, Universidade de São Paulo, São Paulo, 2000.

BARUQUE-RAMOS, J.; HISS, H.; CONVERTI, A.; GONÇALVES, V.M.; RAW, I. Accumulation of organic acids in cultivations of Neisseria meningitidis C. Journal Industrial Microbiol Biotechnol, 2006.

BHATNAGAR, B.N.; FRASCH, C.E. Expression of Neisseria meningitidis iron-regulated outer membrane proteins, including a 70-kilodalton transferring receptor, and their potential for use in vaccines. Infection and Immunity, v. 58, p. 2875-2881, 1990.

BIER, O. Microbiologia e imunologia. 24a . ed. São Paulo: Melhoramentos, 1985. p. 539 e 985 .

BLACK, J.R.; DYER, D.W.; THOMPSON, M.K.; SPARLING, F. Human immune response to iron-repressible outer membrane proteins of Neisseria meningitidis. Infection and Immunity, v.54, p. 710-713, 1986.

* ASSOCIAÇÃO BRASILEIRA DE NORMAS TÉCNICAS. NBR 6023: Informação e documentação: referências: elaboração. Rio de Janeiro, 2002. 
BORROW, R.; AABERGE, I.S.; SANTOS, G.F.; EUDEY, T.L.; OSTER, P.; GLENNIE, A.; FINDLOW, J.; HØIBY, E.A.; ROSENQVIST, E.; BALMER, P.; MARTIN, D. Interlaboratory standardization of the measurement of serum bactericidal activity by using human complement against meningococcal serogroup B, strain 44/76-SL, before and after vaccination with the Norwegian Menbvac outer membrane vesicle vaccine. Clinical and Diagnostic Laboratory Immunology, v.12, n. 8, p. 970-976, 2005.

BOSLEGO, J.; GARCIA, J.; CRUZ, C.; ZOLLINGER, W.; BRANDT, B.; RUIZ, S.; MARTINEZ, M.; ARTHUR, J.; UNDERWOOD, P.; SILVA, W.; MORAN, E.; HANKINS, W.; GILLY, J. MAYS, J. Efficacy, safety, and immunogenicity of a meningococcal group B (15:p1.3) outer membrane protein vaccine in Iquique, Chile. Vaccine, v. 13, n. 9, p. 821-829, 1995.

BRANDILEONE, M.C.C.; ZANELLA, R.C.; VIEIRA, V.S.D.; SACCHI, C.T.; MILAGRES, L.G.; FRASCH, C.E. Indution of iron regulated during normal growth of Neisseria meningitidis in a chemically defined medium. Revista do Instituto de Medicina Tropical de São Paulo, v. 36, n. 4, p. 301-310, 1994.

BULLEN, J.J. The significance of iron in infection. Journal of Infectious Diseases, v.3, p. 1127-1138, 1981.

CAPECCHI, B.; ADU-BOBIE, J.; DI MARCELLO, F.; CIUCCHI, L.; MASIGNANI, V.; TADDEI, A.; RAPPUOLI, R.; PIZZA, M.; ARICÓ, B. Neisseria meningitidis NadA is a new invasin which promotes bacterial adhesion to and penetration into human epithelial cells. Molecular Microbiology, v. 55, n. 3, p. 687-698, 2005.

CATLIN, B.W. Nutritional profiles of Neisseria lactamica, gonorrhoeae and meningitidis, in chemically defined media and the use of growth requirements for gonococcal typing. Journal of Infectious Diseases, v. 128, n. 2, p. 178-194, 1973.

CAUGANT, D.A.; FROHOLM, L.O.; BOVRE, K.; HOLTRN, E., FRASCH, C.E.; MOCCA, L.F.; ZOLLINGER, W.D.; SELANER, R.K. Intercontinental spread of a genetically distinctive complex of clones of Neisseria meningitidis causing epidemic disease. Proc. Natl. Acad. Sci. USA., v. 83, p. 4927-4931, 1986.

CENTRO DE VIGILÂNCIA EPIDEMIOLÓGICA 2006. Boletim Epidemiológico Paulista. Disponível em: www.cve.saude.sp.gov.br. Acesso em: setembro/2006.

CLAASSEN, I.; MEYLIS, J.; VAN DER LEY, P.; PEETERS, C.; BRONS, H.; ROBERT, J.; BORSBOOM, D.; VAN DER ARK, A.; VAN STRAATERN, I.; ROHOLL, P.; KUIPERS, B.; POOLMAN, J. Production, characterization and control of a Neisseria meningitidis 
hexavalent class 1 outer membrane protein containing vesicle vaccine. Vaccine, v. 14, n. 10, p. 1001-1008, 1996.

COMANDUCCI, M.; BAMBINI, S.; BRUNELLI, B.; ADU-BOBIE, J.; ARICÓ, B.; CAPECCHI, B.; GIULIANI, M.M.; MASIGNANI, V.; SANTINI, L.; SAVINO, S.; GRANOFF, D.M.; CAUGANT, D.A.; PIZZA, M.; RAPPUOLI, R.; MORA, M. NadA, a novel vaccine candidate of Neisseria meningitidis. The Journal of Experimental Medicine, v. 195, n. 11, p. 1445-1454, 2002.

CORRÊA, A.P. Estudo da formulação da vacina anti-meningocócica polissacarídeo C, conjugada a vesícula de membrana externa B de Neisseria meningitidis. 49 f. Dissertação (Mestrado em Biotecnologia) - Instituto de Ciências Biomédicas, Universidade de São Paulo, São Paulo, 2002.

DE VOE, I. W.; GILCHRIST, J.E. Release of endotoxin in the form of cell wall blebs during in vitro growth of Neisseria meningitidis. The Journal of Experimental Medicine, v. 138, p. 1156-1167, 1973.

DIFCO LABORATORIES. Difco Manual. 10 Editora Detrit, Difco, 1984. p.582-584.

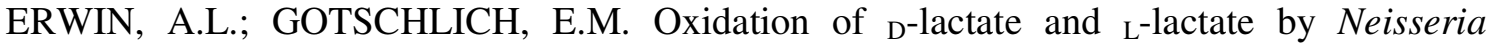
meningitidis: Purification and cloning of meningococcal $\mathrm{D}^{-}$-lactate dehidrogenase. Journal of Bacteriology, v.175, n. 20, p. 6382-6391, 1993.

ERWIN, A.L.; GOTSCHLICH, E.M. Cloning of a Neisseria meningitidis gene for L-lactate dehydrogenase $\left(\mathrm{L}_{\mathrm{L}} \mathrm{LDH}\right)$ : evidence for a second meningococcal ${ }_{\mathrm{L}}-\mathrm{LDH}$ with different regulation. Journal of Bacteriology, v.178, p. 4807-4813, 1996.

ETCHART, N.; BAATEN, B.; ANDERSEN, S.R.; HYLAND,L.; WONG, S. Y. C.; HOU, S. Intranasal immunisation with inactivated RSV and bacterial adjuvants indues mucosal protection and abrogates eosinophilia upon challenge. Eur. Journal Immunology, v. 36, p. 1136-1144, 2006.

EVANS, R.Transferrins and their interactions with mammalian and bacterial receptors. Disponível em: http://www.kcl.ac.uk/.../nutritional/staff/revans.html. Acesso em: 21 abr. 2007.

FLETCHER, L.D.; BERNFIELD, L.; BARNIAK, V.; FARLEY, J.E.; HOWELL, A.; KNAUF, M.; OOI, P.; SMITH, R.P.; WEISE, P.; WETHERELL, M.; XIE, X.; ZAGURSKY, R.; ZHANG, Y.; ZLOTNICK, G.W. Vaccine potential of the Neisseria meningitidis 2086 lipoprotein. Infection and Immunity, v. 72, n. 4, p. 2088-2100, 2004. 
FOCACCIA, R. Meningites Bacterianas. In: VERONESI, R.; FOCACCIA, R. Tratado de Infectologia. São Paulo: Editora Atheneu, 1996. p. 805-831.

FRASCH, C.E. Meningococcal Vaccines: past, present and future. In: CARTWRIGHT K. Meningococcal Disease. Chichester, UK: Wiley, p. 246-283, 1995.

FRASCH, C.E.; GOTSCHLICH, E.C. An membrane protein of Neisseria meningitidis group B responsible for serotype specificity. The Journal of Experimental Medicine, v. 140, p. 87-104, 1974.

FRASCH, C.E.; PEPPLER, M.S. Protection against group B Neisseria meningitidis disease: Preparation of soluble protein and protein-polysaccharide immunogens. Infection and Immunity, v. 37, n. 1, p. 271-280, 1982.

FRASCH, C.E.; VAN ALPHEN, L.; HOLST, J.; POOLMAN, J.T.; ROSENQVIST, E. Outer membrane protein vesicle vaccines for meningococcal disease. In: POLLARD, A.J.; MAIDEN, M.C.J. Methods in Molecular Medicine. Totowa: Humana Press, v. 66, p. 81107, 2001.

FRASCH, C.E.; ZAHRADNK, J.M.; WANG, L.Y.; MOCCA, L.F.; TSAI, C.M. Antibody response of adults to an aluminum hydroxide-adsorbed Neisseria meningitidis serotype $2 b$ protein-group B polysaccharide vaccine. Journal of Infectious Diseases, v. 158, p. 710-718, 1988.

FREDRIKSEN, J.H.; ROSENQVIST, E.; WEDEGE, E.; BRYN, K.; BJUNE, G.; FROHOLM, L.O.; LINDBAK, A.K.; MOGSTER, B.; NAMORK, E.; RYE, U.; STABBETORP, G.; WINSES, R.; AASE, B.; CLOSS, O. Production, characterization snd control of MenB-Vaccine "Folkehelsa": an outer membrane vesicle vaccine against group B meningococcal disease. NIHP Ann., v. 14, p. 67-80, 1991.

FREDRIKSEN, J.H.; SCIORTINO, C.V. \& MCINTOSH, M.A. Role of iron in microbe-host interactions. Journal of Infectious and Disease, 5: 5759-5777, 1983.

FU, J.; BAILEY, J.; KING, J.J.; PARKER, C.B.; ROBINETT, R.; KOLODIN, D.G.; GEORGE, H.A.; HERBER, W.K. Recent advancein the large scale fermentation of Neisseria meningitidis group $\mathrm{B}$ for the production of an outer membrane protein complex. Bio/technology, v. 13, p. 170-174, 1995. 
FUKASAWA, L.O. Desenvolvimento de uma vacina conjugada natimeningocócica sorogrupos B/C. 152 f. Tese (Doutorado em Biotecnologia) Instituto de Ciências Biomédicas, Universidade de São Paulo, São Paulo, 2004.

FUKASAWA, L.O. Obtenção e avaliação imunológica de vacina conjugada antimeningocócica sorogrupos B e C. 103 f. Dissertação (Mestrado em Biotecnologia) Instituto de Ciências Biomédicas, São Paulo, 2002.

GIRARD, M.P.; PREZIOSI, M-P.; AGUADO, M-T.; KIENY, M.P. Areview of vaccine research and development: meningococcal disease. Vaccine, v. 24, p. 4692-4700, 2006.

GIULIANI, M.M.; ADU-BOBIE, J.; COMANDUCCI, M.;ARICÓ, B.;SAVINO, S.;SANTINI, L.; BRUNELLI, B.;BAMBINI, S.; BIOLCHI, A.; CAPECCHI, B.; CARTOCCI, E.; CIUCCHI, L.; DI MARCELLO, F.;FERLICCA, F.; GALLI, B.; LUZZI, E.; MASIGNANI, V.; SERRUTO, D.; VEGGI, D.; CONTORNI, M.; MORANDI, M.; BARTALESI,A.; CINOTTI, V.; MANNUCCI, D.;TITTA, F.; OVIDI, E.;WELSCH, J.A.; GRANOFF, D.; RAPPUOLI, R.;PIZZA, M. A universal vaccine for serogroup B meningococcus. PNAS, v. 103, n. 29, p. 10834-10839, 2006.

GOMBERT, A. K. Produção de troponina C em Escherichia coli: estudo da indução por lactose e obtenção de alta concentração celular. São Paulo, 134 f. Dissertação (Mestrado) Escola Politécnica, Universidade de São Paulo, 1996.

GOMES, S.L.; SILVA, M.B.; RIBAS, J.C.; RUGAI, E.; AMOROSINO, A.; CAVE, J.J.D. Meningite cerebrospinal e sulfamidação maciça, preventiva. Revista Instituto Adolfo Lutz, v. 10, p. $77-85,1950$.

HISS, H. Cinética de processos fermentativos. In: SCHMIDELL, W.; LIMA, U. A.; AQUARONE, E.; BORZANI, W. Biotecnologia Industrial: Engenharia Bioquímica. São Paulo: Editora Edgard Blücher, 2001. V. 2, cap. 6, p. 93-122.

HOLBEIN, B.E. Differences in virulence for mice between disease and carrier strains of Neisseria meningitidis. Canad. J. Microbiol., v. 27, p. 738-741, 1981.

IVERSSON, L.B. Aspectos epidemiológicos da meningite meningocócica no município de São Paulo (Brasil) no período de 1968 a 1974. Revista de Saúde Pública, v. 10: p. 1-16, 1976.

JÓDAR, L.; FEAVERS, I.M.; SALLSBURRY, D.; GRANOFF, D.M. DEVELOPMENT OF VACCINES AGAINST MENINGOCOCCAL DISEASE. Lancet, v. 357, n. 9316, p. 4199$1508,2002$. 
JOHNSTON, K.H.; GOTSCHLICH, E.C. Isolation and characterization of the outer membrane of Neisseria gonorrhoeae. Journal of Bacteriology, v. 119, n. 1, p. 250-257, 1974.

KAHANER, D.; MOLER, C.; NASH, S. Numerical methods and software. Editora Englewood Cliffs, Prentice Hall, 1989.

LEIGHTON, M.P.; KELLY, D.J.; WILLIAMSON, M.P.; SHAW, J.G. An NMR and enzyme study of the carbon metabolism of Neisseria meningitidis. Microbiology, v. 147, p. 14731482, 2001.

LOWRY, O.H.; ROSEBROUGH, N.J.; FARR, A.L.; RANDALL, R.J. Protein measurement with the Folin phenol reagent. Journal of Biology Chemistry, v.193, p. 265-275, 1951.

LUEDEKING, R.; PIRET, E.L. A kinetic study of the latic acid fermentation. Batch process at controlled $\mathrm{pH}$. Batch process at controlled $\mathrm{pH}$. Journal Biochemistry Microbiology Tecnology Engineering, v.1, p. 393, 1959.

MAZZA, C.C.; GALVÃO, P.A.A.; FOCACCIA, R. Doença meningocócica. In: VERONESI, R. Doenças Infecciosas e Parasitárias. 8. ed. Rio de Janeior: Guanabara Koogan, 1991. p. 498-505.

MILAGRES, L.G.; GORLA, M.C.O; SACCHI, C.T.; RODRIGUES, M.M. Specificity of bactericidal antibody response to serogrup B meningococcal strains in brazilian children after immunization with an outer membrane vaccine. Infection and Immunity, v. 66, n. 10, p. 4755-4761, 1998.

MILAGRES, L.G.; RAMOS, S.R.; SACCHI, C.T., MELLES, C.E.A.; VIEIRA, V.S.D.; SATO, H.; BRITO, G.S.; MORAES, J.C.; FRASCH, C.E. Immune response of brazilian children to a Neisseria meningitidis serogroup B outer membrane protein vaccine: comparison with efficacy. Infection and Immunity, v. 62, n. 10, p. 4419-4424, 1994.

MORSE, S.A.; HEBELER B.H. Effect of $\mathrm{pH}$ on the growth and glucose metabolism of Neisseria gonorrhoeae. Infection and Immunity, v. 21, p. 87-95, 1978.

MORAES, J.C.; PERKINS, B.A.; CAMARGO, M.C.C.; HIDALGO, N.T.R.; BARBOSA, H.A.; SACCHI, C.T.; GRAL, I.M.L.; GATTAS, V.L.; VASCONCELOS, H.G.; PLIKAYTIS, B.D.; WENGER, J. D.; BROOME, C.V. Protective efficacy of a serogroup B meningococcal vaccine in São Paulo, Brazil. Lancet, v. 340, p. 1074-1078, 1992. 
MORLEY, S.L.; POLLARD, A.J. Vaccine prevention of meningococcal disease, coming soon? Vaccine, v. 20, p. 666-687, 2002.

MÜLLER, H.; HINTON, J.A. A protein-free medium for primary isolation of the gonococcus and meningococcus. Proc. Soc. Exp. Biol. Med., 48: 330, 1941.

NEW BRUNSWICK. Bioflo 2000 User's Guide. Edison, NJ, 1996.

NORONHA, C.P.; STRUCHINER, C.J.; HALLORAN, M.E. Assessment of the direct effectiveness of BC meningococcal vaccine in Rio de Janeiro, Brazil: a case-control study. International Journal Epidemiology, v. 24, p. 1050-1057, 1995.

PAZ, M.F. Influência da composição do meio de cultura sobre as produtividades em polissacarídeo da Neisseria meningitidis sorogrupo $\mathrm{C}$ cultivada em processo descontínuo submerse. 71 f. Dissertação (Mestrado em Biotecnologia) - Instituto de Ciências Biomédicas, Universidade de São Paulo, São Paulo, 1997.

PAZ, M.F.; BARUQUE-RAMOS, J.; HISS, H.; VICENTIN, M.A.; LEAL, M.B.B.; RAW, I. Polysaccharide prodution in batch processo f Neisseria meningitidis serogroup $\mathrm{C}$ comparing Franz, modified Franz and Catlin 6 cultivation media. Brazilian Journal of Microbiology, v.34, p. 27-32, 2003.

PELCZAR Jr. M.J.; CHAN, E.C.S.; KRIEG, N.R. Microbiologia I: Conceitos e Aplicações. $2^{a}$ ed. São Paulo. Makron Books, 1996. p. 301.

PETTERSSON-FERNHOLM, A.M. Caracterization of two iron-regulated outer membrane proteins, the lactoferrin receptor and FrpB, of Neisseria meningitidis. $113 \mathrm{f}$. Tese (Ph.Tthesis) - Utrecht: Universiteit Utrecht, Faculteit Biologie, 1994.

PIRT, J. Principles of microbe and cell cultivation. New York, John Wiley, 1975.

POLLARD, A.J.; FRASCH, C.E. Development of natural immunity of Neisseria meningitidis. Vaccine, v. 19, p. 1327-1346, 2001.

POLLARD, A.J.; MOXON, E.R. The meningococcus tamed? Arch. Dis. Child, v. 87, p. 1317, 2002. 
POOLMAN, J.T. Development of a meningococcal vaccine. Infectious Agents and Disease, v. 4, p. 13-28, 1995.

POOLMAN, J.T. Polysaccharides and membrane vaccines. In: NIZRAHI, A. Bacterial vaccines. New York: Wiley-Liss, 1990. p. 57-86.

SAMASEGARAN, P.; HODBEN, H.J. Methodos in legume Rhizobium technology Hawai, University of Hawai, 1985. 367 p.

SAMBROOK, J.; FRITSCH, E. F.; MANIATIS, T. Molecular cloning: A laboratory manual. USA: Cold Spring Harbour Laboratory Press, 1989. 3 vol.

SANTOS, S.; BARUQUE-RAMOS, J.; TANIZAKI, M.M.; LEBRUN, I.; SCHENKMAN, R.P.F. Production of outer membrane vesicles (OMV) in batch cultivation of Neisseria meningitidis serogroup B. Brazilian Journal of Microbiology, v. 37, p. 488-493, 2006.

SCHENKMAN, R.P.F.; VASSOLER, U.M.; MOME, C.M.P. Produção de vacina contra meningite B. In: REUNIÃO ANNUAL DO INSTITUTO BUTANTAN, 58, 2001, São Paulo. Resumo... Memorias do Instituto Butantan, 2001, p. 23.

SIMÕES, D.A.; URIBELARREA, J.L.; ARROYO, G. Lissage software para tratamento de dados de fermentação. Desenvolvido no IPT - São Paulo, 1992.

Site: htt:// http://images.google.com.br/images?hl=pt-R\&q=n.+meningitidis\&gbv=2. Acesso em: jun. de 2006.

SMITH, H.; YATES, E.A.; COLE, J.A.; PARSONS, N.J. Lactate Stimulation of Gonococcal Metabolism in Media Containing Glucose: mechanism, Impact on Pathogenicity, and Wider Implications for Other Pathogens. Infection and Immunity. v. 69, n. 11, p. 6565-6572, 2001.

TETTILIN, H.; SAUDERS, N.J.; HEIDELBERG, J.; JEFFRIES, A.C.; NELSON, K.E.; EISEN, J.A.; KETCHUM, K.A.; HOOD, D.W.; PEDEN, J.F.; DODSON, R.J.; NELSON, W.C.; GWINN, M.L.; DEBOY, R.; PETERSON, J.D.;HICKEY, E.; HALF, D.B.; SALZBERG, S.L.; WHITE, O.; PARKSEY, D.S.; BLAIR, E.; CITTONE, H.; CLARK, E.B.; COTTON, M.D.; SCARLATO, V.; MASIGNANI, V.; PIZZA, M.; GRANDI, G.; SUN, L.; SMITH, H.O.; FRASER, C.M.; MOXON, E.R.; RAPPUOLI, R.; VENTER, J.C. Complete genome sequence of Neisseria meningitidis serogrupo B strain MC58. Science, v. 287, n. 10, p. 1809-1815, 2000. 
URENHA, L.C.; PRADELLA, J.G.C.; RODRIGUES, M.F.A. Esterilização do equipamento. In: SCHMIDELL, W.; LIMA, U. A.; AQUARONE, E.; BORZANI, W. Biotecnologia Industrial: Engenharia Bioquímica. São Paulo: Editora Edgard Blücher, 2001. V. 2, cap. 6, p. 93-122.

ZOLLINGER, W.D. New and improved vaccines against meningococcal disease. In: WOODROW, G.L.; KAPER, J.B.; COBON, G.S. New generation of vaccines. New York: Marcel Dekker, 1997. p. 469-488. 


\section{ANEXOS}

Anexo 7.1: Tabelas resultados suavizados 
Tabela 7.1.1 - Resultados suavizados do ensaio 2, em meio Catlin sem ferro, grupo B, durante $20 \mathrm{~h}$ de cultivo.

\begin{tabular}{|c|c|c|c|c|c|c|c|c|c|c|}
\hline Tempo (h) & DO suav & $X \operatorname{suav}(g / L)$ & S suav (g/L) & P suav (mg/L) & dX/dt (g/L.h) & (-dS/dt) (g/L.h) & dP/dt (mg/L.h) & $\mu \mathrm{x}\left(\mathrm{h}^{-1}\right)$ & $\mu s$ (g/g.h) & $\mu p(\mathrm{mg} / \mathrm{g} . \mathrm{h})$ \\
\hline 0 & 0,100 & 0,047 & 2,780 & ….............. & 0,0050 & $\ldots \ldots$ & …............. & 0,05 & $\ldots \ldots$ & ….............. \\
\hline 1 & 0,179 & 0,084 & 2,780 & ................ & 0,1663 & 0,0000 & ................ & 0,93 & 0,00 & ............... \\
\hline 2 & 0,537 & 0,252 & 2,546 & .............. & 0,4785 & 0,4370 & .............. & 0,89 & 0,11 & .............. \\
\hline 3 & 0,916 & 0,431 & 1,935 & ............. & 0,2911 & 0,7216 & ............. & 0,32 & 0,31 & .............. \\
\hline 4 & 1,156 & 0,543 & 1,283 & ............... & 0,1929 & 0,5737 & ................ & 0,17 & 0,31 & .............. \\
\hline 5 & 1,318 & 0,619 & 0,836 & ................ & 0,1328 & 0,3467 & ................ & 0,10 & 0,21 & ................ \\
\hline 6 & 1,426 & 0,670 & 0,516 & .............. & 0,0846 & 0,2944 & .............. & 0,06 & 0,20 & .............. \\
\hline 7 & 1,492 & 0,701 & 0,220 & 4,200 & 0,0500 & 0,2769 & $-0,3375$ & 0,03 & 0,19 & $-0,24$ \\
\hline 8 & 1,528 & 0,718 & 0,033 & 4,265 & 0,0233 & 0,1073 & 0,4506 & 0,02 & 0,08 & 0,32 \\
\hline 9 & 1,540 & 0,724 & $-0,016$ & 5,143 & 0,0034 & 0,0026 & 1,2075 & 0,00 & 0,00 & 0,87 \\
\hline 10 & 1,542 & 0,725 & $-0,012$ & 6,108 & $-0,0005$ & $-0,0083$ & 0,8200 & 0,00 & $-0,01$ & 0,59 \\
\hline 11 & 1,543 & 0,725 & 0,000 & 7,079 & 0,0013 & $-0,0020$ & 1,1589 & 0,00 & 0,00 & 0,84 \\
\hline 12 & 1,492 & 0,701 & $-0,001$ & 8,501 & $-0,0342$ & $-0,0031$ & 1,7227 & $-0,02$ & 0,00 & 1,25 \\
\hline 13 & 1,519 & 0,714 & 0,000 & 10,713 & $-0,0210$ & 0,0001 & 2,6809 & $-0,01$ & 0,00 & 1,94 \\
\hline 14 & 1,535 & 0,721 & 0,000 & 14,430 & $-0,0109$ & 0,0003 & 4,5095 & $-0,01$ & 0,00 & 3,25 \\
\hline 15 & 1,542 & 0,725 & 0,000 & 19,240 & $-0,0038$ & 0,0001 & 4,8650 & 0,00 & 0,00 & 3,47 \\
\hline 16 & 1,544 & 0,725 & 0,000 & 23,507 & 0,0002 & 0,0000 & 3,5427 & 0,00 & 0,00 & 2,48 \\
\hline 17 & 1,450 & 0,681 & 0,000 & 26,073 & $-0,0503$ & 0,0000 & 1,4623 & $-0,03$ & 0,00 & 1,00 \\
\hline 18 & 1,384 & 0,650 & 0,000 & 25,000 & $-0,0752$ & 0,0000 & $-2,4726$ & $-0,05$ & 0,00 & $-1,61$ \\
\hline 19 & 1,310 & 0,616 & 0,000 & 23,400 & $-0,0620$ & 0,0000 & 0,4086 & $-0,05$ & 0,00 & 0,25 \\
\hline 20 & 1,280 & 0,602 & 0,000 & ............ & 0,0122 & 0,0000 & ............ & 0,01 & 0,00 & 0,00 \\
\hline
\end{tabular}


Tabela 7.1.2 - Resultados suavizados do ensaio 3, em meio Catlin sem ferro, grupo B, durante $20 \mathrm{~h}$ de cultivo.

\begin{tabular}{|c|c|c|c|c|c|c|c|c|c|c|}
\hline Tempo (h) & DO suav & $X \operatorname{suav}(g / L)$ & S suav (g/L) & P suav (mg/L) & dX/dt (g/L.h) & (-dS/dt) (g/L.h) & dP/dt (mg/L.h) & $\mu \mathrm{x}\left(\mathrm{h}^{-1}\right)$ & $\mu \mathrm{s}$ (g/g.h) & $\mu p(\mathrm{mg} / \mathrm{g} . \mathrm{h})$ \\
\hline 0 & 0,088 & 0,041 & 2,400 & 0,531 & 0,0306 & 0,0125 & 0,4083 & 0,35 & 0,00 & 0,02 \\
\hline 1 & 0,130 & 0,061 & 2,345 & 1,153 & 0,0919 & 0,0982 & 0,7555 & 0,70 & 0,01 & 0,05 \\
\hline 2 & 0,429 & 0,202 & 2,217 & 1,746 & 0,4522 & 0,1744 & 0,5028 & 1,05 & 0,04 & 0,10 \\
\hline 3 & 0,851 & 0,400 & 1,938 & 2,269 & 0,3796 & 0,3750 & 0,6466 & 0,45 & 0,15 & 0,26 \\
\hline 4 & 1,123 & 0,528 & 1,467 & 3,431 & 0,1753 & 0,5379 & 1,5813 & 0,16 & 0,28 & 0,83 \\
\hline 5 & 1,223 & 0,575 & 0,931 & 5,272 & 0,0373 & 0,5151 & 1,9696 & 0,03 & 0,30 & 1,13 \\
\hline 6 & 1,230 & 0,578 & 0,494 & 7,008 & $-0,0183$ & 0,3613 & 1,4798 & $-0,01$ & 0,21 & 0,86 \\
\hline 7 & 1,213 & 0,570 & 0,203 & 8,149 & $-0,0161$ & 0,2228 & 0,8183 & $-0,01$ & 0,13 & 0,47 \\
\hline 8 & 1,197 & 0,563 & 0,048 & 8,457 & $-0,0167$ & 0,0958 & $-0,0692$ & $-0,01$ & 0,05 & $-0,04$ \\
\hline 9 & 1,178 & 0,554 & $-0,002$ & 8,210 & $-0,0214$ & 0,0138 & $-0,2563$ & $-0,02$ & 0,01 & $-0,14$ \\
\hline 10 & 1,156 & 0,543 & $-0,005$ & 8,283 & $-0,0214$ & $-0,0055$ & 0,5719 & $-0,02$ & 0,00 & 0,31 \\
\hline 11 & 1,149 & 0,540 & $-0,001$ & 9,777 & $-0,0068$ & $-0,0024$ & 2,4875 & $-0,01$ & 0,00 & 1,34 \\
\hline 12 & 1,092 & 0,513 & 0,000 & 13,641 & $-0,0972$ & 0,0000 & 5,0475 & $-0,09$ & 0,00 & 2,59 \\
\hline 13 & 0,980 & 0,461 & 0,000 & 19,138 & $-0,1259$ & 0,0002 & 6,1357 & $-0,13$ & 0,00 & 2,83 \\
\hline 14 & 0,864 & 0,406 & 0,000 & 27,916 & $-0,1301$ & 0,0000 & 10,7651 & $-0,15$ & 0,00 & 4,37 \\
\hline 15 & 0,616 & 0,289 & 0,000 & 39,086 & $-0,3203$ & 0,0000 & 11,0929 & $-0,52$ & 0,00 & 3,21 \\
\hline 16 & 0,358 & 0,168 & 0,000 & 49,137 & $-0,1989$ & 0,0000 & 8,5274 & $-0,56$ & 0,00 & 1,43 \\
\hline 17 & 0,225 & 0,106 & 0,000 & 54,123 & $-0,0753$ & 0,0000 & 2,0987 & $-0,33$ & 0,00 & 0,22 \\
\hline 18 & 0,185 & 0,087 & 0,000 & 55,156 & $-0,0143$ & 0,0000 & 0,0401 & $-0,08$ & 0,00 & 0,00 \\
\hline 19 & 0,180 & 0,085 & 0,000 & 54,648 & $-0,0035$ & 0,0000 & $-1,2968$ & $-0,02$ & 0,00 & $-0,11$ \\
\hline 20 & 0,161 & 0,076 & 0,000 & 52,079 & $-0,0429$ & 0,0000 & $-4,0827$ & $-0,27$ & 0,00 & $-0,31$ \\
\hline
\end{tabular}


Tabela 7.1.3 - Resultados suavizados do ensaio 4, em meio Catlin sem ferro, grupo B, durante 20 h de cultivo.

\begin{tabular}{|c|c|c|c|c|c|c|c|c|c|c|}
\hline Tempo (h) & DO suav & $X \operatorname{suav}(g / L)$ & S suav (g/L) & P suav (mg/L) & dX/dt (g/L.h) & (-dS/dt) (g/L.h) & dP/dt (mg/L.h) & $\mu \mathrm{x}\left(\mathrm{h}^{-1}\right)$ & $\mu \mathrm{s}$ (g/g.h) & $\mu p(\mathrm{mg} / \mathrm{g} . \mathrm{h})$ \\
\hline 0 & 0,190 & 0,089 & 2,485 & 1,338 & 0,0504 & $-0,0163$ & ........... & 0,27 & 0,00 & .......... \\
\hline 1 & 0,214 & 0,101 & 2,504 & 1,338 & 0,1044 & $-0,0041$ & 0,4375 & 0,49 & 0,00 & 0,04 \\
\hline 2 & 0,423 & 0,199 & 2,452 & 1,649 & 0,2985 & 0,1186 & 0,2663 & 0,71 & 0,02 & 0,05 \\
\hline 3 & 0,839 & 0,394 & 2,228 & 2,034 & 0,4656 & 0,3183 & 0,5850 & 0,55 & 0,13 & 0,23 \\
\hline 4 & 1,121 & 0,527 & 1,828 & 3,109 & 0,1336 & 0,4628 & 1,5032 & 0,12 & 0,24 & 0,79 \\
\hline 5 & 1,196 & 0,562 & 1,348 & 5,245 & 0,0264 & 0,4849 & 2,5399 & 0,02 & 0,27 & 1,43 \\
\hline 6 & 1,205 & 0,566 & 0,879 & 7,243 & $-0,0024$ & 0,4391 & 1,5137 & 0,00 & 0,25 & 0,86 \\
\hline 7 & 1,204 & 0,566 & 0,520 & 8,385 & $-0,0007$ & 0,2896 & 0,8262 & 0,00 & 0,16 & 0,47 \\
\hline 8 & 1,203 & 0,565 & 0,266 & 9,008 & $-0,0007$ & 0,2165 & 0,4587 & 0,00 & 0,12 & 0,26 \\
\hline 9 & 1,203 & 0,565 & 0,094 & 9,283 & 0,0007 & 0,1281 & 0,1856 & 0,00 & 0,07 & 0,10 \\
\hline 10 & 1,213 & 0,570 & 0,015 & 9,671 & 0,0018 & 0,0388 & 0,6186 & 0,00 & 0,02 & 0,35 \\
\hline 11 & 1,208 & 0,568 & $-0,003$ & 10,580 & 0,0067 & 0,0019 & 1,2305 & 0,01 & 0,00 & 0,70 \\
\hline 12 & 1,208 & 0,568 & $-0,002$ & 12,356 & $-0,0140$ & $-0,0030$ & 2,1773 & $-0,01$ & 0,00 & 1,24 \\
\hline 13 & 1,174 & 0,552 & 0,000 & 14,111 & $-0,0469$ & $-0,0008$ & 1,4633 & $-0,04$ & 0,00 & 0,81 \\
\hline 14 & 1,137 & 0,535 & 0,000 & 15,778 & $-0,0298$ & 0,0001 & 1,8686 & $-0,03$ & 0,00 & 1,00 \\
\hline 15 & 1,104 & 0,519 & 0,000 & 17,846 & $-0,0384$ & 0,0001 & 2,2664 & $-0,03$ & 0,00 & 1,18 \\
\hline 16 & 1,066 & 0,501 & 0,000 & 20,033 & $-0,0414$ & 0,0000 & 2,2543 & $-0,04$ & 0,00 & 1,13 \\
\hline 17 & 1,014 & 0,477 & 0,000 & 22,421 & $-0,0661$ & 0,0000 & 2,7929 & $-0,07$ & 0,00 & 1,33 \\
\hline 18 & 0,925 & 0,435 & 0,000 & 26,161 & $-0,1159$ & 0,0000 & 4,9574 & $-0,13$ & 0,00 & 2,16 \\
\hline 19 & 0,774 & 0,364 & 0,000 & 32,719 & $-0,1908$ & 0,0000 & 8,5998 & $-0,25$ & 0,00 & 3,13 \\
\hline 20 & 0,535 & 0,251 & 0,000 & 44,243 & $-0,2908$ & 0,0000 & 14,8895 & $-0,54$ & 0,00 & 3,74 \\
\hline
\end{tabular}


Tabela 7.1.4 - Resultados suavizados do ensaio 5, em meio de Catlin sem ferro com concentração inicial de lactato triplicada, grupo

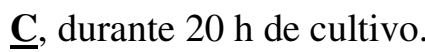

\begin{tabular}{|c|c|c|c|c|c|c|c|c|c|c|}
\hline Tempo (h) & DO suav & $X \operatorname{suav}(g / L)$ & S suav (g/L) & P suav (mg/L) & dX/dt (g/L.h) & (-dS/dt) (g/L.h) & dp/dt (mg/L.h) & $\mu \times\left(h^{-1}\right)$ & $\mu s$ (g/g.h) & $\mu p(\mathrm{mg} / \mathrm{g} . \mathrm{h})$ \\
\hline 0 & 0,128 & 0,060 & 7,400 & 0,268 & 0,0025 & .......... & f........ & 0,02 & .......... & ......... \\
\hline 1 & 0,213 & 0,100 & 7,400 & 0,268 & 0,1585 & 0,0937 & ......... & 0,75 & 0,01 & ......... \\
\hline 2 & 0,435 & 0,204 & 7,249 & 0,268 & 0,2746 & 0,2161 & 0,5757 & 0,63 & 0,04 & 0,12 \\
\hline 3 & 0,714 & 0,336 & 6,941 & 0,910 & 0,2841 & 0,3991 & 0,7374 & 0,40 & 0,13 & 0,25 \\
\hline 4 & 1,002 & 0,471 & 6,413 & 1,799 & 0,2904 & 0,6093 & 1,0676 & 0,29 & 0,29 & 0,50 \\
\hline 5 & 1,294 & 0,608 & 5,872 & 3,029 & 0,2935 & 0,4856 & 1,4901 & 0,23 & 0,30 & 0,91 \\
\hline 6 & 1,582 & 0,743 & 5,393 & 5,136 & 0,2851 & 0,4613 & 2,6492 & 0,18 & 0,34 & 1,97 \\
\hline 7 & 1,886 & 0,887 & 4,994 & 8,577 & 0,3129 & 0,3503 & 3,9484 & 0,17 & 0,31 & 3,50 \\
\hline 8 & 2,140 & 1,006 & 4,645 & 12,014 & 0,1986 & 0,3371 & 2,9103 & 0,09 & 0,34 & 2,93 \\
\hline 9 & 2,287 & 1,075 & 4,357 & 14,365 & 0,0996 & 0,2448 & 1,7737 & 0,04 & 0,26 & 1,91 \\
\hline 10 & 2,349 & 1,104 & 4,145 & 15,255 & 0,0276 & 0,1910 & 0,2722 & 0,01 & 0,21 & 0,30 \\
\hline 11 & 2,352 & 1,105 & 3,907 & 15,261 & $-0,0172$ & 0,2689 & 0,1013 & $-0,01$ & 0,30 & 0,11 \\
\hline 12 & 2,330 & 1,095 & 3,677 & .......... & $-0,0290$ & 0,1983 & $\ldots \ldots \ldots$ & $-0,01$ & 0,22 & .......... \\
\hline 13 & 2,288 & 1,076 & 3,494 & 22,168 & $-0,0583$ & 0,1759 & 5,4282 & $-0,03$ & 0,19 & 5,84 \\
\hline 14 & 2,194 & 1,031 & 3,297 & 26,667 & $-0,1212$ & 0,2087 & 4,3239 & $-0,06$ & 0,22 & 4,46 \\
\hline 15 & 2,082 & 0,978 & 3,108 & 33,155 & $-0,1110$ & 0,1737 & 8,3710 & $-0,05$ & 0,17 & 8,19 \\
\hline 16 & 1,938 & 0,911 & 2,930 & 42,852 & $-0,1666$ & 0,1827 & 10,8172 & $-0,09$ & 0,17 & 9,85 \\
\hline 17 & 1,778 & 0,836 & 2,730 & 54,568 & $-0,1554$ & 0,2080 & 12,1765 & $-0,09$ & 0,17 & 10,18 \\
\hline 18 & 1,618 & 0,761 & 2,531 & 66,608 & $-0,1597$ & 0,1823 & 11,3232 & $-0,10$ & 0,14 & 8,61 \\
\hline 19 & 1,460 & 0,686 & 2,370 & .......... & $-0,1428$ & 0,1174 & ............. & $-0,10$ & 0,08 & .......... \\
\hline 20 & 1,360 & 0,639 & 2,340 & 79,435 & $-0,0434$ & $-0,0794$ & $-0,8142$ & $-0,03$ & $-0,05$ & $-0,52$ \\
\hline
\end{tabular}


Tabela 7.1.5 - Resultados suavizados do ensaio 6, em meio de Catlin sem ferro com concentração inicial de lactato triplicada, grupo

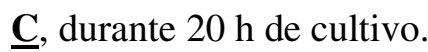

\begin{tabular}{|c|c|c|c|c|c|c|c|c|c|c|}
\hline Tempo (h) & DO suav & $X \operatorname{suav}(\mathrm{g} / \mathrm{L})$ & S suav (g/L) & P suav $(\mathrm{mg} / \mathrm{L})$ & dX/dt (g/L.h) & (-dS/dt) (g/L.h) & dP/dt (mg/L.h) & $\mu \mathrm{x}\left(\mathrm{h}^{-1}\right)$ & $\mu s$ (g/g.h) & $\mu p(\mathrm{mg} / \mathrm{g.h})$ \\
\hline 0 & 0,111 & 0,052 & 8,100 & 1,033 & 0,0036 & ......... & $-0,4395$ & 0,03 & ......... & $-0,02$ \\
\hline 1 & 0,178 & 0,084 & 8,100 & 0,652 & 0,1413 & ......... & $-0,2666$ & 0,79 & ......... & $-0,02$ \\
\hline 2 & 0,444 & 0,209 & 8,100 & 0,610 & 0,3661 & $-0,0009$ & 0,2373 & 0,82 & 0,00 & 0,05 \\
\hline 3 & 0,778 & 0,366 & 8,030 & 1,295 & 0,3750 & 0,1470 & 1,1168 & 0,48 & 0,05 & 0,41 \\
\hline 4 & 1,443 & 0,678 & 7,810 & 2,346 & 0,9086 & 0,2890 & 1,5035 & 0,63 & 0,20 & 1,02 \\
\hline 5 & 2,587 & 1,216 & 7,460 & 6,123 & 1,2465 & 0,4010 & 5,6640 & 0,48 & 0,49 & 6,89 \\
\hline 6 & 3,516 & 1,653 & 7,020 & 13,235 & 0,6455 & 0,4850 & 7,8372 & 0,18 & 0,80 & 12,95 \\
\hline 7 & 3,936 & 1,850 & 6,500 & 19,724 & 0,2342 & 0,5440 & 5,1136 & 0,06 & 1,01 & 9,46 \\
\hline 8 & 4,099 & 1,926 & 5,940 & 23,121 & 0,0996 & 0,5790 & 1,9556 & 0,02 & 1,12 & 3,77 \\
\hline 9 & 4,168 & 1,959 & 5,350 & 24,348 & 0,0427 & 0,5910 & 0,6006 & 0,01 & 1,16 & 1,18 \\
\hline 10 & 4,204 & 1,976 & 4,780 & 24,312 & 0,0279 & 0,5410 & $-0,4585$ & 0,01 & 1,07 & $-0,91$ \\
\hline 11 & 4,233 & 1,990 & 4,280 & 23,895 & 0,0025 & 0,4500 & $-0,1829$ & 0,00 & 0,89 & $-0,36$ \\
\hline 12 & 4,225 & 1,986 & 3,860 & 24,332 & 0,0145 & 0,4110 & 1,2484 & 0,00 & 0,82 & 2,48 \\
\hline 13 & 4,230 & 1,988 & 3,380 & 29,202 & $-0,0080$ & 0,5930 & 8,0759 & 0,00 & 1,18 & 16,06 \\
\hline 14 & 4,231 & 1,988 & 2,630 & 39,253 & 0,0069 & 0,9080 & 11,7046 & 0,00 & 1,81 & 23,27 \\
\hline 15 & 4,240 & 1,993 & 1,630 & 51,967 & 0,0100 & 1,0500 & 13,4021 & 0,00 & 2,09 & 26,71 \\
\hline 16 & 4,239 & 1,992 & 0,647 & 65,413 & $-0,0191$ & 0,8600 & 13,1685 & 0,00 & 1,72 & 26,28 \\
\hline 17 & 4,132 & 1,942 & 0,042 & 77,660 & $-0,0953$ & 0,3030 & 11,0037 & 0,00 & 0,60 & 21,92 \\
\hline 18 & 4,205 & 1,976 & $-0,042$ & 85,223 & $-0,0513$ & 0,0509 & 4,6527 & $-0,01$ & 0,10 & 9,19 \\
\hline 19 & 4,247 & 1,996 & 0,023 & 88,029 & 0,0013 & 0,0436 & 1,4910 & $-0,02$ & 0,08 & 2,90 \\
\hline 20 & 4,010 & 1,885 & 0,023 & 89,268 & $-0,1511$ & 0,0300 & 1,5185 & $-0,04$ & 0,06 & 2,86 \\
\hline
\end{tabular}


Tabela 7.1.6 - Resultados suavizados do ensaio 7, em meio de Catlin sem ferro com pulso de lactato e aminoácidos na $6^{\mathrm{a}} \mathrm{h}$ de cultivo, grupo D, durante $20 \mathrm{~h}$ de cultivo.

\begin{tabular}{|c|c|c|c|c|c|c|c|c|c|c|}
\hline Tempo (h) & DO suav & $X \operatorname{suav}(g / L)$ & S suav (g/L) & P suav (mg/L) & dX/dt (g/L.h) & (-dS/dt) (g/L.h) & dP/dt (mg/L.h) & $\mu \mathrm{x}\left(\mathrm{h}^{-1}\right)$ & $\mu s$ (g/g.h) & $\mu p(\mathrm{mg} / \mathrm{g} . \mathrm{h})$ \\
\hline $\mathbf{0}$ & 0,138 & 0,065 & 2,290 & 0,005 & 0,0204 & 0,012 & $\ldots \ldots$ & 0,15 & 0,00 & ........ \\
\hline 1 & 0,271 & 0,127 & 2,240 & 0,005 & 0,2240 & 0,0982 & 0,2470 & 0,83 & 0,01 & 0,03 \\
\hline 2 & 0,523 & 0,246 & 2,030 & 0,905 & 0,2680 & 0,3020 & 1,4000 & 0,51 & 0,07 & 0,34 \\
\hline 3 & 0,771 & 0,362 & 1,640 & 2,130 & 0,2240 & 0,4640 & 1,1100 & 0,29 & 0,17 & 0,40 \\
\hline 4 & 0,965 & 0,454 & 1,180 & 3,260 & 0,1620 & 0,4450 & 1,2000 & 0,17 & 0,20 & 0,54 \\
\hline 5 & 1,060 & 0,498 & 0,780 & 4,640 & 0,0597 & 0,3420 & 1,6100 & 0,06 & 0,17 & 0,80 \\
\hline \multirow[t]{2}{*}{6} & 1,130 & 0,531 & 0,500 & 6,540 & 0,0961 & 0,2130 & 2,2600 & 0,09 & 0,11 & 1,20 \\
\hline & & 0,000 & 2,800 & & & 0,3290 & & & 0,17 & \\
\hline 7 & 1,350 & 0,635 & 2,790 & 9,560 & 0,2940 & 0,2990 & 3,6400 & 0,22 & 0,19 & 2,31 \\
\hline 8 & 1,620 & 0,761 & 2,240 & 13,200 & 0,2550 & 0,7100 & 3,7200 & 0,16 & 0,54 & 2,83 \\
\hline 9 & 1,870 & 0,879 & 1,640 & 17,200 & 0,2440 & 0,5010 & 4,0700 & 0,13 & 0,44 & 3,58 \\
\hline 10 & 2,080 & 0,978 & 1,220 & 21,200 & 0,1880 & 0,3680 & 4,0000 & 0,09 & 0,36 & 3,91 \\
\hline 11 & 2,250 & 1,058 & 0,809 & 24,600 & 0,1510 & 0,4160 & 2,9100 & 0,07 & 0,44 & 3,08 \\
\hline 12 & 2,390 & 1,123 & 0,503 & 27,400 & 0,1160 & 0,2240 & 2,9600 & 0,05 & 0,25 & 3,32 \\
\hline 13 & 2,490 & 1,170 & 0,271 & 31,200 & 0,0846 & 0,2260 & 4,3700 & 0,03 & 0,26 & 5,11 \\
\hline 14 & 2,560 & 1,203 & 0,089 & 35,700 & 0,0557 & 0,1350 & 4,7100 & 0,02 & 0,16 & 5,67 \\
\hline 15 & 2,600 & 1,222 & 0,017 & 40,000 & 0,0342 & 0,0219 & 3,8800 & 0,01 & 0,03 & 4,74 \\
\hline 16 & 2,620 & 1,231 & 0,009 & 43,700 & 0,0584 & 0,0032 & 3,7500 & 0,02 & 0,00 & 4,62 \\
\hline 17 & 2,590 & 1,217 & 0,017 & 47,300 & $-0,0570$ & 0,0097 & 3,6600 & $-0,02$ & 0,01 & 4,46 \\
\hline 18 & 2,520 & 1,184 & 0,022 & 51,800 & $-0,0933$ & 0,0005 & 5,7200 & $-0,04$ & 0,00 & 6,77 \\
\hline 19 & 2,420 & 1,137 & 0,015 & 59,400 & $-0,2420$ & 0,0104 & 9,9300 & $-0,10$ & 0,01 & 11,29 \\
\hline 20 & 2,320 & 1,090 & 0,005 & 59,400 & $-0,0856$ & 0,0074 & $\ldots \ldots$. & $-0,04$ & 0,01 & $\ldots \ldots$. \\
\hline
\end{tabular}


Tabela 7.1.7 - Resultados suavizados do ensaio 8, em meio de Catlin sem ferro com pulso de lactato e aminoácidos na $6^{\mathrm{a}} \mathrm{h}$ de cultivo, grupo D, durante $20 \mathrm{~h}$ de cultivo.

\begin{tabular}{|c|c|c|c|c|c|c|c|c|c|c|}
\hline Tempo (h) & DO suav & $\mathrm{X} \operatorname{suav}(\mathrm{g} / \mathrm{L})$ & $\mathrm{S}$ suav $(\mathrm{g} / \mathrm{L})$ & $P$ suav (mg/L) & dX/dt (g/L.h) & (-dS/dt) (g/L.h) & $(\mathrm{dp} / \mathrm{dt})(\mathrm{mg} / \mathrm{L.h})$ & $\mu x\left(h^{-1}\right)$ & Hs (g/g.h) & $\mu p(\mathrm{mg} / \mathrm{g} . \mathrm{h})$ \\
\hline $\mathbf{0}$ & 0,118 & 0,055 & 2,290 & $-0,061$ & 0,0375 & 0,1900 & $\ldots \ldots . .$. & 0,32 & 0,01 & ........ \\
\hline 1 & 0,257 & 0,121 & 2,320 & $-0,061$ & 0,2260 & 0,1060 & 0,0674 & 0,88 & 0,01 & 0,01 \\
\hline 2 & 0,573 & 0,269 & 2,160 & 0,424 & 0,3760 & 0,2200 & 0,8570 & 0,66 & 0,06 & 0,23 \\
\hline 3 & 0,877 & 0,412 & 1,850 & 1,580 & 0,2400 & 0,3820 & 1,3900 & 0,27 & 0,16 & 0,57 \\
\hline 4 & 1,070 & 0,503 & 1,400 & 3,070 & 0,1560 & 0,4850 & 1,5200 & 0,15 & 0,24 & 0,76 \\
\hline 5 & 1,170 & 0,550 & 0,950 & 4,260 & 0,0626 & 0,3800 & 1,0500 & 0,05 & 0,21 & 0,58 \\
\hline \multirow[t]{2}{*}{6} & 1,300 & 0,611 & 0,700 & 5,940 & 0,2100 & 0,0656 & 2,2900 & 0,16 & 0,04 & 1,40 \\
\hline & & 0,000 & 3,100 & & & 0,4370 & & & 0,27 & \\
\hline 7 & 1,590 & 0,747 & 3,230 & 8,570 & 0,3580 & 0,4820 & 3,0900 & 0,23 & 0,36 & 2,31 \\
\hline 8 & 2,060 & 0,968 & 2,460 & 12,300 & 0,5450 & 0,7710 & 4,5700 & 0,26 & 0,75 & 4,42 \\
\hline 9 & 2,560 & 1,203 & 1,660 & 18,300 & 0,4530 & 0,6770 & 7,0600 & 0,18 & 0,81 & 8,49 \\
\hline 10 & 2,950 & 1,387 & 1,050 & 25,600 & 0,3390 & 0,5150 & 7,3200 & 0,11 & 0,71 & 10,15 \\
\hline 11 & 3,240 & 1,523 & 0,673 & 32,400 & 0,2350 & 0,2440 & 6,3900 & 0,07 & 0,37 & 9,73 \\
\hline 12 & 3,430 & 1,612 & 0,463 & 38,400 & 0,1470 & 0,2440 & 5,5700 & 0,04 & 0,39 & 8,98 \\
\hline 13 & 3,540 & 1,664 & 0,316 & 43,700 & 0,0755 & 0,1130 & 5,1000 & 0,02 & 0,19 & 8,49 \\
\hline 14 & 3,590 & 1,687 & 0,203 & 48,700 & 0,0204 & 0,0613 & 4,9800 & 0,01 & 0,10 & 8,40 \\
\hline 15 & 3,590 & 1,687 & 0,094 & 53,600 & $-0,0061$ & 0,0990 & 5,0100 & 0,00 & 0,17 & 8,45 \\
\hline 16 & 3,580 & 1,683 & 0,025 & 59,000 & $-0,0301$ & 0,0409 & 5,8600 & $-0,01$ & 0,07 & 9,86 \\
\hline 17 & 3,520 & 1,654 & 0,009 & 65,600 & $-0,0912$ & 0,0039 & 7,5300 & $-0,03$ & 0,01 & 12,46 \\
\hline 18 & 3,390 & 1,593 & 0,010 & 65,600 & $-0,1790$ & 0,0051 & ........ & $-0,05$ & 0,01 & $\ldots \ldots$. \\
\hline 19 & 3,140 & 1,476 & 0,015 & 65,600 & $-0,3250$ & 0,0107 & ........ & $-0,10$ & 0,02 & ........ \\
\hline 20 & 2,720 & 1,278 & 0,030 & 65,600 & $-0,5300$ & 0,0079 & ....... & $-0,19$ & 0,01 & ........ \\
\hline
\end{tabular}


Tabela 7.1.8 - Resultados suavizados do ensaio 9, em meio de Catlin sem ferro com concentrações iniciais de lactato e aminoácidos dobradas, grupo E, durante $20 \mathrm{~h}$ de cultivo.

\begin{tabular}{|c|c|c|c|c|c|c|c|c|c|c|}
\hline Tempo (h) & DO suav & $X \operatorname{suav}(\mathrm{g} / \mathrm{L})$ & S suav (g/L) & P suav $(\mathrm{mg} / \mathrm{L})$ & dX/dt (g/L.h) & (-dS/dt) (g/L.h) & dP/dt (mg/L.h) & $\mu \mathrm{x}\left(\mathrm{h}^{-1}\right)$ & $\mu s$ (g/g.h) & $\mu p(\mathrm{mg} / \mathrm{g.h})$ \\
\hline 0 & 0,146 & 0,069 & 3,855 & 0,741 & $-0,0054$ & $\ldots \ldots$. & $-1,4451$ & $-0,04$ & $\ldots \ldots$ & $-0,10$ \\
\hline 1 & 0,207 & 0,097 & 3,855 & 0,554 & 0,1541 & $-0,1781$ & 0,9473 & 0,74 & $-0,02$ & 0,09 \\
\hline 2 & 0,522 & 0,245 & 3,814 & 2,550 & 0,4844 & 0,2633 & 2,7507 & 0,93 & 0,06 & 0,67 \\
\hline 3 & 1,302 & 0,612 & 3,295 & 5,105 & 0,9652 & 0,7465 & 2,4555 & 0,74 & 0,46 & 1,50 \\
\hline 4 & 2,174 & 1,022 & 2,361 & 8,151 & 0,7375 & 1,0751 & 3,4762 & 0,34 & 1,10 & 3,55 \\
\hline 5 & 2,568 & 1,207 & 1,463 & 11,260 & 0,1456 & 0,7297 & 2,8528 & 0,06 & 0,88 & 3,44 \\
\hline 6 & 2,731 & 1,284 & 0,892 & 14,079 & 0,1895 & 0,4249 & 2,8965 & 0,07 & 0,55 & 3,72 \\
\hline 7 & 2,988 & 1,404 & 0,588 & 17,555 & 0,3096 & 0,1975 & 4,0199 & 0,10 & 0,28 & 5,65 \\
\hline 8 & 3,254 & 1,529 & 0,471 & 21,563 & 0,2243 & 0,0475 & 4,1423 & 0,07 & 0,07 & 6,34 \\
\hline 9 & 3,439 & 1,616 & 0,467 & 26,132 & 0,1463 & $-0,0250$ & 5,1421 & 0,04 & $-0,04$ & 8,31 \\
\hline 10 & 3,550 & 1,669 & 0,482 & 31,364 & 0,0786 & $-0,0077$ & 5,8963 & 0,02 & $-0,01$ & 9,84 \\
\hline 11 & 3,599 & 1,692 & 0,489 & 39,076 & 0,0214 & $-0,0061$ & 10,1037 & 0,01 & $-0,01$ & 17,09 \\
\hline 12 & 3,596 & 1,690 & 0,491 & 54,195 & $-0,0255$ & 0,0005 & 19,1110 & $-0,01$ & 0,00 & 32,30 \\
\hline 13 & 3,558 & 1,672 & 0,495 & 72,049 & $-0,0566$ & $-0,0076$ & 16,6589 & $-0,02$ & $-0,01$ & 27,85 \\
\hline 14 & 3,476 & 1,634 & 0,499 & 87,114 & $-0,1134$ & $-0,0022$ & 13,7247 & $-0,03$ & 0,00 & 22,42 \\
\hline 15 & 3,297 & 1,550 & 0,506 & 100,000 & $-0,2253$ & $-0,0088$ & 12,3148 & $-0,07$ & $-0,01$ & 19,08 \\
\hline 16 & 3,074 & 1,445 & 0,507 & 112,251 & $-0,2181$ & 0,0045 & 12,4292 & $-0,07$ & 0,01 & 17,96 \\
\hline 17 & 2,872 & 1,350 & 0,515 & 126,367 & $-0,1849$ & $-0,0170$ & 14,9218 & $-0,06$ & $-0,02$ & 20,14 \\
\hline 18 & 2,702 & 1,270 & 0,537 & 139,035 & $-0,1539$ & $-0,0223$ & 11,0397 & $-0,06$ & $-0,03$ & 14,02 \\
\hline 19 & 2,570 & 1,208 & 0,550 & 148,712 & $-0,1074$ & 0,0012 & 9,9837 & $-0,04$ & 0,00 & 12,06 \\
\hline 20 & 2,490 & 1,170 & 0,525 & 162,340 & $-0,0509$ & 0,0536 & 18,9413 & $-0,02$ & 0,06 & 22,17 \\
\hline
\end{tabular}


Tabela 7.1.9 - Resultados suavizados do ensaio 10, em meio de Catlin sem ferro com concentrações iniciais de lactato e aminoácidos dobradas, grupo E, durante $20 \mathrm{~h}$ de cultivo.

\begin{tabular}{|c|c|c|c|c|c|c|c|c|c|c|}
\hline Tempo (h) & DO suav & $\mathrm{X} \operatorname{suav}(\mathrm{g} / \mathrm{L})$ & S suav (g/L) & $P$ suav $(\mathrm{mg} / \mathrm{L})$ & dX/dt (g/L.h) & $(-d S / d t)(g / L . h)$ & dP/dt (mg/L.h) & $\mu x\left(h^{-1}\right)$ & $\mu s$ (g/g.h) & $\mu \mathrm{p}(\mathrm{mg} / \mathrm{g} . \mathrm{h})$ \\
\hline 0 & 0,141 & 0,066 & 4,375 & 0,830 & $-0,0035$ & $\ldots \ldots$ & 0,5294 & $-0,02$ & $\ldots \ldots$ & 0,04 \\
\hline 1 & 0,181 & 0,085 & 4,375 & 1,186 & 0,1644 & ....... & 0,3773 & 0,91 & ....... & 0,05 \\
\hline 2 & 0,649 & 0,305 & 4,421 & 2,262 & 0,7042 & 0,2629 & 1,6384 & 1,09 & 0,08 & 0,12 \\
\hline 3 & 1,388 & 0,652 & 3,821 & 4,141 & 0,7490 & 0,8788 & 2,0525 & 0,54 & 0,57 & 1,07 \\
\hline 4 & 2,096 & 0,985 & 2,872 & 6,182 & 0,6412 & 0,9949 & 2,0083 & 0,31 & 0,98 & 2,02 \\
\hline 5 & 2,506 & 1,178 & 1,880 & 7,525 & 0,2725 & 0,9644 & 1,3245 & 0,11 & 1,14 & 2,37 \\
\hline 6 & 2,934 & 1,379 & 0,992 & 11,407 & 0,5627 & 0,7872 & 5,6223 & 0,19 & 1,09 & 1,83 \\
\hline 7 & 3,616 & 1,699 & 0,476 & 15,185 & 0,7507 & 0,2810 & 3,3640 & 0,21 & 0,48 & 9,55 \\
\hline 8 & 4,212 & 1,980 & 0,331 & 23,251 & 0,4559 & 0,0320 & 11,6827 & 0,11 & 0,06 & 6,66 \\
\hline 9 & 4,773 & 2,243 & 0,367 & 33,737 & 0,1328 & $-0,0820$ & 9,5908 & 0,03 & $-0,18$ & 26,21 \\
\hline 10 & 4,573 & 2,149 & 0,427 & 43,378 & 0,2731 & $-0,0397$ & 9,7810 & 0,06 & $-0,09$ & 20,62 \\
\hline 11 & 4,900 & 2,303 & 0,444 & 53,479 & $-0,0006$ & $-0,0047$ & 10,5100 & 0,00 & $-0,01$ & 22,53 \\
\hline 12 & 4,870 & 2,289 & 0,481 & 65,004 & 0,0624 & $-0,0545$ & 12,4239 & 0,01 & $-0,12$ & 24,06 \\
\hline 13 & 4,871 & 2,289 & 0,502 & 78,421 & $-0,0562$ & 0,0055 & 14,1045 & $-0,01$ & 0,01 & 28,44 \\
\hline 14 & 4,817 & 2,264 & 0,490 & 92,603 & $-0,0817$ & 0,0138 & 13,9542 & $-0,02$ & 0,03 & 31,93 \\
\hline 15 & 4,598 & 2,161 & 0,481 & 105,114 & $-0,3255$ & 0,0023 & 11,0838 & $-0,07$ & 0,00 & 30,16 \\
\hline 16 & 4,321 & 2,031 & 0,498 & 114,106 & $-0,3062$ & $-0,0266$ & 7,3092 & $-0,07$ & $-0,05$ & 22,51 \\
\hline 17 & 3,880 & 1,824 & 0,510 & 120,553 & $-0,6791$ & $-0,0002$ & 5,9945 & $-0,18$ & 0,00 & 13,33 \\
\hline 18 & 2,758 & 1,296 & 0,500 & 127,438 & $-1,6670$ & 0,0154 & 7,5576 & $-0,60$ & 0,02 & 7,77 \\
\hline 19 & 0,341 & 0,160 & 0,490 & 135,855 & $-3,2699$ & 0,0040 & 8,4034 & $-9,59$ & 0,00 & 1,21 \\
\hline 20 & 0,341 & 0,160 & 0,495 & 142,497 & ........ & $-0,0152$ & 4,0068 & ........ & 0,00 & 1,35 \\
\hline
\end{tabular}


Tabela 7.1.10 - Resultados suavizados do ensaio 11, em meio de Catlin sem ferro com concentrações iniciais de lactato e aminoácidos dobradas, grupo E, durante $20 \mathrm{~h}$ de cultivo.

\begin{tabular}{|c|c|c|c|c|c|c|c|c|c|c|}
\hline Tempo (h) & DO suav & $X \operatorname{suav}(\mathrm{g} / \mathrm{L})$ & $\mathrm{S}$ suav $(\mathrm{g} / \mathrm{L})$ & $P$ suav $(\mathrm{mg} / \mathrm{L})$ & dX/dt (g/L.h) & (-dS/dt) (g/L.h) & dP/dt (mg/L.h) & $\mu \mathrm{x}\left(\mathrm{h}^{-1}\right)$ & $\mu \mathrm{s}(\mathrm{g} / \mathrm{g} . h)$ & $\mu p(\mathrm{mg} / \mathrm{g} . \mathrm{h})$ \\
\hline $\mathbf{0}$ & 0,122 & 0,057 & 2,610 & 1,225 & 0,0264 & $\ldots \ldots$. & 1,2880 & 0,22 & $\ldots \ldots .$. & 0,07 \\
\hline 1 & 0,189 & 0,089 & 2,610 & 1,752 & 0,1620 & 0,7994 & 0,0521 & 0,86 & 0,07 & 0,00 \\
\hline 2 & 0,665 & 0,313 & 1,935 & 1,819 & 0,7211 & 0,5622 & 0,4533 & 1,08 & 0,18 & 0,14 \\
\hline 3 & 1,482 & 0,697 & 1,465 & 4,063 & 0,8540 & 0,3915 & 3,6631 & 0,58 & 0,27 & 2,55 \\
\hline 4 & 2,074 & 0,975 & 1,124 & 8,401 & 0,3673 & 0,3036 & 4,6619 & 0,18 & 0,30 & 4,55 \\
\hline 5 & 2,314 & 1,088 & 0,812 & 12,175 & 0,1333 & 0,3074 & 3,0841 & 0,06 & 0,33 & 3,35 \\
\hline 6 & 2,383 & 1,120 & 0,543 & 15,904 & 0,0254 & 0,2331 & 4,0873 & 0,01 & 0,26 & 4,58 \\
\hline 7 & 2,431 & 1,143 & 0,344 & 18,895 & 0,0690 & 0,1676 & 2,1282 & 0,03 & 0,19 & 2,43 \\
\hline 8 & 2,529 & 1,189 & 0,107 & 20,628 & 0,1097 & 0,0754 & 1,5711 & 0,04 & 0,09 & 1,87 \\
\hline 9 & 2,592 & 1,218 & 0,048 & 22,798 & 0,0263 & 0,0434 & 2,5855 & 0,01 & 0,05 & 3,15 \\
\hline 10 & 2,610 & 1,227 & 0,202 & 24,825 & 0,0084 & 0,1168 & 1,9863 & 0,00 & 0,14 & 2,44 \\
\hline 11 & 2,611 & 1,227 & 0,017 & 29,384 & $-0,0072$ & 0,0208 & 6,8215 & 0,00 & 0,03 & 8,37 \\
\hline 12 & 2,590 & 1,217 & 0,003 & 34,142 & $-0,0333$ & 0,0086 & 4,5602 & $-0,01$ & 0,01 & 5,55 \\
\hline 13 & 2,546 & 1,197 & $-0,001$ & 42,236 & $-0,0523$ & 0,0000 & 13,4938 & $-0,02$ & 0,00 & 16,15 \\
\hline 14 & 2,490 & 1,170 & 0,000 & 69,955 & $-0,0604$ & $-0,0008$ & 38,0959 & $-0,02$ & 0,00 & 44,58 \\
\hline 15 & 2,427 & 1,141 & 0,000 & 102,705 & $-0,0636$ & $-0,0002$ & 27,7011 & $-0,03$ & 0,00 & 31,60 \\
\hline 16 & 2,251 & 1,058 & 0,000 & 124,917 & $-0,0476$ & 0,0000 & 17,3733 & $-0,02$ & 0,00 & 18,38 \\
\hline 17 & 2,304 & 1,083 & 0,000 & 138,754 & $-0,0572$ & 0,0000 & 10,9526 & $-0,02$ & 0,00 & 11,86 \\
\hline 18 & 2,364 & 1,111 & 0,000 & 148,124 & $-0,0625$ & 0,0000 & 8,4388 & $-0,03$ & 0,00 & 9,38 \\
\hline 19 & 2,210 & 1,039 & 0,000 & 156,934 & $-0,0337$ & 0,0000 & 9,8321 & $-0,02$ & 0,00 & 10,21 \\
\hline 20 & 2,185 & 1,027 & 0,000 & 156,934 & $-0,0156$ & 0,0000 & 9,8321 & $-0,01$ & 0,00 & 10,10 \\
\hline
\end{tabular}


Tabela 7.1.11 - Resultados suavizados do ensaio 12, em meio de Catlin sem ferro com concentrações iniciais de lactato e aminoácidos dobradas e sem glicerol, grupo F, durante $20 \mathrm{~h}$ de cultivo.

\begin{tabular}{|c|c|c|c|c|c|c|c|c|c|c|}
\hline Tempo (h) & DO suav & $\mathrm{X} \operatorname{suav}(\mathrm{g} / \mathrm{L})$ & S suav $(\mathrm{g} / \mathrm{L})$ & $P$ suav $(\mathrm{mg} / \mathrm{L})$ & dX/dt (g/L.h) & (-dS/dt) (g/L.h) & dP/dt (mg/L.h) & $\mu \mathrm{x}\left(\mathrm{h}^{-1}\right)$ & $\mu s$ (g/g.h) & $\mu p(\mathrm{mg} / \mathrm{g} . \mathrm{h})$ \\
\hline 0 & 0,122 & 0,057 & 6,000 & 0,672 & $-0,0280$ & $\ldots \ldots$ & 0,1611 & $-0,23$ & $\ldots \ldots$. & 0,01 \\
\hline 1 & 0,162 & 0,076 & 6,000 & 0,552 & 0,1250 & $\ldots \ldots$ & $-0,1603$ & 0,77 & ......... & $-0,01$ \\
\hline 2 & 0,355 & 0,167 & 6,000 & 1,093 & 0,3330 & ....... & 1,1867 & 0,94 & ......... & 0,20 \\
\hline 3 & 1,190 & 0,559 & 6,000 & 2,977 & 1,1600 & 1,5244 & 2,3499 & 0,97 & 0,85 & 1,31 \\
\hline 4 & 2,160 & 1,015 & 4,527 & 4,948 & 0,7970 & 1,4671 & 1,7896 & 0,37 & 1,49 & 1,82 \\
\hline 5 & 2,720 & 1,278 & 2,860 & 6,934 & 0,3930 & 1,7892 & 2,3913 & 0,14 & 2,29 & 3,06 \\
\hline 6 & 3,200 & 1,504 & 1,390 & 10,784 & 0,5260 & 1,1694 & 4,8032 & 0,16 & 1,76 & 7,22 \\
\hline 7 & 3,700 & 1,739 & 0,512 & 14,990 & 0,4640 & 0,6153 & 3,7306 & 0,13 & 1,07 & 6,49 \\
\hline 8 & 4,100 & 1,927 & 0,103 & 18,457 & 0,3430 & 0,2304 & 3,3505 & 0,08 & 0,44 & 6,46 \\
\hline 9 & 4,400 & 2,068 & $-0,006$ & 22,751 & 0,2670 & 0,0148 & 5,1256 & 0,06 & 0,03 & 10,60 \\
\hline 10 & 4,630 & 2,176 & $-0,004$ & 28,608 & 0,1920 & $-0,0127$ & 6,4316 & 0,04 & $-0,03$ & 14,00 \\
\hline 11 & 4,770 & 2,242 & 0,003 & 35,298 & 0,0953 & $-0,0033$ & 6,7896 & 0,02 & $-0,01$ & 15,22 \\
\hline 12 & 4,830 & 2,270 & 0,008 & 41,872 & 0,0134 & $-0,0063$ & 6,1997 & 0,00 & $-0,01$ & 14,07 \\
\hline 13 & 4,840 & 2,275 & 0,013 & 46,948 & 0,0166 & $-0,0019$ & 4,2646 & 0,00 & 0,00 & 9,70 \\
\hline 14 & 4,850 & 2,280 & 0,008 & 52,285 & $-0,0215$ & 0,0084 & 6,2951 & 0,00 & 0,02 & 14,35 \\
\hline 15 & 4,790 & 2,251 & 0,003 & 59,111 & $-0,1010$ & 0,0024 & 7,3230 & $-0,02$ & 0,01 & 16,49 \\
\hline 16 & 4,600 & 2,162 & 0,005 & 66,861 & $-0,2580$ & $-0,0050$ & 8,1416 & $-0,06$ & $-0,01$ & 17,60 \\
\hline 17 & 4,300 & 2,021 & 0,009 & 75,324 & $-0,3420$ & $-0,0029$ & 8,7508 & $-0,08$ & $-0,01$ & 17,69 \\
\hline 18 & 3,940 & 1,852 & 0,010 & 82,626 & $-0,3690$ & $-0,0002$ & 7,6562 & $-0,09$ & 0,00 & 14,18 \\
\hline 19 & 3,660 & 1,720 & 0,010 & 93,815 & $-0,2520$ & 0,0003 & 16,9769 & $-0,07$ & 0,00 & 29,20 \\
\hline 20 & 3,290 & 1,546 & 0,010 & 121,091 & $-0,5580$ & $-0,0006$ & 39,8306 & $-0,17$ & 0,00 & 61,59 \\
\hline
\end{tabular}


Anexo 7.2: Curvas de D.O. 540nm X Massa seca (g/L) 

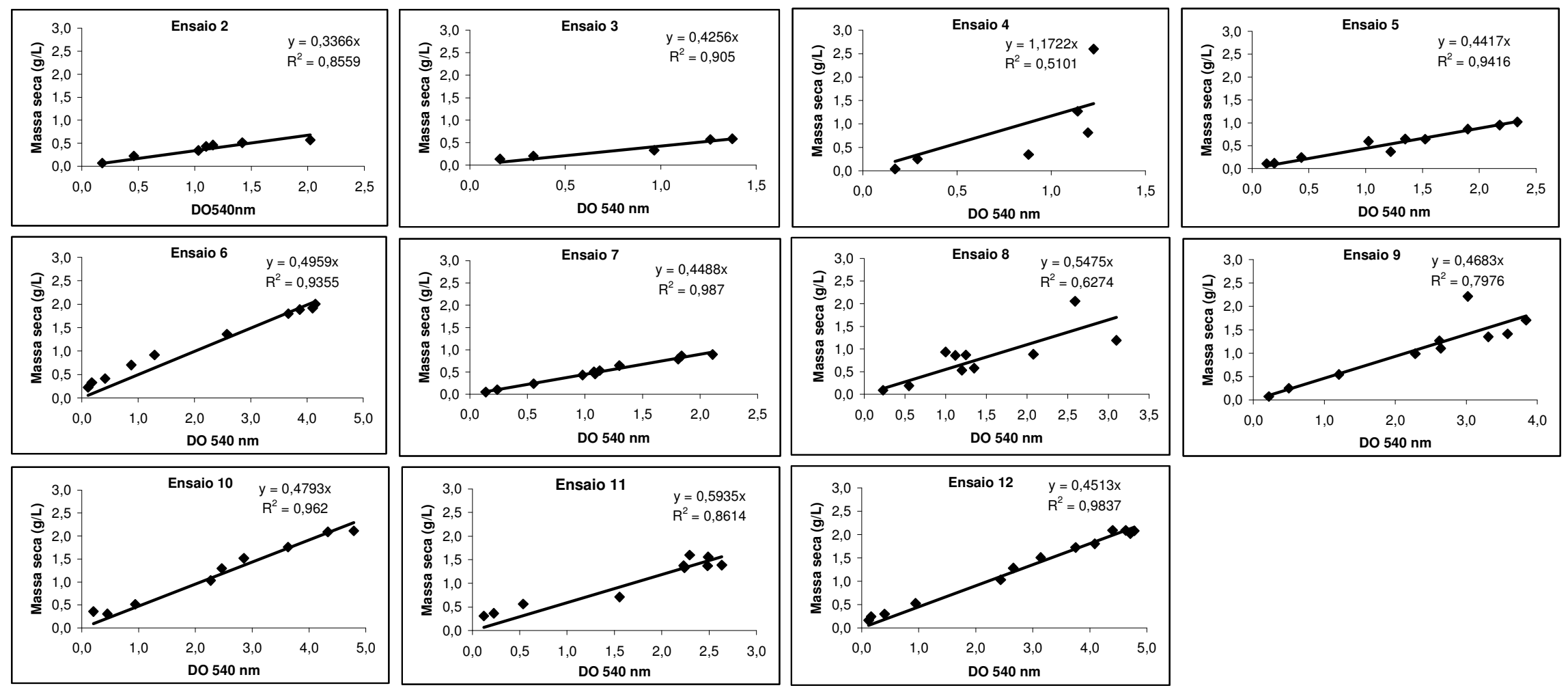

Figura 7.2.1 - Curvas de D.O. 540nm versus Massa seca (g/L), com as linhas de tendência, considerando: interseção no ponto zero, equação e coeficiente de correlação. 
Anexo 7.3: Resultados e curvas de produção de amônia 
Tabela 7.3.1 - Resultados experimentais de amônia nos cultivos em biorreator.

\begin{tabular}{|c|c|c|c|c|c|}
\hline $\begin{array}{l}\text { Tempo } \\
\text { (h) }\end{array}$ & $\begin{array}{c}\text { Amônia (g/L) } \\
\text { Grupo B }\end{array}$ & $\begin{array}{c}\text { Amônia (g/L) } \\
\text { Grupo C }\end{array}$ & $\begin{array}{c}\text { Amônia (g/L) } \\
\text { Grupo D }\end{array}$ & $\begin{array}{c}\text { Amônia }(\mathrm{g} / \mathrm{L}) \\
\text { Grupo E }\end{array}$ & $\begin{array}{c}\text { Amônia }(\mathrm{g} / \mathrm{L}) \\
\text { Grupo F }\end{array}$ \\
\hline 0 & 0,135 & 0,135 & 0,135 & 0,135 & 0,135 \\
\hline 1 & 0,135 & 0,135 & 0,135 & 0,135 & 0,135 \\
\hline 2 & 0,135 & 0,135 & 0,135 & 0,135 & 0,135 \\
\hline 3 & 0,135 & 0,135 & 0,135 & 0,135 & 0,135 \\
\hline 4 & 0,135 & 0,135 & 0,094 & 0,135 & 0,135 \\
\hline 5 & 0,135 & 0,526 & 0,149 & 0,135 & 0,135 \\
\hline 6 & 0,135 & 0,510 & 0,198 & ……... & 0,135 \\
\hline 7 & 0,211 & .......... & .......... & ․․….... & 0,180 \\
\hline 8 & …….... & 0,688 & 0,437 & …….... & 0,162 \\
\hline 9 & 0,192 & 0,554 & 0,097 & 0,080 & 0,183 \\
\hline 10 & ............ & 0,612 & 0,133 & 0,083 & 0,185 \\
\hline 11 & ........... & 0,443 & 0,137 & 0,089 & 0,173 \\
\hline 12 & 0,207 & 0,544 & 0,347 & 0,123 & ……... \\
\hline 13 & 0,245 & 0,461 & ……... & 0,131 & 0,147 \\
\hline 14 & 0,371 & ........... & 0,457 & 0,148 & 0,156 \\
\hline 15 & 0,639 & 0,396 & 0,636 & 0,171 & ……... \\
\hline 16 & ........... & 0,369 & 0,782 & 0,289 & 0,156 \\
\hline 17 & 0,859 & 0,759 & ․․…... & ……... & 0,152 \\
\hline 18 & ……... & ․․….... & 0,729 & 0,476 & 0,131 \\
\hline 19 & 0,975 & ........... & 0,827 & 0,529 & 0,180 \\
\hline 20 & 1,207 & $\ldots \ldots \ldots$ & 1,204 & $\ldots \ldots \ldots$ & 0,139 \\
\hline
\end{tabular}

Na tabela 7.3.1 estão os valores experimentais de amônia dos ensaios 3, 5, 7, 10 e 12, representando os grupos B, C, D, E e F, respectivamente. 

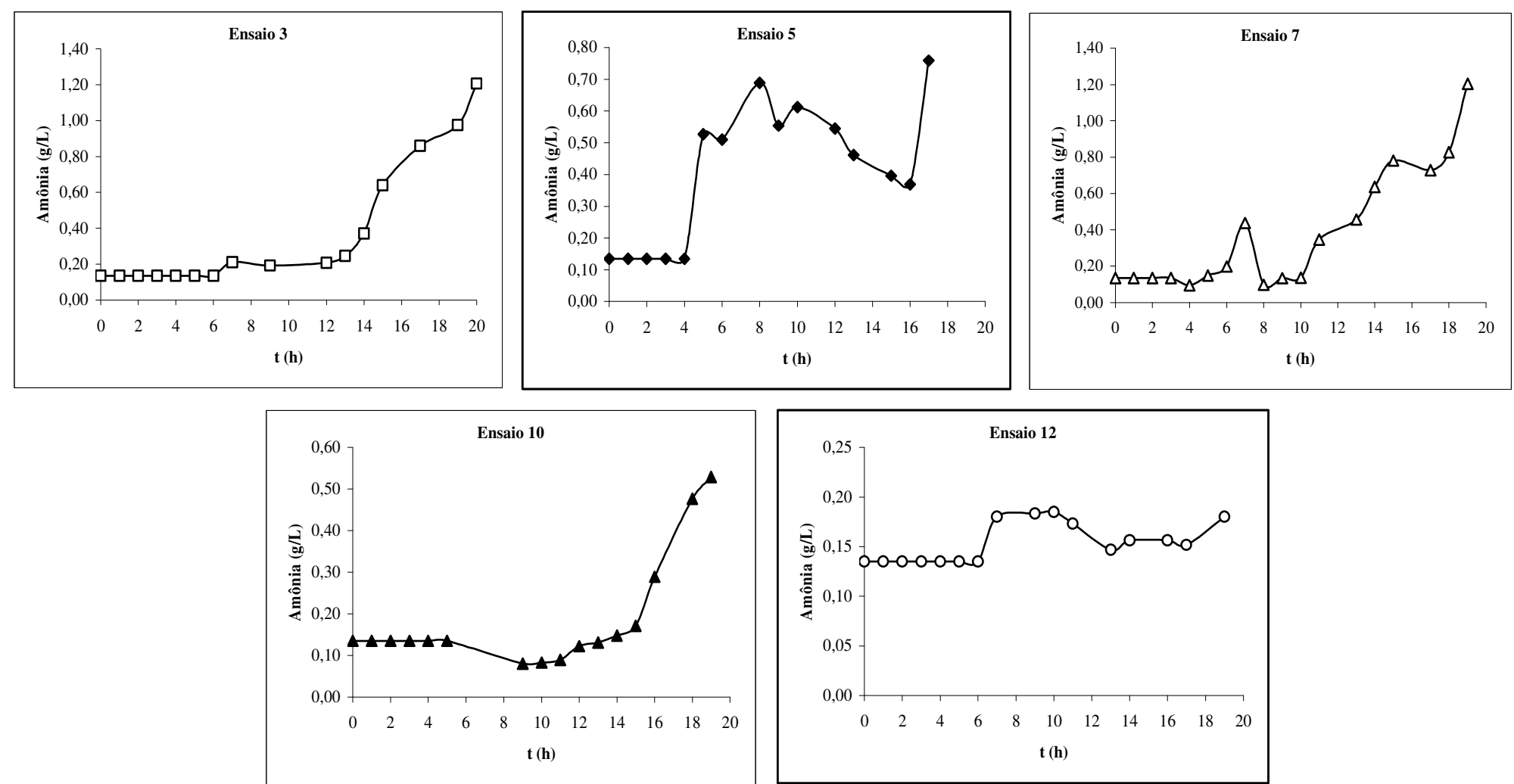

Figura 7.3.1 - Curvas de produção de amônia $\left(\mathrm{NH}_{4}\right)$ dos ensaios $3(\square), 5(\square), 7(\Delta), 10(\mathbf{\Delta})$ e 12(०), representando os grupos B, C, D, E e F respectivamente. 
Anexo 7.4: Curvas experimentais e suavizada 

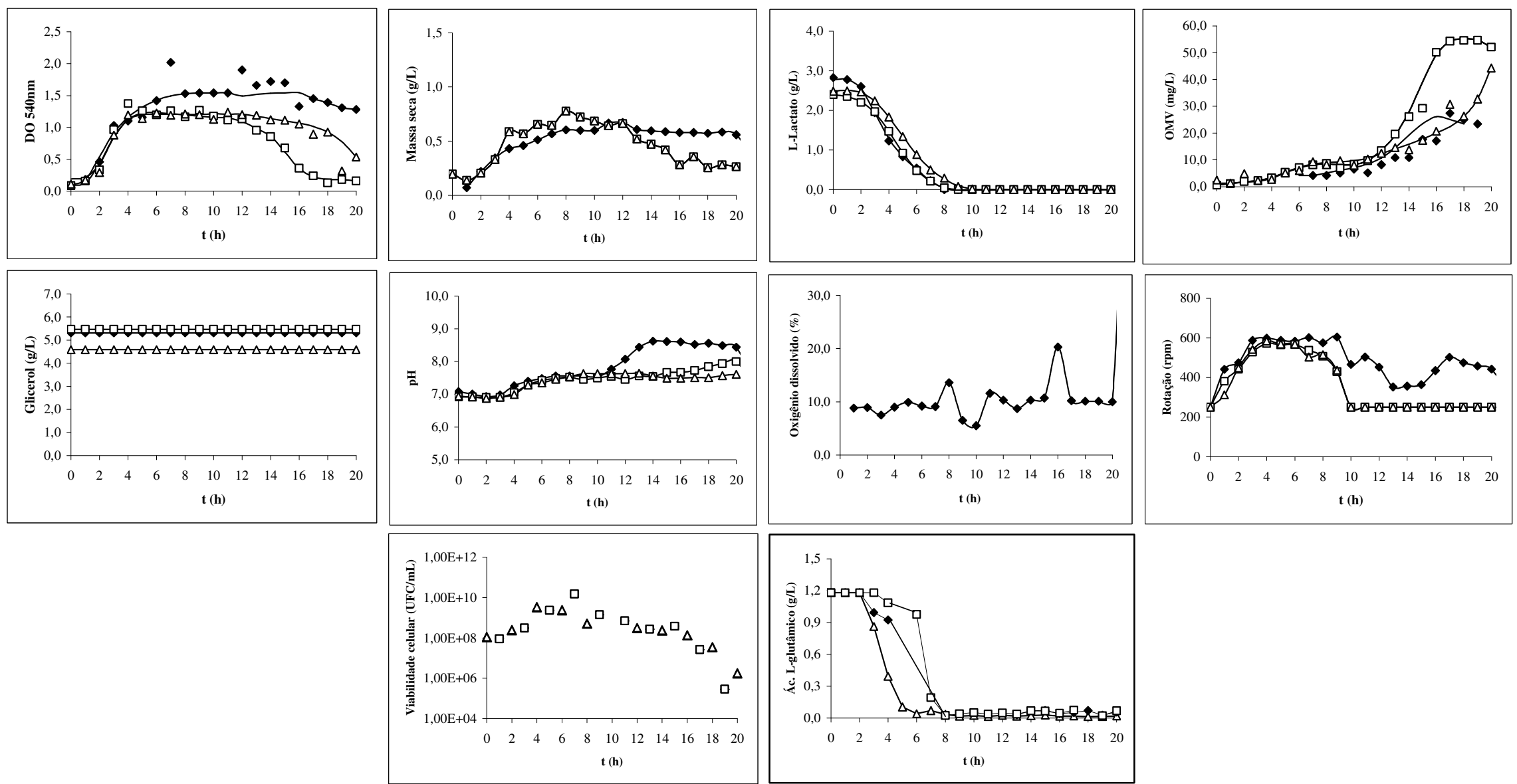

Figura 7.4.1 - Curvas experimentais dos ensaios $2(\bullet), 3(\square)$ e $4(\Delta)$ representando $D_{540 \mathrm{~nm}}$, massa seca $(\mathrm{g} / \mathrm{L}), \mathrm{lactato}(\mathrm{g} / \mathrm{L}), \mathrm{OMV}(\mathrm{mg} / \mathrm{L})$, glicerol $(\mathrm{g} / \mathrm{L}), \mathrm{pH}$, oxigênio dissolvido $(\%)$, rotação por minuto $(\mathrm{rpm})$, viabilidade celular $(\mathrm{UFC} / \mathrm{mL})$ e ácido L-glutâmico $(\mathrm{g} / \mathrm{L})$ e curvas suavizadas de $\mathrm{DO}_{540 \mathrm{~nm}}$, lactato $(\mathrm{g} / \mathrm{L})$ e $\mathrm{OMV}(\mathrm{mg} / \mathrm{L})$. Os respectivos valores estão descrito nas tabelas 3.3 a 3.5 e tabelas 7.1.1 a 7.1.3 do anexo 7.1. Todos ocorrido no período de $20 \mathrm{~h}$ de cultivo em meio Catlin sem ferro, grupo B. 

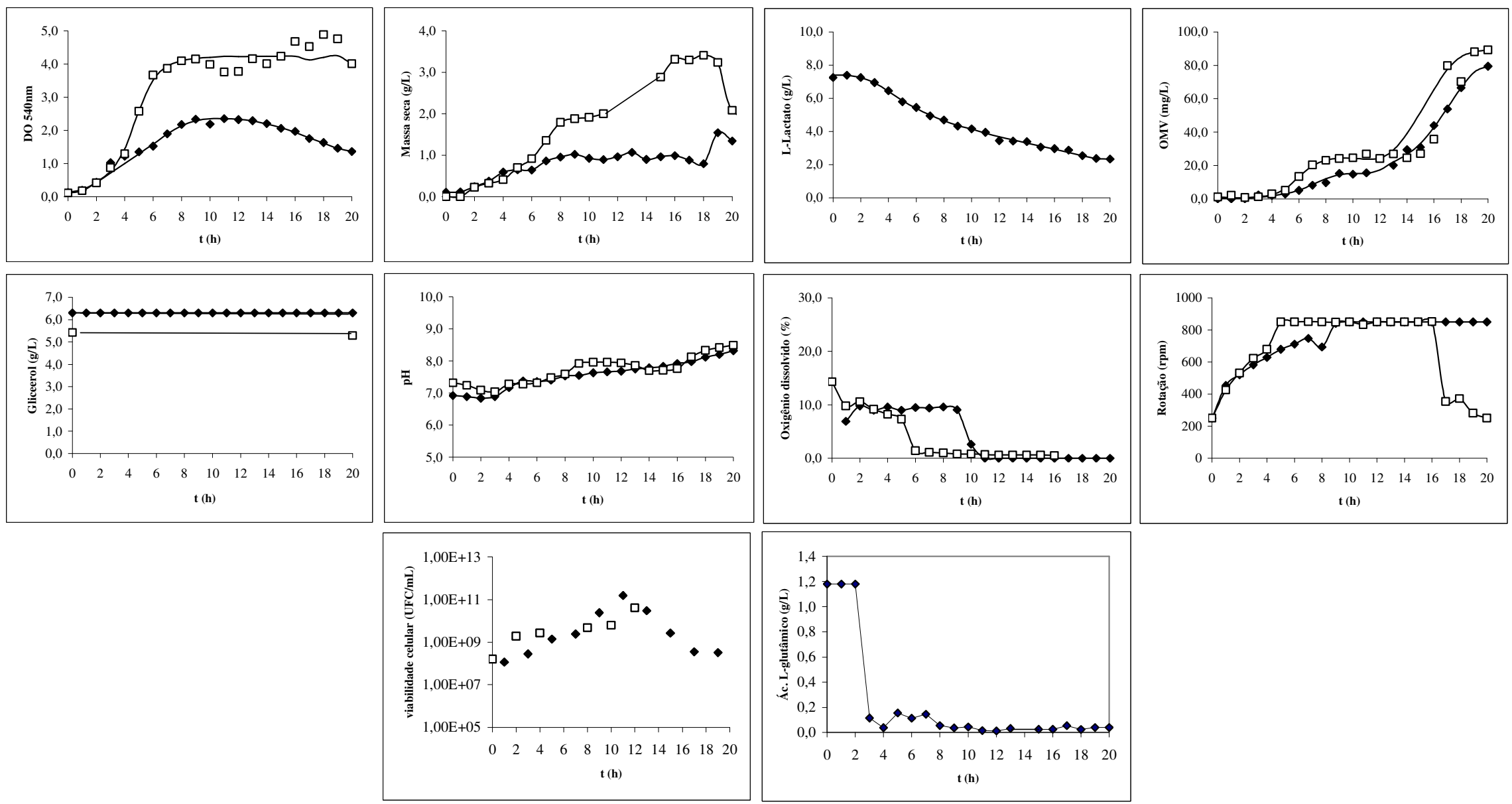

Figura 7.4.2 - Curvas experimentais dos ensaios $5(\downarrow)$ e $6(\square)$ representando DO 540nm, massa seca (g/L), lactato (g/L), OMV (mg/L), glicerol $(\mathrm{g} / \mathrm{L}), \mathrm{pH}$, oxigênio dissolvid o $(\%)$ e rotação por minuto $(\mathrm{rpm})$ e curvas suavizadas de DO 540nm, Lactato (g/L) e OMV (mg/L). Os respectivos valores estão descrito nas tabelas 3.6 e 3.7 e tabelas 7.1.4 e 7.1.5 do anexo 7.1. Ambos ocorridos no período de 20 $\mathrm{h}$ de cultivo em meio Catlin sem ferro, com concentrações de lactato triplicado desde o inicio do cultivo, grupo C. 

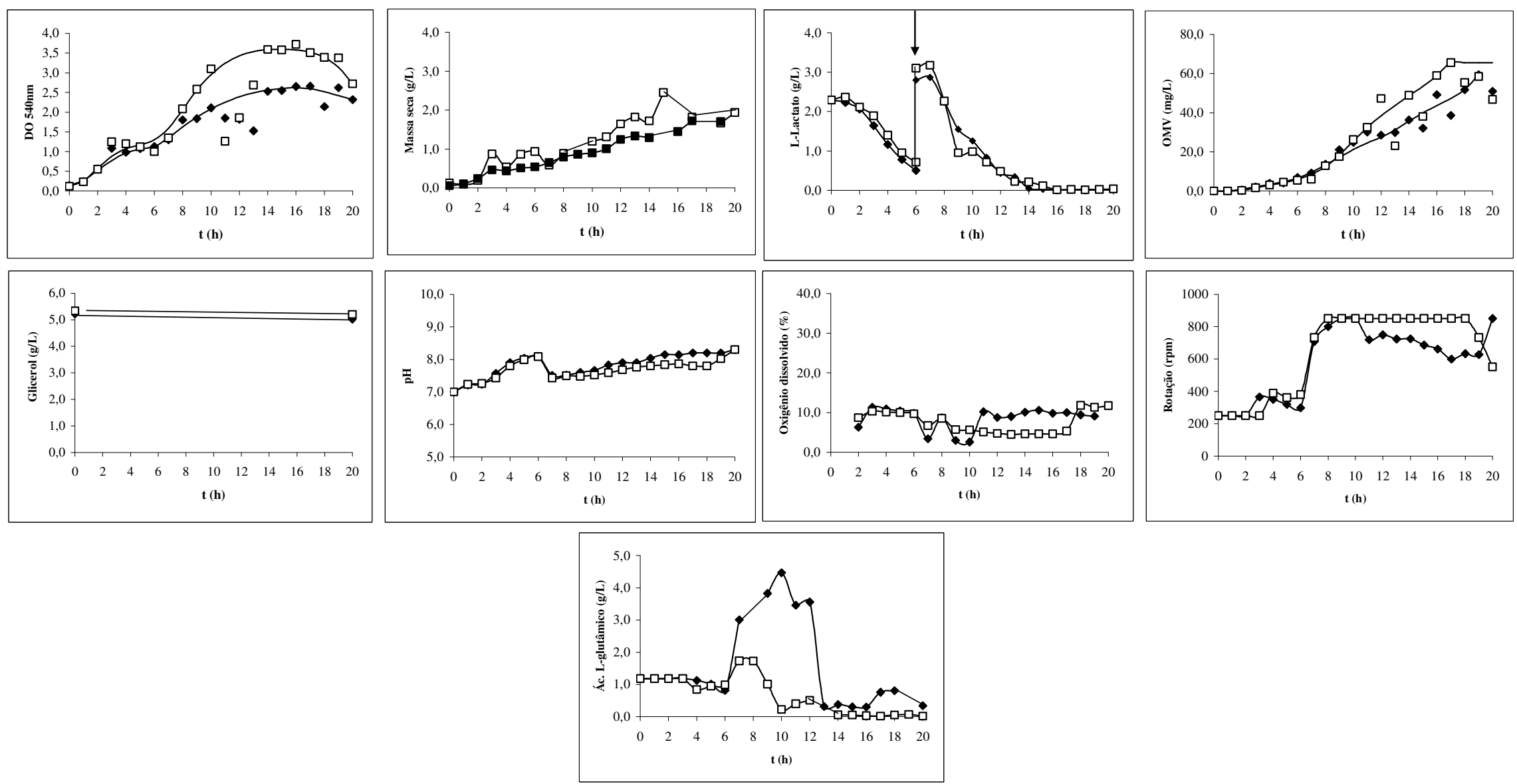

Figura 7.4.3 - Curvas experimentais dos ensaios $7(\diamond)$ e $8(\square)$ representando DO 540nm, massa seca (g/L), lactato (g/L), OMV (mg/L), glicerol $(\mathrm{g} / \mathrm{L}), \mathrm{pH}$, oxigênio dissolvido $(\%)$, rotação por minuto $(\mathrm{rpm})$, ácido L-glutâmico $(\mathrm{g} / \mathrm{L})$ e curvas suavizadas de DO 540nm, Lactato $(\mathrm{g} / \mathrm{L})$ e $\mathrm{OMV}(\mathrm{mg} / \mathrm{L})$. Os respectivos valores estão descrito nas tabelas 3.8 e 3.9 e tabelas 7.1.6 e 7.1.7 do anexo 7.1. Ambos ocorrido durante $20 \mathrm{~h}$ decultivo em meio Catlin sem ferro, com pulso de concentrações de aminoácidos e lactato na $6^{\mathrm{a}} \mathrm{h}$ de cultivo, grupo D. 

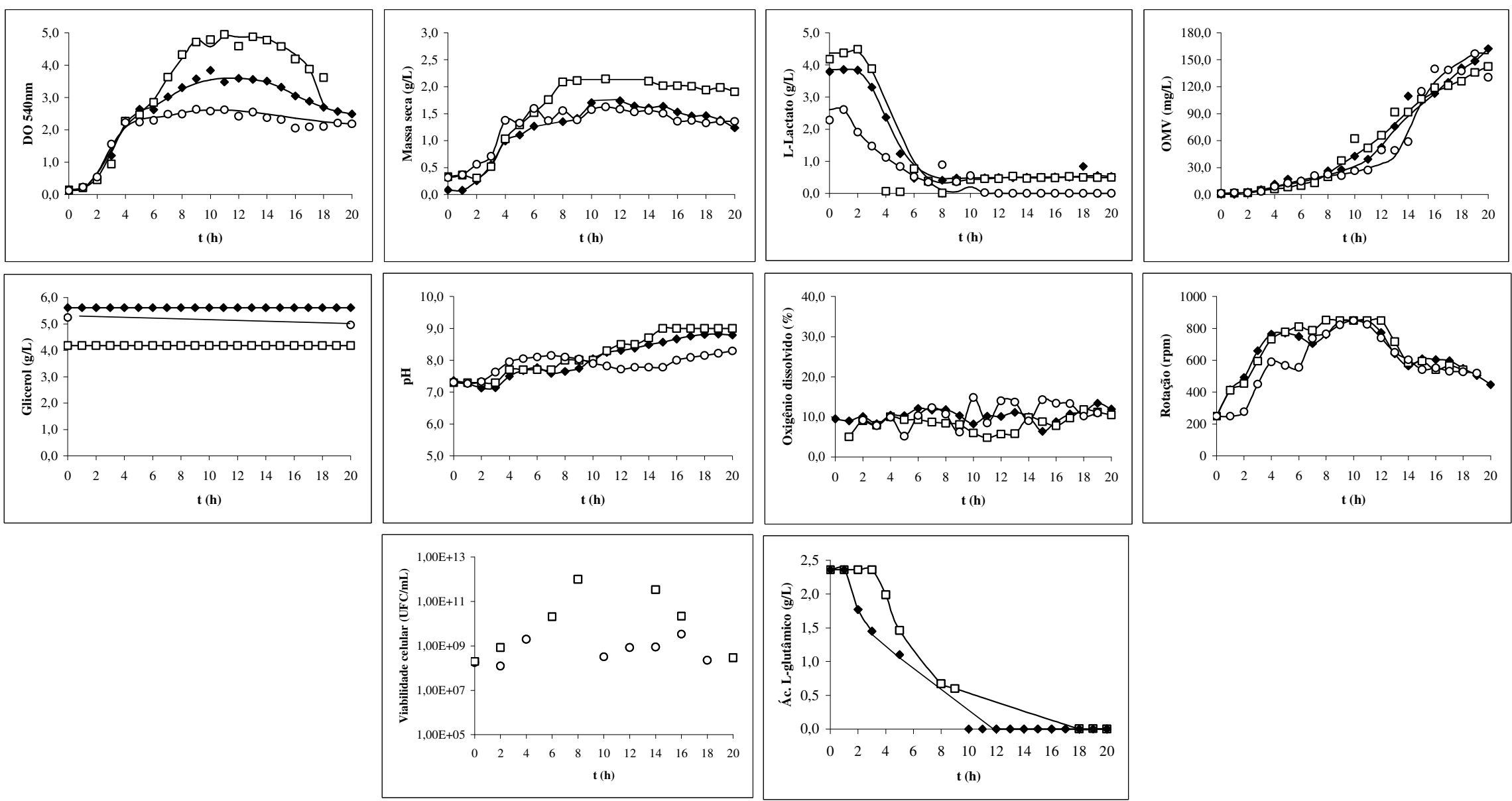

Figura 7.4.4 - Curvas dos ensaios $9(\diamond), 10(\square)$ e11 (o) representando $\mathrm{DO}_{540 \mathrm{~nm}}$, massa seca (g/L), lactato (g/L), OMV (mg/L), glicerol (g/L), pH oxigênio dissolvido $(\%)$, rotação por minuto $(\mathrm{rpm})$, viabilidade celular $(\mathrm{UFC} / \mathrm{mL})$ e ácido L-glutâmico $(\mathrm{g} / \mathrm{L})$ e curvas suavizadas de $\mathrm{DO}_{540 \mathrm{~nm}}$, lactato $(\mathrm{g} / \mathrm{L})$ e $\mathrm{OMV}(\mathrm{mg} / \mathrm{L})$. Os respectivos valores estão descrito nas tabelas 3.10 a 3.12 e tabelas 7.1.8 a 7.1.10 do anexo 7.1. Todos ocorridos durante $20 \mathrm{~h}$ de cultivo em meio Catlin sem ferro, com concentrações de aminoácidos e lactato dobrados desde início do cultivo, grupo E. 

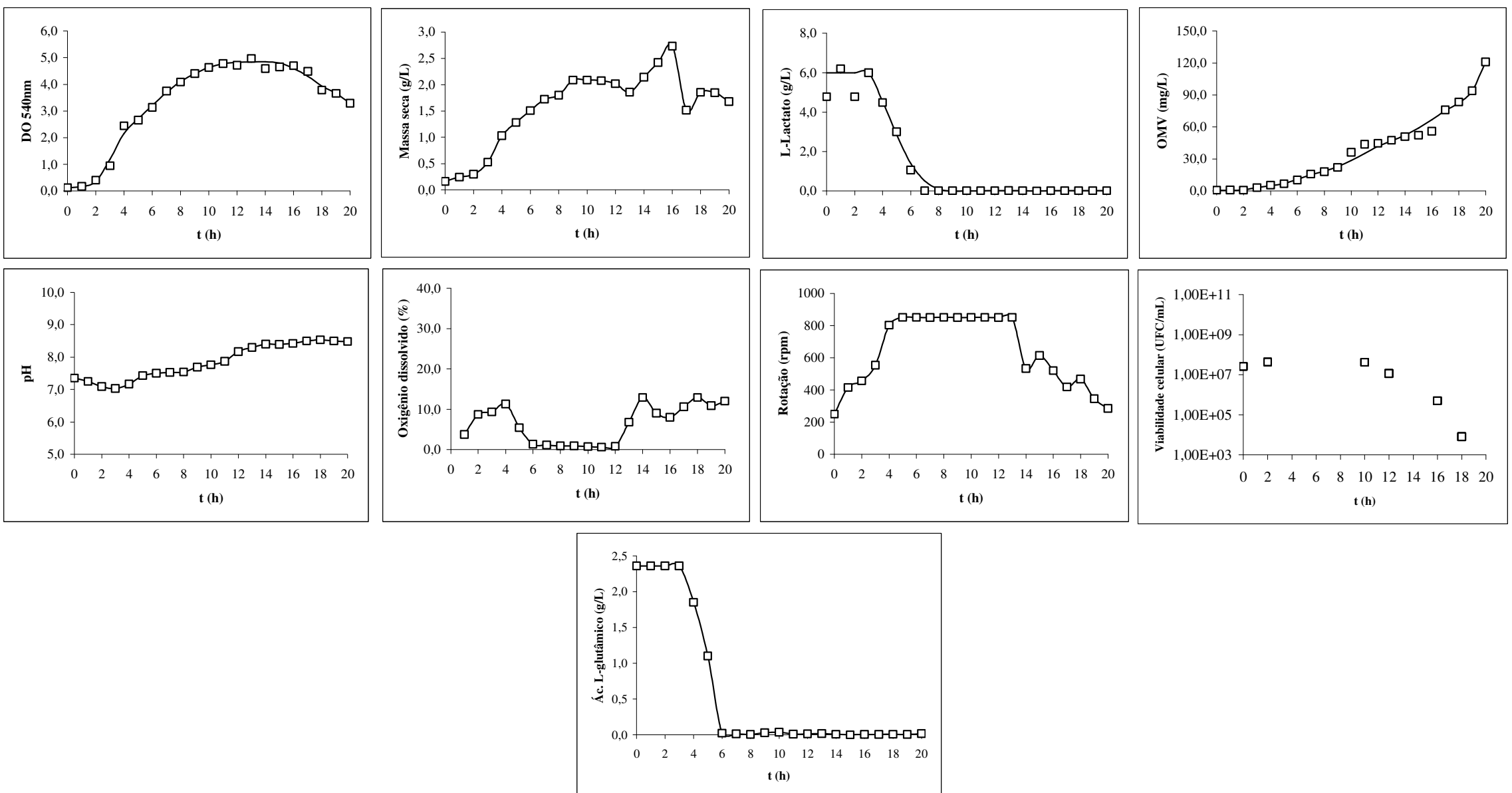

Figura 7.4.5 - Curvas do ensaio $12(\square)$ representando $\mathrm{DO}_{540 \mathrm{~nm}}$, massa seca $(\mathrm{g} / \mathrm{L})$, lactato $(\mathrm{g} / \mathrm{L}), \mathrm{OMV}(\mathrm{mg} / \mathrm{L})$, pH, oxigênio dissolvido $(\%)$, rotação por minuto $(\mathrm{rpm})$, viabilidade celular $(\mathrm{UFC} / \mathrm{mL})$ e ácido L-glutâmico e curvas suavizadas de $\mathrm{DO}_{540 \mathrm{~nm}}$, lactato $(\mathrm{g} / \mathrm{L}) \mathrm{e}$ OMV (mg/L). Os seus respectivos valores estão descrito na tabela 3.13 e tabela 7.1.11 do anexo 7.1. Ensaio corrido no período de $20 \mathrm{~h}$ de cultivo em meio Catlin sem ferro, com concentrações iniciais de aminoácidos e lactato dobrados e glicerol ausente, grupo $\mathbf{F}$. 
Anexo 7.5: Artigo Publicado 
Brazilian Journal of Microbiology (2006) 37:488-493

ISSN 1517-8382

\title{
PRODUCTION OF OUTER MEMBRANE VESICLES (OMV) IN BATCH CULTIVATION OF NEISSERIA MENINGITIDIS SEROGROUP B
}

\author{
Silvia Santos ${ }^{1}$, Júlia Baruque-Ramos ${ }^{2 *}$; Marta Massako Tanizaki ${ }^{1}$; Ivo Lebrun ${ }^{1}$; Rocilda Perazzini Furtado Schenkman ${ }^{1}$ \\ ${ }^{1}$ Instituto Butantan, Av. Dr. Vital Brazil, 1500, São Paulo, SP, Brazil; ${ }^{2}$ Universidade de São Paulo, Escola de Artes, Ciências e \\ Humanidades (EACH-USP), São Paulo- SP, Brazil
}

Submitted: December 13, 2005; Returned to authors for corrections: April 27, 2006; Approved: October 13, 2006

\begin{abstract}
Meningococcal disease is an important cause of death and morbidity throughout the world. Nearly 330,000 cases and 35,000 deaths occur yearly. Neisseria meningitidis, serogroup B strain N.44/89, is prevalent in Brazil. Its outer membrane vesicles (OMV) with iron regulated proteins (IRP) are released to the culture medium and are used as antigen for vaccine production. In order to have knowledge about the kinetic parameters, especially the final OMV concentration values, 20 - $\mathrm{h}$ batch cultivations were carried out in Catlin medium with iron restriction. Process conditions comprised: $7 \mathrm{~L}$ bioreactor, $36^{\circ} \mathrm{C}, 0.5 \mathrm{~atm}$, overlay air flowrate of $1 \mathrm{~L} / \mathrm{min}$, agitation varying from $250 \mathrm{rpm}$ to $850 \mathrm{rpm}$ and dissolved oxygen control set at $10 \%$ of saturation condition. Biomass was determined by optical density at $540 \mathrm{~nm}$ and dry weight. Glycerol, lactate, $\mathrm{pH}$ and dissolved oxygen were measured from samples taken during cultivation. Outer membrane vesicle (OMV) concentration was determined by Lowry's method after ultracentrifugation. IRP presence was verified by SDS-PAGE. Highest biomass value, corresponding to the highest initial lactate concentration $(7.84 \mathrm{~g} / \mathrm{L})$ was achieved at the $9^{\text {th }}$ hour process time corresponding to $1.0 \mathrm{~g} / \mathrm{L}$ dry biomass and 2.3 optical density at $540 \mathrm{~nm}$. Lactate consumption was directly related to cell growth (yield factor: $0.24 \mathrm{~g}$ dry biomass / g lactate). Glycerol concentration in the medium did not change significantly during the process. OMV concentration reached the highest value of $80 \mathrm{mg} / \mathrm{L}$ at end cultivation time. The obtained results suggest that lactate is a main limiting growth factor and the maximum amount of antigen is obtained during stationary growth and cell death phases.
\end{abstract}

Key words: Neisseria meningitidis, outer membrane vesicles, culture medium, vaccine, submerged batch cultivation

\section{INTRODUCTION}

Meningococcal disease is an important cause of death and morbidity throughout the world. Nearly 330,000 cases and 35,000 deaths occur yearly (20). Besides disease and death, meningococcal meningitis is responsible for severe lesions, especially neurological, such as mental retardation, auditive deficiency, etc (16). In Brazil this disease has been a serious public health problem with high incidence and lethality in the last decades (7).
According to a common antimeningococcal vaccine project, against meningitis $\mathrm{B}$ and $\mathrm{C}$, a vaccine containing outer membrane vesicles (OMV) from $N$. meningitidis B expressing iron regulated proteins (IRP) from a strain with high incidence in Brazil ( $\mathrm{N} \mathrm{44/89)}$ was suggested by Instituto Butantan, Instituto Adolpho Lutz and Fiocruz. The OMV must have the minimum amount of lipo-oligo-saccharide (LOS endotoxin), a constituent of these vesicles, in order to diminish the vaccine toxicity level, but maintaining vesicle integrity. In the Instituto Butantan the production process of $N$. meningitidis $\mathrm{C}(3,19)$;

*Corresponding Author. Mailing address: Universidade de São Paulo, Escola de Artes, Ciências e Humanidades - Av. Arlindo Bettio 1000. Cep 03828-000. São Paulo, SP, Brasil. Tel.: (11) 3091-1027. E-mail: ibaruque@usp.br 
Production of OMV in cultivation $N$. meningitidis

the evaluation of the importance of a second serogroup B strain as vaccine component (9); the obtainment of vesicles with appropriate characteristics (with IRP expression and with low level of LOS); the conjugation process of $N$. meningitidis C polysaccharide with $N$. meningitidis B OMV $(12,13)$ were studied. In addition, it is worth mentioning that $\mathrm{OMV}$ also are employed as carriers of polysaccharides in conjugated vaccines against Haemophilus influenzae and in vaccines against pneumonia $(2,11)$.

Aiming at process optimization for OMV production, the $N$. meningitidis $\mathrm{B}$ growth kinetics and the yield evaluation of the amounts of produced OMV must be better studied. This means to identify the principal limitations, to determinate factors of OMV generation and to understand the relationship between cell growth and released OMV yield in the cultivation broth.

The objective of the present work is to study the growth, substrate consumption and released OMV production kinetics of Neisseria meningitidis, serogroup B strain N44/89, in bioreactor, aiming at the increase of OMV yield and the use of these data for further development and scaling up of the vaccine production process.

\section{MATERIALS AND METHODS}

\section{Process Conditions}

\section{Preliminary cultivation runs}

Eight cultivation runs were carried out according to the factorial planning design $2^{3}(5)$ each one in shaken flasks of 300 $\mathrm{mL}$ capacity with $100 \mathrm{~mL}$ of Catlin medium without iron compounds, incubated at $300 \mathrm{rpm}$ and temperature controlled at $36 \pm 0.5^{\circ} \mathrm{C}$. The inoculum for each flask was prepared as that used in bioreactor cultivations (described below). The initial optical density at $540 \mathrm{~nm}$ was near 0.1 at the beginning of cultivations. The values adopted for the initial concentrations of L-glutamic acid, glycerol and lactate are listed in Table 1. The analysis of the effects was based on the optical density at 540 $\mathrm{nm}$ and released OMV values in each flask contents after 8 hours of cultivation.

\section{Cultivation runs in bioreactor}

The inoculum of Neisseria meningitidis Serogroup B - N 44/89 (Instituto Adolpho Lutz, São Paulo, Brazil) was prepared according to Gotschlich et al. (14). The content of one ampoule of the meningococcal strain, maintained at $-80^{\circ} \mathrm{C}$, in $1.0 \mathrm{~mL}$ Catlin

Table 1. Factorial planning design and analysis of results of preliminary experiments carried out in shaker.

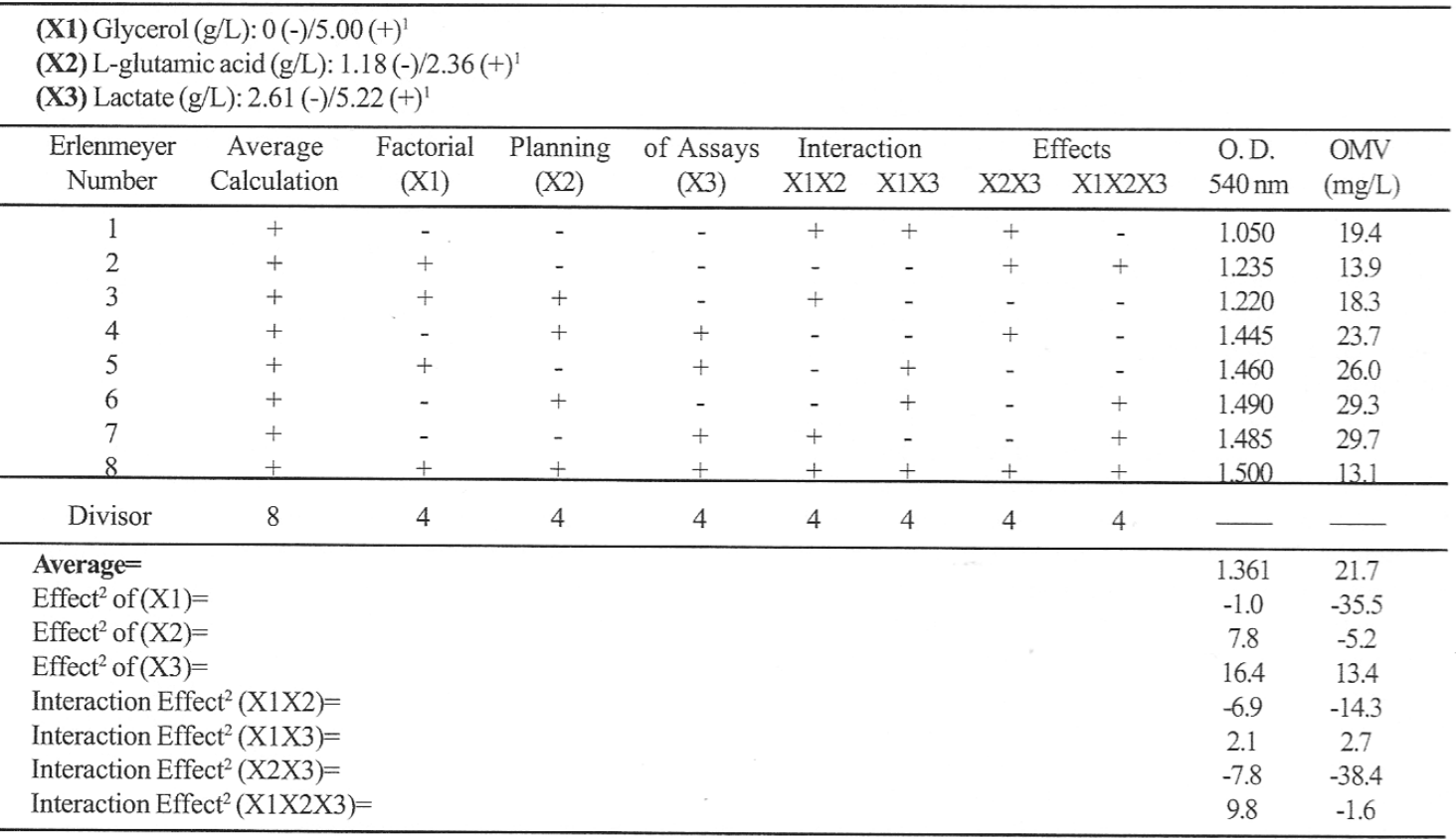

${ }^{1}$ Original concentrations in Catlin medium: 5.00, 1.18 and $7.500 \mathrm{~g} / \mathrm{L}$ glycerol, L-glutamic acid and sodium lactate (50\% solution) respectively; ${ }^{2}$ Calculated in terms of percentage in relation to the respective average. 
medium without iron compounds (8) plus 30\% glycerol, was streaked out onto 5 Müller-Hinton agar slant tubes (18) and incubated at $36^{\circ} \mathrm{C}$ for $18-20 \mathrm{~h}$ in a candle $\operatorname{jar}\left(5-10 \% \mathrm{CO}_{2}\right)$. The cells from each slant tube were resuspended in the liquid Catlin medium without iron compounds and then transferred to five $500 \mathrm{~mL}$ conical flasks, each containing $100 \mathrm{~mL}$ Catlin medium without iron compounds and incubated at $36^{\circ} \mathrm{C}$ for $3 \mathrm{~h}$ on a rotary shaker at $250 \mathrm{rpm}$. In order to verify possible contaminations, microscopic examinations were carried out using the Gram technique (4). The contents of conical flasks, corresponding to an initial optical density near 0.1 at $540 \mathrm{~nm}$, were used to inoculate a $7 \mathrm{~L}$ (total capacity) bioreactor (New Brunswick, model Bioflo 2000, New Jersey, NY) containing 4.2 L Catlin medium without iron compounds. The medium for the inoculum as well as for the bioreactor was sterilized by filtration through Millipore filters with $0.2 \mu \mathrm{m}$ mean pore diameter. Composition of Catlin medium without iron compounds (g per liter) was: $5.850 \mathrm{NaCl} ; 0.401 \mathrm{NH}_{4} \mathrm{Cl} ; 0.186 \mathrm{KCl} ; 2.678$ $\mathrm{Na}_{2} \mathrm{HPO}_{4} .12 \mathrm{H}_{2} \mathrm{O} ; 0.170 \mathrm{KH}_{2} \mathrm{PO}_{4} ; 0.647$ sodium citrate. $2 \mathrm{H}_{2} \mathrm{O} ; 7.500$ sodium lactate $\left(50 \%\right.$ solution); $0.616 \mathrm{MgSO}_{4} .7 \mathrm{H}_{2} \mathrm{O} ; 0.037$ $\mathrm{CaCl}_{2} .2 \mathrm{H}_{2} \mathrm{O} ; 1.180 \mathrm{~L}$-glutamic acid; $0.021 \mathrm{~L}$-serine; $0.010 \mathrm{~L}$ cysteine. $\mathrm{HCl} . \mathrm{H}_{2} \mathrm{O} ; 0.105 \mathrm{~L}$-arginine. $\mathrm{HCl} ; 0.150$ glicine; 0.001 $\mathrm{MnSO}_{4} \cdot \mathrm{H}_{2} \mathrm{O} ; 5.000$ glycerol. The $\mathrm{pH}$ was adjusted to 7.0 with a $5 \mathrm{~N} \mathrm{NaOH}$ solution. The bioreactor operating conditions were: temperature $=36.0^{\circ} \mathrm{C}$; air flow rate $=1 \mathrm{~L} / \mathrm{min}(0.22 \mathrm{vvm})$; upper aeration, $\mathrm{k}_{\mathrm{L}} \cong 5.3 \mathrm{~h}^{-1}$; agitation frequency $=$ between 250 and $850 \mathrm{rpm}$; dissolved oxygen controlled at $10 \%$. The vessel head pressure was maintained at $0.5 \mathrm{~atm}$. Two Rushton six blade disc turbines $(\phi=6.5 \mathrm{~cm})$ were used for mixing, one located at $5.0 \mathrm{~cm}$ from the vessel bottom and the other at $15.0 \mathrm{~cm}$ from the first turbine. The $\mathrm{pH}$ was measured by an on-line sterilizable electrode (Ingold model 465-90, Mettler-Toledo, Alphaville-Barueri, Brazil). Dissolved oxygen concentration was detected by an on-line polarographic electrode (Ingold model 531, Mettler-Toledo, Alphaville-Barueri, Brazil). The $100 \%$ point was calibrated one hour before the inoculation, under the same cultivation conditions.

\section{Analytical Methods}

Cell concentration was expressed as optical density at 540 $\mathrm{nm}$ and dry biomass weight per liter $(\mathrm{g} / \mathrm{L})$ after centrifugation of a known-volume sample at 3,220xg during 30 minutes, followed by pellet drying at $60^{\circ} \mathrm{C}$ for $48 \mathrm{~h}$. Colony forming units (CFU) were determined by counting the colonies of a previously diluted sample grown in chocolate Müller-Hinton agar medium (10) at $37^{\circ} \mathrm{C}$ for 24 hours. For glycerol concentration measures, the used method (1) was based on glycerol oxidation by sodium periodate, where glycerol reacts with sodium periodate in acid solution generating aldehyde and formic acid. The formic acid was titrated with a $\mathrm{NaOH}$ solution $(0.125 \mathrm{~N})$ and the consumed volume corresponded to the glycerol concentration. Lactate concentrations were determined employing an automatic enzymatic analyzer(Yellow Spring, model YSI 2700 Select, Yellow Springs, Ohio, USA). OMV were separated from supernatant cultivation after ultracentrifugation (Beckman, L8-M Ultracentrifuge, Palo Alto, CA, USA) of $50 \mathrm{~mL}$ samples at 30,000 $\mathrm{rpm}$ during 3 hours and resuspended in $0.5 \mathrm{~mL}$ water. Protein concentration in OMV resupensions were estimated by Lowry's method (17) and compared to a bovine serum albumin standard. To verify IRP presence an electrophoresis method was employed (21). A standardized amount of OMV sample was resuspended in a SDS-PAGE sample buffer containing mercaptoethanol and urea, which was heated to $100^{\circ} \mathrm{C}$ for 2 minutes and applied to a $10 \%$ acrylamide/bisacrylamide gel. After the run the gel was stained with $0.1 \%$ Coomassie blue. The expression of IRP in the fractionated OMV extracts was estimated by the presence of 70-108 kDa bands (6).

\section{RESULTS AND DISCUSSION}

Analysis of the effects of the factorial planning on the preliminary assays

The calculated effects and their interactions are presented in Table 1. According to the results of the final optical density at $540 \mathrm{~nm}$ the main effect was caused by the increase of initial sodium lactate (carbon source) concentrations in the cultivation medium. The variation of glycerol concentrations, another potential carbon source for the bacteria, did not seem to cause any effect on final cell concentration values. Moreover, the determination of the initial and final glycerol concentrations showed that this compound was not consumed during the cultivations (data not shown). However, analyzing the assays according to OMV concentration results, despite lactate concentrations still able to promote a positive effect, the main effect was promoted by the variation of glycerol concentrations and their interactions with L-glutamic acid and sodium lactate. In this way, despite glycerol concentration increase in the cultivation medium did not seem to promote cell growth, it possibly could exert a protective effect on $\mathrm{OMV}$ generation. Lglutamic acid concentration variation did not promote any significant effect at the employed levels.

These preliminary conclusions, therefore, allowed for the planning of the assays carried out in bioreactor. In these experiments, the original glycerol and L-glutamic acid concentrations were maintained. In order to study the influence of sodium lactate on cell growth and OMV generation, two extreme concentration values were chosen: one of them reproducing the original concentration in Catlin medium (7.50 $\mathrm{g} / \mathrm{L}$ of a $50 \%$ sodium lactate solution corresponding to $2.61 \mathrm{~g} / \mathrm{L}$ lactate) and the other, three-fold higher, a condition of excess of this compound $(22.5 \mathrm{~g} / \mathrm{L}$ of a $50 \%$ sodium lactate solution corresponding to $7.84 \mathrm{~g} / \mathrm{L}$ lactate). In addition, these extreme limits were chosen to study the limitating or inhibiting influence of this substrate on cell growth and released OMV production. 
Analysis of results obtained in experiments carried out in bioreactor

Typical growth curves are shown in Figure 1a, lactate consumption and $\mathrm{pH}$ in Figure $1 \mathrm{~b}$ and OMV release in Figure 1c. Comparing these kinetics, the substrate limitation is evident
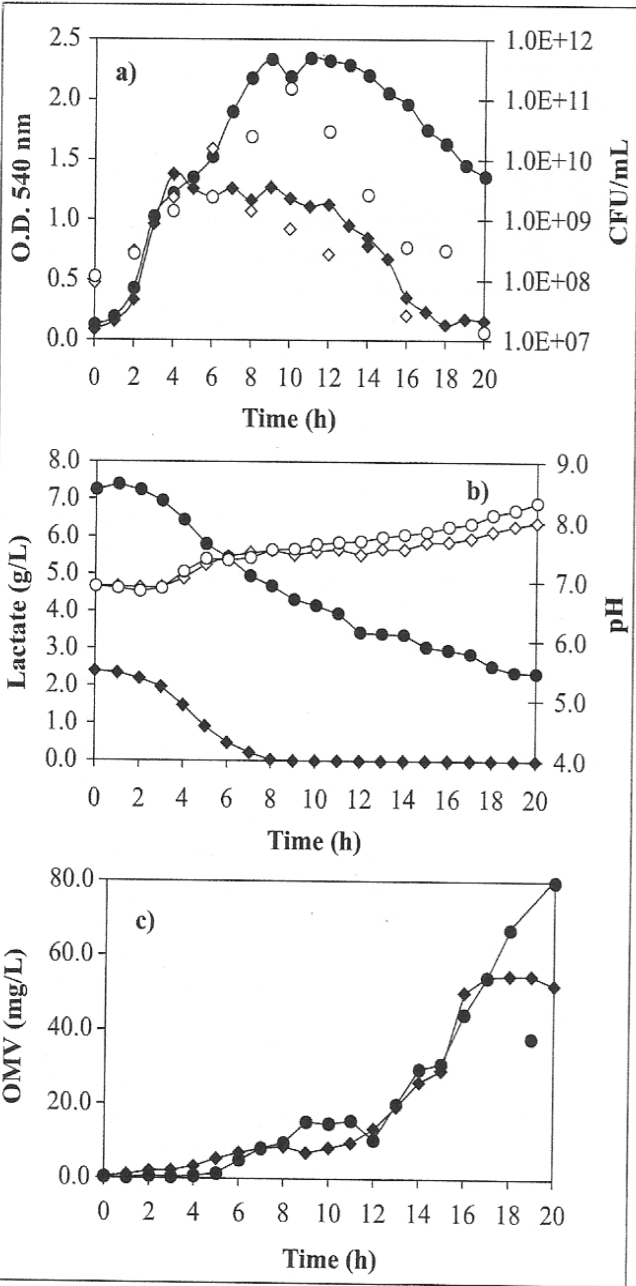

Figure 1. Growth, lactate consumption, $\mathrm{pH}$ and OMV formation kinetics - Assay with $2.61 \mathrm{~g} / \mathrm{L}$ initial lactate concentration: (a) O.D. $(\diamond)$ and CFU/mL $(\diamond)$; (b): Lactate $(\diamond)$ and $\mathrm{pH}(\diamond)$, (c): OMV in supernatant $(\$)$; Assay with $7.84 \mathrm{~g} / \mathrm{L}$ initial lactate concentration: (a): O.D. (O) and CFU/mL (O), (b): Lactate ( and $\mathrm{pH}(\mathrm{O})$, (c): OMV in supernatant $(\bullet)$. when $2.61 \mathrm{~g} / \mathrm{L}$ lactate was used in the medium (Figures 1a and 1b). In this experiment, the maximum cell concentration occurred at the $4^{\text {th }}$ hour whereas the lactate exhaustion occurred at the $8^{\text {th }}$ hour. Nevertheless OMV release to the cultivation medium began significantly from the $12^{\text {th }}$ hour on until the end of cultivation (Figure 1c) reaching the maximum value of near 60 mg per liter of cultivation. Cell population death occurred during this period and this fact was evidenced by the colony forming unit decrease (Figure 1a),

On the other hand, when $7.84 \mathrm{~g} / \mathrm{L}$ lactate was used in the medium, limitation by this substrate did not occur (Figures 1a and $\mathrm{lb}$ ). The optical density at $540 \mathrm{~nm}$ almost doubled in comparison to the other assay results, corresponding to $1.0 \mathrm{~g} /$ $\mathrm{L}$ dry biomass, but even in this way growth was limited by another substrate, which may be iron or another compound. Comparing both growth curves, they are almost the same until the $4^{\text {th }}$ cultivation hour. It can be concluded that the lactate excess at the level employed in the present work did not inhibit cell growth, even considering the excess of this substrate until the end of cultivation. Meanwhile as in the other assay, in this one OMV release to the cultivation medium also began significantly from the $12^{\text {th }}$ hour until the end of cultivation (Figure 1c) reaching the value of $80 \mathrm{mg} / \mathrm{L}$, i.e., $33 \%$ higher than the previous result.

It is worth mentioning that in both assays, there was IRP generation, marked by the presence of bands between 70 and $108 \mathrm{kDa}$ (Figure 2). Moreover, the determination of glycerol concentrations showed that this compound was not consumed during the cultivation periods (data not shown). In this way, the utility of glycerol in the cultivation medium still remains unclear. Also in both assays, $\mathrm{pH}$ increase, from 7.0 to values higher than 8.0, during cultivation time was observed (Figure 1b). According to these results, probably L-glutamic acid (main nitrogen source) was consumed, generating ammonia. In addition, this amino acid could be present in insufficient amounts for the cultivation requirements. These data lead to the supposition that the L-glutamic acid concentrations must be monitored and its initial concentration in the cultivation medium optimized in future studies according to the adopted process conditions.

Only one reference was found in the literature, which describes a suitable process of OMV production from $N$. meningitidis serogroup cultivations (11). According to this study, the original Catlin medium was modified to Catlin 6 medium, whose main carbon source is supplied by $10 \mathrm{~g} / \mathrm{L}$ of initial glucose concentration. However, despite those authors having described a final cell concentration of $5 \mathrm{~g} / \mathrm{L}$ dry biomass, they employed a medium with iron compounds and they did not elucidate the amount of obtained OMV and if its origin was from the supernatant or from the whole cultivation broth.

It was demonstrated that lactate is the main carbon source when original Catlin medium is employed for $N$. meningitidis 
Santos, S. et al.

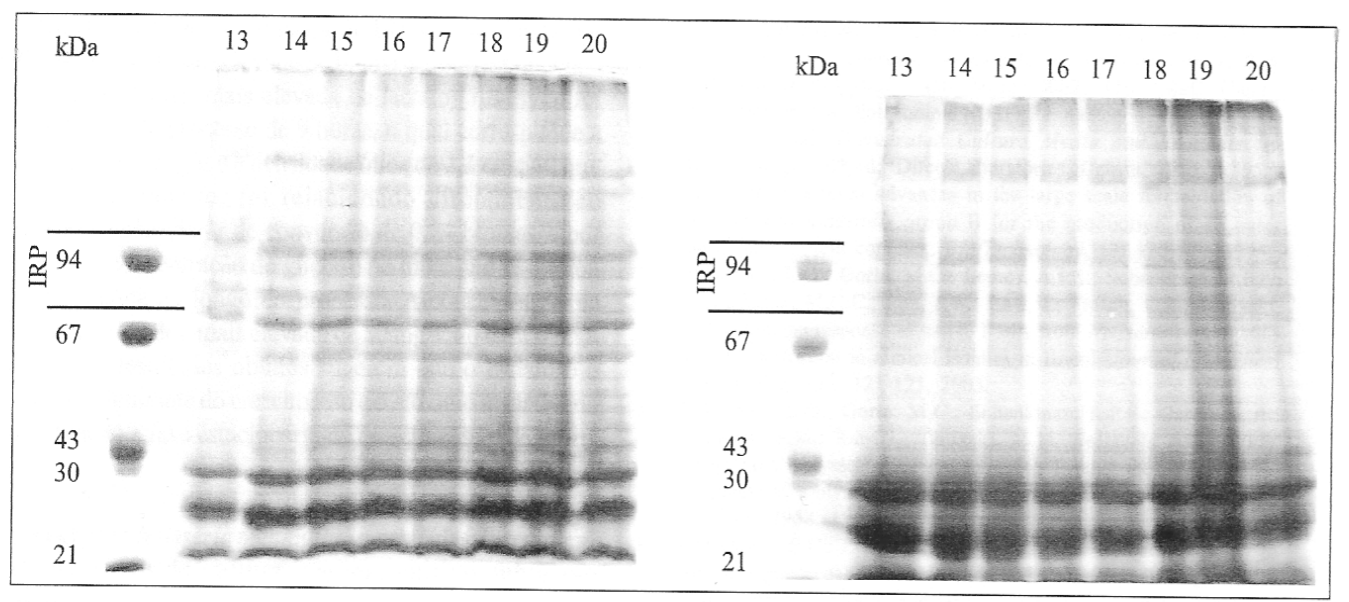

Figure 2. Expression of IRP (range from 70 to $108 \mathrm{kDa}$ indicated by arrows) in the fractionated OMV extracts. First line from left side indicates the molecular weight standards. Lines 13 to 20 correspond to the fractionated OMV extract at the respective cultivation hour. (a) Assay with $2.61 \mathrm{~g} / \mathrm{L}$ initial lactate concentration. (b) Assay with $7.84 \mathrm{~g} / \mathrm{L}$ initial lactate concentration.

serogroup B cultivation. According to the present study, considering an estimated relationship of 0.5 between the values of dry biomass and optical density at $540 \mathrm{~nm}$, the dry biomass/ lactate yield factor $\left(\mathrm{Y}_{\mathrm{X} / \mathrm{S}}\right)$ is near $0.24 \mathrm{~g} / \mathrm{g}$. The degradation of lactate by $N$. meningitidis $\mathrm{B}$ is described together with its genome and its functions (23). According to this study, the lactate degradation is accomplished by way of an intact tricarboxylic acid cycle (TCA), as well as pentose-phosphate and Entner-Doudoroff pathways. Probably the lactatedehydrogenase key enzymes can develop the two-way function of lactate generation (glycolysis) or lactate absorption (gluconeogenesis) in these pathways $(15,22)$.

In conclusion, the supplemental addition of three-fold more initial lactate concentration in Catlin medium in relation to the original initial concentration leads to an increase of $33 \%$ final OMV concentration (near $80 \mathrm{mg} / \mathrm{L}$ ) with confirmation of IRP presence. The OMV release, from cell surface to the cultivation medium, seems to be more intense during stationary growth and cell population death phases. The utility of glycerol in the culture medium still remains unclear, since it has been not consumed in cultivations. However, despite the positive preliminary results, the initial concentration of carbon sources (lactate and glycerol) as well as nitrogen source concentration must be optimized in future studies according to the adopted process conditions.

\section{ACKNOWLEDGMENTS}

Financial support from Fundação Butantan is gratefully acknowledged. We would like to thank CNPq for the research fellowship. The authors would also like to thank Mr. Lourivaldo Inácio de Souza, Mr. Máximo de Moraes, Mr. Hélio Fernandes Chagas, Mrs. Inês do Amaral Maurelli, Mrs. Salete Vargas and Mrs. Fátima Aparecida Mendonça de Oliveira for their technical support.

\section{RESUMO}

\section{Produção de Vesículas da Membrana Externa (OMV) em Cultivo Batelada de Neisseria meningitidis Sorogrupo B}

A doença meningocócica é uma causa importante de morte a nível mundial. Aproximadamente 330.000 casos e 35.000 mortes ocorrem anualmente. A cepa N.44/89 do sorogrupo B de Neisseria meningitidis é prevalente no Brasil. Suas vesículas de membrana externa (OMV - "outer membrane vesicles"), com proteínas reguladoras de ferro (IRP - "iron regulated proteins") liberadas no meio de cultura, são empregadas como antígeno para a produção da vacina. A fim ter o conhecimento sobre os parâmetros cinéticos, especialmente os valores finais da concentração de OMV, cultivos batelada de 20 hs foram realizados no meio de Catlin com limitação do ferro. As condições de processo compreenderam: biorreator de 7 litros, $36^{\circ} \mathrm{C}, 0,5$ atm, vazão de ar de $1 \mathrm{~L} / \mathrm{min}$, agitação variando entre 250 a 850 $\mathrm{rpm}$, controle do oxigênio dissolvido em $10 \%$ da condição de saturação. A biomassa foi determinada pela densidade ótica em $540 \mathrm{~nm}$ e peso seco. Glicerol, lactato, pH e oxigênio dissolvido foram medidos das amostras retiradas durante o cultivo. A concentração de OMV foi determinada pelo método de Lowry 
após ultracentrifugação. A presença de IRP foi verificada por SDS-PAGE. O valor mais elevado de biomassa, correspondendo à concentração inicial mais elevada de lactato $(7,84 \mathrm{~g} / \mathrm{L})$ foi obtido no tempo de processo de 9 horas, o qual corresponde a biomassa seca de $1,0 \mathrm{~g} / \mathrm{L}$ e a densidade ótica de $2,3 \mathrm{em} 540 \mathrm{~nm}$. $\mathrm{O}$ consumo de lactato. foi relacionado diretamente ao crescimento celular (fator de conversão de 0,24 biomassa por lactato $\mathrm{g} / \mathrm{g}$ ). A concentração do glicerol no meio não se alterou significativamente ao longo do processo. A concentração de OMV alcançou o valor mais elevado de $80 \mathrm{mg} / \mathrm{L}$ no tempo final de cultivo. Os resultados obtidos sugerem que o lactato é o principal fator limitante do crescimento e o máximo do antígeno é obtido durante a fase estacionária de crescimento e de morte celular.

Palavras-chave: Neisseria meningitidis, vesículas de membrana externa, meio de cultura, vacina, cultivo submerso descontínuo

\section{REFERENCES}

1. A.O.C.S. Method Ea 6-51. In: Official Methods and Recommended Practices of the American Oil Chemistry Society, AOCS, Illinois, 1987, p.6-51.

2. Ahonkhai et al., Clinical experience with PedvaxHIB, a conjugate vaccine of Haemophilus influenzae type b polysaccharide-Neisseria meningitidis outer membrane protein. Vaccine, 9(S): 38-43, 1991.

3. Baruque-Ramos, J.; Hiss, H.; Arauz, L.J.; Mota, R.L.; Ricci-Silva, M.E.; Paz, M.F.; Tanizaki, M.M.; Raw, I. Polysaccharide production of Neisseria meningitidis (Serogroup C) in batch and fed-batch cultivations. Biochemical Engineering Journal, 23: 231-240, 2005.

4. Bier O. Microbiologia e Imunologia. $24^{\text {th }}$ ed. Ed. Melhoramentos, São Paulo, 1985,1234p.

5. Box, G.E.P.; Hunter, W.G.; Hunter J.S. Statistics for Experimenters. John Wiley \& Sons, New York, 1978, 653p.

6. Brandileone, M.C.C.; Zanella, R.C.; Vieira, V.S.D.; Sacchi, C.T, Milagres, L.G.; Frasch, C.E. Induction of iron regulated proteins during normal growth of Neisseria meningitidis in a chemical defined medium. Rev. Inst. Med. Trop., 36(4): 301-310, 1994.

7. Brazilian Epidemiological Vigilance Center, 2004. Prevenção dâ doença meningocócica e estratégia de controle. www.cve.saude.sp.gov.br actualized in april/2004, consulted in may/2005.

8. Catlin W. Nutritional profiles of Neisseria gonorrhoeae, Neisseria meningitidis, and Neisseria lactamica in chemically defined media and the use of growth requirement for gonococcal typing. The Journal of Infectious Disease, 128(2): 178-194, 1973.
9. Corrêa, A.P. Estudo de formulação das vacina anti-meningocócica polissacarideo $C$, conjugada a vesícula de membrana externa $B$ de Neisseria meningitidis. São Paulo, 2002, 47p. (MsC Thesis, Interunidades em Biotecnologia USP/I. Butantan/ IPT).

10. Difco manual. Dehydrated Culture Media and Reagents for Microbiology, $10^{\text {th }}$ ed., Difco Laboratories, Detroit, 1985, p.595.

11. Fu, J. et al. Recent advances in the large scale fermentation of Neisseria meningitidis group B for the production of an outer membrane protein complex. Bio/Technology, 13: 170-174, 1995.

12. Fukasawa, L.O.; Gorla, M.C.; Lemos, A.P.S.; Schenkman, R.P.F Brandileone, M.C.C.; Fox, J.W.; Raw, I.; Frasch, C.E.; Tanizaki, M.M. Immune response to native NadA from Neisseria meningitidis and its expression in clinical isolates in Brazil. Journal of Medical Microbiology, 52: 121-125, 2003.

13. Fukasawa, L.O,; Gorla, M.C.; Schenkman, R.P.F.; Garcia, L.R.; Carneiro, S.M.; Raw, I.; Tanizaki, M.M. Neisseria meningitidis serogroup C polysaccharide and serogroup B outer membrane vesicle conjugate as a bivalent meningococcus vaccine candidate. Vaccine. 17: 2951-2958, 1999

14. Gotschlich, E.C.; Liu, T.Y.; Artenstein, M.D. Human immunity to the meningococcus - III. preparation and immunochemical properties of the series A, series B and series $C$ meningococcal polysaccharides. J. Exp. Med., 129: 1349-1365, 1969.

15. Leighton, M.P.; Kelly, D.J.; Williamson, M.P.; Shaw, J.G. An NMR and enzyme study of the carbon metabolism of Neisseria meningitidis. Microbiology, 147: 1473-1482, 2001.

16. Lepow, M.L.; Perkins, B.A.; Hughes, P.A.; Poolman, J.T. Meningococcal vaccine. In: Plotkin AS, Orenstein WA eds. Vaccine, $3^{\text {rd }}$ Ed. Philadelphia, Saunders, 1999, p.711-727.

17. Lowry, O.H.; Rosebrough, N.J.; Farr, A.L.; Randall, R.H. Protein measurement with the Folin phenol reagent. J. Biochem. Chem., 193: 265-275, 1951.

18. Müller, H.; Hinton, J.A. A protein-free medium for primary isolation of the gonococcus and meningococcus. Proc. Soc. Exp. Biol. Med., 48: 330,1941

19. Paz, M.F.; Baruque-Ramos, J.; Hiss, H.; Vicentin, M.A.; Leal, M.B.B.; Raw, I. Polysaccharide production in batch process of Neisseria meningitidis serogroup C comparing Frantz, modified Frantz and Catlin 6 cultivation media. Braz. J. Microbiol., 34(1): 27-32, 2003.

20. Romero, J.D.; Outschoorn, I.M. Current status of meningococcal group B vaccine candidates: capsular or noncapsular? Clinical Microbiology Reviews, 7: 559-575, 1994.

21. Sambrook J.; Fritsch E.F.; Maniats T. Molecular cloning: a laboratory manual. $2^{\text {nd }}$ ed. Cold Spring Harbor Lab Press, New York, 1989, v. A.3, p.6.1-6.60.

22. Smith, H.; Yates, E.A.; Cole, J.A.; Parsons, N.J. Lactate stimulation of gonococcal metabolism in media containing glucose: mechanism, impact on pathogenecity, and wider implications for other pathogens. Infection and Immunity, 69(11): 6565-6572, 2001.

23. Tettelin, N.J. et al. Complete genome sequence of Neisserid meningitidis serogroup B strain MC58. Science, 287: 1809-1815, 2000. 